\title{
Entwicklung von diagnostischen Methoden zum Nachweis von europäischen humanpathogenen Arboviren
}

\author{
Dissertation \\ zur Erlangung des mathematisch-naturwissenschaftlichen Doktorgrades \\ „Doctor rerum naturalium“ \\ der Georg-August-Universität Göttingen \\ im Promotionsgrundprogramm Biologie \\ der Georg-August University School of Science (GAUSS) \\ vorgelegt von \\ Dora Elisabeth Finkeisen \\ aus Northeim
}

Göttingen 2014 


\section{Betreuungsausschuss}

Prof. Dr. U. Groß, Institut für Medizinische Mikrobiologie, UMG

PD Dr. W. Kramer, Abtlg. Molekulare Genetik, Institut für Mikrobiologie und Genetik

PD Dr. M. Weidmann, Abteilung für Virologie, UMG

\section{$\underline{\text { Mitglieder der Prüfungskommission }}$}

Referent: $\quad$ Prof. Dr. U. Groß, Institut für Medizinische Mikrobiologie, UMG

Korreferent: PD Dr. W. Kramer, Abteilung Molekulare Genetik, Institut für Mikrobiologie und Genetik

Weitere Mitglieder der Prüfungskommission:

Prof. Dr. Dr. C.- P. Czerny, Abteilung Tierhygiene und Mikrobiologie mit Veterinäruntersuchungslabor, Tierärztliches Institut

Prof. Dr. C. Lüder, Institut für Medizinische Mikrobiologie, UMG

Prof. Dr. S. Pöhlmann, Abteilung Infektionsbiologie, Deutsches Primatenzentrum

Prof. Dr. W. Stühmer, Abteilung Molekulare Biologie Neuronaler Signale, Max-Planck-Institut für Experimentelle Medizin 


\section{Danksagung:}

Als erstes möchte ich mich bei Prof. Dr. med. Frank T. Hufert für die Überlassung des Themas, die freundliche Aufnahme in seine Arbeitsgruppe und die Ermöglichung der Doktorarbeit in der Abteilung für Virologie der Universitätsmedizin Göttingen bedanken.

Besonders danken möchte ich PD Dr. rer. nat. Manfred W. Weidmann für die hervorragende Betreuung während meiner Arbeit, auch über die Grenzen Deutschlands hinaus bis nach Schottland.

Bei Prof. Dr. Uwe Groß und PD Dr. Wilfried Kramer möchte ich mich für die Betreuung meiner Doktorarbeit und die Übernahme des Amtes des Referenten bzw. des Korreferenten bedanken.

Ein großes Dankeschön geht an RNDr. Daniel Růžek PhD (Department of Molecular Ecology of Parasites, Ceske Budejovice, Czech Republic), Dr. Boris Klempa (Institute of Virology, Slovak Academy of Science (IVSAS), Bratislava, Slovakia), OFA Dr. Gerhard Dobler (Institut für Mikrobiologie der Bundeswehr, München, Deutschland), Maria João Alves (Center for Vectors and Infectious Diseases Research, National Institute of Health, Águas de Moura, Portugal) und Koray Ergunay MD. PhD Assistant Prof (Hacettepe University Faculty of Medicine, Ankara, Turkey) für die freundliche Bereitstellung der seltenen arboviralen Positivseren.

Mein Dank gilt besonders Dr. rer. nat. Meik Dilcher, der in jeder Lebenslage ein offenes Ohr für alle meine Fragen hatte. Die wissenschaftlichen Diskussionen und die gute Zusammenarbeit werden mir fehlen. Natürlich möchte ich mich an dieser Stelle bei der gesamten Arbeitsgruppe Hufert für die tolle Arbeitsatmosphäre bis zum bitteren Ende bedanken und wünsche jedem Einzelnen nach Schließung der Abteilung für Virologie viel Erfolg auf dem weiteren Berufsweg. Tanja Gall und Andrea Paluschkiwitz möchte ich für die schönen Stunden während (ein S3-Labor ohne Tanja kann ich mir gar nicht vorstellen) und vor allem neben dem Laboralltag danken. Wahre Freundschaften halten ein Leben lang, egal wo man sich auf der Welt befindet.

Ich danke Arne, der immer für mich da ist, egal wie es grade läuft und der hoffentlich noch lange einen wichtigen Platz in meinem Leben einnehmen wird.

Darüber hinaus bedanke ich mich besonders bei meinen Eltern, Lothar und Cornelia, die mich mein ganzes Leben stets unterstützt haben. Danke! 


\section{Inhaltsverzeichnis}

\section{Abkürzungsverzeichnis}

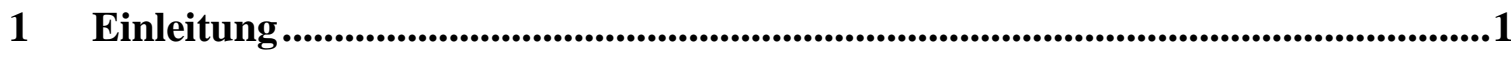

1.1 Europäische Arboviren - Mögliche Auslöser aseptischer Meningoenzephalitis und ihre Verbreitung.

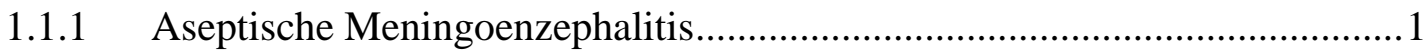

1.1.2 Europäische Arboviren und ihre Verbreitung ..........................................2

1.1.3 Arthropoden auf dem Weg in unseren Wohnraum: Biodiversitätsverlust, Klimawandel und Globalisierung ............................................................. 7

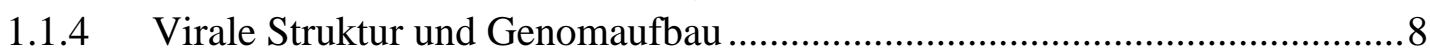

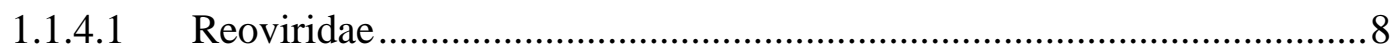

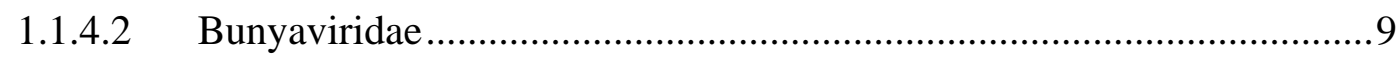

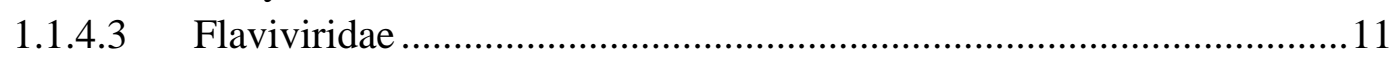

1.2 Cytometric-Bead-Array (CBA) und bisher bestehende Nachweismethoden...... 12

1.2.1 Bestehende Nachweismethoden............................................................. 12

1.2.2 Aufbau und Prinzip der xMAP Technologie - Bio-Plex ${ }^{\circledR}$ MAGPIX $^{\mathrm{TM}}$ -

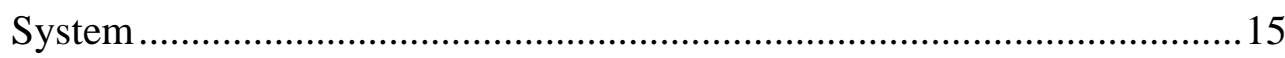

1.2.3 Multiplex Cytometric-Bead-Array (CBA) - Simultaner Antikörpernachweis von europäischen Arboviren .................................................................. 18

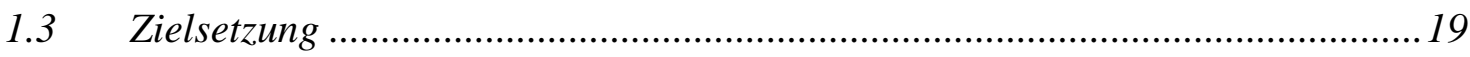

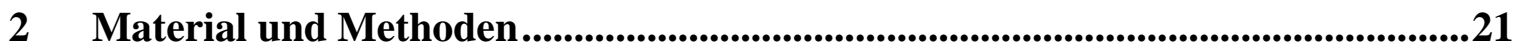

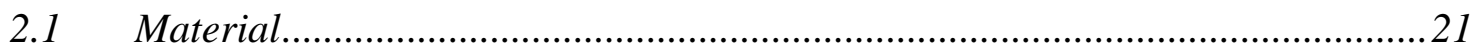

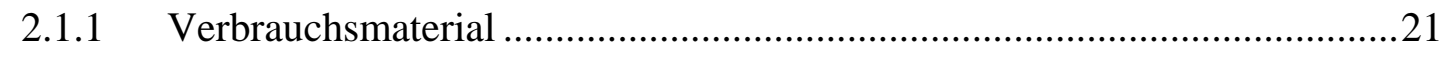

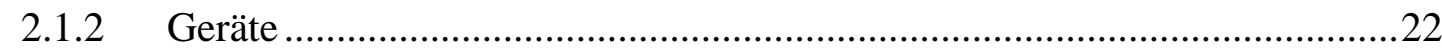

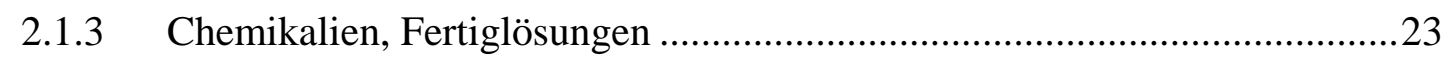

2.1.4 Lösungen, Medien und Puffer..................................................................24

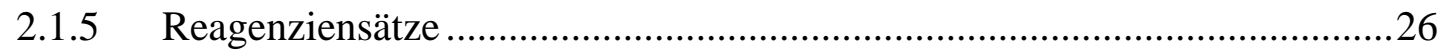

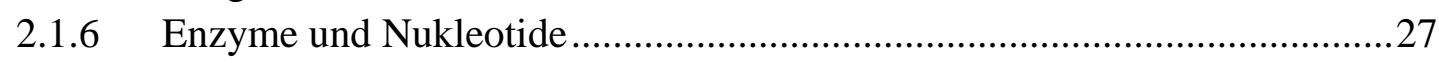

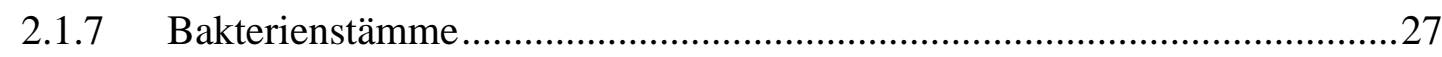

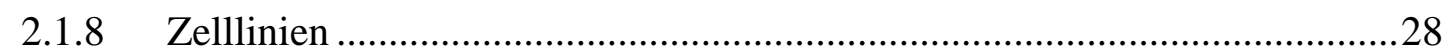

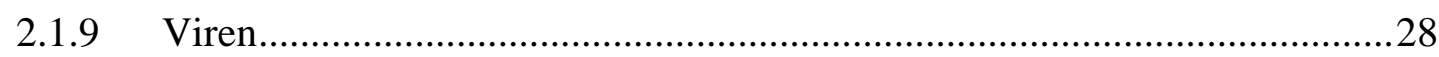

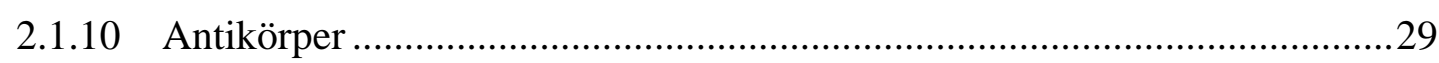

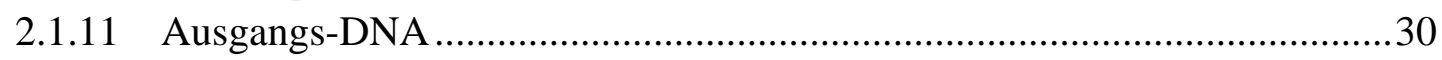

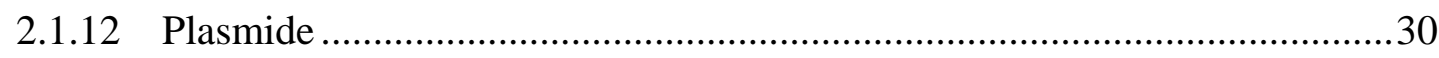

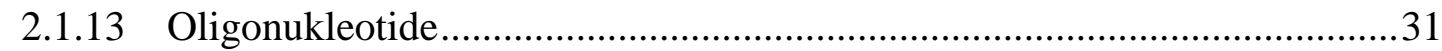

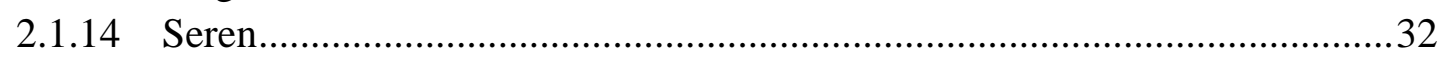

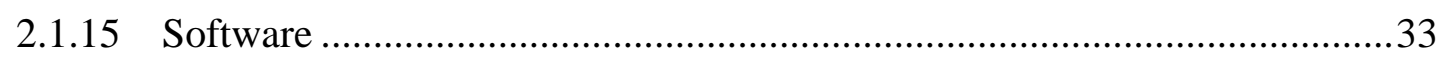


\begin{tabular}{ll} 
Inhaltsverzeichnis & II \\
\hline
\end{tabular}

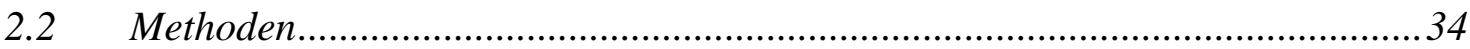

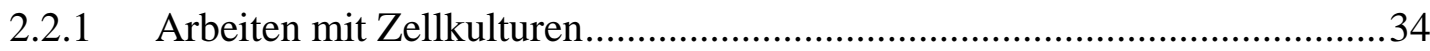

2.2.1.1 Anzucht von Viren in Zellkultur......................................................... 34

2.2.1.2 Fixierung infizierter Zellen auf Objektträger......................................35

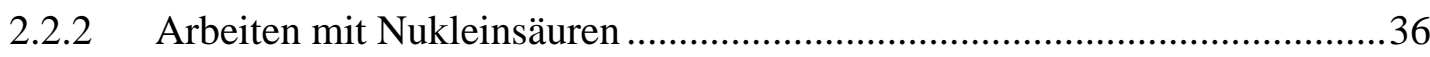

2.2.2.1 Spektrophotometrische Konzentrations- und Reinheitsbestimmungen 36

2.2.2.2 Polymerase-Ketten-Reaktion (PCR) ....................................................36

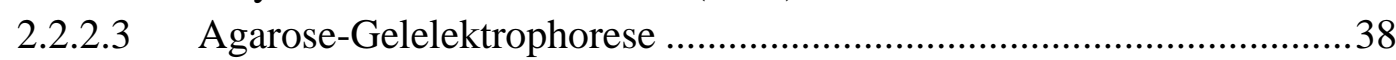

2.2.2.3.1 Analytische und präparative Agarose-Gelelektrophorese .................38

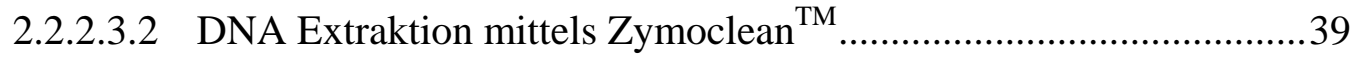

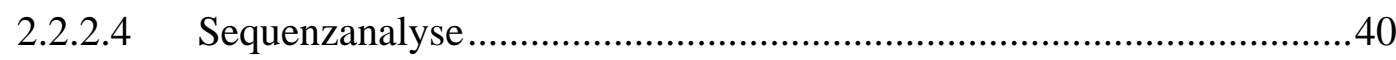

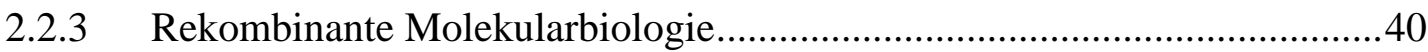

2.2.3.1 Donorvektor Herstellung mittels StarGate ${ }^{\circledR}$ Technologie ....................40

2.2.3.2 Herstellung des Expressionsvektors mittels StarGate ${ }^{\circledR}$ Technologie ...42

2.2.3.3 Transformation rekombinanter DNA in E. coli top 10 bzw. BL21(DE3)

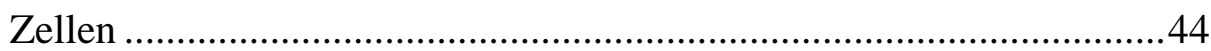

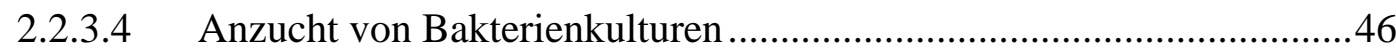

2.2.3.5 Präparation von Plasmid-DNA ….......................................................46

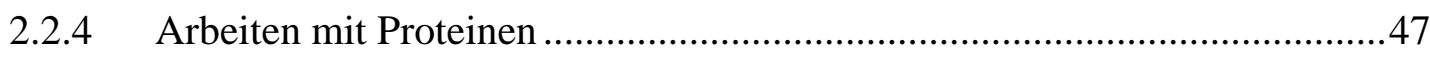

2.2.4.1 Proteinexpression in E. coli BL21(DE3) Zellen...................................47

2.2.4.2 SDS-Polyacrylamid-Gelelektrophorese (SDS-PAGE) ........................48

2.2.4.3 Transfer von Proteinen auf Polyvinylidenfluorid (PVDF) Membran

$($,Western Blot") .......................................................................49

2.2.4.4 Spezifischer Nachweis exprimierter Proteine mittels Strep-tag ${ }^{\circledR} \mathrm{II}$ Antikörper („Immunoblot-Analyse“) ................................................49

2.2.4.5 Solubilisierung unlöslicher Proteine ...................................................5 50

2.2.4.6 Reinigung von Proteinen mittels Strep-tag ${ }^{\circledR} /$ Strep-Tactin ${ }^{\circledR}$ Technologie

2.2.4.7 Dialyse von Proteinen mittels Slide-A-Lyzer ${ }^{\mathrm{TM}}$ G2 Dialyse Kassetten53

2.2.4.8 Proteinkonzentrationsbestimmung mittels Bicinchoninsäure (BCA) ...53

2.2.5 Detektionsmethoden für Antikörper aus Serum.......................................54

2.2.5.1 Immunfluoreszenz Test (IFT) zur Kontrolle der Positivseren ...............54

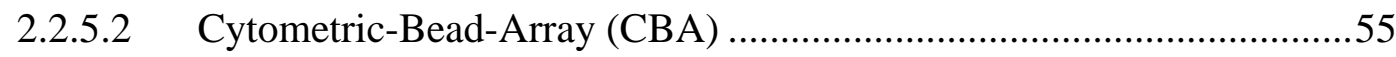

2.2.5.2.1 Kopplung von viralen Oberflächenproteinen an magnetische carboxylierte Mikrokugeln (Beads) ..............................................55

2.2.5.2.2 Nachweis der Kopplung mittels Strep-tag ${ }^{\circledR}$ II spezifischem fluoreszenzmarkiertem Antikörper..................................................58

2.2.5.2.3 Ermittlung der CBA Sensitivität mittels Positivseren .......................59

2.2.5.2.4 Ermittlung der Kreuzreaktivität und Entwicklung des CBA als

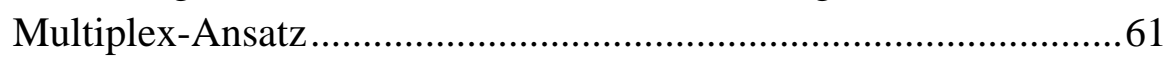

2.2.5.2.5 Multiplex-CBA - Nachweis von Antikörpern gegen europäische Arboviren in Patientenproben.......................................................62

2.2.5.2.6 Grenzwert-Berechnungen und Auswertung des Multiplex-CBA.....63 
3.1 Amplifikation arboviraler Oberflächenproteingene .........................................66

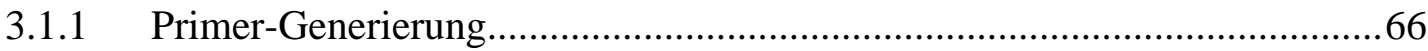

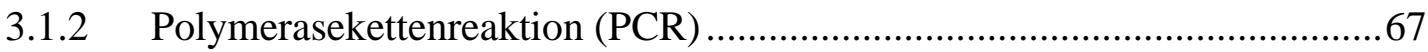

3.2 Ligation, Transformation und Sequenzierung ..............................................68

3.2.1 Ligation der amplifizierten DNA-Fragmente in den Donorvektor pENTRYIBA51 und Transfer in den Expressionsvektor pASG-IBA5 ......................68

3.2.2 Kontrollverdau und Sequenzierung der rekombinanten Donorvektoren .....69

3.2.3 Transformation in kompetente E. coli Zellen ......................................... 71

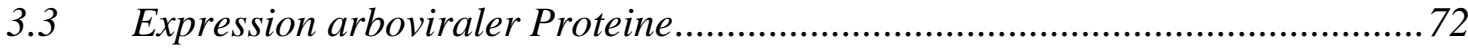

3.3.1 In vivo Proteinexpression in E. coli Bakterienkulturen...............................72

3.3.2 Reinigung, Dialyse und Quantifizierung aller exprimierten Proteine...........74

3.3.3 Spezifischer Protein-Nachweis mittels Western-Blot ..................................75

3.4 Bestätigung verwendeter Positivseren durch Immunfluoreszenztest (IFT) ....... 77

3.5 Entwicklung des CBA als Multiplex-Test................................................... 79

3.5.1 Beweis der Kopplung spezifischer arboviraler Proteine an farbkodierte Populationen magnetischer carboxylierter Beads ......................................79

3.5.2 Vermeidung falsch positiver Ergebnisse durch verbliebene E. coli Proteine..

3.5.3 Entwicklung interner Kontrollen und Notwendigkeit der Präadsorption ....83

3.5.3.1 Entwicklung interner CBA Kontrollen ............................................83

3.5.3.2 Präadsorption der Seren zur Vermeidung falsch positiver Ergebnisse. 84

3.5.4 Sensitivität der gekoppelten Beadpopulationen und optimale Serenverdünnung für Multiplex-Ansätze ................................................86

3.5.5 Ermittlung der Kreuzreaktivität nah verwandter Arboviren ........................8 88

3.5.6 Grenzwertberechnung Multiplex-CBA ................................................90

3.5.7 IgM- und IgG- Antikörpernachweis gegen europäische humanpathogene Arboviren (Multiplex-CBA) .............................................................. 91

3.5.7.1 Auswertung Multiplex-CBA .......................................................92

3.5.7.1.1 Fall 1: Keine arbovirale Infektion: IgM und IgG negativ. ...............92

3.5.7.1.2 Fall 2: Verdacht auf arbovirale Infektion, die Wochen oder Monate zurückliegt: IgM negativ, IgG positiv ..........................................92

3.5.7.1.3 Fall 3: Verdacht auf akute arbovirale Infektion: IgM positiv, IgG

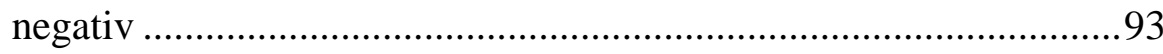

3.5.7.1.4 Fall 4: Verdacht auf akute arbovirale Infektion: IgM positiv, IgG positiv

3.5.7.2 Bestätigung der Multiplex-CBA Ergebnisse durch Mehrfachmessung auffälliger Seren .........................................................................99

3.5.7.3 Bestätigung der Multiplex-CBA Ergebnisse durch Doppelproben ......97

3.5.7.4 Zusammenfassung Multiplex-CBA und IFT-Bestätigung....................99 
6.1 Zusammenfassung: Sequenzanalyse Lasergene ${ }^{T M}$.........................................126

6.1.1 Sequenzanalyse aller rekombinanten Donorplasmide (Strategy View)....126

6.1.2 Beispiel: BATV-N-pENTRY (Alignment) ...............................................127

6.2 Zusammenfassung: Ergebnisse CBA Präadsorptions-Test..............................128

6.3 Zusammenfassung: Ergebnisse CBA Sensitivitätstest ....................................128

6.3.1 MFI (PE) aller Sensitivitätstests, IgG-Antikörper, $n=3$ (Daten) ................128

6.3.2 Einzeldarstellung Sensitivität Typ I und Typ II (GraphPad Prism 6) ........129

6.4 Zusammenfassung: Ergebnisse Multiplex-CBA Kreuzreaktivitätstest.............131

6.4.1 MFI (PE) aller Kreuzreaktivitätstests, IgG-Antikörper, n=3 (Daten) ........131

6.4.2 Kreuzreaktivitätstest mit erwarteten Kreuzreaktionen (GraphPad Prism 6)....

6.4.3 Kreuzreaktivitätstest ohne Kreuzreaktion (GraphPad Prism 6) ..................133

6.5 Zusammenfassung: Ergebnisse Multiplex-CBA Negativseren.........................134

6.5.1 MFI (PE) 45 Negativseren zur Grenzwertberechnung IgG (Daten) ..........134

6.5.2 MFI (PE) 45 Negativseren zur Grenzwertberechnung IgM (Daten) ..........134

6.5.3 Zusammenfassung: Grenzwertberechnung IgG und IgM ........................135

6.6 Zusammenfassung: Ergebnisse Multiplex-CBA Patientenproben ....................135

6.6.1 MFI (PE) Patientenproben IgG $n=1$ (Daten)............................................. 135

6.6.2 MFI (PE) Patientenproben IgM n=1 (Daten) ........................................... 136

6.6.3 Bestätigung Multiplex-CBA durch Untersuchung weiterer Proben des selben Patienten (Zeitraum der Probennahme innerhalb von zwei Wochen)

6.6.4 Bestätigung seropositiver Patientenproben auf arbovirale IgG-Antikörper durch Mehrfachmessung (Daten)....

6.6.5 Bestätigung seropositiver Patientenproben auf arbovirale IgM-Antikörper durch Mehrfachmessung (Daten)

6.6.6 Graphische Darstellung Patientenseren Fall 2 (GraphPad Prism 6) ...........140

6.6.7 Graphische Darstellung Patientenseren Fall 3 (GraphPad Prism 6) ...........141

6.6.8 Graphische Darstellung Patientenseren Fall 4 (GraphPad Prism 6) ...........143 


\section{Abkürzungsverzeichnis}

$\begin{array}{ll}\text { Abb. } & \text { Abbildung } \\ \text { ad } & \text { auffüllen auf } \\ \text { Amp } & \text { Ampicillin } \\ \text { AHT } & \text { Anhydrotetracyclin } \\ \text { APS } & \text { Ammoniumperoxodisulfat } \\ \text { AS } & \text { Aminosäure } \\ \text { bp } & \text { Basenpaar(e) } \\ \text { BSA } & \text { Bovine Serum Albumin (Rinderserumalbumin) } \\ \text { BP } & \text { Beadpopulation } \\ \text { CBA } & \text { Cytometric Bead Array } \\ \text { cDNA } & \text { komplementäre DNA (englisch: complementary DNA) } \\ \text { CPE } & \text { Cytopathischer Effekt } \\ \text { ddH } 2 \mathrm{O} & \text { doppelt-destilliertes Wasser } \\ \text { Da } & \text { Dalton } \\ \text { DMEM } & \text { Dulbeccós modified Eagle- medium } \\ \text { DMF } & \text { N,N-Dimethylformamid } \\ \text { DNA } & \text { Desoxyribonukleinsäure (englisch: desoxyribonucleic acid) } \\ \text { dNTPs } & \text { Desoxynucleosidtriphosphate (dATP, dGTP, dCTP, dTTP) } \\ \text { dpi } & \text { Tage nach Infektion (englisch: days past infection) } \\ \text { ds } & \text { Doppelstrang- } \\ \text { E. coli } & \text { Escherichia coli } \\ \text { EDTA } & \text { Ethylendiamintetraacetat-Dinatriumsalz } \\ \text { Endkonz. } & \text { Endkonzentration } \\ \text { EtOH } & \text { Ethanol } \\ \text { FKS } & \text { Fetales Kälberserum } \\ \text { FSME } & \text { Frühsommer-Meningoenzephalitiserkrankung } \\ \text { h } & \text { Stunde } \\ \text { HEPES } & \text { N-2Hdroxyethylpiperazin-N'-2-ethansulfonsäure } \\ & \end{array}$




\begin{tabular}{|c|c|}
\hline HRP & Meerrettich-Peroxidase (englisch: $\underline{\text { horseradish-peroxidase) }}$ \\
\hline IFT & Immunfluoreszenz Test \\
\hline $\operatorname{IgG}$ & Immunglobulin $\mathrm{G}$ \\
\hline $\operatorname{IgM}$ & Immunglobulin $\mathrm{M}$ \\
\hline Kana & Kanamycin \\
\hline $\mathrm{kb}$ & Kilobasen \\
\hline $\mathrm{kDa}$ & Kilodalton \\
\hline 1 & Liter \\
\hline Lsg. & Lösung \\
\hline M & molar \\
\hline $\mathrm{mA}$ & Milliampere \\
\hline MEM & minimum essential medium \\
\hline MFI & mediane Fluoreszenzintensität \\
\hline $\mathrm{mg}$ & Milligramm \\
\hline $\min$ & Minute \\
\hline $\mathrm{ml}$ & Milliliter \\
\hline $\mathrm{mM}$ & millimolar \\
\hline MW & Molekulargewicht in Dalton \\
\hline MWCO & Molekulargewichts Cutoff in Dalton \\
\hline n.d. & nicht determiniert \\
\hline $\mathrm{nm}$ & Nanometer \\
\hline nt & Nukleotide \\
\hline PAGE & Polyacrylamid-Gelelektrophorese \\
\hline PBS & Phosphat gepufferte Salzlösung \\
\hline & (englisch: phosphate buffered saline) \\
\hline PCR & Polymerase-Ketten-Reaktion \\
\hline & (englisch: polymerase chain reaction) \\
\hline $\mathrm{pH}$ & negativer dekadischer Logarithmus der H+-Ionenkonzentration \\
\hline PVDF & Polyvinylidenfluorid \\
\hline RNA & Ribonukleinsäure (englisch: ribonuleic acid) \\
\hline RT & Raumtemperatur \\
\hline SDS & Sodium Dodecyl Sulfate/Lauryl Sulfate (Natriumdodecylsulfat) \\
\hline
\end{tabular}




\begin{tabular}{ll}
\hline sec & Sekunde \\
ss & Einzelstrang- \\
Tab. & Tabelle \\
TAE & Tris-Acetat-EDTA-Puffer \\
Taq & Thermus aquaticus \\
TE & Tris-EDTA-Puffer \\
TEMED & N,N,N'N'-Tetramethylethylendiamin \\
Tm & Schmelztemperatur \\
Tris & Tris-(hydroxymethyl)-aminomethan \\
U & Unit \\
ü. N. & über Nacht \\
UpM & Umdrehungen pro Minute \\
US & Ultraschall \\
UV & Ultraviolett \\
V & Volt \\
VP & Virales Protein \\
v/v & Volumenverhältnis (volume/volume) \\
w/v & Gewichtsverhältnis (weight/volume) \\
z.B. & zum Beispiel \\
X-Gal & 5-Brom-4-chlor-3-indoxyl-B-D-galactopyranosid \\
ZNS & Zentralnervensystem \\
$\mu$ & Mikro- \\
\hline & \\
\hline
\end{tabular}

Alle chemischen Elemente wurden mit den üblichen Symbolen abgekürzt.

Alle Viren wurden mit den üblichen Buchstaben abgekürzt zusätzlich befindet sich eine erläuternde Tabelle in der Einleitung (Tabelle 1.1). 


\section{$1 \quad$ Einleitung}

\subsection{Europäische Arboviren - Mögliche Auslöser aseptischer Meningoenzephalitis und ihre Verbreitung}

\subsubsection{Aseptische Meningoenzephalitis}

Als Meningitis wird allgemein eine entzündliche Erkrankung der Hirnhäute (Meningen) bezeichnet. Kommt es im Verlauf der Infektion zu einer Beteiligung des Gehirns, so wird von einer Meningoenzephalitis gesprochen. Die häufigste Ursache der Meningitis sind virale Infektionen (Herpesviren, Enteroviren, Paramyxoviren und bestimmte Arboviren). ZNS-Infektionen können auch durch Bakterien (z.B. Listeria monocytogenes, Mycobacterium tuberculosis, Borrelia burgdorferi) oder seltener auch durch Pilze (z. B. Cryptococcus neoformans) und Parasiten (z.B. Toxoplasma gondii) (Solomon, Hart $\&$ Beeching, 2007) hervorgerufen werden.

Als aseptische Meningitis wird eine Meningitis, die nicht durch eine bakterielle Infektion ausgelöst wurde, bezeichnet. Virale Meningitiden stellen damit eine Form der aseptischen Meningitis dar. Symptome wie hohes Fieber, ein schweres, allgemeines Krankheitsgefühl mit grippeähnlichen Symptomen und zunehmende, unerträgliche Kopfschmerzen, Übelkeit mit Erbrechen sowie eine verstärkte Empfindlichkeit gegenüber Licht, Lärm und Berührung können auftreten. Im späteren Verlauf tritt eine Nackensteifigkeit auf. Spätfolgen einer Meningoenzephalitis können Hörstörungen, Krampfleiden, Hirnnervenlähmungen, Entwicklungsrückstand, Verhaltensstörungen, Hydrozephalus (nur beim Fetus), psychische Defektsyndrome und Ataxien sein (Oechtering \& Petzold, 2012; Scheibe \& Schulz, 1991).

Die Frühsommer-Meningoenzephalitis („FSME“, englisch: tick-borne encephalitis = „TBE“) ist in Deutschland eine endemische Viruskrankheit und nach der LymeBorreliose (Erreger: Borrelia burgdorferi) die zweithäufigste von Zecken übertragene Krankheit. In 20\% der Fälle manifestiert sich eine Infektion als aseptische Meningitis und aseptische Meningoenzephalitis (Misić, Daković \& Ruzić, 2009). Die klinischen Symptome einer TBEV-Infektion reichen von mildem Fieber bis $\mathrm{zu}$ schweren neurologischen Schäden (2\% der Fälle) (Burke, 2001). 


\subsubsection{Europäische Arboviren und ihre Verbreitung}

Arboviren (englisch: arthropode-borne virus) werden durch Arthropoden-Vektoren (Arthropoda = Gliederfüßer) übertragen, hierzu zählen unter anderem verschiedene Stechmücken-, Sandmücken- und Zeckenarten. Sie gehören unterschiedlichen Familien von RNA-Viren an: u.a. den Flavi-, Bunya-, Toga-, Reo-, und Picornaviren und rufen Krankheiten wie Gelbfieber, Denguefieber, West-Nil-Fieber, Sandmückenfieber und die in Mitteleuropa von Zecken übertragene TBE hervor.

Das rïhsommer-Meningoenzephalitis-Virus („FSME“ englisch: tick-borne encephalitis virus $\left.=, T B E V^{\prime \prime}\right)$ ist sowohl in Deutschland als auch in Europa das am häufigsten vorkommende humanpathogene Arbovirus (Danielova et al., 2006; Lindgren \& Gustafson, 2001; Lindgren, Talleklint \& Polfeldt, 2000). Es existieren taxonomisch zwei Familien von Zecken, die sog. Ixodidae (Schildzecken) und die Argasidae (Lederzecken). Prototyp für die Familie der Ixodidae ist Ixodes ricinus, der Gemeine Holzbock, der den Hauptüberträger aller durch Zecken übertragenen menschlichen Erkrankungen in Europa darstellt (Süss J., 2004). Neben den Ixodes, welche vorwiegend in Gebieten dichter Vegetation mit hoher Luftfeuchtigkeit (Gebüsch, Laub- und Mischwald) vorkommen (Gray, 2002), zählen ebenso Dermacentor (Buntzecke, bevorzugt warme und trockenere Gebiete: sonnige Hänge, Trockenrasen) und Haemaphysalis $\mathrm{zu}$ den in Europa vorkommenden Virus übertragenden Schildzecken. Weitere ebenfalls von Zecken übertragene Viren wurden in Tabelle 1.1 aufgelistet.

Das West-Nil-Fieber, eine von Stechmücken auf den Menschen übertragene Krankheit bleibt zwar in $80 \%$ der West Nil Virus (WNV) - Infektionen des Menschen asymptomatisch, allerdings entwickeln 20\% der Betroffenen Fieber und bei knapp unter 1\% manifestieren sich neurologische Erkrankungen wie eine aseptische Meningoenzephalitis (Artsob et al., 2009). WNV wurde erstmals 1937 in Afrika (West-Nil Provinz Sudan) beschrieben. In Europa fand man 1963 das erste europäische Isolat aus Patienten und Stechmücken in Frankreich (Hubalek \& Halouzka, 1999), zuvor waren Fälle aus Afrika, Süd-Afrika und Australien bekannt (Schultze-Amberger et al., 2012). In Rumänien gab es 1996 eine größere Epidemie (Tsai et al., 1998), 1999 sprang es nach Amerika über (Lanciotti et al., 1999). Nach Hubalek und Halouzka wurde WNV in Portugal, der Slowakei, Moldawien, Ukraine, Ungarn, Rumänien, Tschechien und Italien isoliert, demnach ist es nur noch eine Frage der Zeit, wann die Zahl der WNV- 
Erkrankungen in Deutschland steigt (siehe Abb. 1.2). Als Vektoren kommen mehrere Stechmückenarten der Gattungen Culex, Aedes, Culiseta und Anopheles in Betracht. Diese Vektoren übertragen auch andere, bislang vernachlässigte Viren wie: Tahyna Virus (TAHV), Batai Virus (BATV) und Inkoo Virus (INKV).

Toskana Virus (TOSV) Infektionen können, wie bereits aus Italien (Nicoletti, Ciufolini \& Verani, 1996) und Spanien (Echevarria et al., 2003; Navarro et al., 2004) bekannt, Auslöser aseptischer Meningitis oder aseptischer Meningoenzephalitis sein (Nicoletti et al., 1991). Als Überträger des Virus kommen einige der Sandmückenarten der Gattung Phlebotomus in Frage. Weitere Vertreter aus dieser Sandmücken-Fieber-Gruppe sind Sandfly Fever Naples Virus (SFNV), Sandfly Fever Sicilian Virus (SFSV), Sandfly Fever Turkey Virus (SFTV), deren Infektionen in den meisten Fällen Symptome des Phlebotomusfiebers verursachen. Hierbei handelt es sich um eine nicht tödliche etwa zwei bis vier Tage anhaltende milde fiebrige Erkrankung, assoziiert mit Unwohlsein und Grippe-ähnlichen Symptomen. Sandmücken sind 2mm kleine sandfarbene Stechmücken mit einer Lebenserwartung von bis zu 40 Tagen. Ihre theoretische Verbreitungsgrenze liegt bei $10^{\circ} \mathrm{C}$ Jahresisothermie, was eine Verbreitung entlang des Rheingrabens bis Köln theoretisch ermöglicht. Zwei Arten von Sandmücken Ph. mascittii und Ph. perniciosus wurden bereits in Rheinland-Pfalz (Wasgau) und Baden-Württemberg (Breisgau) beschrieben (Naucke et al., 2008). Des Weiteren wurden Sandmücken in Belgien, England, Frankreich, Griechenland, Italien, Portugal, Schweiz und Spanien gesichtet (Depaquit et al., 2010), daher sollte in Zukunft den von Sandmücken übertragenen Phleboviren mehr Aufmerksamkeit gewidmet werden.

In Europa bleibt in etwa 70\% aller Fälle aseptischer Meningoenzephalitis das ätiologische Agens ungeklärt. In den letzten 20-30 Jahren konnten alle erwähnten und in Tabelle 1.1 zusammengefassten europäischen Arboviren mit neurologischen Erkrankungen beim Menschen in Verbindung gebracht werden. Diese Viren könnten ursächlich zu etwa 50\% der ungeklärten aseptischen Meningoenzephalitiden beitragen. (Bigl, 2001; Davison et al., 2003; Nowak, Boehmer \& Fuchs, 2003; Rockx et al., 2006; Studahl, Bergstrom \& Hagberg, 1998). Mit Ausnahme des Frühsommer-Meningoenzephalitis Virus (TBEV) und des West Nil Virus (WNV) sind virale Infektionen mit Batai Virus (BATV), Bhanja Virus (BHAV), Erve Virus (ERVEV), Eyach Virus (EYAV), Inkoo Virus (INKV), Palma 
Virus (PALV), Sandfly Fever Naples Virus (SFNV), Sandfly Fever Sicilian Virus (SFSV), Sandfly Fever Turkey Virus (SFTV), Tahyna Virus (TAHV), Toscana Virus (TOSV), Tribec Virus (TRBV) und Uukuniemi Virus (UUKV) nur wenig erforscht. Dabei ist durch vorherige Forschungsergebnisse bereits bekannt, dass neben TBEV (Lindquist \& Vapalahti, 2008) und WNV (Tsai et al., 1998; Tyler, 2001) noch weitere europäische Arboviren, wie das durch Sandmücken übertragene TOSV (Schwarz, Gilch \& Jager, 1995) und SFTV (Ergunay et al., 2012), sowie das durch Stechmücken übertragene TAHV (Bardos, 1974) und die von Zecken übertragenen Viren: EYAV (Malkova et al., 1980), TRBV (Gresikova, Rajcani \& Hruzik, 1966; Libikova, Tesarova \& Rajcani, 1970), ERVEV (Chastel et al., 1989; Treib et al., 1998) und BHAV (Balducci et al., 1970; Hubalek, 1987) aseptische Meningoenzephalitis verursachen können.

Abb. 1.1 zeigt die Verbreitung der in Zeckenspezies nachgewiesenen in dieser Arbeit untersuchten Viren in Europa. TBEV wurde nicht dargestellt. Die TBE kommt, mit Ausnahme der Iberischen Halbinsel, in den Beneluxstaaten und Großbritannien überall in Europa vor. In Abb. 1.2 und Abb. 1.3 ist zum Vergleich die Verbreitung der Stechmücken- und Sandmücken-übertragenen Viren in Europa dargestellt.

Alle verfügbaren Daten weisen darauf hin, dass in Europa durch Arthropoden-Vektoren übertragene Viruserkrankungen ein zunehmendes Problem darstellen, das auch in Deutschland weiter an Bedeutung gewinnen wird (Süss J., 2004).

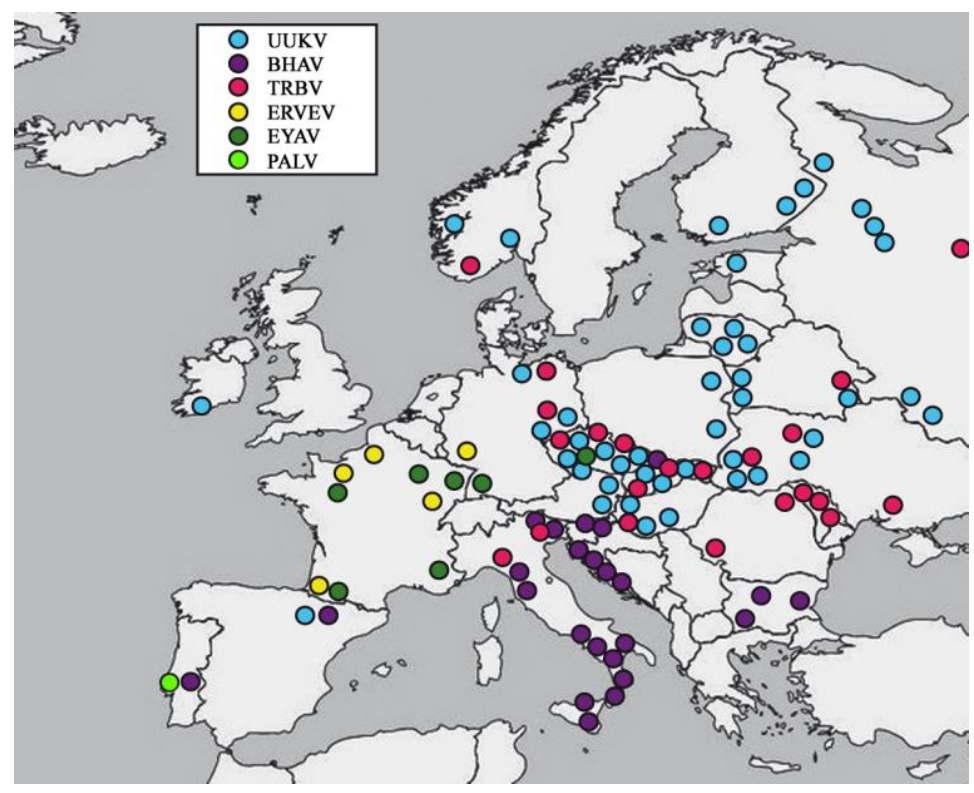

Abb. 1.1: Verbreitung von zeckenübertragenen Viren in Europa. Nachgewiesen durch Virusisolation bzw. Antikörperdetektion unter Verwendung von Daten aus (Dobler, 1996; Hubalek \& Rudolf, 2012; Rhese-Küpper B, 1976; Süss J, 1995; Süss J., 2004). 


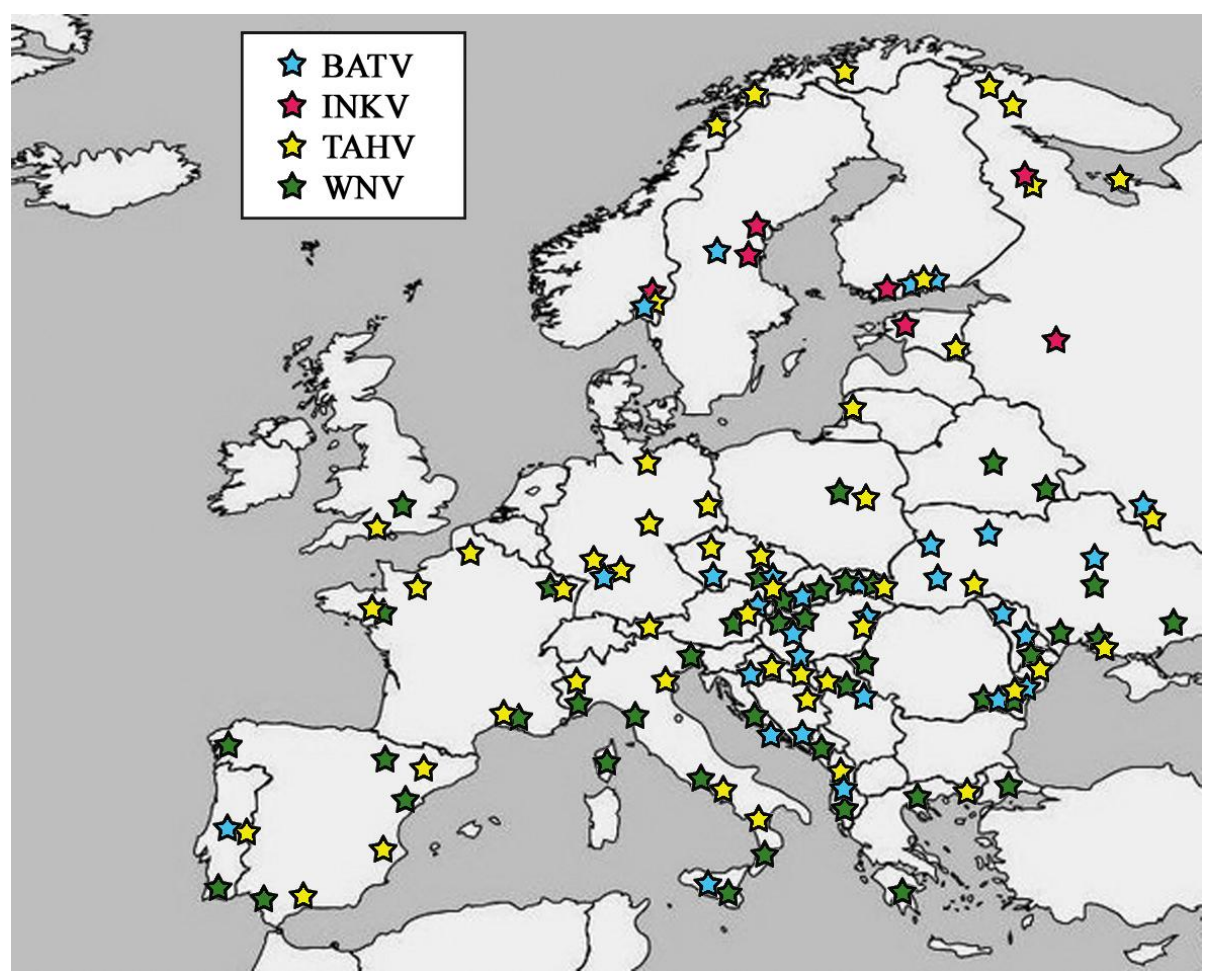

Abb. 1.2: Verbreitung von stechmückenübertragenen Viren in Europa. Nachgewiesen durch Virusisolation bzw. Antikörperdetektion unter Verwendung von Daten aus (Hubalek, 2008; Hubalek \& Halouzka, 1999; Sissy T. Sonnleitner, 2013)

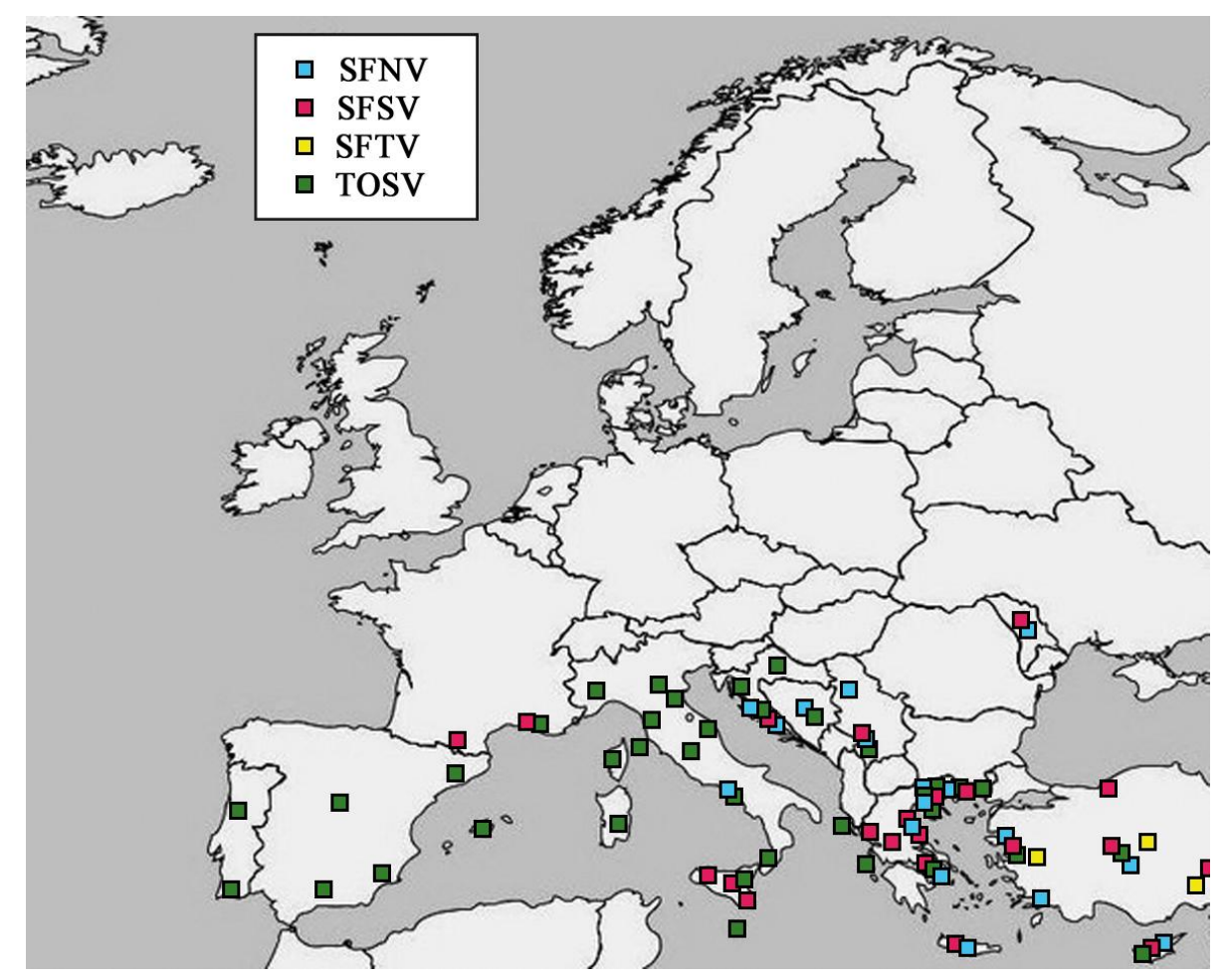

Abb. 1.3: Verbreitung von sandmückenübertragenen Viren in Europa. Nachgewiesen durch Virusisolation bzw. Antikörperdetektion unter Verwendung von Daten aus (Alkan et al., 2013; Anagnostou \& Papa, 2013; Carhan et al., 2010; Ergunay et al., 2011; Hukic \& Salimovic-Besic, 2009) 
Tabelle 1.1: Europäische Arboviren, deren Vektoren und verursachte Krankheitsbilder

\begin{tabular}{|c|c|c|c|c|}
\hline Virus & Familie & Genus & Vektor & Krankheitsbild \\
\hline $\begin{array}{l}\text { Eyach Virus } \\
\text { (EYAV) }\end{array}$ & Reoviridae & Coltivirus & $\begin{array}{l}\text { Zecke } \\
\text { (Ixodes spp.) }\end{array}$ & $\begin{array}{l}\text { Enzephalitis, Poly- } \\
\text { radiculoneuritis }\end{array}$ \\
\hline $\begin{array}{l}\text { Tribec Virus } \\
\text { (TRBV) }\end{array}$ & Reoviridae & Orbivirus & $\begin{array}{l}\text { Zecke } \\
\text { (Ixodes ricinus, } \\
\text { Haemaphysalis } \\
\text { punctata) }\end{array}$ & $\begin{array}{l}\text { Fieber, Meningo- } \\
\text { enzephalitis }\end{array}$ \\
\hline $\begin{array}{l}\text { Erve Virus } \\
\text { (ERVEV) }\end{array}$ & Bunyaviridae & Nairovirus & $\begin{array}{l}\text { Zecke (Ixodes spp., } \\
\text { Dermacentor } \\
\text { marginatus) }\end{array}$ & $\begin{array}{l}\text { ZNS- } \\
\text { Hämorrhagien }\end{array}$ \\
\hline $\begin{array}{l}\text { Bhanja Virus } \\
\text { (BHAV) }\end{array}$ & Bunyaviridae & Phlebovirus & $\begin{array}{l}\text { Zecke } \\
\text { (Haemaphysalis } \\
\text { spp.) }\end{array}$ & $\begin{array}{l}\text { Fieber, Meningo- } \\
\text { enzephalitis }\end{array}$ \\
\hline $\begin{array}{l}\text { Palma Virus } \\
(\text { PALV) }\end{array}$ & Bunyaviridae & Phlebovirus & $\begin{array}{l}\text { Zecke } \\
\text { (Haemaphysalis } \\
\text { punctata) }\end{array}$ & $\begin{array}{l}\text { Bisher beim } \\
\text { Menschen nicht } \\
\text { diagnostiziert. }\end{array}$ \\
\hline $\begin{array}{l}\text { Uukuniemi } \\
\text { Virus } \\
\text { (UUKV) }\end{array}$ & Bunyaviridae & Phlebovirus & $\begin{array}{l}\text { Zecke } \\
\text { (Ixodes ricinus) }\end{array}$ & $\begin{array}{l}\text { Enzephalitis, } \\
\text { neuropathologische } \\
\text { Störungen }\end{array}$ \\
\hline $\begin{array}{l}\text { Tick Borne } \\
\text { Enceph. Virus } \\
\text { (TBEV) }\end{array}$ & Flaviviridae & Flavivirus & $\begin{array}{l}\text { Zecke } \\
\text { (Ixodes ricinus) }\end{array}$ & $\begin{array}{l}\text { Fieber, } \\
\text { Enzephalitis }\end{array}$ \\
\hline $\begin{array}{l}\text { Tahyna Virus } \\
\text { (TAHV) }\end{array}$ & Bunyaviridae & $\begin{array}{l}\text { Ortho- } \\
\text { bunyavirus }\end{array}$ & $\begin{array}{l}\text { Stechmücke (Aedes } \\
\text { spp.,Culex spp., } \\
\text { Culiseta annulata) }\end{array}$ & $\begin{array}{l}\text { ZNS-Infektion, } \\
\text { Fieber, Grippe- } \\
\text { ähnlich }\end{array}$ \\
\hline $\begin{array}{l}\text { Batai Virus } \\
\text { (BATV) }\end{array}$ & Bunyaviridae & $\begin{array}{l}\text { Ortho- } \\
\text { bunyavirus }\end{array}$ & $\begin{array}{l}\text { Stechmücke } \\
\text { (Anopheles spp., } \\
\text { Aedes communis) }\end{array}$ & $\begin{array}{l}\text { Fieber mit } \\
\text { Bronchopneumonie } \\
\text { oder Gastritis }\end{array}$ \\
\hline $\begin{array}{l}\text { Inkoo Virus } \\
\text { (INKV) }\end{array}$ & Bunyaviridae & $\begin{array}{l}\text { Ortho- } \\
\text { bunyavirus }\end{array}$ & $\begin{array}{l}\text { Stechmïcke } \\
\text { (Aedes spp., } \\
\text { Culiseta spp.) }\end{array}$ & $\begin{array}{l}\text { Enzephalitis, } \\
\text { Meningitis }\end{array}$ \\
\hline $\begin{array}{l}\text { West Nil Virus } \\
\text { (WNV) }\end{array}$ & Flaviviridae & Flavivirus & $\begin{array}{l}\text { Stechmücke } \\
\text { (Aedes spp.,Culex } \\
\text { spp.,Culicoides spp.) }\end{array}$ & Enzephalitis \\
\hline $\begin{array}{l}\text { Sandfly Fever } \\
\text { Naples Virus } \\
\text { (SFNV) }\end{array}$ & Bunyaviridae & Phlebovirus & $\begin{array}{l}\text { Sandmücke } \\
\text { (Phlebotomus spp.) }\end{array}$ & Phlebotomusfieber \\
\hline $\begin{array}{l}\text { Sandfly Fever } \\
\text { Sicilian Virus } \\
\text { (SFSV) }\end{array}$ & Bunyaviridae & Phlebovirus & $\begin{array}{l}\text { Sandmücke } \\
\text { (Phlebotomus spp.) }\end{array}$ & Phlebotomusfieber \\
\hline $\begin{array}{l}\text { Sandfly Fever } \\
\text { Turkey Virus } \\
\text { (SFTV) }\end{array}$ & Bunyaviridae & Phlebovirus & $\begin{array}{l}\text { Sandmücke } \\
\text { (Phlebotomus spp.) }\end{array}$ & Phlebotomusfieber \\
\hline $\begin{array}{l}\text { Toscana Virus } \\
\text { (TOSV) }\end{array}$ & Bunyaviridae & Phlebovirus & $\begin{array}{l}\text { Sandmücke } \\
\text { (Phlebotomus spp.) }\end{array}$ & $\begin{array}{l}\text { Phlebotomusfieber } \\
\text { Enzephalitis, seröse } \\
\text { Meningitis (2-12\%) }\end{array}$ \\
\hline
\end{tabular}




\subsubsection{Arthropoden auf dem Weg in unseren Wohnraum: Biodiversitätsverlust, Klimawandel und Globalisierung}

Vor dem Hintergrund einer beginnenden Klimaveränderung ist eine zunehmende Dynamik, auch der Arthropodenpopulation und damit der Vektoren der Arboviren zu erwarten. „Die Zeiten, in denen man von exotischen Erregern sprechen und sich gleichzeitig in Europa sicher vor ihnen fühlen konnte, sind vorbei“ (Martin Pfeffer, Institut für Tierhygiene und Öffentliches Veterinärwesen, AfT- Frühjahrssymposium 2009). Bei den Arboviren ist neben dem Anstieg der globalen Reise- und Handelstätigkeit des Menschen das Klima der wichtigste Faktor, der es einem exotischen Erreger ermöglicht einen natürlichen Übertragungszyklus in unseren Breitengraden zu etablieren (Martin Pfeffer, 2009). Arthropoden gehören zu den wechselwarmen Tieren, sie sind von ihrer Umgebungstemperatur abhängig (ektotherm). Temperatur und Wetter beeinflussen ihre Vermehrungsrate und ihren Lebensraum (Semenza \& Menne, 2009).

Bisher kam der Großteil der Arboviren hauptsächlich in den Tropen und Subtropen vor, jedoch steigt die Anzahl der durch Gliedertiere übertragenen Virusinfektionen weltweit an und die Verbreitung nimmt zu (Süss J., 2004). Wie schon in Abb. 1.1 bis Abb. 1.3 gezeigt, sind Zecken, Stechmücken und Sandmücken bereits in vielen Teilen Europas präsent, Tendenz steigend. Wird auf lange Sicht gesehen das Klima für Stechmücken zu heiß und $\mathrm{zu}$ trocken, werden die Sandmücken aus den südlichen Breitengraden verschwinden und sich in Europa mehr und mehr ausbreiten (Semenza \& Menne, 2009). Mildere und länger anhaltende Wärmeperioden vom Frühling bis Herbst, sowie kürzere und mildere nasse Winter ermöglichen es den blutsaugenden Arthropoden über einen immer größer werdenden Zeitraum Wirte $\mathrm{zu}$ beißen, Blut $\mathrm{zu}$ saugen und so die Verbreitung der Arboviren zu forcieren.

Umweltkatastrophen, wie Überschwemmungen verdrängen zwar beispielsweise Zecken aus ihren Lebensräumen, bieten dafür aber Stechmücken und Sandmücken optimale Bedingungen zur Eiablage (Hubalek et al., 2005). Zecken hingegen erobern jetzt schon Höhenlagen oberhalb von 800m über NN (Daniel et al., 2004; Danielova et al., 2006).

Doch das Klima ist nicht der einzige Faktor, der zur Verbreitung der Arboviren in Europa beträgt. Bevölkerungswachstum und die damit einhergehende Erweiterung von Wohngebieten des Menschen führen bei den Arthropoden zu einer Anpassung ihres Brut- und Jagdverhaltens. Wo Stechmücken noch vor einigen Jahren ihre Eier in Tümpeln und 
Baumhöhlen ablegten und sich von umherstreifenden Wildtieren ernährten, dienen heutzutage Regenwassertonnen als Brutplatz und der Mensch wird zur leicht verfügbaren Nahrungsquelle (Dekoninck et al., 2011). Neben der horizontalen Verbreitung der Arboviren von einem Wirt durch den Biss auf den Nächsten, erfolgt bei den Arthropoden zusätzlich die vertikale transovariale Weitergabe der Viren der Elterngeneration auf die Nachkommen (Danielova et al., 2002; Rosen, 1981; Tesh \& Chaniotis, 1975).

Ebenso ist es möglich, dass im Zuge der Globalisierung Mücken (Aedes albopictusAsiatische Tigermücke) aus Italien, als blinde Passagiere mit dem Güterverkehr über die Schweiz beziehungsweise Österreich nach Deutschland kommen (Prof. Egbert Tannich, BNITM, Gemeinsame Pressemittilung Nr. 02/2013). Bereits 2011 wurden zwei Arten (Aedes albopictus und Aedes japonicus japonicus) in Südwest-Deutschland nachgewiesen (Werner et al., 2012). Drei Arten Aedes albopictus, Aedes atropalpus und Aedes aegypti wurden bis 2010 an mehreren Orten in den Niederlanden nachgewiesen (Scholte et al., 2010). In Schiffslieferungen mit Glücksbambus aus China 2005 Aedes albopictus (Scholte, 2007), in Lieferungen gebrauchter Reifen 2009 Aedes atropalpus (Scholte et al., 2009) und in Reifenlieferungen aus Florida 2010 Aedes aegypti (Brown et al., 2011) gelangten die Mücken in die Niederlande. Als größter Seehafen Europas nimmt Rotterdam eine große Bedeutung im Im- und Export von Waren ein. So könnten durch weitere Transportwege via Schiff auf dem Rhein oder via LKW über die Autobahnen die Mücken mit der importierten Ware nahezu unbemerkt nach Deutschland gelangen.

Die Entwicklung von Virusnachweisverfahren und serologischen Verfahren würde den Anteil aseptischer arboviraler Meningoenzephalitiden am Gesamtanteil der aseptischen Meningoenzephalitis-Fälle in Endemiegebieten ermöglichen und einen Aufschluss über die tatsächliche Verbreitung der Arboviren in Europa ermöglichen.

\subsubsection{Virale Struktur und Genomaufbau}

\subsubsection{Reoviridae}

TRBV (Genus Orbivirus) und EYAV (Genus Coltivirus) gehören zu der Familie der Reoviridae. Das Genom der Reoviren besteht aus 10-12 doppelsträngigen RNASegmenten mit einer Gesamtlänge von ca. $20 \mathrm{~kb}$ bei den Orbiviren und ca. $30 \mathrm{~kb}$ bei den 
Coltiviren (siehe Abb. 1.4 A-C) die für 10-13 Proteine kodieren. TRBV wurde erstmalig 1963 aus Zecken aus dem Tribec-Gebirge (Slowakei) isoliert (Gresikova et al., 1965; Libikova et al., 1964), EYAV 1972 in Eyach, einem Ortsteil von Eutingen im Gäu, nähe Tübingen, Deutschland, aus Ixodes ricinus (Rhese-Küpper B, 1976).

Die nicht-umhüllten Viruspartikel sind aus drei Kapsidschichten aufgebaut, dem inneren, mittleren und äußeren Kapsid (siehe Abb. 1.4 A). Diese bestehen bei den Orbiviren aus den viralen Proteinen VP3 (inneres Kapsid), VP7 (mittleres Kapsid), VP2 und VP5 (äußeres Kapsid). Auf Grund einer abweichenden Nomenklatur der Segmente der Coltiviren ist das VP6 von EYAV vergleichbar mit dem VP5 von TRBV, liegt ebenfalls auf Segment 6 und kodiert für ein Protein des äußeren Kapsids.
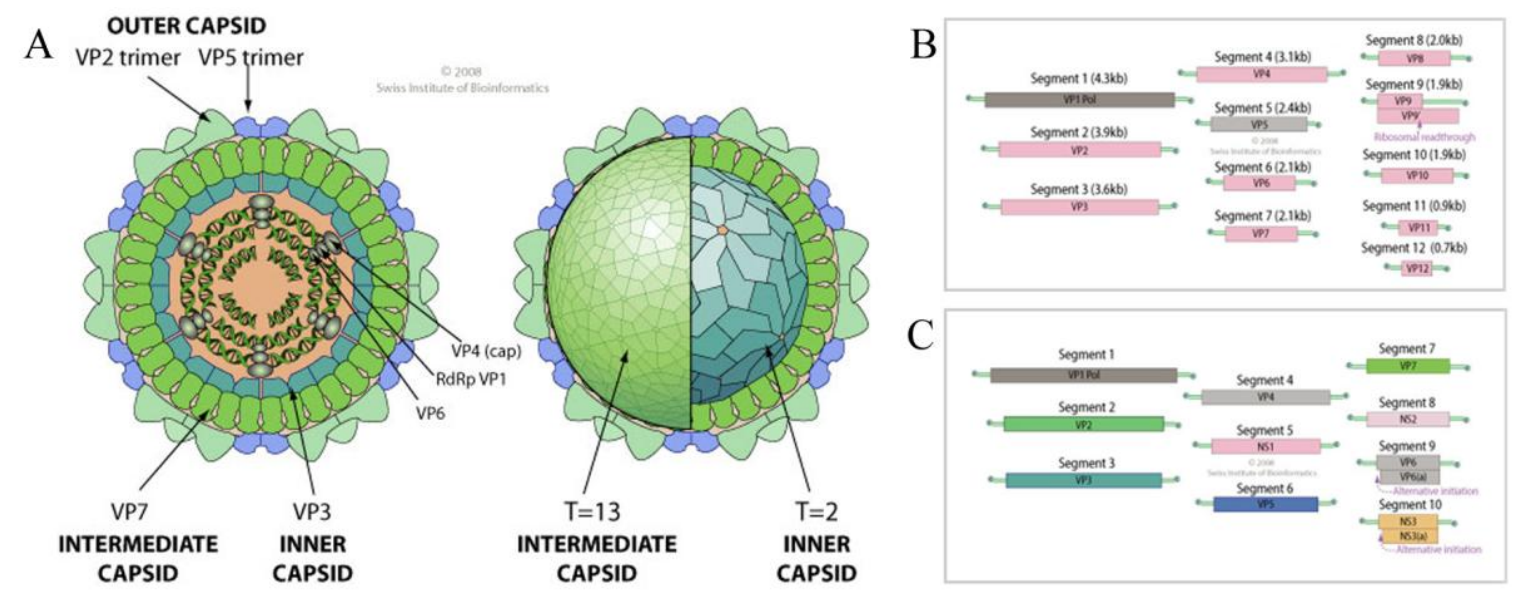

Abb. 1.4: Darstellung Struktur und Genom von Orbivirus und Coltivirus, Familie der Reoviridae. (Quelle: ViralZone, SIB Swiss Institute of Bioinformatics) A: Darstellung der Struktur eines Viruspartikels (hier Orbivirus), unterteilt in inneres (VP3), mittleres (VP7) und äußeres (VP2 und VP5) Kapsid. Durchmesser: $60-80 \mathrm{~nm}$. B: Darstellung des Virusgenoms der Coltiviren mit 12 doppelsträngigen RNASegmenten, die für 13 Proteine kodieren und einer Gesamtlänge von ca. 30kb. C: Darstellung des Virusgenoms der Orbiviren mit 10 doppelsträngigen RNA-Segmenten, die für 12 Proteine kodieren und einer Gesamtlänge von ca. 20kb.

\subsubsection{Bunyaviridae}

Die Familie Bunyaviridae ist eine der größten Virenfamilien und umfasst mehr als 350 Mitglieder weltweit. Sie wurden unterteilt in fünf verschiedene Genera: Phlebovirus, Nairovirus, Orthobunyavirus, Hantavirus und Tospovirus (Fauquet, 2005).

Auch in dieser Arbeit gehört ein großer Teil der Viren zur Familie der Bunyaviren: Nairovirus (ERVEV), Orthobunyavirus (TAHV, INKV, BATV) und Phlebovirus 
(BHAV, PALV, UUKV, SFSV, SFNV, SFTV, TOSV). Das Genom der Bunyaviren besteht aus 3 negativen, linearen einzelsträngigen RNA-Segmenten. Diese sogenannten

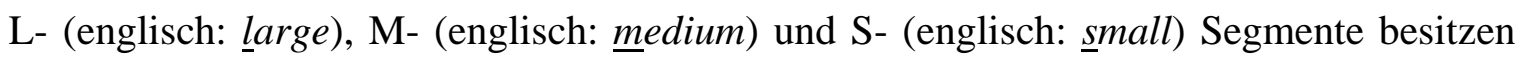
eine Größe von 6,4-12,2kb bzw. 3,2-4,9kb bzw. 1-3kb und kodieren für 4-6 Proteine (siehe Abb. 1.5 B-C).

Das L-Segment kodiert eine RNA-abhängige RNA Polymerase (L), das M-Segment zwei Oberflächen Glykoproteine (Gn und Gc) und für einige Viren ebenso ein NichtstrukturProtein (NSm), das S-Segment ein Nukleoprotein $(\mathrm{N})$ und in einigen Fällen ein Nichtstruktur-Protein (NSs).

ERVEV wurde erstmalig 1982 in Saulges, Frankreich aus Hausspitzmäusen isoliert (Chastel et al., 1989), TAHV 1958 in Tahyna / Solwakei (Bardos \& Danielova, 1959), INKV 1964 in Inkoo / Finnland (Brummer-Korvenkontio et al., 1973), BATV 1955 in Kuala Lumpur / Malaysia (Karabatsos, 1978). Calovo Virus ein Stamm des europäischen BATV weist auf Nukleinsäureebene eine über $80 \%$ ige Homologie in S- M- und LSegment zu BATV auf (Dilcher et al., 2013). Isoliert wurde Calovo Virus 1962 aus Stechmücken in der damaligen Tschechoslowakei (Bardos \& Cupkova, 1962). In dieser Arbeit wurde mit BATV gearbeitet, das eine 97\%ige Homologie des N-Proteins auf Proteinebene zu Calovo Virus zeigt. Das N-Protein des BATV detektiert entsprechend auch Antikörper gegen den europäischen BATV Stamm Calovo Virus. UUKV wurde 1959 in Uukuniemi, Finnland aus Zecken (Oker-Blom, 1964) und BHAV 1954 ebenfalls aus Zecken in Bhanjanagar / Indien (Shah \& Work, 1969) isoliert und ist seitdem mehrmals im Mittelmeerraum beschrieben worden. (siehe Abb. 1.1). Das erste Mal in Europa wurde BHAV 1967 in Italien isoliert (Verani et al., 1970). PALV wurde erstmalig 1992 in Portugal (Filipe et al., 1994) isoliert.

Bei den Sandmückenfieberviren erstmals klinisch beschrieben von Alois Pick 1886 in der Balkanregion wurde 1943 SFSV isoliert: zuerst aus dem Serum eines kranken Soldaten in Ägypten während des Zweiten Weltkrieges und später aus Seren erkrankter Soldaten amerikanischer Truppen auf Sizilien. Nahezu zeitgleich wurde 1944 aus Seren erkrankter Soldaten SFNV in Neapel isoliert (Sabin, 1951). Es folgten die Isolationen des TOSV 1971 in der Toskana / Italien (Verani, Nicoletti \& Ciufolini, 1984) und verhältnismäßig neu 2010 SFTV aus Patientenseren in der Türkei (Carhan et al., 2010). 
Nach 6 Monaten Stationierung auf Zypern waren schwedische Soldaten seropositiv auf SFNV, SFSV und TOSV (Eitrem, Vene \& Niklasson, 1990), wahrscheinlich bedingt durch Kreuzreaktivitäten des dort vorkommenden zypriotischen Sandmückenfiebervirus Stammes SFCV, das sich in 6,7\% zu SFSV auf Nukleinsäureebene unterscheidet (Eitrem, Stylianou \& Niklasson, 1991; Papa et al., 2006).
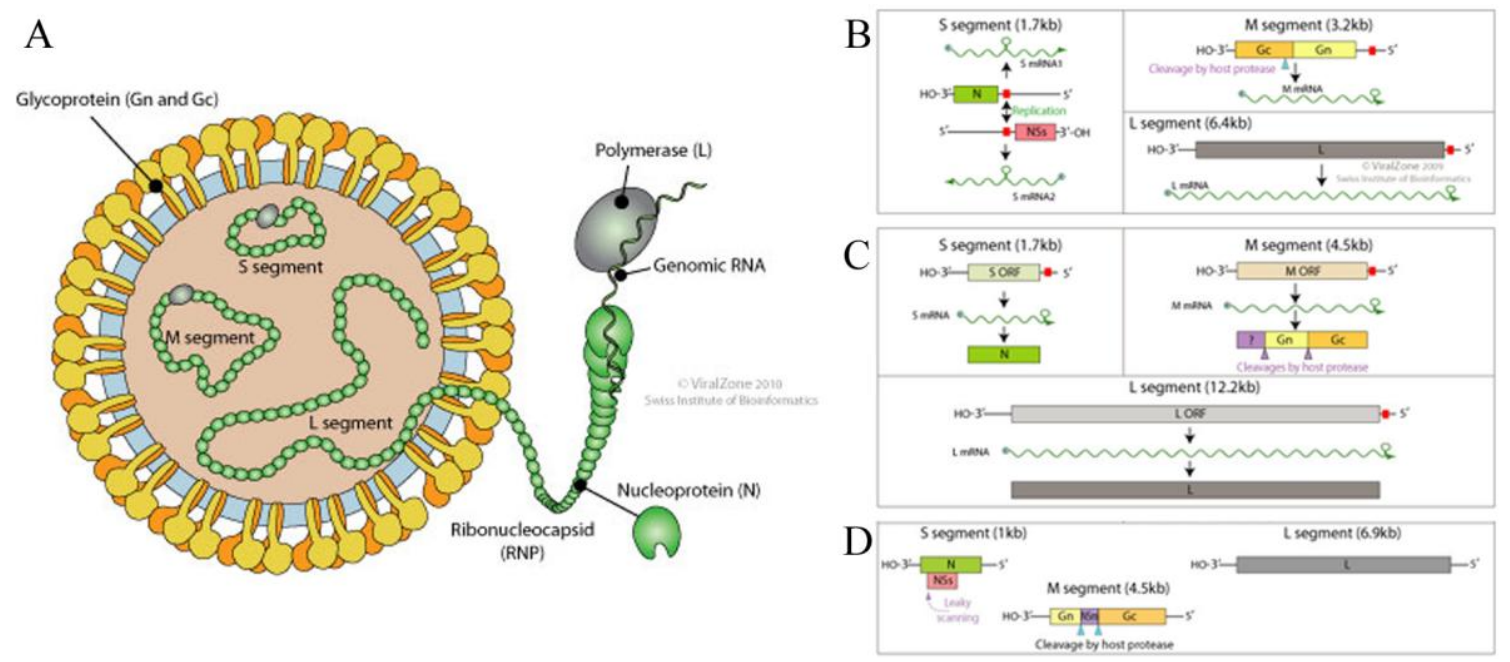

Abb. 1.5: Darstellung Struktur und Genom der Bunyaviridae. (Quelle: ViralZone, SIB Swiss Institute of Bioinformatics) A: Darstellung der Struktur eines Viruspartikels. Durchmesser: 80-120nm. Darstellung des Virusgenoms der Phleboviren (B), Nairoviren (C), Orthobunyaviren (D) mit ihren jeweils unterschiedlich großen drei negativen, einzelsträngigen RNA-Segmenten: S (1-3kb), M (3,2-4,9kb), $\mathrm{L}(6,4-12,2 \mathrm{~kb})$.

\subsubsection{Flaviviridae}

TBEV und WNV gehören zu der Familie der Flaviridae. Das Genom der Flaviviren besteht aus einem linearen, einzelsträngigen RNA-Segment mit einer Gesamtlänge von ca. 10-12kb (siehe Abb. 1.6 B), das für ein Polyprotein kodiert, welches durch wirtseigene Proteasen prozessiert wird. Teile dieses Polyproteins kodieren für das KapsidProtein (englisch: Capsid C), das Membran-Protein (M), die E-Dimere (englisch: envelope: E). NS1, NS2A und NS2B kodieren für unterschiedliche Nichtstrukturproteine, blau dargestellt in Abb. 1.6.

TBE wurde erstmalig 1931 von H. Schneider (Schneider, 1931) in Österreich als epidemische akute Meningitis serosa beschrieben und TBEV konnte 1949 isoliert werden (Kolman JM, 1973). WNV wurde im Rahmen einer Malariastudie 1937 im West-NilDistrikt von Uganda entdeckt und isoliert. 


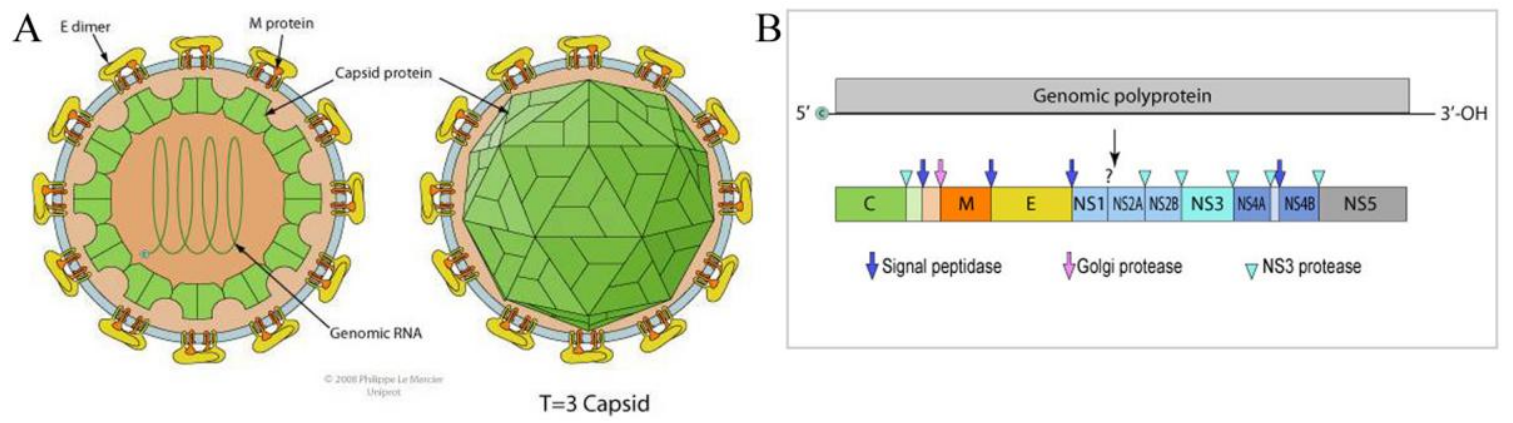

Abb. 1.6: Darstellung Struktur und Genom der Flaviviridae. (Quelle: ViralZone, SIB Swiss Institute of Bioinformatics) A: Darstellung der Struktur eines Viruspartikels. Durchmesser: 50nm. B: Darstellung des Virusgenoms mit einem linearen einzelsträngigen RNA-Segment, das ein Polyprotein kodiert.

\subsection{Cytometric-Bead-Array (CBA) und bisher bestehende Nachweismethoden}

\subsubsection{Bestehende Nachweismethoden}

Um einzuordnen, wo die verschiedenen diagnostischen Nachweismethoden ansetzen ist in Abb. 1.7 das diagnostische Fenster dargestellt, in dem der Virustiter und die AntikörperAntwort des Organismus gegen die Zeit aufgetragen sind. Nach einer Virusinfektion vermehren sich die Viren im Körper, der Titer steigt an (Virämie). In dieser kurzen Phase können die Viren direkt z.B. durch PCR-Techniken oder durch einen gegen virale Antigene gerichteten ELISA (englisch: Enzyme Linked Immunos orbent $\underline{\text { Assay) }}$ nachgewiesen werden. Da die akute Phase relativ kurz ist und Symptome einer Infektion oft erst zu einem späteren Zeitpunkt auftreten, gestaltet sich die rechtzeitige Probenentnahme oftmals schwierig.

Im weiteren Verlauf der Krankheit werden durch die Immunantwort Antikörper (in der frühen Phase IgM, später IgG) gebildet. Diese im Serum enthaltenen Antikörper können nach der Detektion Rückschlüsse auf die zuvor stattgefundene Infektion geben und eventuelle Spätfolgen durch anschließende Behandlung minimieren.

Die diagnostische Lücke beschreibt den Zeitraum zwischen dem Zeitpunkt der Infektion und dem Zeitpunkt ab dem die vorhergehende oder akute Anwesenheit eines Pathogens (z.B. Virus) in einem Organismus durch einen spezifischen Test sicher nachgewiesen werden kann.

Als extremes Beispiel sei die HIV-Infektion genannt. Hier kann ein Zeitraum von bis zu zwölf Wochen vergehen bis Antikörper im Serum nachweisbar werden. 
Ein weiteres Beispiel ist die TBEV-Infektion, bei der bereits acht Tagen nach Infektion Antikörper (sowohl gegen Struktur Glykoprotein E, wie auch gegen Nichtstruktur Glykoprotein NS1) in Serum und Spinalflüssigkeit auftreten, diese sind mindestens bis zu zwei Monate nachweisbar (Matveeva et al., 1995). Bei einer potentiellen TBEV-Infektion muss ein signifikanter Serumtiteranstieg gemessen werden, damit das Ergebnis als bewiesen positiv bewertet werden kann. Signifikant bedeutet im Falle von austitrierbaren Testverfahren (z.B. Hämagglutinationstest, IFT, ELISA) einen Anstieg von mindestens zwei Titerstufen. Dazu sind eine Blutabnahme möglichst rasch nach Infektion und eine zweite nach weiteren zwei Wochen nötig. Wird der Zeitpunkt der zweiten Abnahme zu früh gewählt, kann der Anstieg nicht oder nicht signifikant nachweisbar sein und es kann zu einem falsch negativen Ergebnis kommen.

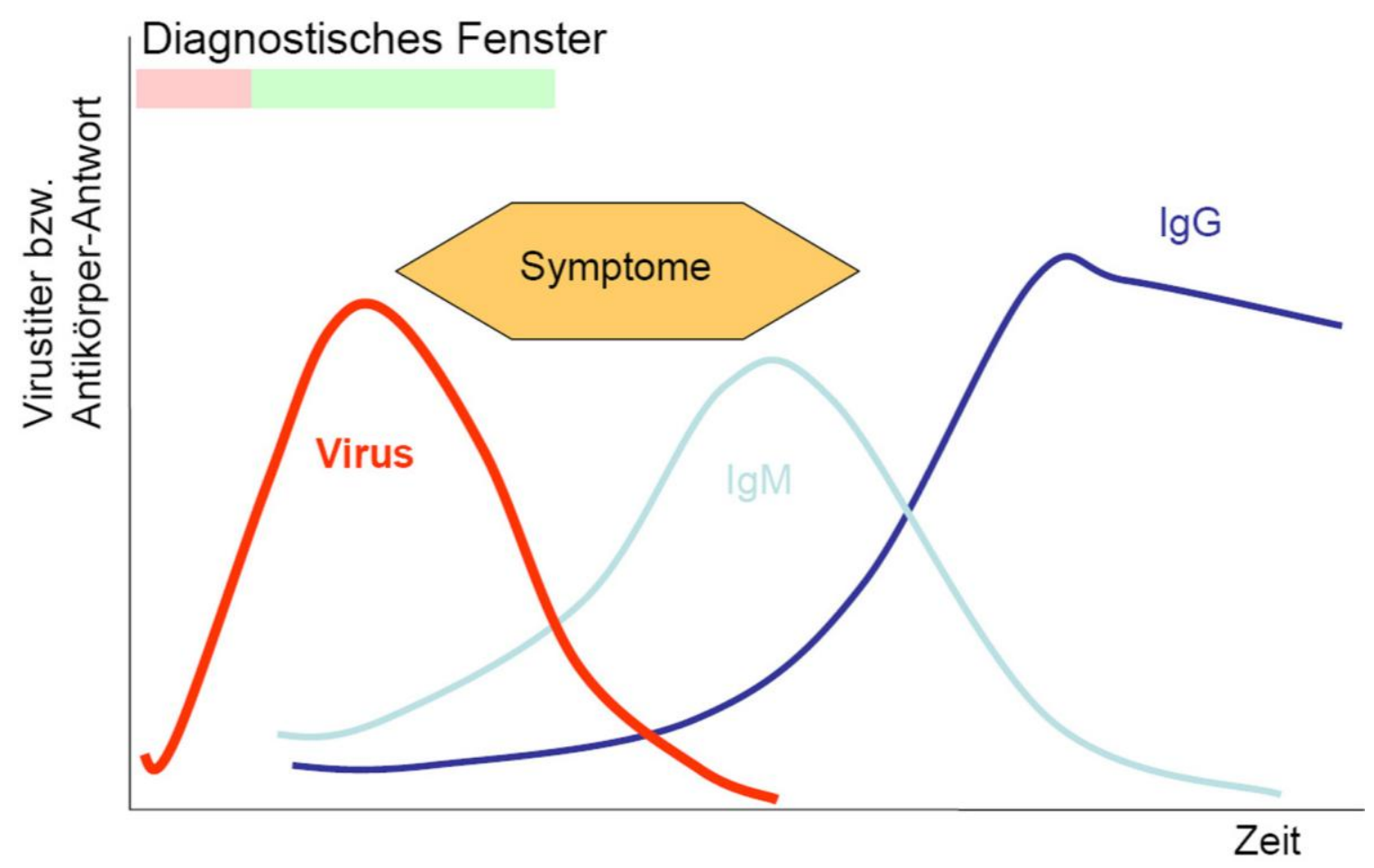

Abb. 1.7: Diagnostisches Fenster. Darstellung des Virustiters bzw. der Antikörper-Antwort nach Infektion mit einem Erreger aufgetragen gegen die Zeit. (Quelle: http://molecular-virology.uni-hd.de)

Die Länge der diagnostischen Lücke ist von Virus zu Virus unterschiedlich und muss bei einem Multiplex-Test berücksichtigt werden. 
Obwohl sich die Probenentnahme wegen der zuvor genannten Gründe als schwierig gestaltet, wurde an einem Real-Time-PCR-Verfahren zum Direktnachweis des Virus für TRBV, UUKV, SFTV, BHAV und PALV gearbeitet (Weidmann et al., 2003b; Weidmann et al., 2008b). Andere auf PCR-Techniken beruhende Nachweise von TBEV (Suss et al., 1996) und Bunyaviren der Bunyamwera und Kalifonien Serogruppe (Kuno et al., 1996; Weidmann et al., 2003b) wurden ebenfalls über die Jahre etabliert. Weiterhin wurden RT-nested-PCR und Real-Time-PCR Verfahren für TOSV und andere Phleboviren (Weidmann et al., 2008b) und ein moderneres Microarray basiertes Nachweissystem zum Nukleinsäurenachweis entwickelt. Diese sogenannte Multiplex Ligation Dependent Probe Amplification (MLPA) wurde mit einem DurchflussMicroarray kombiniert und steht theoretisch für TBEV, TOSV, SFSV, SFNV, TAHV, INKV, BATV, UUKV zur Verfügung (Hasib et al., 2011).

Als letztes im Bereich der direkten Virusnachweismethoden sei das Next-GenerationSequencing erwähnt. Diese Methode ist hochspezifisch, jedoch vergleichsweise zeit- und kostenintensiv und konnte bereits zur Bestimmung der Genome von BATV, BHAV, PALV, TRBV und ERVEV erfolgreich eingesetzt werden (Dilcher et al., 2012a; Dilcher et al., 2012b; Dilcher et al., 2012c). An einer Anwendung zum ungerichteten Nachweis aseptischer Meningoenzephalitis-auslösender Viren in Patientenmaterialien wird noch gearbeitet.

Serologische Nachweise von Antikörpern nach Virusinfektion existieren bislang größtenteils in Form von enzymatischen Immunadsorptionsverfahren (EIA) inklusive ELISA (basierend auf einer enzymatischen Farbreaktion) und IFT (Immunfluoreszenztest siehe Kap. 2.2.5.1).

Zum Nachweis von TBEV IgG Antikörpern existieren mehrere industriell hergestellte EIA-Tests (englisch: Enzyme Immuno Assay). In einer früheren Studie wurden sechs dieser Tests auf Sensitivität und Spezifität miteinander verglichen (Niedrig et al., 2001). Es hat sich gezeigt, dass alle Tests durch Kreuzreaktionen zu verwandten Flaviviren (Gelbfieber-Virus und Dengue-Virus) mitunter zu falsch positiven Ergebnissen geführt haben, so dass eine Verbesserung der Sensitivität und der Spezifität dieser Tests empfohlen wurde. 
Ebenfalls können mit dem IFT indirekt Antikörper (IgG und IgM) durch eine Inkubation Virus-infizierter Zellen mit einem Serum und anschließender Inkubation mit einem zweiten fluoreszenzgekoppelten spezifischen Antikörper gegen die Serumantikörper mittels Fluoreszenzmikroskopie nachgewiesen werden (Connie, Mahon \& Manuselis, 1995). Nachteil dieser Methode ist die nicht gleichbleibende Auswertung der Ergebnisse, da die Fluoreszenz subjektiv durch eine Person durch Betrachtung mit einem Fluoreszenzmikroskop bestimmt und so über ein positives oder negatives Ergebnis entschieden wird.

Sowohl ELISA wie auch IFT sind für Einzelanalysen ausgelegt (pro Testansatz wird in der Regel der Nachweis von Antikörpern gegen einen Erreger untersucht). Entsprechend zeitintensiv und aufwändig gestaltet sich die Überprüfung eines Serums auf Antikörper gegen mehrere Erreger (Khan et al., 2005).

Die Entwicklung eines Tests der falsch positive Ergebnisse durch Kreuzreaktionen ausschließt, eine hohe Spezifität und Sensitivität aufweist, objektiv auswertbar ist und simultan ein ganzes Spektrum verschiedener Virenantikörper in einem Ansatz nachweisen kann und entsprechend nur ein geringes Probenvolumen benötigt, wäre demnach wünschenswert und ist Ansatzpunkt dieser Arbeit.

\subsubsection{Aufbau und Prinzip der xMAP Technologie - Bio-Plex ${ }^{\circledR}$ MAGPIX ${ }^{\mathrm{TM}}$-System}

Die Messungen des in dieser Arbeit entwickelten Tests wurden mit einem relativ neuen auf Fluoreszenz-basierenden Detektionsgerät namens MAGPIX $^{\mathrm{TM}}$ Multiplex Reader (Luminex Corporation) durchgeführt.

Das MAGPIX ${ }^{\mathrm{TM}}$-System beruht auf dem Prinzip der xMAP-Technologie lizensiert von Luminex Corp. und ermöglicht qualitative und quantitative Analysen von Proteinen und Nukleinsäuren (Houser, 2012). Es handelt sich um ein Analyseinstrument, welches statt der anfälligen Laser bisheriger Durchflusszytometer (z.B. FACS Canto II) lichtemittierende Dioden (LEDs) verwendet. Benutzt werden dabei für Multiplex-Tests derzeit bis zu 50 farbkodierte magnetische Mikrokugeln (Beads) pro Testansatz, bei einer derzeitigen Auswahl von 80 unterschiedlichen Bio-Plex Pro magnetic COOH-Beads (Bio Rad). Die Farbkodierung der Beads wird durch ihre Füllung mit unterschiedlichen 
Verhältnissen zweier Fluoreszenzfarbstoffe (rot und infrarot: genaue Zusammensetzung Firmengeheimnis von Luminex Corp.) erreicht, was eine eindeutige Zuordnung der einzelnen Beadpopulationen bei Auftragung beider Fluoreszenzsignale gegeneinander ermöglicht (siehe Abb. 1.8).

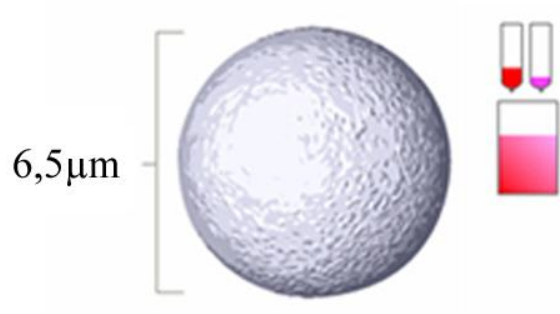

Bio-Plex Pro magnetic $\mathrm{COOH}$ Beads

$1.25 \times 10^{7}$ Beads $/ \mathrm{ml}$
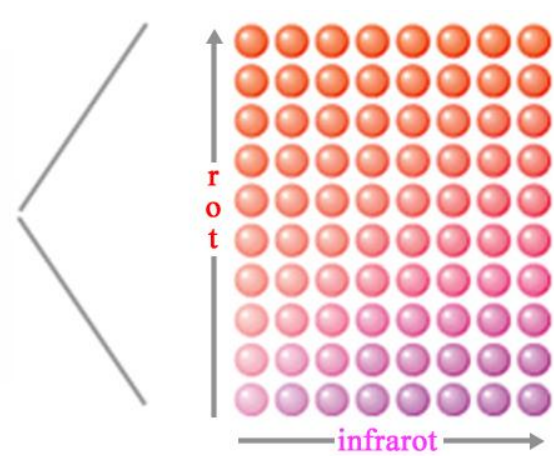

Farbkodierung

Beadpopulationen

Abb. 1.8: Darstellung der multiplex Technologie mit Mikrokugeln (Beads). Die Beads sind farbkodiert durch Füllung mit unterschiedlichen Verhältnissen zweier Fluoreszenzfarbstoffe (rot und infrarot). Derzeit werden bis $\mathrm{zu} 80$ verschiedene magnetische Beadpopulationen der Firma BioRad angeboten. (Quelle: http://www.bio-rad.com/magpix)

Bei der Messung am MAGPIX ${ }^{\mathrm{TM}}$-System wird der Ansatz nicht wie bei einem Durchflusszytometer vereinzelt und jede Mikrokugel (Bead) separat in einem laminaren Strom an verschiedenen Lasern vorbeigeführt sondern komplett in eine Kammer gezogen und dort auf einer Magnetplatte verteilt und immobilisiert (siehe Abb. 1.9). Anschließend erfolgt das Auslesen aller Beads parallel mit Hilfe eines CCD-Bildsensors (englisch: charge-coupled device).

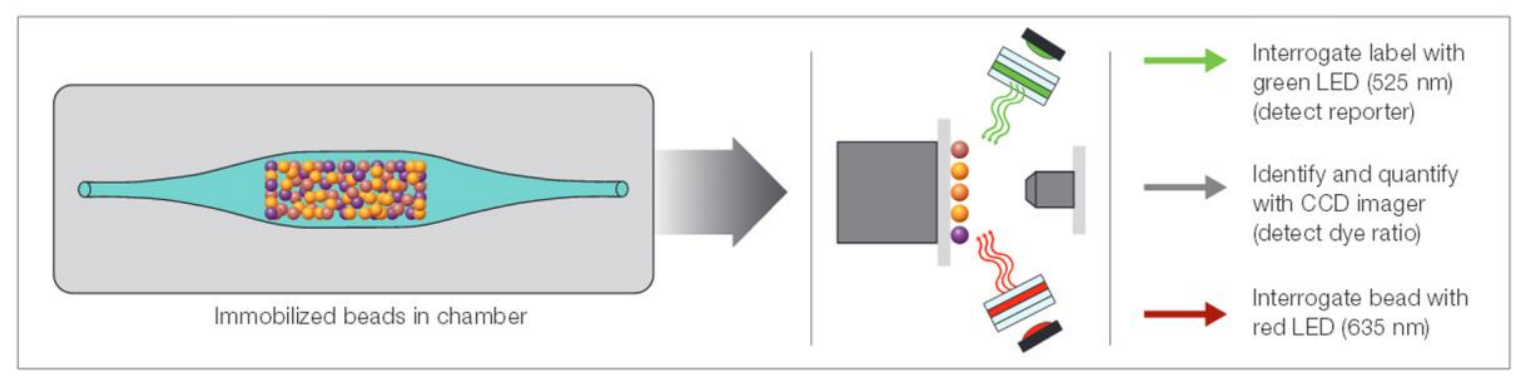

Abb. 1.9: Darstellung der immobilisierten magnetischen Beads beleuchtet mit LED's und abgebildet durch CCD Technologie. Die rote LED (635nm) dient zur Abfrage der internen Verhältnisse der zwei Fluoreszenzfarbstoffe zur Identifizierung der internen Farbkodierung. Die grüne LED (525nm) dient zur Signalabfrage des Reporterfluoreszenzfarbstoffes zur Bestimmung der medianen Fluoreszenzintensität (MFI) (Quelle: (Houser, 2012)). 
In der Kammer werden die Beads mit einer roten LED mit einer Wellenlänge von 635nm bestrahlt, dies dient zur Identifizierung der vorhandenen Beadpopulationen an Hand der Farbkodierung. Die Eigenschaft, dass die eingesetzten Fluoreszenzfarbstoffe (rot und infrarot) sich bei gemeinsamen Wellenlängen anregen lassen (635nm) aber über unterschiedliche, charakteristische Emissionsspektren verfügen (Maxima bei 680nm bzw. 775nm), ermöglicht die Differenzierung der einzelnen Beadpopulationen (siehe Abb. 1.10). Parallel $\mathrm{zu}$ der roten LED werden die Beads mit einer grünen LED (525nm) bestrahlt, was eine gleichzeitige Abfrage für das Phycoerythrin (PE)-Signal ermöglicht. Absorptionsspektrum siehe ebenfalls Abb. 1.10 in gelbgestrichelt dargestellt und das Emissionsmaximum bei $575 \mathrm{~nm}$.

Aufgenommen werden alle Signale mittels CCD-Bildsensor, der bereits 1970 von Willard Boyle und George E. Smith erfunden wurde. Dieses lichtempfindliche elektronische Bauelement, dessen Funktion auf dem inneren Photoeffekt beruht wird heutzutage in Videokameras und Digitalkameras eingesetzt. Der CCD-Flächensensor ermöglicht das einfache Erfassen zweidimensionaler Bilder, deren Informationen digital gespeichert werden. Diese Informationen werden dann zur Auswertung des gemessenen Testes verwendet und zeigen u.a. die mediane Fluoreszenzintensität (MFI) für PE und die Anzahl der gemessenen Beads pro Beadpopulation. Ebenfalls kann für Quantitative Tests eine Konzentrationsermittlung an Hand einer mitgeführten Standardreihe erfolgen.

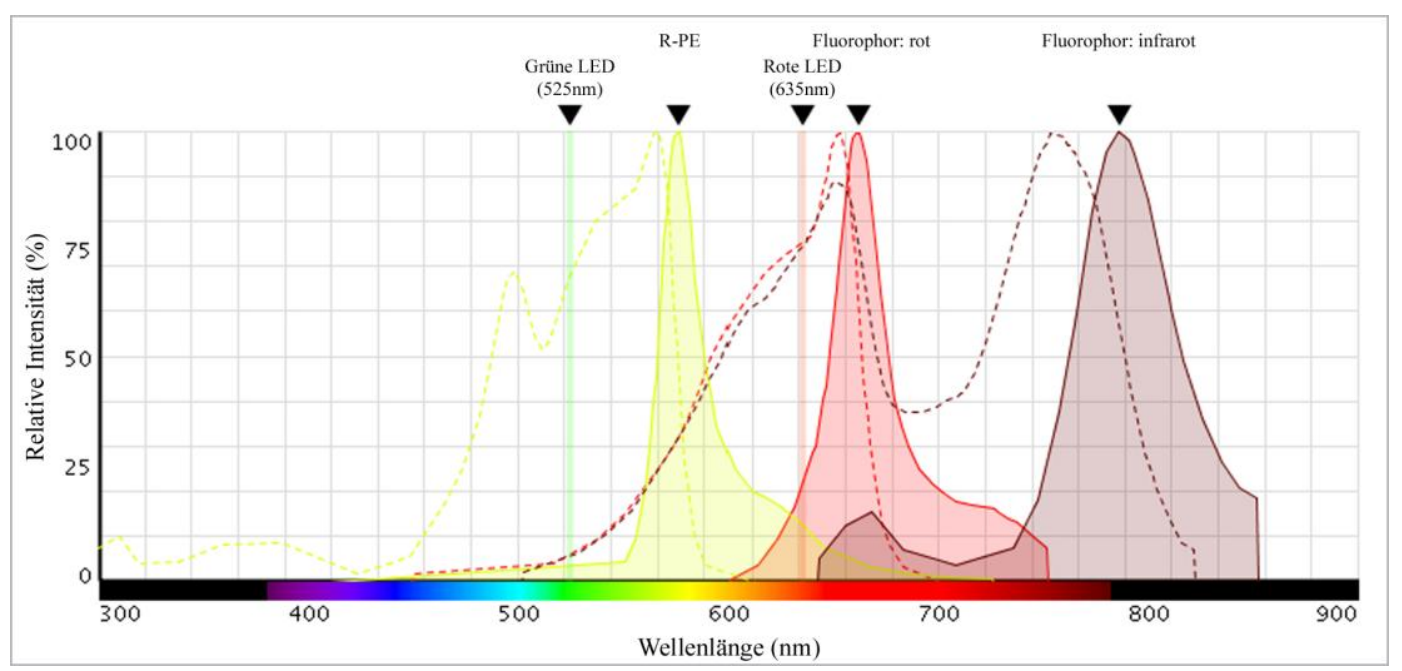

Abb. 1.10: Darstellung der Absorptions- und Emissionsmaxima bekannter Fluoreszenzfarbstoffe. Dargestellt sind die Absorptionsmaxima von PE (480nm, 565nm), APC (650nm), AF750-APC (650nm, $775 \mathrm{~nm})$ als gestrichelte Linien, die Emissionsmaxima von PE (575nm), APC (680nm), AF750-APC (775nm) als schraffierte Bereiche. Zusätzlich sind die anregenden LED Signale der Wellenlängen der grünen LED $(525 \mathrm{~nm})$ und roten LED $(635 \mathrm{~nm})$ angegeben. (Quelle: www.lifetechnologies.com, Fluorescence Spectra Viewer ) 


\subsubsection{Multiplex Cytometric-Bead-Array (CBA) - Simultaner Antikörpernachweis von europäischen Arboviren}

Bei dem in dieser Arbeit entwickelten zytometrischen Kugel-Test-Verfahren (englisch: Cytometric-Bead-Array „CBA“) handelt es sich um einen serologischen Nachweis von Antikörpern gegen humanpathogene Arboviren. Die Entwicklung des CBA als Simultannachweis (Multiplex-Nachweis) von Antikörpern ermöglicht die parallele Detektion gegen ein ganzes Spektrum an Viren in einer einzigen Patientenprobe. Es wurden insgesamt 15 durch Zecken, Stechmücken und Sandmücken übertragene europäische Arboviren (siehe Tabelle 1.1) erfasst.

Das Prinzip des CBA ist in Abb. 1.11 dargestellt und beschreibt einen auf Beads basierenden Flüssigphasen-Immunadsorptionstest. Im ersten Schritt werden mit Antigenen gekoppelte Beadpopulationen mit einem Serum inkubiert, dabei binden die antiviralen Antikörper des Serums spezifisch an die viralen Antigene auf den Beads. Im folgenden Schritt wird mit einem fluoreszenzmarkiertem Zweitantikörper inkubiert, der spezifisch an den $\mathrm{F}_{\mathrm{c}}$-Teil des Erstantikörpers bindet. Die Farbkodierung der Beads und das PE-Signal werden durch Fluoreszenzsignalmessung am MAGPIX ${ }^{\mathrm{TM}}{ }_{-S y s t e m}$, wie in Kapitel 1.2.2 beschrieben, gemessen und ausgewertet.

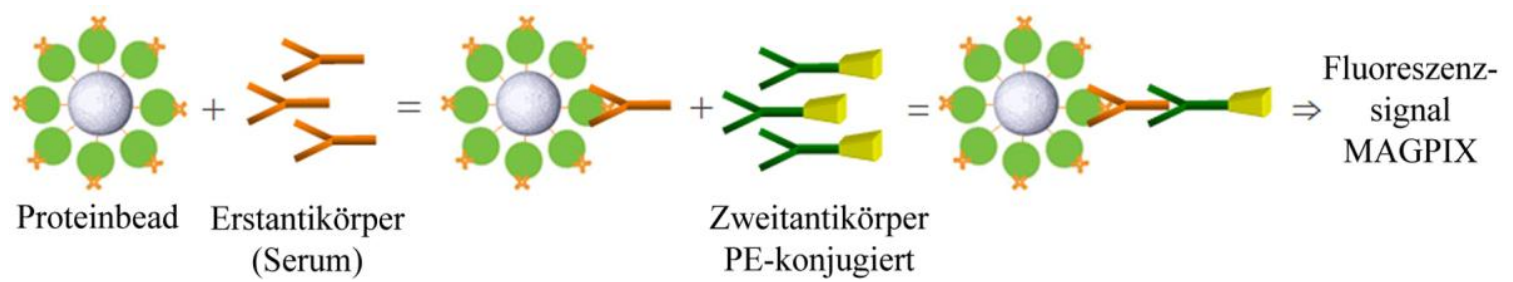

Abb. 1.11: Schematische Darstellung: Prinzip Cytometric-Bead-Array (CBA). Im ersten Inkubationsschritt binden die anti-viralen Antikörper des Serums spezifisch an die viralen Antigene auf den Proteinbeads. Im zweiten Inkubationsschritt bindet der fluoreszenzmarkierte Zweitantikörper spezifisch an den $\mathrm{F}_{\mathrm{c}}$-Teil des Erstantikörpers. Die Fluoreszenzsignalmessung erfolgt am MAGPIX ${ }^{\mathrm{TM}}$-System.

Hintergrund dieser Methode sind die Abwehrreaktionen unseres Immunsystems bei Infektionserkrankungen. Im Verlauf der Erkrankung kommt es zur Bildung von Antikörpern. Diese Antikörper sind gegen ein bestimmtes Virus gerichtet und besitzen die Fähigkeit spezifisch an Antigene auf der Virenoberfläche zu binden, so dass diese Viren vom Immunsystem erkannt und vernichtet werden können (siehe auch Kap.1.2.1).

Für den CBA wurden rekombinante virale Oberflächenproteine: Nukleoprotein $\mathrm{N}$ der Bunyaviren, Nichtstrukturprotein NS1 der Flaviviren und die Oberflächenproteine VP6 
bzw. VP7 der Reoviren (siehe Kap.1.1.4) mit antigenen Eigenschaften exprimiert, gereinigt und kovalent an unterschiedliche farbkodierte Beadpopulationen gekoppelt.

Der Vorteil des CBA gegenüber den anderen in Kap.1.2.1 beschriebenen diagnostischen Nachweismethoden ist die Ermöglichung einer gleichzeitigen Detektion verschiedener Antikörper in einer Patientenprobe. Durch die simultane Messung wird das benötigte Probenvolumen gering gehalten und die Zeit zur Durchführung des Testes stark reduziert (Morgan et al., 2004).

Ein weiterer Vorteil des CBA ist die Bindungskinetik in flüssiger Phase die eine höhere Reaktionskinetik als an der festen Phase der EIA-Systeme erlaubt (Khan et al., 2005; Lal et al., 2005). Dadurch kann eine höhere Sensitivität des CBAs in kürzeren Inkubationszeiten im Vergleich zu ELISA- und IFT-Techniken erreicht werden.

Das Potential der auf Beads basierenden Multiplex-Tests im Vergleich zu bekannten anderen Nachweismethoden wurde bereits im Jahr 2000 erkannt (Vignali, 2000). Die Idee hingegen wurde schon Jahre zuvor aufgegriffen, 1982 wurde der erste Test zum Nachweis von humanem IgG entwickelt (Lisi et al., 1982). Mittlerweile steht eine Vielzahl von Bead-Assays zur Verfügung, mitunter zur Detektion humaner Antikörper gegen West Nil Virus (Wong et al., 2004) oder der Zytokin-Nachweis nach Virusinfektion (Maino \& Maecker, 2004).

Einen Multiplex-Test für Arboviren auf Bead basierenden Fluoreszenzmessungen suchte man bisher allerdings vergebens.

\subsection{Zielsetzung}

Die Mehrzahl der beim Menschen auftretenden aseptischen Meningitis und Enzephalitis Fälle sind ätiologisch ungeklärt. Eine Reihe von europäischen Arboviren stehen im Verdacht Auslöser dieser Erkrankungen zu sein. Diese Wissenslücke gründet sich vor allem auf dem Mangel an standardisierten diagnostischen Verfahren.

Ziel dieser Arbeit war die Entwicklung eines Multiplex-CBA-Verfahrens zum simultanen Nachweis von Antikörpern (IgM und $\operatorname{IgG}$ ) gegen 15 verschiedene europäische humanpathogene Arboviren. 
Die dazu erforderlichen Schritte umfassen eine Vielzahl von aufeinander folgenden Techniken aus dem Bereich der Virologie, Zellbiologie, Molekularbiologie und Proteinchemie:

$\star$ Virusanzucht aller aufgezählten Arboviren (RNA-Viren)

$\star$ Amplifikation von Oberflächenproteingenen mittels PCR

^ Ligation der Oberflächenproteingene in Ausgangs- und Expressionsvektoren

$\star$ Proteinexpression, Proteinreinigung und Proteinquantifizierung

$\star$ Testung von polyklonalen Maus- und Humanseren (Positivseren)

^ Entwicklung eines IFTs zur Überprüfung der Positivseren

^ Entwicklung des CBAs zur Sensitivitäts- und Spezifitätsermittlung der Antigene zur Antikörperdetektion

$\star$ Übertragung des CBAs auf einen Multiplex-CBA

Evaluation des Multiplex-CBAs an Hand von Patientenmaterial

Das entwickelte Multiplex-CBA-Verfahren wurde final an Proben erkrankter Patienten evaluiert, um neue Erkenntnisse über das Vorkommen und die Verbreitung von Arboviren bei ZNS-Erkrankungen zu erhalten. Mit dem hier entwickelten Testverfahren steht erstmals ein diagnostisches Verfahren zum Simultannachweis für die wichtigsten 15 europäischen Arboviren bereit und macht so künftig auch eine Risikoanalyse für das öffentliche Gesundheitswesen möglich. 


\section{Material und Methoden}

\subsection{Material}

\subsubsection{Verbrauchsmaterial}

Tabelle 2.1: Verbrauchsmaterial

\begin{tabular}{|c|c|}
\hline Material & Bezugsquelle/ Hersteller \\
\hline 96 K Microplatte F-Form & $\begin{array}{l}\text { Greiner Bio-One GmbH, Frickenhausen, } \\
\text { DE }\end{array}$ \\
\hline Falconröhrchen $(15 \mathrm{ml}, 50 \mathrm{ml})$ & Sarstedt AG \& Co, Nümbrecht, DE \\
\hline Filterpapier & Whatman GmbH, Dassel, DE \\
\hline Gewebekulturschalen (100x20mm) & $\begin{array}{l}\text { Greiner Bio-One GmbH, Frickenhausen, } \\
\text { DE }\end{array}$ \\
\hline Handschuhe - Latex und Nitril & Mikroflex Corporation, Vienna, AT \\
\hline Mikroschraubgefäße $(2,0 \mathrm{ml})$ & Sarstedt AG \& Co, Nümbrecht, DE \\
\hline Objektträger multitest slide 12 well & $\begin{array}{l}\text { MP Biomedicals Germany } \mathrm{GmbH} \text {, } \\
\text { Eschwege, DE }\end{array}$ \\
\hline PCR- Reaktionsgefäße $(0,2 \mathrm{ml})$ & Biozym Scientific GmbH,Oldendorf, DE \\
\hline $\begin{array}{l}\text { Pipettenspitzen mit Filter } \\
(10 \mu 1,20 \mu 1,100 \mu 1,200 \mu 1,1000 \mu 1)\end{array}$ & Starlab GmbH, Ahrensberg, DE \\
\hline $\begin{array}{l}\text { Pipettenspitzen ohne Filter } \\
(0,1-10 \mu 1,1,0-100 \mu 1,101-1000 \mu 1)\end{array}$ & Starlab GmbH, Ahrensberg, DE \\
\hline Protein-Lo-bind Tubes $(0,5 \mathrm{ml}, 1,5 \mathrm{ml})$ & Eppendorf AG, Hamburg, DE \\
\hline PVDF-Membran (0,3x 3,0m Rolle) & $\begin{array}{l}\text { Amersham Biosciences Europe } \mathrm{GmbH} \text {, } \\
\text { Freiburg, DE }\end{array}$ \\
\hline Safe-Lock-Tubes $(0,5 \mathrm{ml}, 1,5 \mathrm{ml}, 2 \mathrm{ml})$ & Eppendorf AG, Hamburg, DE \\
\hline Schikanekolben (1000ml) & SCHOTT AG, Mainz, DE \\
\hline $\begin{array}{l}\text { Serologische Pipetten } \\
(1 \mathrm{ml}, 2 \mathrm{ml}, 5 \mathrm{ml}, 10 \mathrm{ml}, 25 \mathrm{ml})\end{array}$ & $\begin{array}{l}\text { Greiner Bio-One GmbH, Frickenhausen, } \\
\text { DE }\end{array}$ \\
\hline $\begin{array}{l}\text { Slide-A-Lyzer G2 Dialysekassetten } \\
\text { (3500 MWCO) }\end{array}$ & Thermo Scientific, Rockford, USA \\
\hline Strep-Tactin-Sepharose Säulen & IBA GmbH, Göttingen, DE \\
\hline Zellkulturflaschen (T25, T75) & $\begin{array}{l}\text { Greiner Bio-One } \mathrm{GmbH} \text {, Frickenhausen, } \\
\mathrm{DE}\end{array}$ \\
\hline
\end{tabular}




\subsubsection{Geräte}

Tabelle 2.2: Geräte

\begin{tabular}{|c|c|}
\hline Geräte & Bezugsquelle/ Hersteller \\
\hline $\begin{array}{l}\text { 96-Well Microtiter Plate Magnetic } \\
\text { Separation Rack }\end{array}$ & $\begin{array}{l}\text { New England Biolabs GmbH, Frankfurt } \\
\text { am Main, DE }\end{array}$ \\
\hline Bakterienbrutschrank & $\begin{array}{l}\text { Heraeus Instruments } \mathrm{GmbH} \text {, Hannover, } \\
\mathrm{DE}\end{array}$ \\
\hline Chemidoc XRS System & $\begin{array}{l}\text { Bio Rad Laboratories GmbH, München, } \\
\text { DE }\end{array}$ \\
\hline Gefrierschrank $\left(-20^{\circ} \mathrm{C}\right)$ & Liebherr GmbH, Ochsenhausen, DE \\
\hline Gefrierschrank $\left(-80^{\circ} \mathrm{C}\right)$ & Thermo Scientific, Rockford, USA \\
\hline Gefriertruhe $\left(-140^{\circ} \mathrm{C}\right)$ & Thermo Scientific, Rockford, USA \\
\hline Gelelektrophoresekammer & Invitrogen Corporation, Kalifornien, USA \\
\hline Heizblock (Thermomixer) & Eppendorf AG, Hamburg, DE \\
\hline Kühlschrank $\left(5^{\circ} \mathrm{C}\right)$ & Liebherr GmbH, Ochsenhausen, DE \\
\hline MAGPIX $^{\circledR}$ & Luminex Corporation, Austin, USA \\
\hline NanoDrop ${ }^{\circledR}$ ND-1000 Spektralphotometer & Thermo Scientific, Rockford, USA \\
\hline Proteingelkammer & $\begin{array}{l}\text { Bio Rad Laboratories GmbH, München, } \\
\text { DE }\end{array}$ \\
\hline Rotator & Snijders, Tilburg, NL \\
\hline Sterilbank & Heraeus Sepatech GmbH, Osterode, DE \\
\hline Thermocycler & Biometra GmbH, Göttingen, DE \\
\hline Ultraschallbad & Bandelin electronic, Berlin, DE \\
\hline Ultraschall-Desintegrator & G. Heinemann, Schwäbisch- Gmüd, DE \\
\hline \multicolumn{2}{|l|}{ Branson-Sonifier Modell 250} \\
\hline Vortex und Plattenvortex & Bender \& Hobein AG, Zürich, CH \\
\hline Waage & $\begin{array}{l}\text { Satorius, Stedim biotech } \mathrm{GmbH} \text {, } \\
\text { Göttingen, DE }\end{array}$ \\
\hline Westernblotkammer & $\begin{array}{l}\text { Bio Rad Laboratories GmbH, München, } \\
\text { DE }\end{array}$ \\
\hline Wippe & Schuett24 GmbH, Göttingen, DE \\
\hline Zentrifuge & Eppendorf AG, Hamburg, DE \\
\hline Zentrifuge (Megafuge 1.0R) & Thermo Scientific, Rockford, USA \\
\hline
\end{tabular}




\subsubsection{Chemikalien, Fertiglösungen}

Tabelle 2.3: Chemikalien

\begin{tabular}{l} 
Substanzen \\
\hline 1-Ethyl-3-(3-dimethylamino-propyl) \\
carbodiimid (EDAC) \\
Acrylamid-Bis-Lsg. (40\%) \\
Agarose \\
Albumin Standard (BSA) 2mg/ml \\
Amidoschwarz \\
Ampicillin \\
Anhydrotetracyclin [25mg] \\
$\beta$ - Mercaptoethanol \\
Bacto ${ }^{\text {TM }}$ - Agar \\
Bacto ${ }^{\text {TM }}$ - Hefeextrakt \\
Bacto ${ }^{\text {TM }}$ - Tryptone \\
D(+) Biotin \\
Bromphenolblau \\
Desoxyribonukleosidtriphosphat (dNTP) \\
Difco ${ }^{\text {TM }}$ Skim Milk \\
di-Natriumhydrogenphosphat \\
Dithiothreitol (DTT) \\
DMEM - Medium \\
Dimethylformamid (DMF)
\end{tabular}

\section{Bezugsquelle/ Hersteller}

Invitrogen $\mathrm{GmbH}$, Karlsruhe, DE

Serva Electrophoresis GmbH, Heidelberg, DE

Biozym Scientific GmbH, Oldendorf, DE

Thermo Scientific, Rockford, USA

TMC-Bio Products, Rockland, USA

Roche Diagnostics GmbH, Mannheim, DE

IBA GmbH, Göttingen, DE

Merck KGaA, Darmstadt, DE

BD Biosciences, Heidelberg, DE

BD Biosciences, Heidelberg, DE

BD Biosciences, Heidelberg, DE

Carl Roth GmbH+Co.KG, Karlsruhe, DE

Merck KGaA, Darmstadt, DE

Fermentas GmbH, Leon-Rot, DE

BD Biosciences, Heidelberg, DE

Carl Roth GmbH+Co.KG, Karlsruhe, DE

Carl Roth $\mathrm{GmbH}+\mathrm{Co} . \mathrm{KG}$, Karlsruhe, DE

Lonza GmbH, Köln, DE

Sigma-Aldrich Chemie GmbH, Steinheim, $\mathrm{DE}$

DNA- Längenstandard (1kbp, 100kbp)

Fermentas GmbH, Leon-Rot, DE

DPBS

Essigsäure

Lonza GmbH, Köln, DE

Merck KGaA, Darmstadt, DE

Ethanol

Ethidiumbromid- Lsg.

Merck KGaA, Darmstadt, DE

Carl Roth GmbH+Co.KG, Karlsruhe, DE

Etylendiamintetraessigsäure (EDTA)

Serva Electrophoresis $\mathrm{GmbH}$, Heidelberg, DE

FluoSave ${ }^{\mathrm{TM}}$ Reagent

Merck KGaA, Darmstadt, DE

Isopropanol

Merck KGaA, Darmstadt, DE 
Glycin

HEPES Puffer (1M)

Kaliumchlorid

Kaliumdihydrogenphosphat

Laemmli Probenpuffer (SDS-PAGE)

MAGPIX $^{\circledR}$ Drive Fluid

Methanol

MEM - Medium

Molekulargewichtsmarker (10-170 kDa)

Natriumchlorid

Natriumlaurylsulfat (SDS)

N-hydroxysulfosuccinimid (NHSS)

$\mathrm{N}, \mathrm{N}, \mathrm{N}^{\prime}, \mathrm{N}^{\prime}$-Tetramethyl-ethylendiamin (TEMED)

Orange Loading Dye (6x)

Penicillin-Streptomycin (PEN / STREP) (je 10000 Units)

Roti $^{\circledR}$-Block (10x)

Salzsäure

Sarkosyl- L

SeraPlus special processed FBS (FKS)

Tris

Tween ${ }^{\circledR} 20$

Trypsin/EDTA Solution X-Gal
Carl Roth GmbH+Co.KG, Karlsruhe, DE

Lonza GmbH, Köln, DE

Carl Roth GmbH+Co.KG, Karlsruhe, DE

Merck KGaA, Darmstadt, DE

Bio Rad Laboratories GmbH, München, DE

Luminex Corporation, Austin, USA

Merck KGaA, Darmstadt, DE

c. c. pro $\mathrm{GmbH}$, Oberdorla, DE

Thermo Scientific, Rockford, USA

Carl Roth GmbH+Co.KG, Karlsruhe, DE

Carl Roth GmbH+Co.KG, Karlsruhe, DE

Invitrogen $\mathrm{GmbH}$, Karlsruhe, DE

Sigma-Aldrich Chemie GmbH, Steinheim, DE

Fermentas GmbH, Leon-Rot, DE

Lonza GmbH, Köln, DE

Carl Roth GmbH+Co.KG, Karlsruhe, DE

Merck KGaA, Darmstadt, DE

Carl Roth GmbH+Co.KG, Karlsruhe, DE

PAN-Biotech GmbH, Aidenbach, DE

Carl Roth GmbH+Co.KG, Karlsruhe, DE

Sigma-Aldrich Chemie GmbH, Steinheim, DE

Biochrom AG, Berlin, DE

Carl Roth GmbH+Co.KG, Karlsruhe, DE

\subsubsection{Lösungen, Medien und Puffer}

Tabelle 2.4: Lösungen, Medien und Puffer

\begin{tabular}{ll}
\hline Name & Zusammensetzung \\
\hline Agarosegel [1\%ig] & 100ml TAE-Puffer [1X], 1g Agarose, $5 \mu 1$ \\
& Ethidiumbromid-Lösung [Endkonz. \\
& $0,5 \mu \mathrm{g} / \mathrm{ml}]$
\end{tabular}


Amidoschwarz-Lösung

APS [10\%]

Blockierungspuffer (Western Blot)

Ethidiumbromid-Lösung

Glucoselösung (S.O.C. Medium)

Laufpuffer (SDS-PAGE)

LB-Agar mit Amp

LB-Agar mit Kana

LB-Medium mit Amp

LB-Medium mit Kana

$\mathrm{Mg}^{2+}$-Lösung (S.O.C. Medium)

PBS [1X]

PBS [10X]

Sarkosyl-Lösung

Sammelgel [12\%] (SDS- PAGE)

SDS [10\%]

S.O.C. Medium 50mg Amidoschwarz gelöst in $112 \mathrm{ml}$

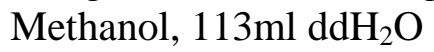

1g Ammoniumperoxodisulfat (APS), ad $100 \mathrm{ml} \mathrm{ddH}_{2} \mathrm{O}$

12g Skim Milk, 120ml Waschpuffer (Western Blot)

$10 \mathrm{mg} / \mathrm{ml}$ in $\mathrm{ddH}_{2} \mathrm{O}$

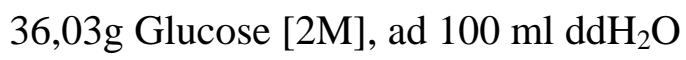

$100 \mathrm{ml}$ TGS [10X], 10ml SDS [10\%], ad $11 \mathrm{ddH}_{2} \mathrm{O}$

$10 \mathrm{~g}$ Bacto $^{\mathrm{TM}}$-Tryptone, $5 \mathrm{~g} \mathrm{Bacto}^{\mathrm{TM}}$-Yeast Extract, $10 \mathrm{~g} \mathrm{NaCl}, 1 \mathrm{ml}$ Ampicillin $[100 \mu \mathrm{g} / \mathrm{ml}], 15 \mathrm{~g}$ Bacto $^{\mathrm{TM}}-$ Agar, ad 11 $\mathrm{ddH}_{2} \mathrm{O}$

10 B Bacto $^{\mathrm{TM}}$-Tryptone, $5 \mathrm{~g}^{\text {Bacto }^{\mathrm{TM}}}{ }_{\text {-Yeast }}$ Extract, $10 \mathrm{~g} \mathrm{NaCl}, 1 \mathrm{ml}$ Kanamycin $[100 \mu \mathrm{g} / \mathrm{ml}], \quad 15 \mathrm{~g}$ Bacto $^{\mathrm{TM}}$-Agar, ad 11 $\mathrm{ddH}_{2} \mathrm{O}$

$10 \mathrm{~g}$ Bacto $^{\mathrm{TM}}$-Tryptone, $5 \mathrm{~g}^{\text {Bacto }}{ }^{\mathrm{TM}}$-Yeast Extract, $10 \mathrm{~g} \mathrm{NaCl}, 1 \mathrm{ml}$ Ampicillin [100 $\mu \mathrm{g} / \mathrm{ml}]$, ad $11 \mathrm{ddH}_{2} \mathrm{O}$

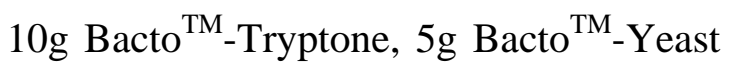
Extract, $10 \mathrm{~g} \mathrm{NaCl}, 1 \mathrm{ml}$ Kanamycin $[100 \mu \mathrm{g} / \mathrm{ml}]$, ad $11 \mathrm{ddH}_{2} \mathrm{O}$

$20,33 \mathrm{~g} \quad \mathrm{MgCl}_{2} * 6 \quad \mathrm{H}_{2} \mathrm{O} \quad[1 \mathrm{M}], \quad 24,65 \mathrm{~g}$ $\mathrm{MgSO}_{4} * 7 \mathrm{H}_{2} \mathrm{O}[1 \mathrm{M}]$, ad $100 \mathrm{ml} \mathrm{ddH}_{2} \mathrm{O}$ pH6,8

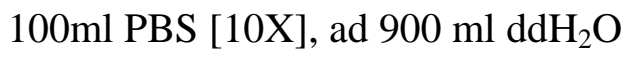

$2 \mathrm{~g} \mathrm{KCl}, 2 \mathrm{~g} \mathrm{KH}_{2} \mathrm{PO}_{4}, 80 \mathrm{~g} \mathrm{NaCl}, 5,76 \mathrm{~g}$ $\mathrm{N}_{2} \mathrm{HPO}_{4}$, ad $11 \mathrm{ddH}_{2} \mathrm{O}$

0,4\% Sarkosyl, 0,1M Tris, pH12,0

$0,25 \mathrm{ml}$ Acrylamid-Bis [40\%], 0,325ml Tris pH6,8 $[1 \mathrm{M}], 1,85 \mathrm{ml} \mathrm{ddH}_{2} \mathrm{O}, 25 \mu \mathrm{l}$

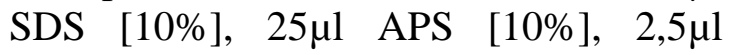
TEMED

$100 \mathrm{~g}$ SDS, ad $11 \mathrm{ddH}_{2} \mathrm{O}$

$2 \mathrm{~g}$ Trypton, $0,5 \mathrm{~g}$ Hefeextrakt, $0,06 \mathrm{~g} \mathrm{NaCl}$ $[10 \mathrm{mM}], 0,02 \mathrm{~g} \mathrm{KCl}[2,5 \mathrm{mM}]$, ad $100 \mathrm{ml}$ $\mathrm{ddH}_{2} \mathrm{O}+1 \mathrm{ml} \mathrm{Mg}^{2+}$-Lösung $+1 \mathrm{ml}$ Glucoselösung 
TAE $[1 \mathrm{X}]$

TAE $[50 \mathrm{X}]$

TGS [10X]

Transferpuffer (Western Blot)

Trenngel [12\%] (SDS- PAGE)

Tris $\mathrm{pH} 6,8[1 \mathrm{M}]$

Tris pH8,8 [1M]

Waschpuffer (Western Blot)

Waschpuffer (Beads-MAGPIX)

Zellkulturmedium - Infektionsmedium

Zellkulturmedium - Wachstumsmedium 40ml TAE [50X] ad 1960ml dd $\mathrm{H}_{2} \mathrm{O}$

242g Tris: 57,1ml Essigsäure, 100ml EDTA pH8,0 [0,5M]

30,22g Tris, $144,13 \mathrm{~g}$ Glycin, $1 \mathrm{~g} \mathrm{NaN}$, ad $11 \mathrm{ddH}_{2} \mathrm{O}$

$3 \mathrm{~g}$ Tris, 14,4g Glycin, ad $11 \mathrm{ddH}_{2} \mathrm{O}$

$2 \mathrm{ml}$ Acrylamid-Bis [40\%], 1,88ml Tris pH8,8 [1M], 1,03ml dd $\mathrm{dH}_{2} \mathrm{O}, 50 \mu \mathrm{l}$ SDS [10\%], 50 $\mu 1$ APS [10\%], $5 \mu 1$ TEMED

$121,14 \mathrm{~g}$ Tris, ad $11 \mathrm{ddH}_{2} \mathrm{O}$

$\mathrm{pH}-$ Wert einstellen mit $\mathrm{HCl}$

$121,14 \mathrm{~g}$ Tris, ad $11 \mathrm{ddH}_{2} \mathrm{O}$

$\mathrm{pH}-$ Wert einstellen mit $\mathrm{HCl}$

100ml PBS [10X], 5ml Tween ${ }^{\circledR} 20$, ad 11 $\mathrm{ddH}_{2} \mathrm{O}$

$50 \mathrm{ml} \mathrm{PBS}+10 \mu 1$ Tween ${ }^{\circledR} 20[0,02 \%]$

500ml DMEM bzw. MEM, 2\% FKS, $10 \mathrm{mM}$ Pen/Strep, 2mM Glutamin, 20mM HEPES

500ml DMEM bzw. MEM, 10\% FKS, $10 \mathrm{mM}$ Pen/Strep, 2mM Glutamin

\subsubsection{Reagenziensätze}

Tabelle 2.5: Reagenziensätze

\begin{tabular}{|c|c|}
\hline Name & Bezugsquelle/ Hersteller \\
\hline $\begin{array}{l}\text { Amersham }^{\mathrm{TM}} \mathrm{ECL}^{\mathrm{TM}} \text { Prime Western } \\
\text { Blotting Detection Reagent }\end{array}$ & GE Healthcare Europe NV, Brüssel, BE \\
\hline Bio-Plex Amine Coupling Kit & $\begin{array}{l}\text { Bio Rad Laboratories GmbH, München, } \\
\text { DE }\end{array}$ \\
\hline $\begin{array}{l}\text { Bio-Plex Pro magnetic COOH Beads } \\
\# 26, \# 27, \# 29, \# 34, \# 35, \# 36, \# 37, \# 42 \text {, } \\
\# 44, \# 46, \# 52, \# 53, \# 54, \# 55, \# 62, \# 63 \text {, } \\
\# 65\end{array}$ & $\begin{array}{l}\text { Bio Rad Laboratories GmbH, München, } \\
\text { DE }\end{array}$ \\
\hline DNA Clean \& Concentrator ${ }^{\mathrm{TM}}-5 \mathrm{Kit}$ & $\begin{array}{l}\text { Zymoclean } \quad \text { Research } \\
\text { Orange, USA }\end{array}$ \\
\hline MAGPIX $^{\circledR}$ Calibration Kit & Luminex Corporation, Austin, USA \\
\hline
\end{tabular}


MAGPIX $^{\circledR}$ Performance Verification Kit

peq GOLD Plasmid Miniprep Kit I

Pierce ${ }^{\circledR}$ BCA Protein Assay Kit

StarGate ${ }^{\circledR}$ Combi Entry Reagent Set

StarGate $^{\circledR}$ Transfer Reagent Set

Strep-tag protein purification Buffer Set

Zymoclean ${ }^{\mathrm{TM}}$ Gel DNA Recovery Kit
Luminex Corporation, Austin, USA

peQlab Biotechnologie GmbH, Erlangen, $\mathrm{DE}$

Thermo Scientific, Rockford, USA

IBA GmbH, Göttingen, DE

IBA GmbH, Göttingen, DE

IBA GmbH, Göttingen, DE

Zymoclean Research Corporation, Orange, USA

\subsubsection{Enzyme und Nukleotide}

Tabelle 2.6: Enzyme und Nukleotide

\begin{tabular}{ll}
\hline Name & Bezugsquelle/ Hersteller \\
\hline Pfu-Ultra ${ }^{\text {TM }}$ II Fusion DNA-Polymerase & Stratagene Europe, Amsterdam, NL \\
HindIII & Fermentas GmbH, Leon-Rot, DE \\
XbaI & Fermentas GmbH, Leon-Rot, DE \\
\hline
\end{tabular}

Alle verwendeten Restriktionsendonukleasen inklusive Puffer wurden von der Firma Fermentas GmbH (Leon-Rot, Deutschland) bezogen. Es handelt sich hierbei um Fast Digest ${ }^{\circledR}$ Enzyme und Puffer.

\subsubsection{Bakterienstämme}

Tabelle 2.7: Bakterienstämme

\begin{tabular}{|c|c|c|}
\hline Stamm & Genotyp & Bezugsquelle/ Hersteller \\
\hline \multirow[t]{3}{*}{ Top 10} & $\Delta$ (mrr-hsdRMS-mcrBC) & IBA GmbH, Göttingen, \\
\hline & $\varphi 801 \mathrm{lacZ} \Delta \mathrm{M} 15 \Delta \mathrm{lacX} 74$ recA1 araD139 & $\mathrm{DE}$ \\
\hline & $\begin{array}{l}\Delta(\text { ara-leu }) 7697 \text { galU galK } \operatorname{rpsL}\left(\operatorname{Str}^{\mathrm{R}}\right) \\
\text { endA1 nupG }\end{array}$ & \\
\hline BL21(DE3) & $\begin{array}{l}\mathrm{F}^{-} \text {ompT gal dcm lon } \mathrm{hsdS}_{\mathrm{B}}\left(\mathrm{r}_{\mathrm{B}}^{-} \mathrm{m}_{\mathrm{B}}^{-}\right) \lambda(\mathrm{DE} 3 \\
\text { [lacI lacUV5-T7 gene } 1 \text { ind1 sam7 nin5]) }\end{array}$ & $\begin{array}{l}\text { Stratagene Europe, Am- } \\
\text { sterdam, NL }\end{array}$ \\
\hline XL1-Blue & $\begin{array}{l}\text { recAl endAl gyrA96 thi-1 hsdR17 supE44 } \\
\text { relAl lac }\left[\mathrm{F}^{\prime} \text { proAB lacIqZDM15 Tn } 10\right. \\
\text { (Tetr) }]^{\mathrm{c}}\end{array}$ & $\begin{array}{l}\text { Zymo Research Corpora- } \\
\text { tion, Orange, USA }\end{array}$ \\
\hline
\end{tabular}




\subsubsection{Zelllinien}

Tabelle 2.8: Zelllinien

\begin{tabular}{llll}
\hline Zelllinie & Teilordnung - Art - Zelltyp & \multicolumn{2}{l}{ Bezugsquelle/ Hersteller } \\
\hline Vero B4 & $\begin{array}{l}\text { Affe }- \text { Afrikanische Grün Meerkatzen } \\
\text { (Cercopithecus aethiops) - Nierenzellen }\end{array}$ & sSchweig, DE \\
Vero E6 & $\begin{array}{l}\text { Affe - Afrikanische Grün Meerkatzen } \\
\text { (Cercopithecus aethiops) - Nierenzellen }\end{array}$ & ATCC, Manassas, USA \\
& \\
\hline
\end{tabular}

\subsubsection{Viren}

Tabelle 2.9: Arboviren

\begin{tabular}{|c|c|c|}
\hline Virus & Passage und Zeitpunkt der Ernte & Bezugsquelle \\
\hline $\begin{array}{l}\text { Batai } \\
\text { (Calovo) } \\
\text { Isolat } 138\end{array}$ & Passage 1, 7dpi ( 03.12.2008) & $\begin{array}{l}\text { Aus Jugoslawien, isoliert u. } \\
\text { lyoph. } 1983 \text { von J. Pilaski, } \\
\text { Universität Düsseldorf }\end{array}$ \\
\hline $\begin{array}{l}\text { Bhanja- } \\
\text { M3811 }\end{array}$ & Passage 4, 7dpi ( 15.04.2011) & $\begin{array}{l}\text { Maria Joâo Alves, Center for } \\
\text { Vectors and Infectious } \\
\text { Diseases Research, National } \\
\text { Institute of Health, Portugal }\end{array}$ \\
\hline Erve & Passage 3, 13dpi ( 25.02.2003 ) & $\begin{array}{l}\text { Gerhard Dobler, Institut für } \\
\text { Mikrobiologie der Bundes- } \\
\text { wehr, München }\end{array}$ \\
\hline $\begin{array}{l}\text { Eyach } \\
\text { Isolat } 73\end{array}$ & Passage 4, 14dpi ( 09.11.2011) & $\begin{array}{l}\text { Isoliert u. lyoph. von Rehse- } \\
\text { Küppers und Pilaski 1980, } \\
\text { Universität Düsseldorf }\end{array}$ \\
\hline Inkoo & Passage 4, 2dpi ( 25.07.2009 ) & $\begin{array}{l}\text { Lyophilisat erhalten von R. E. } \\
\text { Shope, University of Texas, } \\
\text { Galveston, Texas }\end{array}$ \\
\hline $\begin{array}{l}\text { Palma } \\
\text { M3443 }\end{array}$ & Passage 4, 7dpi ( 15.04.2011) & $\begin{array}{l}\text { Maria Joâo Alves, Center for } \\
\text { Vectors and Infectious } \\
\text { Diseases Research, National } \\
\text { Institute of Health, Portugal }\end{array}$ \\
\hline $\begin{array}{l}\text { SF Naples } \\
\text { Oct-85 Sabin }\end{array}$ & Passage 4, 3dpi ( 16.01.2012 ) & $\begin{array}{l}\text { Tino F. Schwarz, Stiftung } \\
\text { Juliusspital, Würzburg }\end{array}$ \\
\hline $\begin{array}{l}\text { SF Sicilian } \\
\text { Oct-85 Sabin }\end{array}$ & Passage 3, 5dpi ( 30.06.2008 ) & $\begin{array}{l}\text { Tino F. Schwarz, Stiftung } \\
\text { Juliusspital, Würzburg }\end{array}$ \\
\hline $\begin{array}{l}\text { SF Turkish } \\
\text { (SFTR19/2) }\end{array}$ & Passage 2, 5dpi ( 14.02.2009) & $\begin{array}{lcr}\text { Isoliert } 2008 \text { von } & \text { Ahmed } \\
\text { Çarhan, } & \text { Refik } & \text { Saydam } \\
\text { National } & \text { Public } & \text { Health } \\
\text { Agency, } & \text { Ankara, Türkei }\end{array}$ \\
\hline $\begin{array}{l}\text { TBEV } \\
\text { Hyper } \\
\text { Isolat } 68\end{array}$ & Passage 1, 16dpi ( 31.07.2008) & $\begin{array}{l}\text { Aus Wien, isoliert und lyoph. } \\
1980 \text { von J. Pilaski, } \\
\text { Universität Düsseldorf }\end{array}$ \\
\hline
\end{tabular}


Tahyna Passage 3, 3dpi ( 24.04.2008)

Isolat 147

Toscana Passage 4, 3dpi ( 13.02.2012)

Virus

ISS.Phl.3

Tribec

Passage 1, 3dpi ( 29.08.2008)

Uukuniemi Passage 1, 7dpi ( 31.01.2008)

West Nil Passage 3, 2dpi ( 25.07.2008)
Isoliert 1982, lyoph. 1983 von J. Pilaski, Universität Düsseldorf

Tino F. Schwarz, Stiftung Juliusspital, Würzburg

Gerhard Dobler, Institut für Mikrobiologie der Bundeswehr, München

Anna Överby, Department of Clinical Microbiology, Laboratory for Molecular Infection Medicine Sweden (MIMS), Umeå University, Sweden Isoliert und lyoph. 1985 von J. Pilaski, Univ. Düsseldorf

\subsubsection{Antikörper}

Tabelle 2.10: Antikörper

\begin{tabular}{|c|c|}
\hline Name & Bezugsquelle/ Hersteller \\
\hline $\begin{array}{l}\text { R-PE-conjugated Affini Pure Goat Anti-Human } \\
\text { IgG, } \mathrm{Fc}_{1} \text { Fragment Specific }\end{array}$ & Dianova GmbH, Hamburg, DE \\
\hline $\begin{array}{l}\text { R-PE-conjugated Affini Pure } \mathrm{F}\left(\mathrm{ab}^{\prime}\right)_{2} \text { Fragment } \\
\text { Donkey Anti-Human IgM Fc5 } 5_{\mu} \text { Fragment specific }\end{array}$ & Dianova GmbH, Hamburg, DE \\
\hline $\begin{array}{l}\text { R-PE-conjugated Affini Pure Goat Anti-Mouse IgG } \\
(\text { subclasses } 1+2 \mathrm{a}+2 \mathrm{~b}+3), \mathrm{Fc}_{\gamma} \text { Fragment Specific }\end{array}$ & Dianova GmbH, Hamburg, DE \\
\hline $\begin{array}{l}\text { R-PE-conjugated Affini Pure } \mathrm{F}\left(\mathrm{ab}^{\prime}\right)_{2} \text { Fragment } \\
\text { Goat Anti-Rabbit IgG }(\mathrm{H}+\mathrm{L})\end{array}$ & Dianova GmbH, Hamburg, DE \\
\hline $\begin{array}{l}\mathrm{Cy}^{\mathrm{TM}} 3 \text { - conjugated Affini Pure Goat Anti-Human } \\
\operatorname{IgA}, \operatorname{IgG}, \operatorname{IgM}(\mathrm{H}+\mathrm{L})\end{array}$ & Dianova GmbH, Hamburg, DE \\
\hline $\begin{array}{l}\mathrm{Cy}^{\mathrm{TM}} \text { 3-conjugated Affini Pure Goat Anti-Mouse } \\
\operatorname{IgG}(\mathrm{H}+\mathrm{L})\end{array}$ & Dianova GmbH, Hamburg, DE \\
\hline Anti-Escherichia coli Polyclonal Rabbit & $\begin{array}{l}\text { Dako Denmark A/S, Glostrup, } \\
\text { DK }\end{array}$ \\
\hline Anti-Rabbit IgG, HRP conjugate (Western Blot) & $\begin{array}{l}\text { Sigma-Aldrich Chemie GmbH, } \\
\text { Stein-heim, DE }\end{array}$ \\
\hline Strep-Tactin-R-PE (Kopplungsbeweis) & IBA GmbH, Göttingen, DE \\
\hline $\begin{array}{l}\text { Strep MAB - Classic, HRP conjugate } \\
{\left[\text { Anti-Strep-tag }{ }^{\circledR} \text { II-HRP] (Western Blot) }\right.}\end{array}$ & IBA GmbH, Göttingen, DE \\
\hline
\end{tabular}




\subsubsection{Ausgangs-DNA}

Tabelle 2.11: Vorhandene cDNA bzw. rekombinante Plasmide mit Zielsequenz

\begin{tabular}{|c|c|c|}
\hline Name & Name und Länge der Zielregi & $\mathbf{n}^{(*)}$ \\
\hline Batai-S-in pCRII Klon 2 & Nukleokapsid Protein Gen (N): & 696bp \\
\hline BhanjaV cDNA & Nukleokapsid Protein Gen (N): & $738 b p$ \\
\hline Erve-pCRII-Mini-Klon 14 & Nukleokapsid Protein Gen (N): & $1887 \mathrm{bp}$ \\
\hline EyachV cDNA 1B & Virales Protein Gen (VP6): & 2094bp \\
\hline Inkoo-S-in pCRII Klon 66 & Nukleokapsid Protein Gen (N): & $702 b p$ \\
\hline PalmaV cDNA & Nukleokapsid Protein Gen (N): & $738 b p$ \\
\hline SFN-S-Segment in pCRII & Nukleokapsid Protein Gen (N): & $756 b p$ \\
\hline SFS-Nr.52 & Nukleokapsid Protein Gen (N): & $735 \mathrm{bp}$ \\
\hline SFT-pCRII-170610-9 & Nukleokapsid Protein Gen (N): & $735 b p$ \\
\hline Tahyna-S-pCRII & Nukleokapsid Protein Gen (N): & $702 b p$ \\
\hline TBEV-NS1-pCRII-Klon 14 & Nichtstruktur Protein Gen (NS1 & :1056bp \\
\hline Toscana-240699 & Nukleokapsid Protein Gen (N): & $756 b p$ \\
\hline Tribec-p7-Adapter-RHR cDNA-B & Virales Protein Gen (VP7): & $1068 b p$ \\
\hline DNA-Uuk-Klon6 & Nukleokapsid Protein Gen (N): & $759 \mathrm{bp}$ \\
\hline WNV-NS1-pCRII Klon3 & Nichtstruktur Protein Gen (NS1 & :1032bp \\
\hline
\end{tabular}

Die verwendete cDNA wurde freundlicherweise zur Verfügung gestellt von PD Dr. rer. nat. Manfred Weidmann, Institut für Virologie Göttingen. Nach Virenanzucht und Virenernte wurde die cDNA mittels Transcriptor Kit von Roche nach Protokoll des Herstellers generiert und teilweise in den pCRII-Vektor (Invitrogen) kloniert.

\subsubsection{Plasmide}

Tabelle 2.12: Plasmide

\begin{tabular}{lll}
\hline Plasmid & Beschreibung & Bezugsquelle/ Hersteller \\
\hline pCRII & 3900bp Klonierungsvektor & Invitrogen GmbH, Karlsruhe, DE \\
pENTRY-IBA51 & 1860bp Donorvektor & IBA GmbH, Göttingen, DE \\
pASG-IBA5 & 3202bp Expressionsvektor & IBA GmbH, Göttingen, DE \\
& N-terminaler Strep-Tag ${ }^{\circledR}$ II & \\
\hline
\end{tabular}




\subsubsection{Oligonukleotide}

Tabelle 2.13: Oligonukleotide

\begin{tabular}{|c|c|}
\hline Name & Sequenz \\
\hline BATV-N-Star-FP & $5^{\prime}{ }^{\prime}$-AGCGGCTCTTCA $\underline{\boldsymbol{A} T \boldsymbol{G}}$ ATTGAGTTGGAATTCAATGATGT-3' \\
\hline BATV-N-Star-RP & 5' -AGCGGCTCTTCTCCCCATACTGATACCAAACTTTGCT-3' \\
\hline BhanjaV-N-SG-FP & 5' -AGCGGCTCTTCA $\underline{\mathbf{A} T \boldsymbol{G} G T T G C A T A C A C T G A C A T C C T T-3 '}$ \\
\hline BhanjaV-N-SG-RP & 5' -AGCGGCTCTTC TCССTTCCAATTTTTCCCAAGCTGC-3’ \\
\hline ERVE-N-Star-FP & 5' -AGCGGCTCTTCA $\underline{\mathbf{A T G} G A G A A C C T A A T T G A C T T T T C G G-3^{\prime}}$ \\
\hline ERVE-N-Star-RP & 5' -AGCGGCTCTTC $\overline{\mathbf{C C C} C T T G A A G A G A T T T A T A G T A G T G T-3^{\prime}}$ \\
\hline EYA-VP6-Star-FP & 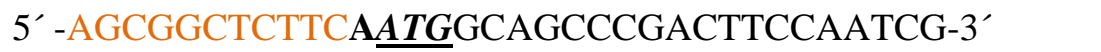 \\
\hline EYA-VP6-Star-RP & 5' -AGCGGCTCTTC $\overline{\mathbf{C C C}}$ GCCTGTTAAAATATCTATAACCG-3' \\
\hline INKV-N-Star-FP & 5'- AGCGGCTCTTCA $\underline{\mathbf{A T G} G G A G A T T T G G T T T T C T A T G A T G-3 '}$ \\
\hline INKV-N-Star-RP & 5'- AGCGGCTCTTCTCCCAGGCAGCTTTACACCAAATTTG-3' \\
\hline PalmaV-N-SG-FP & 5' -AGCGGCTCTTCA $\underline{\mathbf{A T G} G T T G C A T A C A C T G A T A T C C T T A-3^{\prime}}$ \\
\hline PalmaV-N-SG-RP & 5' -AGCGGCTCTTC TCCСTTCCAATTTTTCCCAGGCTGC-3’' \\
\hline SFN-N-Star-FP & 5'- AGCGGCTCTTCA $\underline{\boldsymbol{A} \boldsymbol{T} \boldsymbol{G}}$ TCTGAGGAGAACTATCGTGAG-3' \\
\hline SFN-N-Star-RP & 5'- AGCGGCTCTTCTCCCCGTGCCCACCTTAGAGCAG-3' \\
\hline SFS-N-Star-FP & 5'- AGCGGCTCTTCA $\underline{\boldsymbol{A} T \boldsymbol{T} G A C G A G T A C C A G A A A A T T G C T-3 '}$ \\
\hline SFS-N-Star-RP & 5'- AGCGGCTCTTCTCССCTCTAGTTTCCTGTAAACTTCT-3’’ \\
\hline SFTV-N-Star-FP & 5' -AGCGGCTCTTCA $\underline{\boldsymbol{A} T \boldsymbol{T} G A C G A G T A C C A G A A A A T T G C T-3 '}$ \\
\hline SFTV-N-Star-RP & 5' -AGCGGCTCTTC TCССCTCCAGTTTCCTATAAGCTTC-3’’ \\
\hline TAHV-N-Star-FP & 5'- AGCGGCTCTTCA $\underline{\mathbf{A} T \boldsymbol{G}}$ TCTGATTTGGTTTTTTATGATGTC-3' \\
\hline TAHV-N-Star-RP & 5'- AGCGGCTCTTCTCCCTGGGAGTCTGATTCCAAATTTC-3' \\
\hline TBE-NS1-Star-FP & 5'- AGCGGCTCTTCA $\underline{\mathbf{A T G} G A T G T T G G T T G C G C T G T G G ~-3^{\prime}}$ \\
\hline TBE-NS1-Star-RP & 5'- AGCGGCTCTTCTCCCCGCAACCACCATTGAGCGA -3' \\
\hline TOSV-N-Star-FP & 5'- AGCGGCTCTTCA $\underline{\boldsymbol{A} T \boldsymbol{T}} \mathbf{T C A G A C G A G A A T T A T C G C G A T - 3 '}$ \\
\hline TOSV-N-Star-RP & 5'- AGCGGCTCTTCTCCCCTTGCCAACCTTGGCGCG -3' \\
\hline TRBV-VP7-Star-F & 5'- AGCGGCTCTTCA $\underline{\mathbf{A T G} G A C G C G T A C A C T G C A C G A G ~-3 '}$ \\
\hline TRBV-VP7-Star-R & 5'- AGCGGCTCTTC T्रCCCTGACCCAGCCTGAAGGC -3' \\
\hline UUKV-N-Star-FP & 5'- AGCGGCTCTTCA $\underline{\mathbf{A T G} G C T A T G C C G G A G A A T T G G G ~-3^{\prime}}$ \\
\hline UUKV-N-Star-RP & 5'- AGCGGCTCTTCTCCCGATCAATGATCTGAGGACAGT -3' \\
\hline WNV-NS1-Star-F2 & 5'- AGCGGCTCTTCA $\underline{\mathbf{A T G} G A C A C T G G G T G T G C C A T A G ~-3 '}$ \\
\hline WNV-NS1-Star-R2 & 5'- AGCGGCTCTTCTCCCTGTCTTTTCATCATGTCTCTGT -3’' \\
\hline WNV-NS1-Star-F4 & 5'- AGCGGCTCTTCA $\underline{\mathbf{A T G} G A C A C T G G A T G T G C C A T A G A ~-3^{\prime}}$ \\
\hline WNV-NS1-Star-R4 & 5'- AGCGGCTCTTC TCCCAGCATTCACTTGTGACTGCAC -3' \\
\hline ENTRY-Primer-for2 & $5^{\prime}$-GCGAAACGATCCTCGAAG -3' \\
\hline ENTRY-Primer-rev & 5'- CCCCTGATTCTGTGGATAACCG -3' \\
\hline ASG-Primer-for & 5'- GAGTTATTTTACCACTCCCT -3' \\
\hline ASG-Primer-rev & $5^{\prime}-$ CGCAGTAGCGGTAAACG -3' \\
\hline ERVE-N-internal & $5^{\prime}$-ATGATTGCCAGAAGAGGAGG-3 \\
\hline
\end{tabular}

Orange hervorgehobene Bereiche kennzeichnen die StarCombinase $1^{\mathrm{TM}}$ Erkennungssequenz. FETT hervorgehobene Bereiche kennzeichnen die Kombinatorische Sequenz.

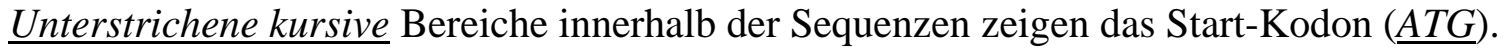




\subsubsection{Seren}

Tabelle 2.14: Positivseren

Name, Virus (Ursprung)

Anti-Calovo, Batai Virus (Maus)

Anti-Bhanja, Bhanja Virus (Maus)

Anti-Erve, Erve Virus (Maus)

Anti-Eyach, Eyach Virus (Maus)

Inkoo Virus

Anti-Palma M4746, Palma Virus (Maus)

Nap1, SFN Virus (Human)

S18, SFS Virus (Human)

SC1, SFT Virus (Human)

Anti-Tahyna 181, Tahyna Virus (Maus)

RSSE-AK IgG, TBE Virus (Maus)

T6, Toscana Virus (Human)
Freundlicher Weise zur Verfügung gestellt von:

RNDr. Daniel Růžek PhD, Department of Molecular Ecology of Parasites, Ceske Budejovice, Czech Republic

Dr. Boris Klempa, Institute of Virology Slovak Academy of Science (IVSAS), Bratislava , Slovakia

OFA Dr. Gerhard Dobler, Institut für Mikrobiologie der Bundeswehr, München, Deutschland

RNDr. Daniel Růžek PhD, Department of Molecular Ecology of Parasites, Ceske Budejovice, Czech Republic

Kein Positivserum vorhanden, Nutzung von Anti-Tahyna 181 wegen bekannter Kreuzreaktivität

Maria João Alves, Center for Vectors and Infectious Diseases Research, National Institute of Health, Águas de Moura, Portugal

Koray Ergunay MD. PhD Assistant Prof, Hacettepe University Faculty of Medicine, Ankara, Turkey

Koray Ergunay MD. PhD Assistant Prof, Hacettepe University Faculty of Medicine, Turkey

Koray Ergunay MD. PhD Assistant Prof, Hacettepe University Faculty of Medicine, Turkey

RNDr. Daniel Růžek PhD, Department of Molecular Ecology of Parasites, Ceske Budejovice, Czech Republic

OFA Dr. Gerhard Dobler, Institut für Mikrobiologie der Bundeswehr, München, Deutschland

Koray Ergunay MD. PhD Assistant Prof, Hacettepe University Faculty of Medicine, Turkey 
Anti-Tribec, Tribec Virus (Maus)

Anti Uuk, Uukuniemi Virus (Maus)

West Nil MIAF MG61369, West Nil Virus (Maus)
Dr. Boris Klempa, Institute of Virology Slovak Academy of Science (IVSAS), Bratislava, Slovakia

RNDr. Daniel Růžek PhD, Department of Molecular Ecology of Parasites, Ceske Budejovice, Czech Republic

OFA Dr. Gerhard Dobler, Institut für Mikrobiologie der Bundeswehr, München, Deutschland

\subsubsection{Software}

Tabelle 2.15: Computerprogramme zur Datenauswertung und Erstellung der Dissertation

\begin{tabular}{|c|c|c|}
\hline Name & Hersteller & Anwendung \\
\hline Adobe-Illustrator & Adobe Systems Inc. & Bildbearbeitung \\
\hline Adobe-Photoshop & Adobe Systems Inc. & Bildbearbeitung \\
\hline EndNote X7 & Thomson Reuters & Literaturverwaltung \\
\hline GraphPad Prism 6 & GraphPadSoftware Inc. & Graphische Datenauswertung \\
\hline Lasergene $^{\mathrm{TM}}$ & DNASTAR Inc. & $\begin{array}{l}\text { DNA-Sequenzanalyse, Plasmidkon- } \\
\text { struktion und phylogen. Analysen }\end{array}$ \\
\hline Microsoft Office 2007 & Microsoft Inc. & Text- und Datenverarbeitung \\
\hline $\begin{array}{l}\text { StarPrimer D’Signer } \\
\text { 3.0.0.3 }\end{array}$ & IBA GmbH & $\begin{array}{l}\text { Berechnung der Oligonukleotid- } \\
\text { sequenzen, Erstellung Klonierungs- } \\
\text { protokolle zur optimalen pENTRY } \\
\text { Klonierung }\end{array}$ \\
\hline xPONENT 4.2 & Luminex Corporation & $\begin{array}{l}\text { Steuerung der Messungen des } \\
\text { Fluoreszenz-Detektions-Systems } \\
\text { basierend auf xMAP }{ }^{\circledR} \text { Technologie } \\
\left(\text { MAGPIX }^{\mathrm{TM}} \text { ) }\right.\end{array}$ \\
\hline
\end{tabular}




\subsection{Methoden}

\subsubsection{Arbeiten mit Zellkulturen}

\subsubsection{Anzucht von Viren in Zellkultur}

Für die Anzucht der Viren aus vorhandenem Virusüberstand (siehe Tabelle 2.9) wurden zwei verschiedene Zelllinien verwendet, Vero-E6- Zellen und Vero-B4-Zellen. Es handelt sich hierbei um zwei etablierte Zelllinien, die beide aus Nierengewebe der grünen Meerkatzen (Cercopithecus aethiops) stammen (Macfarlane \& Sommerville, 1969). Beide Zelllinien weisen eine fibroblastenähnliche Morphologie auf und wachsen adhärent.

Die Vero-E6 Zellen wurden in 12ml Wachstumsmedium mit DMEM, die Vero-B4 Zellen in $12 \mathrm{ml}$ Wachstumsmedium mit MEM unter $5 \% \mathrm{CO}_{2}$ bei $37^{\circ} \mathrm{C}$ in $\mathrm{T} 75$ Zellkulturflaschen kultiviert.

Die Virusinfektion erfolgte nach Erreichen einer etwa 75\%igen Konfluenz der Zellen der jeweiligen empfohlenen Zelllinie (siehe Tabelle 2.16) für optimale Vermehrungs- und Wachstumsbedingungen je Virus.

Tabelle 2.16: Empfohlene Zelllinie je Virus

\begin{tabular}{ll}
\hline Zelllinie & Virus \\
\hline Vero-B4 & UUK, SFN, TRB, SFT, TAH, BAT, SFS, TOS \\
Vero-E6 & ERVE, WNV, BHA, PAL, TBE, INK, EYA \\
\hline
\end{tabular}

Nach Erreichen der gewünschten Konfluenz der Zellen wurde das Wachstumsmedium entfernt, die Zellen mit 5ml PBS [1X] gewaschen und je Virus zwei T75 Zellkulturflaschen mit $1 \mathrm{ml}$ Virusüberstand infiziert. Die Zellen wurden $1 \mathrm{~h}$ bei $37^{\circ} \mathrm{C}$ unter $5 \% \mathrm{CO}_{2}$ inkubiert, anschließend wurden jeweils $11 \mathrm{ml}$ Infektionsmedium (Vero-E6 Zellen mit DMDM, Vero-B4 Zellen mit MEM) zugegeben und bis zum Erreichen des gewünschten cytopathischen Effektes (CPE) von $20-50 \%$ unter $5 \% \mathrm{CO}_{2}$ bei $37^{\circ} \mathrm{C}$ inkubiert. Dieser CPE trat je nach Virus zwischen 1 - 14 Tagen nach Infektion auf. Zusätzlich wurde zu jeder Virusinfektion zeitgleich eine weitere T75 Zellkulturflasche ohne Zugabe von Virus, als Negativkontrolle, mitgeführt (Ergebnisse siehe Kap. 2.2.5.1). 


\subsubsection{Fixierung infizierter Zellen auf Objektträger}

Zur Überprüfung der vorhandenen Positivseren wurde ein Immunfluoreszenztest (IFT) (siehe Kap. 2.2.5.1) entwickelt. Hierzu wurden die mit Virus infizierten Zellen zuvor auf Objektträger mit zwölf voneinander getrennten Feldern fixiert. Die Viren wurden zur ungefährlichen Austestung inaktiviert.

Nach Erreichen eines CPEs von 20-50\% der infizierten Zellen wurde der Zellüberstand abgenommen und verworfen. Die verbliebenen intakten Zellen wurden je Zellkulturflasche mit PBS [1X] gewaschen, hierzu wurden 5ml PBS [1X] zugegeben, die Zellkulturflasche geschwenkt und der Überstand anschließend vollständig entfernt. Das Ablösen der Zellen vom Flaschenboden erfolgte durch Zugabe von 2ml Trypsin-Lösung. Nach kurzem Schwenken wurde die Trypsin-Lösung vorsichtig abgenommen und verworfen, erneut $2 \mathrm{ml}$ Trypsin auf die Zellen gegeben, $2 \mathrm{~min}$ bei $37^{\circ} \mathrm{C}$ stehen gelassen und die Trypsin-Lösung wieder vorsichtig entfernt. Die Zellkulturflaschen wurden sanft mit der Hand angeschlagen, so dass sich die Trypsin-behandelten Zellen vom Boden lösten.

Je Virus wurde entsprechend mit zwei T75 Zellkulturflaschen mit infizierten Zellen und der zugehörigen T75 Zellkulturflasche mit nicht infizierten Zellen (Negativkontrolle) verfahren und anschließend durch Zugabe von 3ml Medium (Vero-E6 Zellen mit DMDM, Vero-B4 Zellen mit MEM) ohne FKS der Inhalt aller drei Zellkulturflaschen in $3 \mathrm{ml}$ Endvolumen vereinigt.

Das so entstandene 2:1 Gemisch (zwei Teile mit Virus infizierten Zellen zu einem Teil nicht infizierter Zellen) wurde auf zuvor mit Isopropanol gereinigten und vollständig getrockneten Objektträger pipettiert. Je Feld wurden $10 \mu 1$ Zellgemisch getropft und bei RT getrocknet. Je Virus wurden 15 Objektträger mit je 12 Feldern vorbereitet.

Nach vollständiger Trocknung wurden die Objektträger in PBS [1X] gewaschen und zur Fixierung und gleichzeitigen Inaktivierung der Viren in ein $-20^{\circ} \mathrm{C}$ kaltes MethanolAceton Gemisch (im Verhältnis 1 Teil Methanol zu 2 Teilen Aceton) gegeben und 30min bei $-20^{\circ} \mathrm{C}$ im Gefrierschrank gelagert.

Abschließend wurden die Objektträger mit PBS [1X] gewaschen, bei RT vollständig getrocknet und bis zur Durchführung des Immunfluoreszenztestes (IFT) bei $-20^{\circ} \mathrm{C}$ gelagert. 


\subsubsection{Arbeiten mit Nukleinsäuren}

\subsubsection{Spektrophotometrische Konzentrations- und Reinheitsbestimmungen}

Die Konzentration wässriger DNA- und RNA-Lösungen kann durch Messung der Absorption von UV-Licht der Wellenlänge von 260nm (Absorptionsmaximum von Nukleotiden) mittels eines Spektralphotometers (Nano Drop ${ }^{\circledR}$ ND-100) bestimmt werden. Verunreinigungen wie aromatische Aminosäuren oder Phenole absorbieren Lichtwellen bei 280nm, so dass durch die Messung der $\mathrm{OD}_{280}$ eine Abschätzung der Reinheit der Nukleinsäurelösung möglich ist. Der Quotient $\mathrm{OD}_{260} / \mathrm{OD}_{280}$ sollte für relativ proteinfreie DNA- bzw. RNA-Präparationen zwischen 1,8 und 2,0 liegen (Sambrook, 1989).

Für die Messung wurden 1,5 $\mu 1$ Probenvolumen eingesetzt und das Gerät gegen den entsprechenden Probenpuffer $\left(\mathrm{ddH}_{2} \mathrm{O}\right)$ geeicht.

\subsubsection{Polymerase-Ketten-Reaktion (PCR)}

Die Polymerase-Ketten-Reaktion (englisch: polymerase chain reaction, kurz PCR) (Mullis \& Faloona, 1987) gehört zu den Standardmethoden der Molekularbiologie und dient zur in vitro Amplifikation großer Mengen einer spezifischen DNA-Sequenz (Template). Diese Vervielfältigung der DNA-Sequenz wird erreicht durch einen dreistufigen zyklischen Prozess:

I. Die Denaturierung:

Der erste Schritt ist die thermische Denaturierung der DNA-Probe durch Temperaturerhöhung auf $95^{\circ} \mathrm{C}$, die DNA-Doppelstränge werden in zwei Einzelstränge geteilt. Das Reaktionsgemisch enthält neben dem entstandenen DNATemplate zusätzlich zwei Oligonukleotidprimer, die thermostabile DNA-Polymerase $P f u$-Ultra ${ }^{\mathrm{TM}}$ II Fusion und die vier Desoxyribonukleotide (dNTPs).

Bei der Pfu-DNA-Polymerase aus Pyrococcus furiosus handelt es sich um eine Polymerase mit Korrekturlesefunktion (englisch: proof-reading) zur Optimierung der Amplifikationsgenauigkeit. 


\section{Die Renaturierung (englisch: Annealing)}

Im zweiten Schritt wird die Temperatur auf ungefähr $5^{\circ} \mathrm{C}$ unterhalb der berechneten Schmelztemperatur $\left(\mathrm{T}_{\mathrm{M}}\right)$, der Temperatur, bei der unter den Pufferbedingungen $50 \%$ der Oligonukleotide dissoziieren, gesenkt. Während der Temperatursenkung paaren die Primer mit den komplementären Sequenzen des DNA-Templates. Je höher diese Annealing-Temperatur ist, desto spezifischer erfolgt die Hybridisierung der Oligonukleotidprimer mit dem DNA-Template.

III. Die Synthese oder Elongation

Im dritten Schritt wird die Temperatur auf $72^{\circ} \mathrm{C}$, dem optimalen Bereich für die katalytische Funktion der Pfu-Ultra ${ }^{\mathrm{TM}}$ II Fusion DNA-Polymerase, erhöht.

Die DNA-Synthese beginnt an den 3'-OH-Enden der Primer. Die Polymerase verlängert (elongiert) in Gegenwart von dNTPs die Primer entlang der einzelsträngigen denaturierten DNA-Matrize. Es entstehen neue DNA-Stränge, deren Sequenz komplementär zum Template ist. Die Elongationszeiten wurden je nach Länge und Art des Templates entsprechend der vom Hersteller der verwendeten Pfu-Ultra ${ }^{\mathrm{TM}}$-II Fusion DNA-Polymerase (etwa $1 \mathrm{~kb}$ pro $15 \mathrm{sec}$ für Plasmid-DNA Templates und $1 \mathrm{~kb}$ pro $30 \mathrm{sec}$ für cDNA-Templates) angegebenen Zeiten berechnet. Jede zusätzliche Strangsynthese bedeutet eine neue Vermehrungsrunde, wobei auch die neusynthetisierten DNA-Stränge als Matrize dienen. Mit jedem neuen Zyklus steigt die Konzentration der amplifizierten Zielsequenzen exponentiell an.

Die PCR-Methode wurde in dieser Arbeit für die Amplifikation von Oberflächenproteingenen bestimmter von Zecken, Stechmücken und Sandmücken übertragenen Viren (siehe Tabelle 1.1), sowie für die Sequenzierungsreaktion (siehe Kap. 2.2.2.4) verwendet.

Die PCR-Reaktion erfolgte in einem automatischen Thermocycler mit beheizbarem Deckel. Die Amplifikationsprodukte wurden durch Präparative-Agarose-Gelelektrophorese (siehe Kap. 2.2.2.3.1) analysiert und extrahiert (siehe Kap. 2.2.2.3.2). 


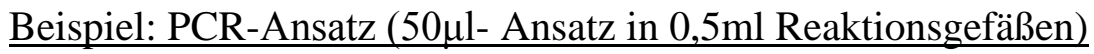

x $\mu 1$ Template (5-30ng)

1, $0 \mu \mathrm{l}$ Primer A $(10 \mathrm{pmol} / \mu \mathrm{l})$

1, $0 \mu$ l Primer B $(10 \mathrm{pmol} / \mu \mathrm{l})$

y $\mu \mathrm{ldd \textrm {d } _ { 2 } \mathrm { O }}$

$1,25 \mu 1 \mathrm{dNTPs}(10 \mathrm{mM}$ each)

5, $0 \mu 1$ 10X Pfu Ultra Buffer

$\underline{1,0 \mu 1}$ Pfu-Ultra ${ }^{\mathrm{TM}}$ II Fusion DNA-Polymerase

$\sum 50,0 \mu 1$

\subsubsection{Agarose-Gelelektrophorese}

Die Agarose-Gelelektrophorese wurde zur Reinigung, Trennung und Analyse von zirkulärer Plasmid-DNA und linearen DNA-Fragmenten verwendet. Aufgrund der negativen Ladung ihrer Phosphatgruppen wandern DNA-Moleküle im elektrischen Feld zur Anode. Wird die angelegte Spannung gering gehalten, so ist die Wanderungsgeschwindigkeit von linearer, doppelsträngiger DNA in einem Agarosegel umgekehrt proportional zum Logarithmus ihres Molekulargewichtes (Helling, Goodman \& Boyer, 1974). Die Banden wurden durch Ethidiumbromidfärbung unter UV-Licht (302nm) am Chemidoc XRS sichtbar, da Ethidiumbromid in die DNA interkaliert. Die Größe der DNA-Fragmente wurde durch Vergleich mit dem DNA- Längenstandard (1kbp, 100kbp) abgeschätzt. Die Konzentrationsbestimmung erfolgte mittels Nano Drop ${ }^{\circledR}$ ND-100 (siehe Kap. 2.2.2.1).

\subsection{Analytische und präparative Agarose-Gelelektrophorese}

Zur analytischen und präparativen Trennung von DNA-Fragmenten wurden Agarosegele mit einer Agarosekonzentration von 1,0\% (w/v) Agarose verwendet und Ethidiumbromid in einer Endkonzentration von 0,5 $\mu \mathrm{g} / \mathrm{ml}$ zugegeben.

Die Agarose wurde durch Aufkochen in TAE-Puffer gelöst und in eine entsprechende Gelkammer mit bis zu 20 Taschen gegossen. 
Die Proben wurden mit 1/6 Volumen Orange Loading Dye [6X] versetzt und in die Taschen des mit TAE-Laufpuffer bedeckten Agarosegels pipettiert. Zusätzlich wurden je nach Größe der aufgetragenen DNA-Proben ein DNA-Längenstandard (1kbp oder $100 \mathrm{kbp}$ ) aufgetragen. Die Elektrophorese erfolgte in TAE-Puffer [1X] bei einer konstanten Spannung von 80V für präparative Agarosegele und 110V für analytische Agarosegele.

Präparative Agarosegele wurden für möglichst kurze Zeit dem UV-Licht ausgesetzt, um Schäden in der DNA-Struktur zu vermeiden. In dieser Zeit wurden die Banden ausgeschnitten und in ein 1,5ml Reaktionsgefäß überführt. Die Gelextraktion erfolgte mittels Zymoclean $^{\mathrm{TM}}$ Gel DNA Recovery Kit (siehe Kap.2.2.2.3.2). Die Nachweisgrenze Ethidiumbromid-gefärbter Gele liegt bei ca. 10ng DNA pro Bande. Das Agarosegel wurde auf dem Chemidoc XRS System mit Hilfe eines Kamerasystems dokumentiert.

\subsection{DNA Extraktion mittels Zymoclean ${ }^{\mathrm{TM}}$}

Für die Extraktion von DNA aus präparativen Agarosegelen wurde der Reagenziensatz Zymoclean ${ }^{\mathrm{TM}}$ Gel DNA Recovery Kit (Zymoclean Research Corporation) verwendet.

Die zuvor am Chemidoc XRS unter UV-Licht (302nm) mit einem Skalpell ausgeschnittenen DNA-Fragmente wurden gewogen und pro 100mg Gewicht mit 300 $\mu$ l ADB Buffer ${ }^{\mathrm{TM}}$ versetzt. Die Ansätze wurden auf $55^{\circ} \mathrm{C}$ maximal $10 \mathrm{~min}$ erhitzt, bis das Gel und die darin enthaltenen DNA-Fragmente vollständig gelöst vorlagen. Anschließend wurde der gesamte Ansatz vollständig auf eine Zymo-Spin $\mathrm{I}^{\mathrm{TM}}$ Säule gegeben und $1 \mathrm{~min}$ bei RT

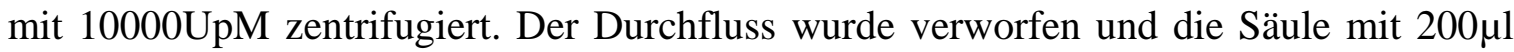
Waschpuffer gewaschen. Nach erneuter Zentrifugation für 30sec bei RT mit 10000UpM wurde der Durchfluss verworfen und der Waschschritt wiederholt. Anschließend wurde die Säule, um alle Reste des Waschpuffers zu entfernen, ohne Zugabe von Flüssigkeit, leer zentrifugiert. Um die DNA-Fragmente von der Säule zu lösen wurde die Säule in ein neues Eppendorf-Reaktionsgefäß überführt und die isolierten DNA-Fragmente durch Zugabe von $10 \mu \mathrm{l} \mathrm{ddH}_{2} \mathrm{O}$ von der Säule eluiert. Zur Konzentrations- und Reinheitsbestimmung siehe Kap. 2.2.2.1. 


\subsubsection{Sequenzanalyse}

Die lineare Sequenzanalyse von DNA-Fragmenten erfolgte nach dem Prinzip der Kettenabbruchmethode (Sanger, Nicklen \& Coulson, 1977) mit fluoreszenzmarkierten Didesoxyribonukleotiden und wurde im Auftrag an die Firma Seqlab vergeben.

Alle pENTRY- und pASG-Konstrukte, in welchen die zu analysierende virale DNA als Insert vorliegt, wurden zuvor per peqGOLD Plasmid Miniprep Kit I (siehe Kap. 2.2.3.5) gereinigt. Je Konstrukt wurden 600ng DNA, $2 \mu 1$ Primer $(10 \mathrm{pmol} / \mu \mathrm{l})$ und ggf. $\mathrm{ddH}_{2} \mathrm{O}$ in einem Endvolumen von $8 \mu 1$ zur weiteren Bearbeitung vorgelegt. Für die Sequenzierung der pENTRY-Konstrukte wurden die pENTRY-Primer (ENTRY-Primer-for2 bzw. ENTRY-Primer-rev) verwendet, für die pASG-Konstrukte entsprechend die pASG Primer (ASG-Primer-for bzw. ASG-Primer-rev). Die Primersequenzen wurden vom Hersteller empfohlen und verwendet, es handelt sich hierbei um Sequenzabschnitte auf den jeweiligen Vektoren, die in der Nähe der Insertionsstelle vor bzw. hinter der kombinatorischen Sequenz liegen (siehe Tabelle 2.13).

\subsubsection{Rekombinante Molekularbiologie}

\subsubsection{Donorvektor Herstellung mittels StarGate ${ }^{\circledR}$ Technologie}

Nachdem die viralen DNA-Fragmente („GOI“ englisch: gene of interest) mittels PCR amplifiziert und an beiden Enden mit kombinatorischen Überhängen (AATG bzw. GGGA) und der StarCombinase $1^{\mathrm{TM}}$ Erkennungssequenz (5'-AGCGGCTCTTC) verlängert wurden (siehe Kap. 2.2.2.2 und Tabelle 2.13), wurden sie mit Hilfe des StarGate ${ }^{\circledR}$ Combi Entry Reagent Set (IBA GmbH) in den Donorvektor pENTRY-IBA51 eingefügt. Es handelt sich hierbei um eine sogenannte „Ein-Schritt-Reaktion“ in der durch Zugabe des GOIs, des pENTRY Vektors und der StarCombinase ${ }^{\mathrm{TM}}$ in einem Schritt durch rekombinatorischen Austausch der gewünschte GOI-tragende Kanamycin resistente Donorvektor erzeugt wird (siehe Abb. 2.1).

Die Ansätze wurden für jeden Virus jeweils nach Angaben des Herstellers pipettiert und $1 \mathrm{~h}$ bei $30^{\circ} \mathrm{C}$ inkubiert. Anschließend erfolgte die Transformation des Donorvektors in E. coli Top 10 chemisch kompetente Zellen (siehe Kap.2.2.3.3). 
Beispiel: Ansatz nach Angaben des Herstellers (IBA GmbH) in 1,5ml Reaktionsgefäßen

$12,0 \mu 1$ PCR-Fragment (auf $2 \mathrm{nM}$ verdünnt mit $\mathrm{ddH}_{2} \mathrm{O}$ )

$1,0 \mu \mathrm{l}$ StarSolution M1

1,0 $\mu 1$ StarSolution M2

1,0 $\mu 1$ StarSolution M3 (zuvor Zugabe des M3-Verdünnungsmittels)

$\underline{10,0 \mu \mathrm{l}} \mathrm{pENTRY-IBA} 51$

$\sum 25,0 \mu 1$

A
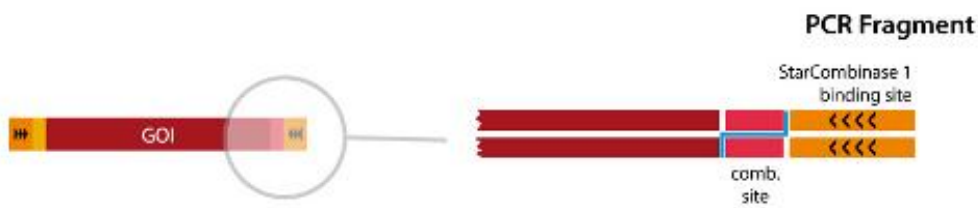

$+$
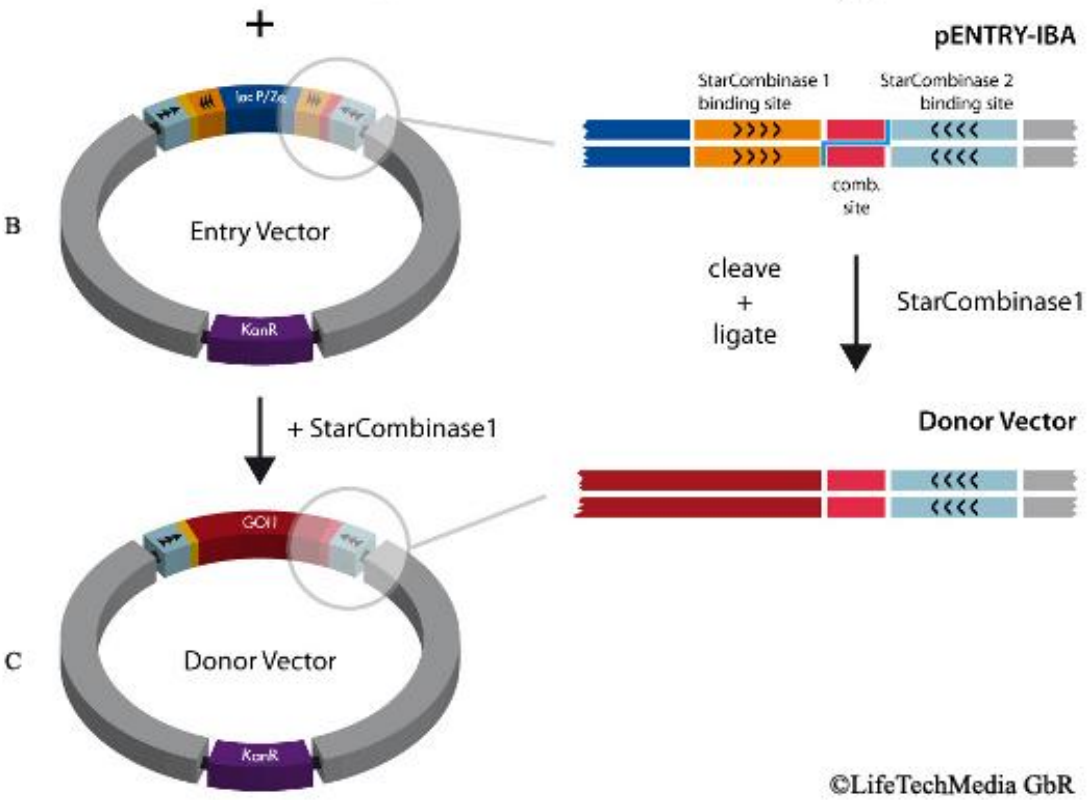

Abb. 2.1: Schematische Darstellung: Donorvektorherstellung mittels StarGate ${ }^{\circledR}$ Technologie (Quelle: IBA GmbH). Durch Zugabe von StarCombinase $1^{\mathrm{TM}}$ wird das PCR-Fragment (GOI) A und der pENTRY Vektor B an den kombinatorischen Sequenzen geschnitten, dabei gehen die StarCombinase ${ }^{\mathrm{TM}}$ Erkennungssequenzen (dargestellt in orange) verloren. Es entstehen Überhänge, die eine gerichtete Ligation von PCRProdukt und Vektor ermöglichen. Der Donorvektor C besitzt die gleichen kombinatorischen Sequenzen, gefolgt von StarCombinase $2^{\mathrm{TM}}$ Erkennungssequenzen (dargestellt in hellblau).

Zur Kontrolle wurde ein Restriktionsverdau mit den Restriktionsendonukleasen HindIII und XbaI empfohlen. Diese werden von verschiedenen Bakterienstämmen synthetisiert und katalysieren die spezifische hydrolytische Spaltung der Phosphodiesterbindungen der DNA innerhalb ihrer palindromischen Erkennungssequenzen. Je nach Enzym entstehen dabei Fragmente mit glatten Enden (englisch: blunt ends), oder mit 3'- bzw. 5'- überhängenden, kohäsiven Enden (englisch: sticky ends). Dabei ist immer das 
3'- Hydroxylende frei, während das 5'- Ende die verbleibende Phosphatgruppe trägt. Aktivität und Spezifität der Restriktionsendonukleasen werden durch Salzkonzentration, Temperatur, $\mathrm{pH}-$ Wert und den Gehalt an zweiwertigen Kationen (besonders $\mathrm{Mg}^{2+}$ ) beeinflusst. Entsprechende Puffer wurden jeweils nach Angaben des Herstellers verwendet. Alle Restriktionsendonukleasen inklusive der Puffer wurden von der Firma Fermentas GmbH bezogen. Es handelt sich hierbei um FastDigest ${ }^{\circledR}$ Enzyme und Puffer.

Beispiel: Analytischer Doppelverdau von rekombinanten Plasmiden

x $\quad \mu$ l Rekombinantes Protein (ca. 300ng)

y $\mu \mathrm{l} \mathrm{ddH}_{2} \mathrm{O}$

$0,5 \mu \mathrm{l}$ FastDigest $^{\circledR}$ Enzym Hind III

$0,5 \mu$ l FastDigest $^{\circledR}$ Enzym Xba I

$\underline{1,0 \mu 1}$ 10X FastDigest ${ }^{\circledR}$ Buffer

$\sum 10,0 \mu 1$

Der $10 \mu 1$-Ansatz wurde in ein $1,5 \mathrm{ml}$ Reaktionsgefäß gegeben, gemischt und $20 \mathrm{~min}$ bei $37^{\circ} \mathrm{C}$ auf einem Thermoblock inkubiert. Anschließend wurden je Restriktionsansatz $2 \mu 1$ Orange Loading Dye [6X] zugegeben und vollständig auf ein analytisches Agarosegel aufgetragen. Die nach dem Restriktionsverdau erhaltenen Fragmente ließen sich durch eine Gelelektrophorese auftrennen, wodurch ihre Längen näherungsweise bestimmt werden konnten (siehe Kap. 2.2.2.3)

An Hand des Restriktionsmusters konnten die hergestellten rekombinanten Plasmide analysiert und durch eine folgende Sequenzanalyse (siehe Kap. 2.2.2.4) bestätigt werden.

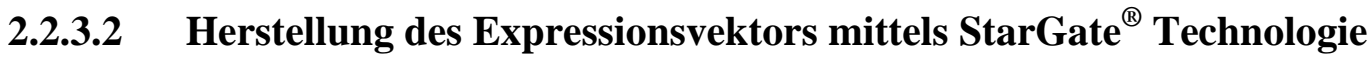

Das StarGate ${ }^{\circledR}$-System stellt ein Klonierungssystem zur schnellen und effizienten Subklonierung eines Gens von einem Donorvektor in einen Akzeptorvektor dar. Ausgehend von einem Donorvektor (siehe Kap. 2.2.3.1) ermöglicht das System durch mischen von StarCombinase $2^{\mathrm{TM}}$, Donor- und Akzeptorvektor die Subklonierung durch eine kombinierte Restriktions- und Ligationsreaktion. Die Wahl des Akzeptorvektors richtet sich nach dem gewünschten Expressionssystem (Säugerzellen, Bakterienzellen (E. coli), 
Insektenzellen, Hefezellen (Saccharomyces cerevisiae)), in die das GOI transformiert werden soll. In dieser Arbeit wurde mit dem Akzeptorvektor pASG-IBA5 gearbeitet. Dieser pASG-IBA Vektor ist dem pASK-IBA Vektor sehr ähnlich und trägt ebenfalls eine Promotor/Operator Region mit tetA Resistenzgen und eignet sich optimal für die Anhydrotetracyclin induzierte Proteinexpression in E. coli Zellen (Skerra, 1994). Durch Verwendung des pASG-IBA5 Vektors wird dem exprimierten Protein N-terminal ein acht Aminosäuren langer Strep-tag ${ }^{\circledR}$ II angefügt.

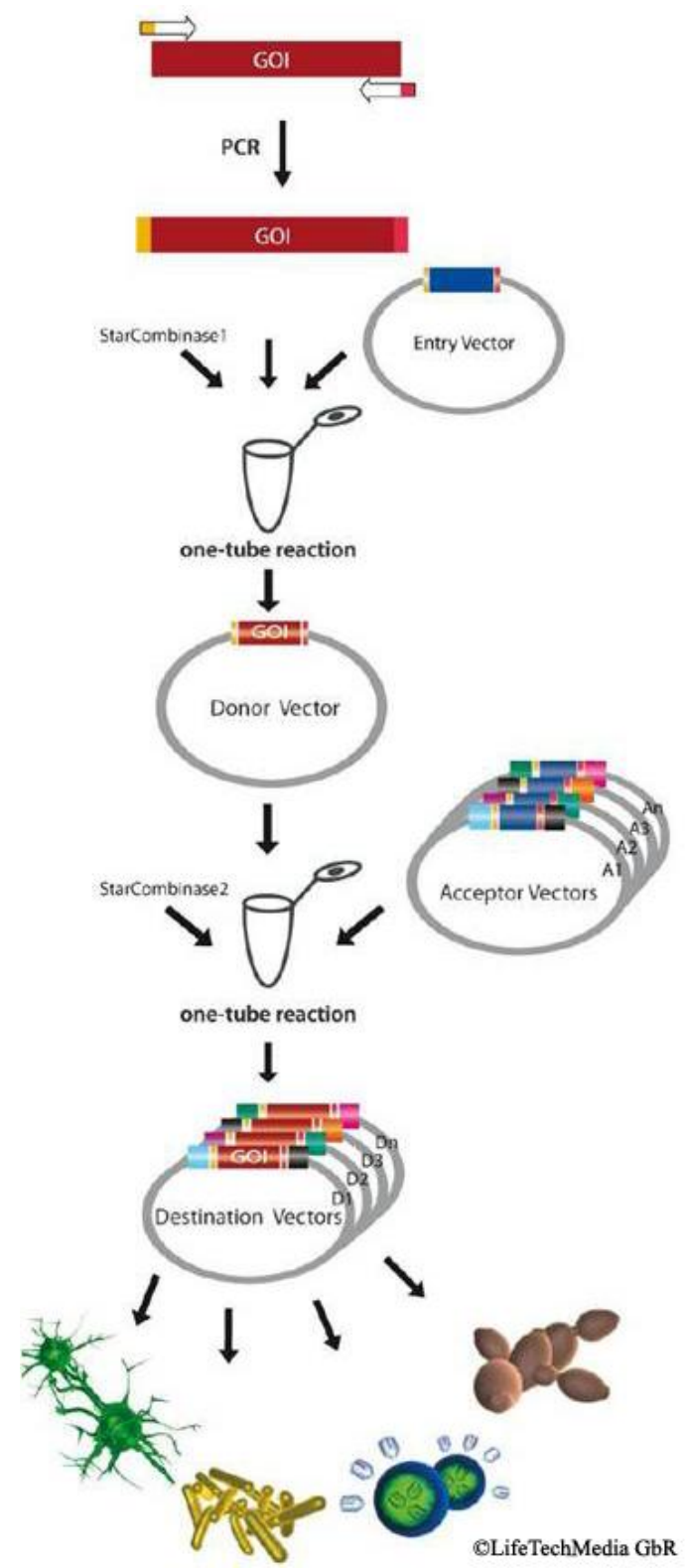

Abb. 2.2: Schematische Darstellung: Expressionsvektorherstellung mittels StarGate ${ }^{\circledR}$ Technologie (Quelle: IBA GmbH). Mischen von Donorvektor, Akzeptorvektor und StarCombinase $2^{\mathrm{TM}}$ führen zu einer kombinierten Restriktions- und Ligationsreaktion. Je nach gewünschtem Expressionssystem (von links: Säugerzellen, Bakterienzellen (E. coli), Insektenzellen, Hefezellen (Saccharomyces cerevisiae)), Promotor und Reinigungs-TAG kann zwischen verschiedenen Akzeptorvektoren gewählt werden. 
Die Ansätze wurden für jeden Virus jeweils nach Angaben des Herstellers pipettiert und $1 \mathrm{~h}$ bei $30^{\circ} \mathrm{C}$ inkubiert. Anschließend erfolgte die Transformation des Donorvektors in E. coli Top 10 chemisch kompetente Zellen (siehe Kap.2.2.3.3).

Beispiel: Ansatz nach Angaben des Herstellers (IBA GmbH) in 1,5ml Reaktionsgefäßen 12,0 $\mu \mathrm{l}$ Donorvektor (auf 2ng / $\mu$ l verdünnt mit $\mathrm{ddH}_{2} \mathrm{O}$ )

$1,0 \mu 1$ StarSolution A1

$1,0 \mu 1$ StarSolution A2

1,0 $\mu 1$ StarSolution A3 (zuvor Zugabe des A3-Verdünnungsmittels) $\underline{10,0 \mu 1}$ pASG-IBA 5

$\sum 25,0 \mu 1$

\subsubsection{Transformation rekombinanter DNA in $E$. coli top 10 bzw. BL21(DE3) Zellen}

Die Zugabe von DNA zu chemisch kompetenten E. coli Zellen ist eine effiziente Methode zum Transfer von DNA (z.B. ein bei einer Ligation entstandenes rekombinantes, zirkuläres Plasmid) in gram-negative und gram-positive Bakterienzellen. Diese Methode basiert darauf, dass exogene DNA von den kompetenten Zellen aufgenommen wird und dient zur Vermehrung des rekombinanten Plasmids bzw. seiner Proteine.

Für die Transformation in E. coli top 10 Zellen (IBA GmbH) wurde je ein Aliquot der „One Shot“" Reaktionen der chemisch kompetenten Zellen auf Eis aufgetaut.

Für die Transformation von pENTRY-Konstrukten in E. coli top 10 Zellen wurden die Zellen mit $10 \mu 1$ Reaktionsansatz versetzt und vorsichtig gemischt. Dieser Ansatz wurde erst $30 \mathrm{~min}$ auf Eis gestellt, dann $5 \mathrm{~min}$ auf $37^{\circ} \mathrm{C}$ erhitzt und erneut $5 \mathrm{~min}$ auf Eis gestellt. Für die Ausbildung der Kanamycin-Resistenz wurden dem Reaktionsansatz 900 $\mu 1$ LBMedium zugegeben und $45 \mathrm{~min}$ bei $37^{\circ} \mathrm{C}$ inkubiert. Anschließend wurden je Ansatz zwei $\mathrm{LB}_{\text {Kana }}$-Agarplatten mit $40 \mu \mathrm{l} \mathrm{X}-\mathrm{Gal}[40 \mathrm{mg} / \mathrm{ml}]$ überzogen. Ausplattiert wurden $100 \mu \mathrm{l}$ Reaktionsansatz bzw. der komplette Rest (nach vorheriger Zentrifugation und resuspendieren in $100 \mu \mathrm{l} \mathrm{LB}-\mathrm{Medium})$. Inkubation erfolgte ü.N. bei $37^{\circ} \mathrm{C}$.

Für die Transformation von pASG-Konstrukten in E. coli top 10 Zellen wurden die Zellen mit $10 \mu \mathrm{l}$ Reaktionsansatz versetzt und vorsichtig gemischt. Dieser Ansatz wurde erst $30 \mathrm{~min}$ auf Eis gestellt, dann $5 \mathrm{~min}$ auf $37^{\circ} \mathrm{C}$ erhitzt und erneut $5 \mathrm{~min}$ auf Eis gestellt. Zwei 
mit $40 \mu 1 \mathrm{X}-\mathrm{Gal}[40 \mathrm{mg} / \mathrm{ml}]$ überzogene $\mathrm{LB}_{\mathrm{Amp}}$-Agarplatten wurden vorbereitet und $10 \mu \mathrm{l}$ Reaktionsansatz bzw. der komplette Rest ausplattiert. Inkubation erfolgte ü.N. bei $37^{\circ} \mathrm{C}$. Die Blau-Weiß-Selektion durch Zugabe von X-Gal zu den Transformationsplatten ermöglichte zusätzlich zur Selektion durch Antibiotikazugabe (pENTRY-Vektor = KanamycinResistenzgen, pASG-Vektor = Ampicillin-Resistenzgen) ein leichtes Erkennen positiver, Insert-tragender Klone. Bei der Ligation wird das vorhandene lacZ-Gen des ursprünglichen Vektors durch das Insert ersetzt, die Transkription des lacZ-Gens wird dadurch unterbrochen und das Enzym B-Galactosidase wird nicht mehr gebildet. Die Folge: X-Gal wird nicht durch B-Galactosidase enzymatisch zu Galactose und 5-Brom-4-chlor-indoxyl gespalten. Bei 5-Brom-4-chlor-indoxyl handelt es sich um einen Farbstoff, der nach Oxidation an der Luft und Dimerisierung den blauen Farbstoff 5,5'-Dibrom-4,4'dichloro-indigo bildet. Kolonien mit positiven Klonen bilden auf der Transformationsplatte weiße Kolonien.

Nach Selektion der Transformanten wurden Übernachtkulturen (siehe Kap. 2.2.3.4) mit Einzelkolonien inokuliert, die Plasmide durch Plasmid-DNA-Minipräparation (siehe Kap. 2.2.3.5) isoliert und rekombinante Plasmide durch einen analytischen Restriktionsverdau (siehe Kap. 2.2.3.1) bzw. Sequenzanalyse (siehe Kap. 2.2.2.4) identifiziert.

Für die Transformation in E. coli BL21(DE3) chemisch kompetente Zellen (freundlicher Weise zur Verfügung gestellt von Dr. rer. nat. Meik Dilcher, UMG Virologie, Göttingen) wurde je ein Aliquot zu 100 $\mu$ l auf Eis aufgetaut und nach Zugabe von $\beta$-Mercaptoethanol [Endkonz. 25mM] erneut 10min auf Eis inkubiert. Das $\beta$-Mercaptoenthanol dient der höheren Transformationseffizienz, kleine Löcher erleichtern das Eindringen der rekombinanten DNA in die Zelle. Den Zellen wurden 40-50ng Plasmid-DNA zugegeben und 30 min auf Eis inkubiert, dann erfolgte ein Hitzeschock für $45 \mathrm{sec}$ bei $42^{\circ} \mathrm{C}$ und ein erneutes Abkühlen auf Eis für 2min. Abschließend wurde dem Reaktionsansatz 900 $\mu 1$ vorgewärmtes SOC-Medium zugegeben und $60 \mathrm{~min}$ bei $37^{\circ} \mathrm{C}$ inkubiert. Anschließend

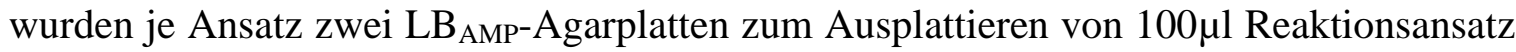
bzw. dem kompletten Rest (nach vorheriger Zentrifugation und resuspendieren in $100 \mu 1$ SOC-Medium) verwendet. Inkubation erfolgte ü.N. bei $37^{\circ} \mathrm{C}$. Für jede Proteinexpression wurde eine neue Transformation in BL21(DE3) Zellen durchgeführt, da diese die Expressionsplasmide mit der Zeit wieder verlieren. Nach Selektion der Transformanten erfolgte die in vivo Expression rekombinanter viraler Proteine (siehe Kap. 2.2.4.1). 


\subsubsection{Anzucht von Bakterienkulturen}

Die Übernachtkultur diente als Ausgangsmaterial für eine DNA-Präparation (siehe Kap. 2.2.3.5) oder als Vorkultur für eine Proteinexpression (siehe Kap. 2.2.4.1). Hierzu wurde je Virus eine rekombinante Einzelkolonie einer Transformationsplatte mit einer sterilen Pipettenspitze in einem $15 \mathrm{ml}$ Falconröhrchen mit 5ml LB-Medium inokuliert. Den Medien wurde zur Selektion der Transformanten ein Antibiotikum z.B. Ampicillin

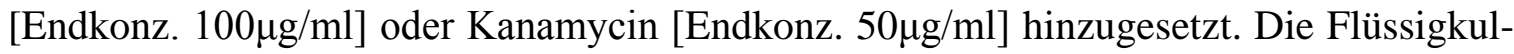
turen wurden mit ca. $150 \mathrm{UpM}$ ü.N. bei $37^{\circ} \mathrm{C}$ geschüttelt.

Die Hauptkultur wurde für die Proteinexpression verwendet. 100ml LB AMP-Medium wurden mit $2 \mathrm{ml}$ einer frischen Übernachtkultur in einem 1000ml Schikanekolben inokuliert und bei $37^{\circ} \mathrm{C}$ mit $110 \mathrm{UpM}$ bis zum Erreichen einer optischen Dichte (OD) von 0,5-0,6 geschüttelt. Anschließend erfolgte die Induktion der Proteinexpression durch Zugabe von Anhydrotetracyclin (siehe Kap. 2.2.4.1).

\subsubsection{Präparation von Plasmid-DNA}

Zur Gewinnung von rekombinanter Plasmid-DNA aus Bakterienkulturen wurde der Reagenziensatz peqGOLD Plasmid Miniprep Kit I (peQlab Biotechnologie GmbH) verwendet. Bei der Präparation wird chromosomale DNA durch Alkalibehandlung denaturiert und nach anschließender Neutralisation ausgefällt, zirkuläre Plasmid-DNA renaturiert durch Erhöhung der Salzkonzentrationen wieder vollständig und bleibt gelöst. Durch Zentrifugation werden die chromosomale DNA, ein großer Teil der RNA und Proteine sedimentiert. Die gelöste Plasmid-DNA verbleibt im Überstand und wird daraufhin auf eine Säule gegeben, gewaschen und in einem letzten Schritt von der Säule eluiert. Verbliebene RNA wird durch RNase A-Behandlung gespalten.

Zur Präparation aller rekombinanten Plasmide wurden je 3,0ml einer Bakterien-Übernachtkultur (siehe Kap. 2.2.3.4) in zwei Schritten in ein 2,0ml Reaktionsgefäß überführt und $1 \mathrm{~min}$ bei RT mit $11000 \mathrm{UpM}$ zentrifugiert. Der Überstand wurde verworfen und die

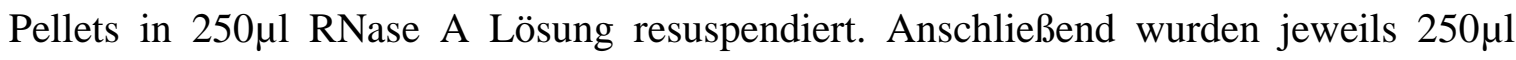
Lösung II zugegeben und durch vier- bis sechsmaliges Invertieren des Reaktionsgefäßes

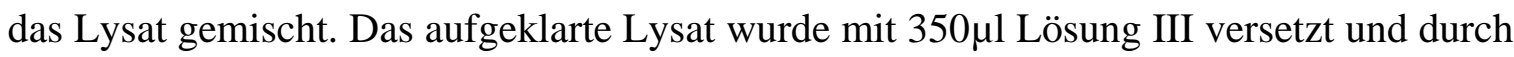
mehrmaliges Invertieren gemischt. Es folgte eine Zentrifugation von $1 \mathrm{~min}$ bei RT mit 
11000UpM. Der Überstand wurde vorsichtig abgenommen und in eine HiBind ${ }^{\circledR}$-Miniprep-Zentrifugensäule überführt. Es folgte ein weiterer Zentrifugationsschritt von $1 \mathrm{~min}$ bei RT mit 11000UpM, hierbei bindet die Plasmid-DNA an die Membran der Säule. Zwei

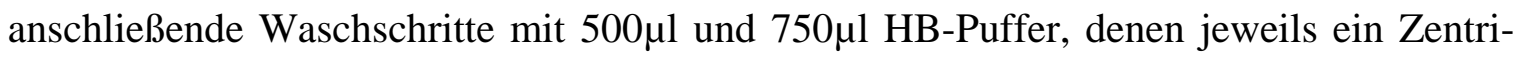
fugationsschritt von $1 \mathrm{~min}$ bei RT mit 11000UpM folgte, befreiten die auf der Membran gebundene DNA von Verunreinigungen. Zum Trocknen der Membran wurde die Säule einmal ohne weitere Zugabe von Lösungen $1 \mathrm{~min}$ bei RT mit 5000UpM zentrifugiert. In einem letzten Schritt wurde die Plasmid-DNA durch Zugabe von $55 \mu 1 \mathrm{ddH}_{2} \mathrm{O}$ von der Säule eluiert und in einem 1,5ml Reaktionsgefäß aufgefangen. Anschließende Lagerung bei $-20^{\circ} \mathrm{C}$.

\subsubsection{Arbeiten mit Proteinen}

\subsubsection{Proteinexpression in $E$. coli BL21(DE3) Zellen}

Durch die Verwendung des StarGate ${ }^{\circledR}$-Klonierungssystems mit dem Expressionsvektor pASG-IBA5 wurden bei sekretierten Proteinen C-terminal zwei Aminosäuren (Glycin, Serin) und N-terminal drei Aminosäuren (Serin, Glycin, Methionin) und der acht Aminosäuren umfassende Strep-tag ${ }^{\circledR}$ II (Tryptophan-Serin-Histidin-Prolin-Glutamin-Phenylalanin-Glutaminsäure-Lysin) angehängt.

Die Hauptkulturen wurden wie in Kap. 2.2.3.4 beschrieben angelegt, nach Erreichen einer OD von 0,5-0,6 wurde die Proteinexpression in den verwendeten E. coli BL21(DE3) Zellen durch Zugabe von $10 \mu \mathrm{l}$ Anhydrotetracyclin [Stock. $2 \mathrm{mg} / \mathrm{ml}$ in DMF, Endkonz. 200ng/ml] induziert. Die Kulturen wurden $3 \mathrm{~h}$ bei $28^{\circ} \mathrm{C}$ und $110 \mathrm{UpM}$ geschüttelt und anschließend durch Zentrifugation in 50ml Falconröhrchen bei 6000UpM für 20min geerntet. Der Überstand wurde verworfen, das Zellpellet ü.N. bei $-20^{\circ} \mathrm{C}$ eingefroren.

Das Aufschließen der Zellen erfolgte mechanisch durch Ultraschall-Behandlung, die gelösten Proteine befanden sich hinterher im Überstand, alle unlöslichen Bestandteile im verbliebenen Pellet nach Zentrifugation (6000UpM, 20min, $5^{\circ} \mathrm{C}$ ), Pellet und Überstand wurden separiert und bei $5^{\circ} \mathrm{C}$ gelagert. 


\subsubsection{SDS-Polyacrylamid-Gelelektrophorese (SDS-PAGE)}

Die SDS-Polyacrylamid-Gelelektrophorese (SDS-PAGE) ermöglicht die Auftrennung von Proteinen nach ihrem Molekulargewicht (Laemmli, 1970). Die elektrophoretische Beweglichkeit von Proteinen in einer Polyacrylamid-Gelmatrix ist von Größe und Form abhängig und wird durch die Nettoladung des Proteins bestimmt. Das anionische Detergenz Natriumlaurylsulfat (englisch: sodium dodecyl sulfate (SDS)) wird von Proteinen quantitativ gebunden und bewirkt in Gegenwart von Thiolreagenzien wie $\beta$-Mercaptoethanol oder Dithiothreitol (DTT) zumeist eine vollständige Denaturierung der Proteine. Die Sulfatgruppen des SDS verleihen den Proteinen eine stark negative Gesamtladung, die der Masse des jeweiligen komplexierten Proteins proportional ist. Die durch das gebunden SDS erworbene negative Ladung ist meist wesentlich größer als die ursprüngliche Ladung des nativen Proteins, die damit vernachlässigbar wird.

Die Wanderungsgeschwindigkeit der Proteine wird somit hauptsächlich durch den Molekularsiebeffekt der Gelmatrix und die angelegte Stromstärke bestimmt. Generell lässt sich sagen, dass für die Trennung von Proteinen im Bereich von 10kDA bis 200kDA Gelkonzentrationen zwischen $8 \%$ und $12.5 \%$ Acrylamid eingesetzt werden. In dieser Arbeit wurde mit 12\%igen Gelen, bestehend aus Trenn- und Sammelgel unterschiedlicher $\mathrm{pH}-$ Werte gearbeitet.

Die Gele wurden in einer Gelelektrophoresekammer fixiert und diese vollständig mit

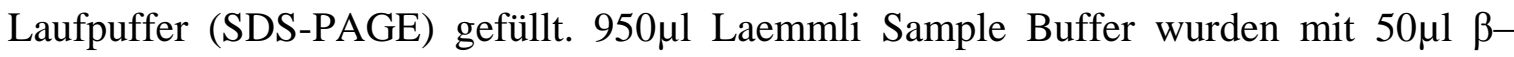
Mercaptoethanol versetzt und im Verhältnis 1:1 mit den Proteinproben gemischt. Zur vollständigen Denaturierung wurden die Ansätze für 5 min bei $95^{\circ} \mathrm{C}$ im Heizblock erhitzt, kurz auf Eis gestellt und mit einer Hamilton-Spritze in die Taschen des Sammelgels eingefüllt. Als Molekulargewichtsmarker wurden 5 4 SDS-PAGE Molecular Weight Standards (Fermentas) aufgetragen.

Die Gelelektrophorese erfolgte $30 \mathrm{~min}$ bei $60 \mathrm{~V}$ bis die Proben vollständig in das Sammelgel eingelaufen waren, danach weitere $60 \mathrm{~min}$ bei $100 \mathrm{~V}$, bis der im Probenpuffer enthaltende Farbmarker die untere Kante des Gels erreichte. Für den spezifischen Nachweis der exprimierten Proteine wurden anschließend Western Blot (siehe Kap. 2.2.4.3) und Immunoblot-Analyse (siehe Kap.2.2.4.4) durchgeführt. 


\subsubsection{Transfer von Proteinen auf Polyvinylidenfluorid (PVDF) Membran (,Western Blot"}

Für den nachfolgenden immunologischen Nachweis wurden die Proteine nach der SDSPolyacrylamid-Gelelektrophorese (SDS-PAGE) (siehe Kap. 2.2.4.2) auf eine Poly $\underline{\text { inyl- }}$ idenfluorid-Membran (PVDF) transferiert (Towbin, Staehlin \& Gordon, 1979). Hierzu wurden die PVDF-Membran und zwei Filterpapiere entsprechend der Gelgröße zurechtgeschnitten und zusammen mit dem ungefärbten Gel luftblasenfrei in einer speziellen Blotkammer wie folgt zusammen gebaut:

\section{Kathodenseite \\ Schwamm \\ Filterpapier \\ Gel \\ PVDF-Membran \\ Filterpapier \\ Schwamm \\ Anodenseite}

Die Kammer wurde vollständig mit Transferpuffer gefüllt. Der Transfer erfolgte bei 350mA, 1h unter Rühren und Kühlen.

\subsubsection{Spezifischer Nachweis exprimierter Proteine mittels Strep-tag ${ }^{\circledR}$ II Antikörper (,Immunoblot-Analyse“)}

Auf PVDF-Membranen immobilisierte rekombinante Proteine können auf Grund ihres N-terminal angehängten Strep-tag ${ }^{\circledR}$ II mit sehr hoher Sensitivität durch monoklonale AntiStrep-tag ${ }^{\circledR}$ II Antikörper nachgewiesen werden.

In dieser Arbeit wurde mit dem Strep MAB - Classic (IBA) gearbeitet, der zuvor mit dem Enzym Meerrettich-Peroxidase (englisch: horseradish-peroxidase, HRP) konjugiert wurde [Anti-Strep-tag ${ }^{\circledR}$ II-HRP]. Unter alkalischen Bedingungen katalysiert die Peroxidase die Oxidation von Luminol, was zu einer Lichtemission bei $425 \mathrm{~nm}$ führt (Prichard \& Cormier, 1968). Eine bestehende Chemilumineszenz weist das Vorhandensein des an den 
Strep-tag ${ }^{\circledR}$ II spezifisch bindenden Antikörpers nach und beweist somit eine erfolgreiche Proteinexpression, bei der das Strep-tag ${ }^{\circledR}$ II angehängte rekombinante Protein exprimiert wurde. Die Intensität der gemessenen Chemilumineszenz ist dabei proportional zur Menge des exprimierten Proteins.

Zur Absättigung von unspezifischen Bindungsstellen wurde die PVDF-Membran zuvor 30min bei RT auf einer Wippe und anschließend ü.N. bei $4^{\circ} \mathrm{C}$ in Blockierungspuffer (Western Blot) inkubiert. Am folgenden Tag wurde die Membran mit Waschpuffer (Western Blot) gewaschen, anschließend mit dem in 50\% Blockierungspuffer (Western Blot) und 50\% Waschpuffer (Western Blot) verdünnten Anti-Strep-tag ${ }^{\circledR}$ II-HRP Antikörper (Verdünnung 1:32000) 1h bei RT schwenkend inkubiert und erneut mit Waschpuffer (Western Blot) gewaschen.

Abschließend wurde die Membran mit einem Gemisch der beiden Amersham ${ }^{\mathrm{TM}} \mathrm{ECL}^{\mathrm{TM}}$ Prime Western Blotting Detection System Lösungen [1ml Lösung A (enthält Luminol) und 1ml Lösung B (enthält Peroxid)] für ca. 5min inkubiert und die Enzymreaktion durch Dokumentation der Chemilumineszenz am Chemidoc XRS ermittelt.

\subsubsection{Solubilisierung unlöslicher Proteine}

Für die Solubilisierung der Proteine, sofern diese nicht ausreichend in gelöster Form nach Proteinexpression und Zellaufschluss (siehe Kap. 2.2.4.1) vorlagen, wurde eine Sarkosyl enthaltende Lösung verwendet. Hierbei ist es wichtig, dass die Proteine nach der Solubilisierung wieder ihre natürliche Sekundärstruktur einnehmen und somit biologisch aktiv bleiben. Frühere Studien haben gezeigt, dass eine Solubilisierung mit 1,5\% Sarkosyl zwar den größten Teil der Proteine in eine lösliche Form überführen, ihre Aktivität hingegen stark herabgesetzt wird (Zhuo et al., 2005) mit 0,3\% Sarkosyl hingegen ausreichend ist für die Überführung von Proteinen in eine lösliche Form bei der die Aktivität erhalten bleibt (R.R. Burgess, 1996).

Eine Sarkosylbehandlung wurde mit den Pellets nach Ultraschallbehandlung (siehe Kap. 2.2.4.1) der Proteinexpressionen der Viren BATV-N, ERVEV-N, TRBV-VP7, TBEVNS1, WNV-NS1 durchgeführt, da diese in zu geringer Konzentration zum Koppeln an Beads (siehe Kap. 2.2.5.2.1) in gelöstem Zustand vorlagen. 
Die bei $-20^{\circ} \mathrm{C}$ gelagerten Pellets wurden in $3 \mathrm{ml}$ PBS $[1 \mathrm{X}]$ resuspendiert, in $15 \mathrm{ml}$ Falconröhrchen überführt und $15 \mathrm{~min}$ bei $4^{\circ} \mathrm{C}$ mit $6000 \mathrm{UpM}$ zentrifugiert. Der Überstand wurde verworfen und das Pellet in 3ml Sarkosyl-Lösung [0,4\% Sarkosyl, 0,1M Tris, pH12,0] aufgenommen und $3 \mathrm{~h}$ bei $4^{\circ} \mathrm{C}$ auf einem Rotator gemischt.

Abschließend wurden alle nicht gelösten Bestandteile durch Zentrifugation $\left(15 \mathrm{~min}, 4^{\circ} \mathrm{C}\right.$, 6000UpM) entfernt und die verbleibenden $3 \mathrm{ml}$ Überstand, die das nun gelöste Protein enthielten, in Dialysekassetten gegen PBS [1X] dialysiert (siehe Kap. 2.2.4.7)

\subsubsection{Reinigung von Proteinen mittels Strep-tag ${ }^{\circledR} /$ Strep-Tactin ${ }^{\circledR}$ Technologie}

Durch Verwendung der pASG-IBA5 Vektoren wurden den rekombinanten viralen Proteinen bei der Expression N-terminal eine Strep-tag ${ }^{\circledR}$ II Affinitätssequenz angehängt, was eine Reinigung durch Säulenchromatographie ermöglichte (Schmidt \& Skerra, 2007). Der 8 Aminosäuren lange Strep-tag ${ }^{\circledR}$ II (Trp-Ser-His-Pro-Gln-Phe-Glu-Lys) beeinflusst dabei weder die Proteinstruktur noch die biologische Aktivität des Proteins als Antigen. Die hohe selektive Reinigung basiert auf der starken Affinität der Bindung von Strep$\operatorname{tag}^{\circledR}$ II an Strep-Tactin ${ }^{\circledR}$, einem von IBA entwickelten Streptavidin-Derivat mit 100fach höherer Bindungsaffinität (Voss \& Skerra, 1997).

Wie in Abb. 2.3 schematisch dargestellt wurde das gesamte Probenvolumen, nach Equilibrierung der Säule durch Zugabe von $2 \mathrm{ml}$ Waschpuffer (Säule), auf die Säule gegeben. Nach fünf Waschschritten von je 1ml Waschpuffer (Säule) folgten sieben Elutionsschritte von je 500 $\mu$ l Elutionspuffer (Säule) [enthält 2,5mM Desthiobiotin]. Der Durchfluss, die Waschschritte und die Eluate wurden in Fraktionen getrennt in 1,5ml Reaktionsgefäßen aufgefangen und mittels SDS-PAGE, Westernblot und ggf. BCA-Test auf Proteingehalt und Reinheit überprüft. Eluate mit genügend hoher Konzentration an viralen Proteinen für eine Kopplung an Beads (siehe Kap. 2.2.5.2.1) wurden vereinigt und gegen PBS [1X] dialysiert (siehe Kap. 2.2.4.7), um störende Substanzen wie z.B. Desthiobiotin aus den Eluaten zu entfernen.

Für die Regeneration der Säule wurden $15 \mathrm{ml}$ Regenerationspuffer (Säule) in drei Schritten auf die Säule gegeben, hierbei wurde das Desthiobiotin des Elutionspuffers von der Säule verdrängt, was durch eine rötliche Färbung der Säule sichtbar wurde. Durch Zugabe von Waschpuffer (Säule) wurde die im Regenerationspuffer enthaltene 
2-(4-Hydroxyphenylazo)-benzoesäure kurz HABA, verantwortlich für die Rotfärbung, vollständig von der Säule entfernt, die Säulen konnten anschließend erneut zur Reinigung des gleichen Proteins verwendet werden. Um Kontaminationen mit anderen exprimierten Proteinen zu vermeiden wurde für jedes rekombinante Protein eine Säule verwendet.

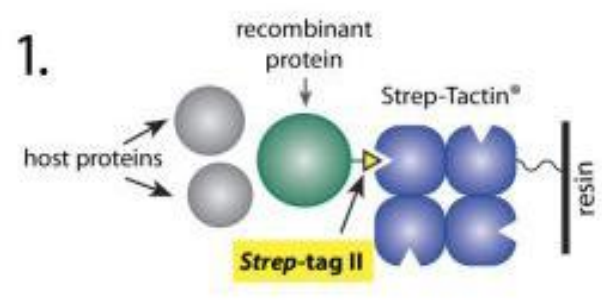

2.

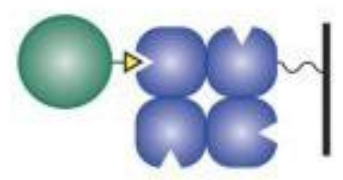

3.

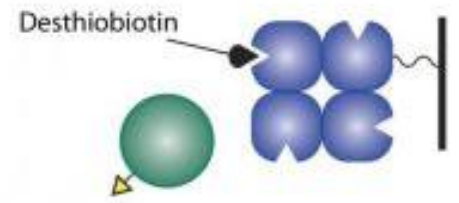

4.

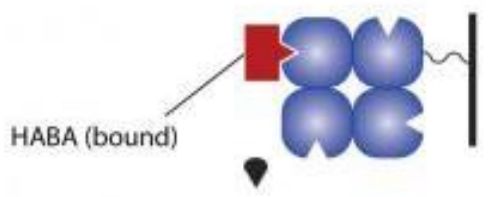

5.

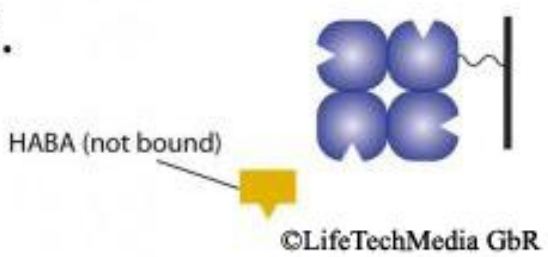

Abb. 2.3: Schematische Darstellung der Reinigung von Strep-tag ${ }^{\circledR}$ II-Fusionsproteinen über eine Strep-Tactin ${ }^{\circledR}$ Sepharose Säule (Quelle: IBA GmbH). 1+2: Strep-tag ${ }^{\circledR}$ II-Fusionsproteine binden spezifisch an Strep-Tactin ${ }^{\circledR}$ Matrix, Verunreinigungen werden in folgenden Waschschritten entfernt. 3: Die gebundenen Strep-tag ${ }^{\circledR}$ II-Fusionsproteine werden durch Zugabe von Elutionspuffer [2,5mM Desthiobiotin] von der Säule verdrängt und eluiert. 4: Regeneration der Säule durch Zugabe von Regenerationspuffer [2-(4-Hydroxyphenylazo)-benzoesäure kurz HABA] und Verdrängung des Desthiobiotins, sichtbar durch die Rotfärbung der Säule. 5: Durch Zugabe von Waschpuffer wird HABA vollständig von der Säule entfernt. 


\subsubsection{Dialyse von Proteinen mittels Slide-A-Lyzer ${ }^{\mathrm{TM}}$ G2 Dialyse Kassetten}

Um störende Substanzen wie Sarkosyl nach Solubilisierung (siehe Kap. 2.2.4.5) oder Desthiobiotin nach Reinigung durch Strep-tag ${ }^{\circledR} /$ Strep-Tactin ${ }^{\circledR}$ Säulen (siehe Kap. 2.2.4.6) aus den Protein-enthaltenden Lösungen zu entfernen wurden die Ansätze gegen PBS [1X] dialysiert. Es handelt sich bei der Dialyse um einen konzentrationsgetriebenen Membranprozess, bei dem nur Moleküle unterhalb der gewählten Porengröße (englisch: Molecular Weight Cut Off, MWCO) der Membran diese passieren können. Größere Moleküle, wie die exprimierten Proteine, werden innerhalb der Membran zurückgehalten.

In dieser Arbeit wurden Slide-A-Lyzer ${ }^{\mathrm{TM}}$ G2 Dialyse Kassetten verwendet, diese besitzen eine semipermeable Membran mit einer Porengröße von 3500Da. und ein Fassungsvolumen von $0,5-3 \mathrm{ml}$.

Die Probe wurde in die Dialysekassette pipettiert und in ein Becherglas mit PBS [1X] gegeben. Das Volumen an Dialysepuffer richtete sich dabei nach dem eingesetzten Probenvolumen: In der Regel wird das 350-fache Volumen des Probenvolumens verwendet, bei 3ml Probe wurde entsprechend jeweils gegen 1050ml PBS [1X] dialysiert.

Auf Grund des osmotischen Drucks stellt sich mit der Zeit ein Konzentrationsgleichgewicht ein, der Puffer wurde mehrfach (nach $2 \mathrm{~h}$, nach $4 \mathrm{~h}$, nach $6 \mathrm{~h}$ ) gewechselt, um den osmotischen Druck weiter aufrecht zu erhalten. Auf diese Weise konnte die Konzentration der ursprünglich vorhandenen unerwünschten Substanzen auf ein vernachlässigbares Maß reduziert werden. Zusätzliches Rühren des Puffers beschleunigt den Prozess (Kunitz \& Simms, 1928).

Am folgenden Tag wurden die Proben mit einer Spritze aus der Dialysekassette gezogen und in $1,5 \mathrm{ml}$ Protein-lo-bind Reaktionsgefäße überführt und bis zur Konzentrationsbestimmung (siehe Kap. 2.2.4.8) bzw. Kopplung (siehe Kap. 2.2.5.2.1) bei $4^{\circ} \mathrm{C}$ gelagert.

\subsubsection{Proteinkonzentrationsbestimmung mittels Bicinchoninsäure (BCA)}

Zur quantitativen Proteinkonzentrationsmessung wurde der Reagenziensatz „BCA Protein Assay Kit"، von Pierce ${ }^{\circledR}$ nach Angaben des Herstellers verwendet.

Hierbei handelt es sich um einen zwei Schritte beinhaltenden colorimetrischen Nachweis. Die gut untersuchte aber unspezifische Methode $\mathrm{Cu}^{2+} \mathrm{zu} \mathrm{Cu}^{+} \mathrm{zu}$ reduzieren, indem in alkalischem Milieu $\mathrm{Cu}^{2+}$-Ionen quantitativ mit Protein einen Komplex bilden, bei dem 
$\mathrm{Cu}^{+}$- Ionen entstehen (Biuret Reaktion) (Gornall, Bardawill \& David, 1949) wird mit der hoch sensitiven BCA-Methode kombiniert. Die $\mathrm{Cu}^{+}$- Ionen reagieren im zweiten Schritt mit Bicinchoninsäure (BCA), welche in wässriger Lösung ein sensitives, stabiles und hochspezifisches Reagenz für $\mathrm{Cu}^{+}$-Ionen darstellt (Smith et al., 1985). Durch die Komplexbildung zweier BCA-Moleküle mit einem $\mathrm{Cu}^{+}$-Ion entsteht ein violettes wasserlösliches Reaktionsprodukt mit starker Absorption bei einer Wellenlänge von $562 \mathrm{~nm}$.

Die Konzentration wurde durch Vergleich der Probe mit einer unter gleichen Bedingungen erstellten Eichkurve eines Proteins bekannter Konzentration (BSA Stock: $2 \mathrm{mg} / \mathrm{ml}$, Eichkurve: $2000 \mu \mathrm{g} / \mathrm{ml}, 1500 \mu \mathrm{g} / \mathrm{ml}, 1000 \mu \mathrm{g} / \mathrm{ml}, 750 \mu \mathrm{g} / \mathrm{ml}, 500 \mu \mathrm{g} / \mathrm{ml}, 250 \mu \mathrm{g} / \mathrm{ml}$, $125 \mu \mathrm{g} / \mathrm{ml}, 25 \mu \mathrm{g} / \mathrm{ml}$ ) photometrisch am Fluostar (Einstellung: 4 Parameter Fit) bestimmt. Bei der BCA-Quantifizierungsmethode wurde die Konzentration des Gesamtproteins nach evtl. nötiger Solubilisierung (2.2.4.5), Reinigung (2.2.4.6) und Dialyse (2.2.4.7) aller exprimierten Proteine gemessen. Dieser Schritt war für die Entwicklung des MultiplexCytometric-Bead-Arrays (CBA) essentiell, um sicherzustellen, dass jeweils die gleiche Menge Protein an Beads gekoppelt wurde (2.2.5.2.1).

\subsubsection{Detektionsmethoden für Antikörper aus Serum}

\subsubsection{Immunfluoreszenz Test (IFT) zur Kontrolle der Positivseren}

Für die Entwicklung neuer diagnostischer Nachweise sind Kontrollen für die Bestimmung der Sensitivität und Spezifität eines Testes unverzichtbar. Für diese Arbeit wurden die in Tabelle 2.14 aufgeführten Seren als Kontrollen verwendet. Um diese Seren eindeutig als Positivseren zu bestimmen wurde zusätzlich ein Immunfluoreszenztest (IFT) entwickelt. Die in den Seren befindlichen viralen Antikörper binden an die mit Virus infizierten Zellen, die Antikörper werden anschließend durch fluoreszenzmarkierte Zweitantikörper, welche spezifisch an den $\mathrm{F}_{\mathrm{c}}$-Teil des Serumantikörpers binden, mittels Fluoreszenzmikroskopie nachgewiesen. Wegen seiner starken Emission bei 570nm nach Absorption von Licht der Wellenlänge von 550nm wurde Cyanin-Typ III (Cy3) als Fluoreszenzfarbstoff gewählt. Für den IFT wurden die mit Virus infizierten Zellen zuvor auf Objektträger mit zwölf voneinander getrennten Feldern fixiert, bei $-20^{\circ} \mathrm{C}$ gelagert (siehe Kap. 2.2.1.2) 
und nach Bedarf verwendet. Die Objektträger wurden nach leichtem Antauen bei Raumtemperatur 5min in einer Glasschalte mit PBS [1X] gewaschen und die Flüssigkeit anschließend vollständig zwischen den Feldern entfernt.

Zur Ermittlung der Sensitivität wurden je Serum Verdünnungsreihen (1:20, 1:40, 1:80, $1: 160,1: 320,1: 640,1: 1280,1: 2560,1: 5120)$ in PBS [1X] angelegt und zusammen mit immer der gleichen Negativkontrolle (1:100) auf die entsprechenden virusspezifischen Objektträger aufgetropft. Pro Feld wurden $20 \mu \mathrm{l}$ Volumen eingesetzt und für $2 \mathrm{~h}$ in einer mit Wasser gefüllten Färbekammer bei $37^{\circ} \mathrm{C}$ im Brutschrank inkubiert. Anschließend wurden die Objektträger zweimal in PBS [1X] gewaschen und die Flüssigkeit wieder vollständig zwischen den Feldern entfernt. Zum Nachweis der Antikörper wurden je nach Herkunft des Serums (Maus oder Mensch) Anti-Maus- oder Anti-Human-IgG mit Cyanin Typ III (kurz: Cy3: Absorption 550nm, Emission 570nm) gekoppelte Zweitantikörper in der vom Hersteller empfohlenen Verdünnung (1:500) verwendet. Pro Feld wurden 20 $\mu 1$ Volumen eingesetzt, Inkubation erfolgte in einer Färbekammer $1 \mathrm{~h}, 37^{\circ} \mathrm{C}$ im Brutschrank, auf Grund des eingesetzten lichtempfindlichen Fluoreszenzfarbstoffs, dunkel abgedeckt. Zum Abschluss wurden die Objektträger erneut zweimal in PBS [1X] gewaschen, getrocknet und mit Fluosafe-Reagenz (Calbiochem) und Deckglas bis zur vollständigen Aushärtung über Nacht bei $4^{\circ} \mathrm{C}$ gelagert. Die unter dem Fluoreszenzmikroskop rot erscheinenden positiven Seren wurden mit einer Kamera dokumentiert (siehe Abb. 3.8 ) und tabellarisch zusammengefasst (siehe Tabelle 3.5).

\subsubsection{Cytometric-Bead-Array (CBA)}

\subsection{Kopplung von viralen Oberflächenproteinen an magnetische carboxylierte Mikrokugeln (Beads)}

Wie in Kap. 1.2.3 beschrieben wurden zum Nachweis viraler Antikörper virale Oberflächenproteine hergestellt und diese an magnetische carboxylierte Mikrokugeln (Beads) gekoppelt (siehe Abb. 2.4). Die Beads sind mit unterschiedlichen Verhältnissen zweier Fluoreszenzfarbstoffe (rot und infrarot) gefüllt, was eine eindeutige Zuordnung der einzelnen Beadpopulationen bei Auftragung beider Fluoreszenzsignale gegeneinander ermöglicht (siehe Einleitung Kap. 1.2.2) 


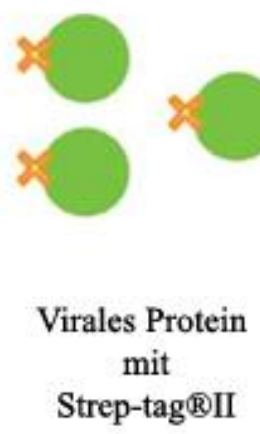

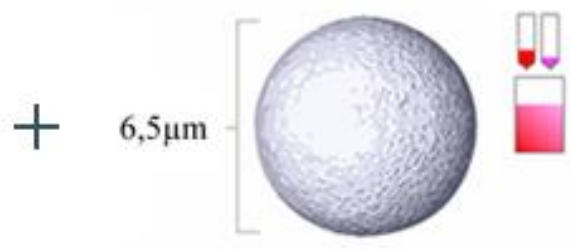

Bio-Plex Pro magnetic COOH Beads

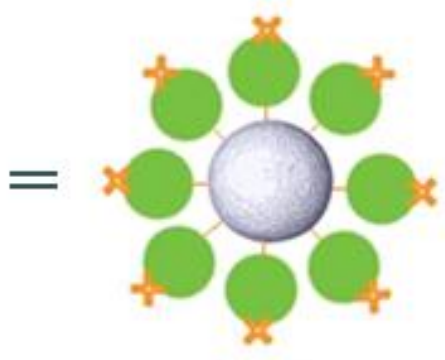

gekoppeltes

Proteinbead

Abb. 2.4: Schematische Darstellung der Kopplung von viralen Proteinen mit magnetischen carboxylierten Beads. Durch eine zweischritt carboxydiimid-Reaktion von primärer Amino-Gruppe des Proteins und der funktionellen Carboxyl-Gruppe auf der Beadoberfläche wurden Proteinbeads hergestellt, die Proteine wurden dabei kovalent an die Beadoberfläche gebunden.

In dieser Arbeit wurde mit Bio-Plex Pro magnetic COOH Beads der Regionen \#26, \#27, \#29, \#34, \#35, \#36, \#37, \#42, \#44, \#46, \#52, \#53, \#54, \#55, \#62, \#63, \#65 gearbeitet. Zur Kopplung wurde jede Beadpopulation mit einem anderen viralen Protein gekoppelt, dabei wurden die Beadpopulationen so gewählt, dass potentiell kreuzreagierende oder nah verwandte Viren möglichst weit voneinander entfernt lagen (siehe Abb. 2.5). Als Kontrollen wurde eine Beadpopulation mit reinem BSA (42), die andere mit E. coli Proteinen (65) einer reinen BL21(DE3)-Expressionskultur gekoppelt.
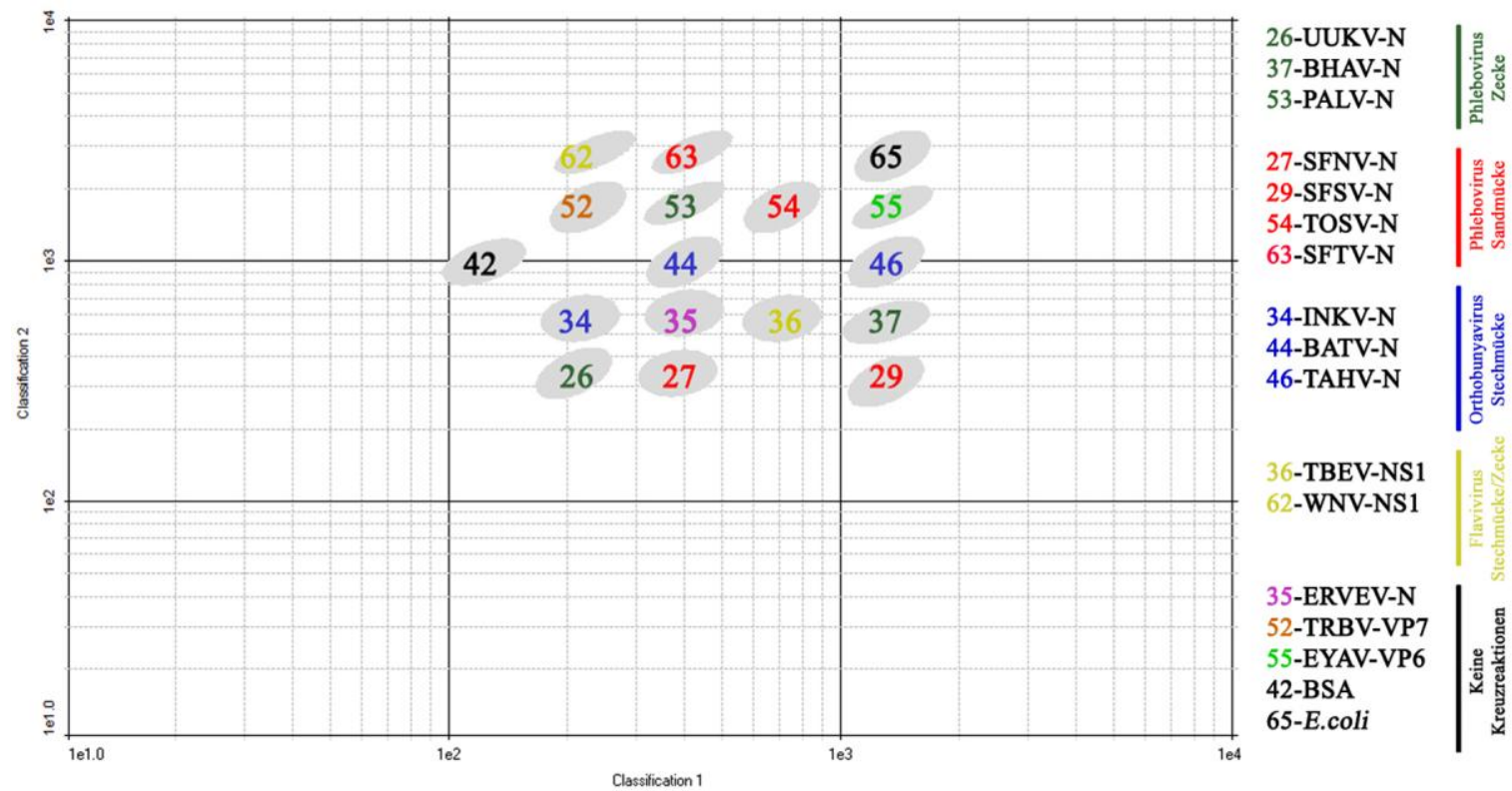

Abb. 2.5: Dot-Plot Darstellung der gekoppelten, nummerierten Bio-Plex Pro magnetic COOH Beads und ihre Lage bei logarithmischer Auftragung der Signale beider internen Fluoreszenzfarbstoffe gegeneinander. Nah verwandte und möglicherweise kreuzreagierende Viren wurden in maximalem Abstand zueinander gewählt. Grün: von Zecken übertragene Phleboviren, Rot: von Sandmücken übertragene Phleboviren, Blau: von Stechmücken übertragene Orthobunyaviren, Gellb: Flaviviren. 


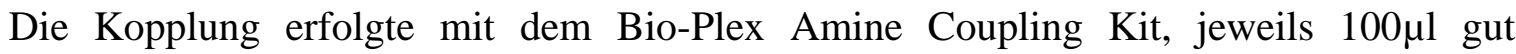
gemischter ungekoppelter Bio-Plex Pro magnetic $\mathrm{COOH}$ Beads wurden in 1,5ml Proteinlo-bind Gefäße gegeben, $3 \mathrm{~min}$ bei $12000 \mathrm{UpM}$, RT zentrifugiert, der Überstand verworfen und das Beadpellet in 100 $\mu 1$ Bead-Wash-Buffer resuspendiert. Nach 10sec mischen mittels Vortexer und 10sec Ultraschallbad wurden der Zentrifugationsschritt wiederholt

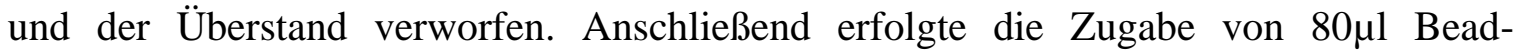
Activation-Buffer, der Ansatz wurde zuerst 30sec mittels Vortexer, dann 30sec mittels Ultraschallbads gemischt. Parallel wurden 1-Ethyl-3-(3-dimethylaminopropyl)carbodiimid (EDAC) [50mg/ml] und N-hydroxysulfosuccinimide sodium salt (NHSS) [50mg/ml] eingewogen, in entsprechender Menge Bead-Activation-Buffer gelöst und jeweils $10 \mu \mathrm{lu}$

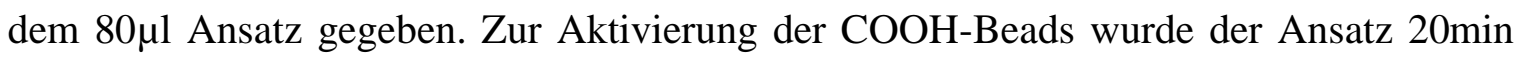
bei RT auf einem Rotator gemischt. Ab diesem Zeitpunkt wurden die Ansätze in Alufolie gehüllt, um direktes Licht auf die aktvierten Beads zu vermeiden.

Nach 20min Aktivierung erfolgten zwei aufeinander folgende Waschschritte mit je $150 \mu 1$ PBS [1X], Zentrifugation 3min bei 12000UpM, Überstand wurde verworfen. Die Beads wurden in $100 \mu 1$ resuspendiert, $30 \mathrm{sec}$ mittels Vortexer gemischt und $15 \mathrm{sec}$ in ein Ultraschallbad gegeben.

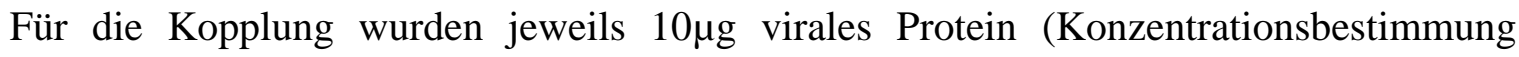
mittels BCA-Test siehe Kap.2.2.4.8) durch Zugabe von entsprechender Menge PBS [1X] auf ein Volumen von $200 \mu 1$ gebracht und zu dem Gemisch aktivierter Beads gegeben. Die Kopplung, bei der die Proteine in einer zweischritt carboxydiimid Reaktion zwischen primärer Amino-Gruppe des Proteins und funktioneller Carboxyl-Gruppe auf der Beadoberfläche kovalent gebunden werden, erfolgte über Nacht bei $4^{\circ} \mathrm{C}$ auf einem Rotator.

Nach der Kopplung wurde der Ansatz zentrifugiert, der Überstand verworfen und die gekoppelten Beads in 500 $\mu$ l PBS [1X] gewaschen. Nach vorsichtigem Mischen mit geringer Geschwindigkeit wurde der Ansatz zentrifugiert und der Überstand verworfen. Zur Blockierung evtl. noch freier Kopplungsstellen wurden den gekoppelten Beads $250 \mu 1$ Blocking-Buffer zugegeben, der Ansatz 15sec vorsichtig gemischt und weitere 30min bei RT auf einen Rotator gestellt. 
Der Ansatz wurde zentrifugiert (12000UpM, 3min,dunkel), der Überstand verworfen und die Beads in 500 $\mu 1$ Storage-Buffer vorsichtig resuspendiert, erneut zentrifugiert, der Überstand verworfen und zum Abschluss wurden die nun fertig gekoppelten Beads in $150 \mu 1$ Storage-Buffer aufgenommen. Laut Hersteller sind die gekoppelten Beads bei $4^{\circ} \mathrm{C}$ Lagerung 1 Jahr haltbar, so dass in allen folgenden Versuchen auf die vorhandenen gekoppelten Stocks zurückgegriffen wurde.

\subsection{Nachweis der Kopplung mittels Strep-tag $^{\circledR}$ II $\quad$ spezifischem fluoreszenzmarkiertem Antikörper}

Zur Überprüfung der Kopplung viraler Antigene an carboxylierte Beads (Bio-Plex Pro magnetic $\mathrm{COOH}$ Beads) wurden $5 \mu 1$ des jeweiligen Stocks (siehe Kap. 2.2.5.2.1) und $95 \mu 1$ Waschpuffer (Beads-MAGPIX) in ein well einer 96-well Platte gegeben und 100 $\mu 1$ verdünntes Konjugat (5 4 l Strep-Tactin-R-PE (bei Proteinen mit Strep-tag $\left.{ }^{\circledR} \mathrm{II}\right)+95 \mu 1$ Drive Fluid) zugegeben. Der Ansatz wurde 15min, dunkel abgedeckt auf einer Wippe inkubiert und alle 5min zusätzlich auf niedrigster Stufe mit einem Plattenvortexer gemixt. Da es sich bei den verwendeten Beads um Bio-Plex Pro magnetic COOH Beads handelte und diese somit magnetische Eigenschaften aufwiesen konnten alle Waschschritte auf einem starken Magneten, dem 96-Well Microtiter Plate Magnetic Separation Rack (New England Biolabs $\mathrm{GmbH}$ ) durchgeführt werden. Hierzu wurde die Mikrotiterplatte 5min auf den Magneten gestellt und der Überstand vorsichtig abgenommen und verworfen. Der Ansatz wurde in $200 \mu 1$ Drive Fluid resuspendiert, kurz gemischt und erneut $5 \mathrm{~min}$ auf den Magneten gestellt, der Überstand abgenommen und verworfen.

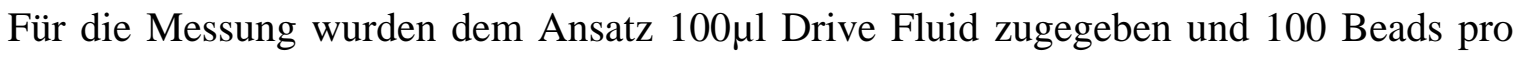
Beadpopulation zur Ermittlung der medianen Fluoreszenzintensität (MFI) am MAGPIX $^{\mathrm{TM}}$-System gemessen. Bei jeder Messung wurde eine Kontrolle in Form von BSAgekoppelten Beads mitgeführt. Eine Kopplung wurde als erfolgreich gewertet, wenn die Beadpopulation ein Fluoreszenzsignal zeigte, die Kontrolle jedoch nicht. Eine schematische Darstellung ist in Abb. 2.6 zu sehen. 


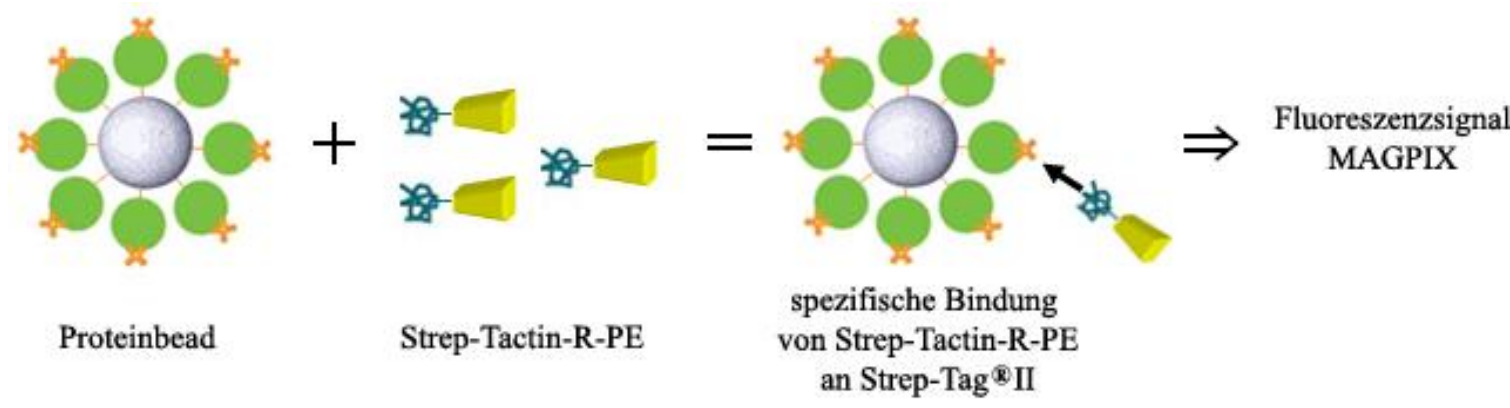

Abb. 2.6: Schematische Darstellung des Kopplungsbeweises. Ausschließlich erfolgreich gekoppelte Proteinbeads ermöglichen durch den zugänglichen Strep-tag ${ }^{\circledR}$ II eine spezifische Bindung des Strep-TactinAntikörpers (konjugiert mit Phycoerythrin) an den Strep-tag ${ }^{\circledR}$ II des rekombinanten viralen Proteins. Nach Bindung kann mittels Messung am MAGPIX ${ }^{\mathrm{TM}}$-System ein Fluoreszenzsignal (PE-Median) detektiert werden.

\subsection{Ermittlung der CBA Sensitivität mittels Positivseren}

Zur Ermittlung der Sensitivität aller in dieser Arbeit hergestellten, mit unterschiedlichen viralen Proteinen gekoppelten Beadpopulationen (siehe Abb. 2.5) wurden die im Immunfluoreszenztest (siehe Kap. 2.2.5.1) getesteten Positivseren als Kontrollen verwendet. Wie in Kap. 1.2.3 beschrieben handelt es sich beim CBA um einen serologischen Antikörpernachweis, bei dem aufeinander folgend Antigen, Erstantikörper und Zweitantikörper eine Bindung eingehen und es letztlich zur Detektion eines Fluoreszenzsignals (PE-Median) kommt.

Da eine Proteinreinigung nicht alle exprimierten, nicht mit Tag versehene Proteine rückstandslos entfernt, wurden die Proteinbeads auf E. coli Proteine überprüft. Wie im Ergebnisteil (Kap. 3.5.2, Tabelle 3.7, Abb. 3.9 und Abb. 3.10) dargestellt konnte eine geringe Menge E. coli Protein (auf Grund der Expressionskultur) nachgewiesen werden, die nach der Kopplung (siehe Kap. 2.2.5.2.1) neben dem eigentlichen viralen Antigen ebenfalls auf der Beadoberfläche gebunden wurden. So könnten Seren mit intrinsisch hohem Titer von E. coli Antikörpern (E. coli gehört zu den gramnegativen Bakterien und ist Bestandteil der tierischen und menschlichen Darmflora, es gibt pathogene und nicht pathogene Stämme, die durch Zufuhr von Wasser und Lebensmitteln aufgenommen werden) zu einem Fluoreszenzsignal führen.

Um falsch positive Signale zu vermeiden, wurde jedes untersuchte Serum mit dem E. coli Lysat einer reinen BL21(DE3) Expressionskultur $1 \mathrm{~h}, 37^{\circ} \mathrm{C}$ inkubiert. Durch diese Präadsorption wurden die E. coli Antikörper noch vor Kontakt mit den Proteinbeads abgefangen. 
Pro Ansatz wurde je ein Serum (siehe Tabelle 2.14) zusammen mit E. coli Lysat (1:60) und PBS $[1 \mathrm{X}]$ auf ein Verhältnis von 1:8 verdünnt, die Präadsorption erfolgte für $1 \mathrm{~h}$ bei $37^{\circ} \mathrm{C}$, anschließend wurden alle löslichen von unlöslichen Bestandteile durch Zentrifugation (5min, 10000UpM, RT) getrennt.

Der Überstand wurde jeweils in Zweierreihen in PBS [1X] verdünnt, beginnend mit der Verdünnung von 1:8, bis zu einer Verdünnung von 1:65536. Der Sensitivitätstest erfolgte

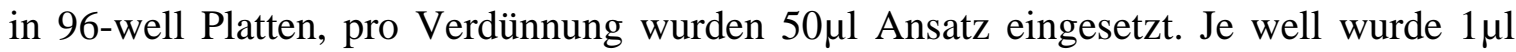
Proteinbead-Stock siehe Kap. 2.2.5.2.1 (immer zum entsprechenden Positivserum passend, siehe Beispiel unten) und $1 \mu 1$ E. coli-Proteinbead-Stock (Kontrolle) zugegeben. $1 \mu 1$ Stock entspricht etwa 8000 Beads.

\section{Beispiel: Ansatz zur CBA Sensitivitätsermittlung von BATV}

50,0 $\mu 1$ mit E. coli Lysat präadsorbiertes Positivserum (BATV)

1,0 $\mu \mathrm{l}$ Stock Beadpopulation Nr. 44 gekoppelt mit BATV-N Protein

1,0 $\mathrm{\mu l}$ Stock Beadpopulation Nr. 65 gekoppelt mit E. coli Protein (Kontrolle)

Der Test wurde dunkel abgedeckt und 1,5h bei RT auf einer Wippe inkubiert. Es folgten zwei Waschschritte (wie in Kap.2.2.5.2.2) auf dem 96-Well Microtiter Plate Magnetic Separation Rack (je 5min auf dem Magneten, der Überstand wurde vorsichtig abgenom-

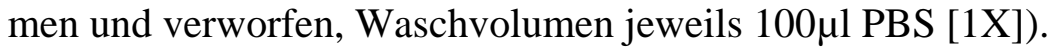

Je nach Ursprung des Serums (siehe Tabelle 2.14) wurden 50 $\mu 1$ Anti-mouse-PE IgG bzw. Anti-human-PE IgG (siehe Tabelle 2.10) je well verdünnt in PBS [1X] als fluoreszenzmarkierter Zweitantikörper eingesetzt. Die Inkubation erfolgte dunkel abgedeckt, 1,5h bei RT auf einer Wippe. Es folgten erneut zwei Waschschritte, wie zuvor beschrieben.

Für die Messung wurden je well dem Ansatz 80 $\mu 1$ Drive Fluid zugegeben, sanft gemischt und jeweils 100 Beads pro Beadpopulation zur Ermittlung der medianen Fluoreszenzintensität [MFI] am MAGPIX ${ }^{\mathrm{TM}}$-System gemessen. Je Serum wurden drei voneinander unabhängige Tests durchgeführt.

Anhand der Sensitivitäten aller untersuchten Proteinbeads wurde eine gemeinsame Verdünnung zum Einsatz im Multiplex-Test ermittelt. 


\subsection{Ermittlung der Kreuzreaktivität und Entwicklung des CBA als Multiplex-Ansatz}

Kreuzreaktionen nah verwandter Viren sind bekannt. Dennoch wurde in dieser Arbeit der Versuch der Entwicklung eines Multiplex-Testes unternommen, der den Nachweis mehrerer viraler Antikörper parallel in nur einem Ansatz ermöglichen soll.

Zur Ermittlung der Kreuzreaktivität wurden die in Kap. 2.2.5.2.3 bereits charakterisierten Positivseren verwendet. Anhand der bisherigen Ergebnisse (Ermittlung des dynamischen Bereichs siehe Kap. 2.2.5.2.3) wurde mit einer Serenverdünnung von 1:200 bei dem Multiplex-CBA Test gearbeitet.

Jedes Positivserum (siehe Tabelle 2.14) wurde mit E. coli Lysat (1:60), Roti-Block (1:10) und PBS [1X] auf ein Verhältnis von Serum zu Rest auf 1:200 verdünnt. Die Präadsorption erfolgte für $1 \mathrm{~h}$ bei $37^{\circ} \mathrm{C}$, anschließend wurden die löslichen von den unlöslichen Bestandteilen durch Zentrifugation (5min, 10000UpM, RT) getrennt.

Der Multiplex-Test wurde in einer 96-well Mikrotiter Platte durchgeführt, pro Ansatz wurden $100 \mu 1$ präadsorbiertes Serum in einem well vorgelegt und jeweils $0,25 \mu 1$ (entspricht etwa 2000 Beads) je Beadpopulation und well zugegeben.

Um eine optimale Verteilung der Proteinbeads inklusive Kontrollen auf die Ansätze zu erreichen, wurden die Beads vorher in einem Mastermix aus den einzelnen ProteinbeadStocks pipettiert, gut gemischt und auf die wells verteilt.

\section{Beispiel: Mastermix-Ansatz (in 0,5ml Protein-lo bind Reaktionsgefäß)}

Es wurden alle 14 Positivseren und 2 Negativseren als Kontrollen eingesetzt, demnach wurde ein Mastermix für $17(14+2+1)$ Ansätze als Ausgang vorgelegt. Es wurden alle vorhandenen Proteinbeads (15) und Kontrollen (2) eingesetzt.

Je Beadpopulation wurden demnach $4,25 \mu \mathrm{l}(0,25 \mathrm{x} 17)$ eingesetzt, was $\mathrm{zu}$ einem

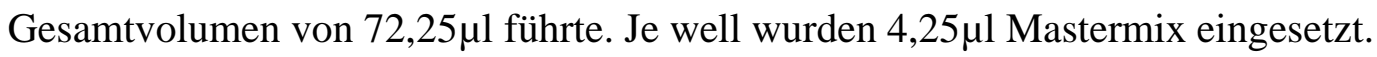

Die erste Inkubation des Testes erfolgte 1,5h bei Raumtemperatur, leicht gemischt durch schwenken auf einer Wippe, dunkel abgedeckt.

Anschließend wurde, wie bereits in Kap. 2.2.5.2.3 ausführlich beschrieben, die Mikrotiterplatte auf einen Magneten gestellt, der Überstand verworfen und jeder Ansatz in $100 \mu 1$ PBS $[1 X]$ gewaschen und der Überstand verworfen. 
Je nach Ursprung des Serums (siehe Tabelle 2.14) wurden 100 $\mu$ l Anti-mouse-PE IgG bzw. Anti-human-PE IgG (siehe Tabelle 2.10) verdünnt in PBS [1X] als fluoreszenzmarkierter Zweitantikörper eingesetzt. Die Inkubation erfolgte dunkel abgedeckt, 1,5h bei

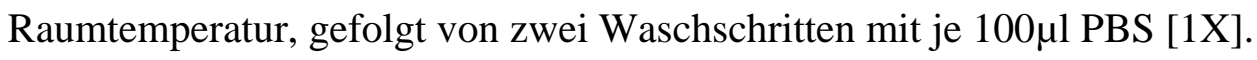

Für die Messung wurden je well dem Ansatz 80 $\mu 1$ Drive Fluid zugegeben, sanft gemischt und jeweils 100 Beads pro Beadpopulation zur Ermittlung der medianen Fluoreszenzintensität am MAGPIX ${ }^{\mathrm{TM}}$-System gemessen. Je Serum wurden drei voneinander unabhängige Tests durchgeführt.

\subsection{Multiplex-CBA - Nachweis von Antikörpern gegen europäische Arboviren in Patientenproben}

Wie schon zuvor in Kap. 2.2.5.2.3 und 2.2.5.2.4 beschrieben wurde mit dem MultiplexCBA ein neuer serologischer Antikörpernachweis entwickelt (Schematische Darstellung siehe Abb. 2.7).

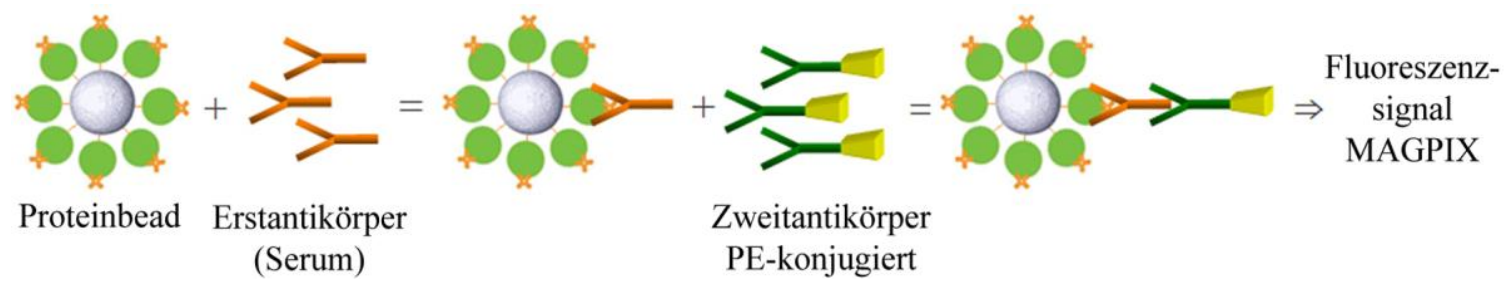

Abb. 2.7: Schematische Darstellung: Prinzip Cytometric Bead Array (CBA). Im ersten Inkubationsschritt binden die anti-viralen Antikörper des Serums spezifisch an die viralen Antigene auf den Proteinbeads. Im zweiten Inkubationschritt bindet der fluoreszenzmarkierte Zweitantikörper spezifisch an den $\mathrm{F}_{\mathrm{c}^{-}}$ Teil des Erstantikörpers. Die Fluoreszenzmessung erfolgt am MAGPIX ${ }^{\mathrm{TM}}$-System.

Zur Evaluation des Testverfahrens wurden die Seren von 111 Patienten mit der klinischen Diagnose der unklaren aseptischen Meningitis oder Meningoenzephalitis mittels Multiplex-CBA getestet, um Rückschlüsse auf eine vorliegende virale Infektionen ziehen zu können und eine Aussage über die Verbreitung dieser bislang vernachlässigten Viren zu erhalten. Alle Seren stammten aus einem TBEV-Endemiegebiet (Oberrheingraben) und wurden von der Arbeitsgruppe von Frau Dr. Meyer-König, Universitätsklinikum Freiburg zur Verfügung gestellt. Durch Voranalysen in Freiburg konnten Herpes Simplex Virus Typ 1 und Typ 2 (HSV-1, HSV-2), Varicella Zoster Virus (VZV), Enteroviren, TBEV und Bakterien wie Borrelia burgdorferi als Auslöser der Erkrankung ausgeschlossen 
werden (Meyer-König et al., 2014 in preparation; Weidmann, Armbruster \& Hufert, 2008a; Weidmann, Meyer-Konig \& Hufert, 2003a).

Um das Infektionsstadium (akute oder zurückliegende Infektion) festzulegen, wurden alle Seren auf IgM- und IgG-Antikörper untersucht. Hierzu wurden fluoreszenzmarkierte anti-IgM- und anti-IgG-Zweitantikörper verwendet.

\subsection{Grenzwert-Berechnungen und Auswertung des Multiplex-CBA}

Der Grenzwert (englisch: cut off) beschreibt den Wert, der das Mindestfluoreszenzsignal eines gekoppelten Proteinbeads angibt, das sicher von einer negativen Probe unterschieden werden konnte.

Ein Standardverfahren bei der Entwicklung serologischer Nachweismethoden ist das Messen gut charakterisierter Positivseren gleichen Ursprungs, an Hand derer ein Grenzwert errechnet wird und dessen Überschreitung zu einem positiven Ergebnis führt. Im Rahmen dieser Arbeit wurde an einem Test zur Detektion von humanen Antikörpern aus menschlichem Serum gearbeitet.

Wie bereits in Kap. 1.1.2 erwähnt, handelt es sich bei den hier untersuchten Arboviren um bislang vernachlässigte Viren. Gut charakterisierte humane Positivseren für alle 15 Viren standen deswegen nicht zur Verfügung. Demnach musste zur Berechnung des Grenzwertes eine andere Methode gewählt werden.

Statt von Positivseren auszugehen, wurden 45 gut charakterisierte humane Negativseren verwendet und alle Grenzwertberechnungen aus Daten der gemessenen Negativseren durchgeführt.

Verglichen wurden 2 Methoden: Die aus Erfahrungsberichten stammende Standardformel (A): Mittelwert addiert mit der sechsfachen Standardabweichung und die nach (Frey, Di Canzio \& Zurakowski, 1998) statistisch definierten Endpunkt Titer Bestimmung für Immuntests (B): Mittelwert addiert mit dem Produkt aus Standardabweichung und Multiplikator $f$. 
Methode (A) zur Grenzwertberechnung:

Mittelwert (MW) der medianen Fluoreszenzintensität (MFI) aller Negativseren addiert mit der sechsfachen Standardabweichung (SD) aller Negativseren. Jeweils pro Beadpopulation (BP). Es ergeben sich demnach für den Multiplex-CBA 17 einzelne Grenzwerte, pro gekoppelter Beadpopulation ein Wert.

$$
\text { Grenzwert }(\mathrm{A})=\mathrm{MW}(\mathrm{MFI})+6 \times \mathrm{SD}
$$

Methode (B) zur Grenzwertberechnung:

Nach (Frey et al., 1998) gehen wir davon aus, dass unbekanntes Patientenmaterial nicht weniger Antikörper, als die hier verwendeten 45 Negativseren aufweisen. Daher wird zur Berechnung des Grenzwertes nur der obere (einseitige) Vertrauensbereich der tVerteilung herangezogen. Der Grenzwert gibt damit eine Prognose zum oberen Limit bezogen auf die Negativkontrollen. Die Berechnungen beziehen sich jeweils auf eine Beadpopulation (BP). Es ergeben sich demnach für den Multiplex-CBA wieder 17 einzelne Grenzwerte, pro gekoppelter Beadpopulation ein Wert.

$$
\text { Grenzwert }(\mathrm{B})=\mathrm{MW}(\mathrm{MFI})+\mathrm{SD} \times f
$$

Mittelwert (MW) der medianen Fluoreszenzintensität (MFI) aller 45 Negativseren addiert mit dem Produkt aus Standardabweichung (SD) aller Negativseren mal Multiplikator $f$.

$$
f=t \times \sqrt{ }(1+1 / n)
$$

In dieser Arbeit sei $n$ die Anzahl an Negativseren, $t$ der $\mathrm{t}$-Wert einer einseitigen $t$-Verteilung mit einer Wahrscheinlichkeit von 99,9999\% $(P=0,999999)$ und einem Freiheitsgrad $v=n-1$. 
Um von einem signifikanten Serumtiteranstieg um zwei Titerstufen (vergleiche austitrierbare Testverfahren wie IFT, ELISA Kap. 1.2.1) sprechen zu können, sind zwei Blutproben eines Patienten innerhalb von zwei Wochen notwendig. Ist dies der Fall, ergeben sich folgende Möglichkeiten:

Fall 1: Erste Probe IgM und IgG negativ.

$\star$ Keine virale Infektion, eine zweite Probe würde die Diagnose bestätigen.

Fall 2: Erste Probe IgM negativ und IgG positiv.

$\star$ Hinweis auf eine virale Infektion, die Wochen bis Monate zurückliegt, eine zweite Probe mit gleichem Ergebnis schließt akute Infektion aus.

Fall 3: Erste Probe IgM positiv und IgG negativ.

$\star$ Hinweis auf eine akute virale Infektion, eine zweite Probe müsste eine Serokonversion zeigen und IgG positiv ausfallen. In dem Fall wäre die Diagnose der akuten Infektion bestätigt.

$\star$ Fällt das Ergebnis der zweiten Probe jedoch identisch aus (IgM positiv, IgG negativ) deutet eine ausbleibende Serokonversion auf ein falsch positives IgM Ergebnis hin oder auf eine polyklonale Stimmulierung, die z.B. bei Infektionen mit B-Zell-tropen Viren auftreten kann.

Fall 4: Erste Probe IgM und IgG positiv.

$\star$ Hinweis auf akute virale Infektion. Sicherung der Diagnose durch zweite Probe mit IgG positivem Ergebnis und Titeranstieg. Ist dies der Fall handelt es sich um eine akute Infektion in der späten Phase, in der bereits weitgehend ein Titer ausgebildet ist. Begründeter Verdacht auf eine kurz zurückliegende Infektion.

Doppelproben lagen nur bei 6 von 111 Patienten vor. Bei allen Einzelproben kann demnach kein signifikanter Serumtiteranstieg ermittelt werden, dennoch kann der CBA durch Vergleich der Patientenprobe mit den definierten Negativseren auf eine vorliegende Infektion hinweisen. 


\section{Ergebnisse}

\subsection{Amplifikation arboviraler Oberflächenproteingene}

\subsubsection{Primer-Generierung}

Zur Amplifikation der viralen Oberflächenproteingene wurden Primer generiert, die an beiden Enden die kombinatorischen Überhänge (AATG bzw. GGGA) sowie die StarCombinase $1^{\mathrm{TM}}$ Erkennungssequenz (5'-AGCGGCTCTTC) einfügten, über die eine Ligation in spezielle StarGate ${ }^{\circledR}$-Vektoren (siehe Kap. 2.2.3.1) ermöglicht wurde.

Ausgehend von den Sequenzen der viralen Oberflächenproteingene ohne Start- und Stopp-Kodon (siehe Tabelle 3.1) wurden alle Primer mit der StarPrimer D’Signer Software (IBA) berechnet (siehe Tabelle 2.13). Die theoretischen Bandenlängen der PCRProdukte (siehe Tabelle 3.1) stimmten mit den Bandengrößen nach PCR überein.

Tabelle 3.1: Übersicht Arboviren

\begin{tabular}{llc}
\hline Virus & Genabschnitt: & \multicolumn{1}{c}{ Länge nach PCR } \\
\hline Batai Virus (BATV) & Nukleokapsid Protein Gen (N): & $726 \mathrm{bp}$ \\
Bhanja Virus (BHAV) & Nukleokapsid Protein Gen (N): & $768 \mathrm{bp}$ \\
Erve Virus (ERVEV) & Nukleokapsid Protein Gen (N): & $1917 \mathrm{bp}$ \\
Eyach Virus (EYAV) & Virales Protein Gen (VP6): & $2124 \mathrm{bp}$ \\
Inkoo Virus (INKV) & Nukleokapsid Protein Gen (N): & $732 \mathrm{bp}$ \\
Palma Virus (PALV) & Nukleokapsid Protein Gen (N): & $768 \mathrm{bp}$ \\
Sandfly Fever Naples Virus (SFNV) & Nukleokapsid Protein Gen (N): & $786 \mathrm{bp}$ \\
Sandfly Fever Sicilian Virus (SFSV) & Nukleokapsid Protein Gen (N): & $765 \mathrm{bp}$ \\
Sandfly Fever Turkey Virus (SFTV) & Nukleokapsid Protein Gen (N): & $765 \mathrm{bp}$ \\
Tahyna Virus (TAHV) & Nukleokapsid Protein Gen (N): & $732 \mathrm{bp}$ \\
Tick Borne Encephalitis Virus (TBEV) & Nichtstruktur Protein Gen (NS1): & $1086 \mathrm{bp}$ \\
Toscana Virus (TOSV) & Nukleokapsid Protein Gen (N): & $786 \mathrm{bp}$ \\
Tribec Virus (TRBV) & Virales Protein Gen (VP7): & $1098 \mathrm{bp}$ \\
Uukuniemi Virus (UUKV) & Nukleokapsid Protein Gen (N): & $789 \mathrm{bp}$ \\
West Nil Virus (WNV) & Nichtstruktur Protein Gen (NS1): & $1062 \mathrm{bp}$ \\
\hline
\end{tabular}




\subsubsection{Polymerasekettenreaktion (PCR)}

Der erste Schritt zur Entwicklung des Cytometric-Bead-Arrays (CBA) bestand in der Amplifikation arboviraler Proteingene (siehe Tabelle 3.1), welche für Proteine mit antigenen Eigenschaften kodieren.

Für die Amplifikation der in Abb. 3.1 gezeigten PCR-Produkte wurde jeweils die Ausgangs-DNA mit den zugehörigen Vorwärts- und Rückwärts-Primern (siehe Tabelle 2.13) in die PCR-Reaktion (siehe Kap. 2.2.2.2) eingesetzt.

Die Ausgangs-DNA (Tabelle 2.11) trug jeweils den offenen Leserahmen (englisch: „open reading frame $O R F^{\prime)}$ ) für das Nukleokapsid-Protein $(\mathrm{N})$ der Bunyaviren, das Nichtstrukturprotein 1 (NS1) der Flaviviren bzw. ein auf der Oberfläche lokalisiertes virales Protein (VP) der Reoviren.

Alle amplifizierten DNA-Fragmente zeigten die erwarteten Größen und wurden wie in Kap. 2.2.2.3 beschrieben ausgeschnitten, isoliert und zur Ligation eingesetzt.
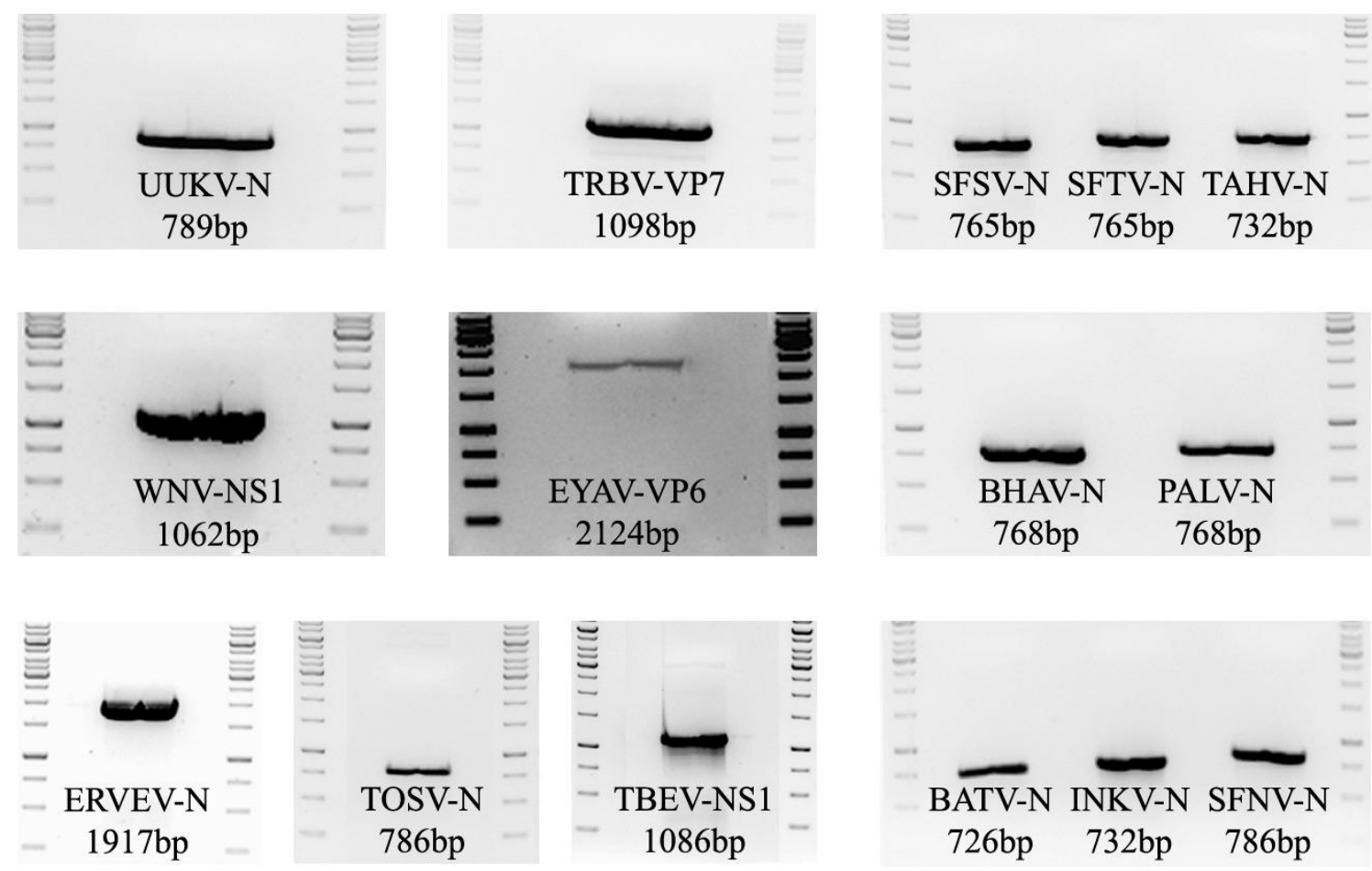

Abb. 3.1: Arbovirale DNA-Fragmente nach Amplifikation und Agarosegelelektrophorese. Es wurden pro Agarosegel [1\%ig] jeweils rechts und links 2,5 $\mu 1$ DNA-Längenstandard (1kb) und mittig 50 $\mu 1$ PCRAnsatz aufgetragen. Jedes Bild wurde mit Namen des Virus, des Proteingens und der erwarteter Bandenlänge versehen. Alle amplifizierten DNA-Fragmente zeigten die erwarteten Bandengrößen. DNA-Längenstandard von unten nach oben: 250bp, 500bp, 750bp, 1000bp, 1500bp, 2000bp, 2500bp, 3000bp, 3500bp, 4000bp, 5000bp, 6000bp, 8000bp, 10000bp. 


\subsection{Ligation, Transformation und Sequenzierung}

\subsubsection{Ligation der amplifizierten DNA-Fragmente in den Donorvektor pENTRY-} IBA51 und Transfer in den Expressionsvektor PASG-IBA5

Das verwendete StarGate ${ }^{\circledR}$-System erforderte im ersten Schritt die Ligation des Amplikons in den Donorvektor pENTRY-IBA51 (siehe Kap. 2.2.3.1). Dies erfolgte für alle 15 Viren mittels StarGate ${ }^{\circledR}$ Combi-Entry-Cloning-Set. Zur Überprüfung der Konstrukte wurde zuerst ein Kontrollverdau mit den Enzymen HindIII und XbaI durchgeführt (siehe Kap.3.2.2), bei korrektem Bandenmuster wurde anschließend jeweils ein Klon zur Sequenzierung (siehe Kap. 2.2.2.4, bzw. Abb. 3.3) gegeben und an Hand der erhaltenen Daten eine Sequenzanalyse (Lasergene ${ }^{\mathrm{TM}}$ ) mit Datenbanksequenzen durchgeführt (siehe Kap.3.2.2: Abb. 3.4) und alle Konstrukte auf mögliche Mutationen überprüft.

Alle Konstrukte konnten hergestellt werden und wurden je nach Virus, Proteingen und Vektor benannt, so steht beispielsweise BATV-N-pENTRY-IBA51 für die Ligation des DNA-Fragmentes für das Nukleokapsid-Protein des Batai-Virus in den Donorvektor pENTRY-IBA51. Nach Überprüfung der hergestellten Donorplasmide auf Richtigkeit der Sequenz wurde das StarGate ${ }^{\circledR}$ Transfer-Reagent-Set zur schnellen Subklonierung der Gene vom Donorvektor pENTRY-IBA51 in das Akzeptorplasmid pASG-IBA5 verwendet. Eine schematische Darstellung des Vektors ist in Abb. 3.2 dargestellt (Quelle: IBA GmbH Datenblatt 5-4005-000).

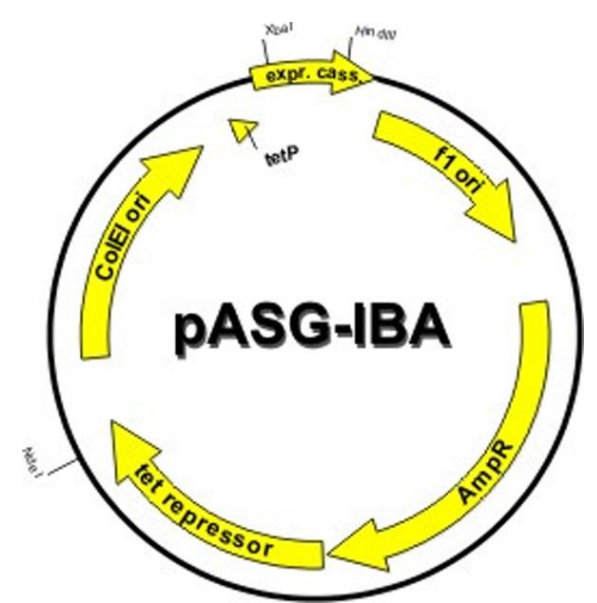

Abb. 3.2: Schematische Darstellung des Expressionsvektors pASG-IBA (Quelle: http://www.ibalifesciences.com/details/product/5-4005-005.html). Der pASG-Vektor ermöglichte die Expression von Strep-tag ${ }^{\circledR}$-Fusionsproteinen in E. coli. Der Vektor trägt den induzierbaren tet-Promotor/Operator (Anhydrotetracyclin, kurz AHT), sowie ein Ampicillin-Resistenzgen und ermöglicht die Expression von Proteinen mit N-terminal angefügtem Strep-tag ${ }^{\circledR}$ II. 


\subsubsection{Kontrollverdau und Sequenzierung der rekombinanten Donorvektoren}

In Abb. 3.3 ist der Kontrollverdau mit den Enzymen HindIII und XbaI aller hergestellten rekombinanten Donorvektoren (pENRTY-IBA51) abgebildet. Die Ansätze wurden auf ein 1\%iges Agarosegel aufgetragen und durch Gelelektrophorese (siehe Kap. 2.2.2.3) aufgetrennt. Alle Ansätze zeigten die erwarteten Bandenmuster, die Bande bei 1819bp entspricht dabei der Größe des linearisierten, geschnittenen pENTRY-IBA51 Vektors, die anderen Banden zeigen die Inserts. Sind mehrere Banden zu sehen, liegt mindestens eine weitere Schnittstelle der eingesetzten Restriktionsendonukleasen innerhalb der Insertsequenz. Die Inserts sind durch die Lage der Schnittstellen der eingesetzten Restriktionsendonukleasen insgesamt 40bp länger als die ursprünglichen viralen Proteingene (siehe Tabelle 2.11).

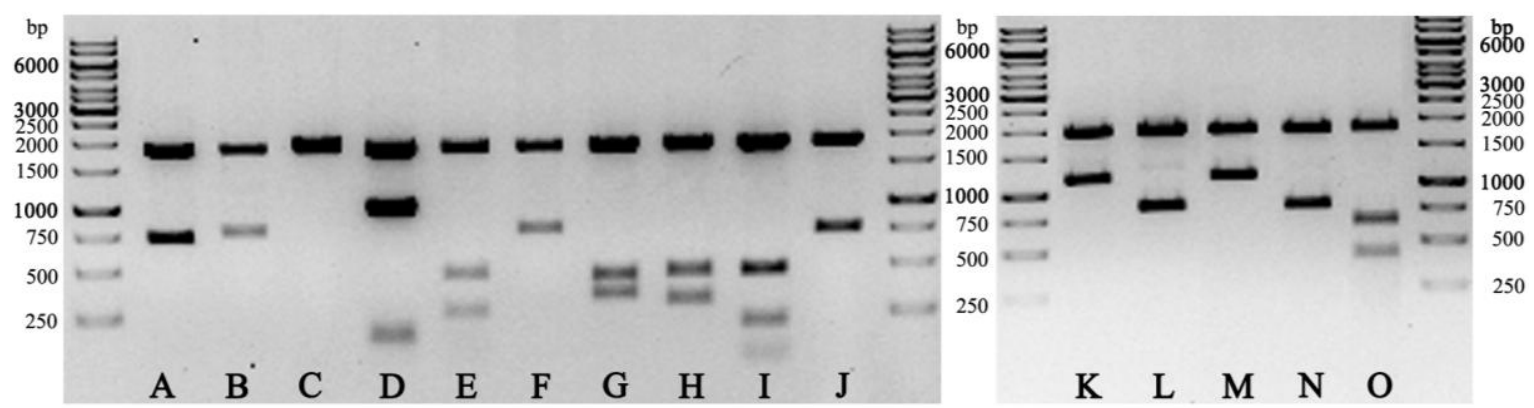

Abb. 3.3: Agarosegel nach Kontrollverdau aller hergestellten rekombinanten Donorplasmide. Es wurden pro Agarosegel [1\%ig] jeweils rechts und links 2,5 $\mu 1$ DNA-Längenstandard $(1 \mathrm{~kb})$ aufgetragen. In Spur A-O wurden jeweils $10 \mu$ l Restriktionsverdau aufgetragen, die in allen Spuren zu sehende Bande bei $1819 b p$ entspricht der Größe es geschnittenen Vektors pENTRY-IBA51 [HindIII und XbaI]. Spur A: BATV-N-pENTRY-IBA51\#1 Insertbande 736bp, Spur B: BHAV-N-pENTRY-IBA51\#2 Insertbande 778bp, Spur C: ERVEV-N-pENTRY-IBA51\#4b Insertbande 1927bp (auf Höhe der Vektorbande), Spur D: EYAV-VP6-pENTRY-IBA51\#8 Insertbande 2134bp [Wegen interner XbaI und HindIII Schnittstellen ergeben sich 3 Banden bei 169bp, 989bp und 976bp], Spur E: INKV-N-pENTRYIBA51\#2 Insertbande 742bp [Wegen interner XbaI Schnittstelle ergeben sich 2 Banden bei 475bp und 267bp], Spur F: PALV-N-pENTRY-IBA51\#3 Insertbande 778bp, Spur G: SFNV-N-pENTRY-IBA51\#2 Insertbande 796bp [Wegen interner XbaI Schnittstelle ergeben sich 2 Banden bei 347bp und 449bp], Spur H: SFSV-N-pENTRY-IBA51\#1 Insertbande 775bp [Wegen interner HindIII Schnittstelle ergeben sich 2 Banden bei 463bp und 312bp], Spur I: SFTV-N-pENTRY-IBA51\#1 Insertbande 775bp [Wegen drei interner HindIII Schnittstellen ergeben sich 4 Banden bei 463bp, 67bp, 208bp und 37bp, letztere ist im Agarosegel nicht mehr zu sehen], Spur J: TAHV-N-pENTRY-IBA51\#1 Insertbande 742bp, Spur K: TBEV-NS1-pENTRY-IBA51\#2 Insertbande 1096bp, Spur L: TOSV-N-pENTRY-IBA51\#1 Insertbande 796bp, Spur M: TRBV-VP7-pENTRY-IBA51\#2 Insertbande 1108bp, Spur N: UUKV-NpENTRY-IBA51\#3 Insertbande 799bp, Spur O: WNV-NS1-pENTRY-IBA51\#2 Insertbande 1072bp [Wegen interner HindIII Schnittstelle ergeben sich 2 Banden bei 653bp und 419bp].

Alle hergestellten rekombinanten Donorplasmide (siehe Tabelle 3.2) wurden wie in Kap. 2.2.2.4 beschrieben zur Sequenzierung gegeben. Die Sequenzanalysen wurden wie im Beispiel für BATV-N (siehe Abb. 3.4) durchgeführt und als sogenannte „Strategy View“ 
bildlich dargestellt. Eine Zusammenfassung aller Sequenzanalysen wurde in Kurzform ohne flankierende pENTRY-Sequenzen in Abb. 6.1 und ebenso beispielhaft die Sequenzanalyse von BATV-N als komplettes Alignment in Abb. 6.2 dem Anhang hinzugefügt.

Die Sequenzanalysen ergaben, dass fast alle Inserts fehlerfrei und in positiver Orientierung vorlagen. Alle Sequenzanalysen (Anhang Abb. 6.1 A-H) zeigten jeweils die Referenzsequenz und die sequenzierte DNA (einmal mit Vorwärts-Primer und einmal mit Rückwärts-Primer beginnend). Sofern die Länge der Sequenzen nicht ausreichte, um das komplette DNA-Fragment zu erfassen, wurde eine weitere Sequenzierung mit internem Primer hinzugefügt (siehe Anhang Abb. 6.1 C). Zusätzlich wurden die Konfliktbalken eingeblendet, schwarz bedeutet keine Mutation vorhanden.

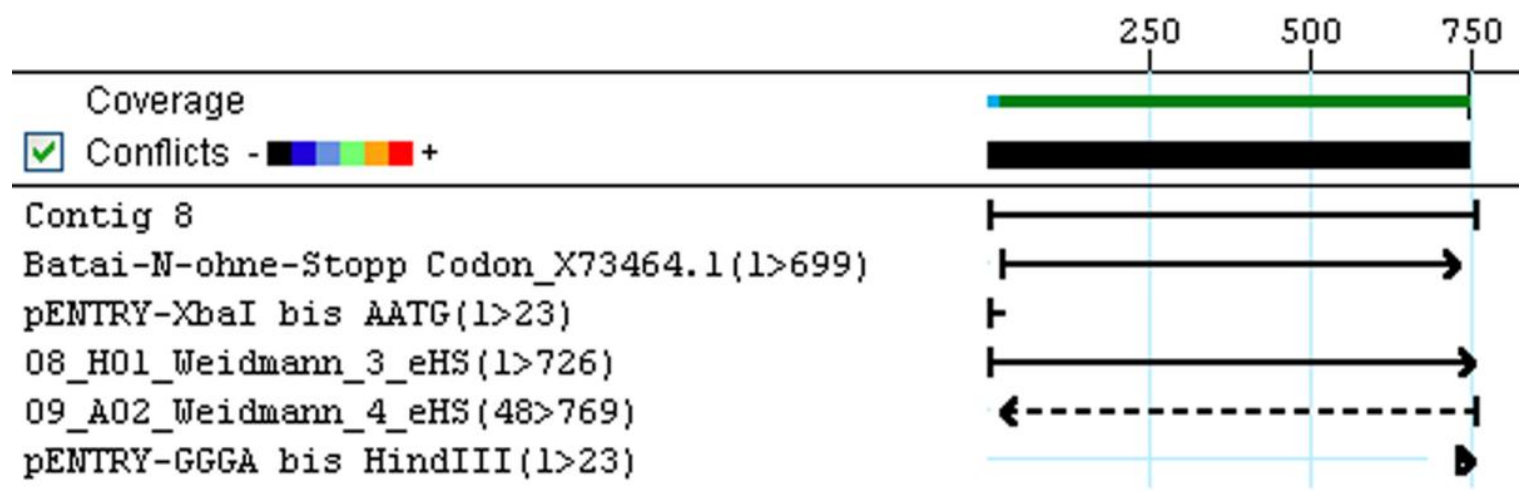

Abb. 3.4: Sequenzanalyse rekombinantes Donorplasmid Beispiel BATV. BATV-N-pENTRY-IBA51\#1. Dargestellt ist der Vergleich der hergestellten DNA-Sequenz nach Ligation in den Donorvektor und Sequenzierung (08 mit Vorwärts-Primer und 09 mit Rückwärtsprimer) mit der Referenzsequenz Batai-Nohne-Stopp Codon_X73464.1 und den flankierenden pENTRY-Sequenzen (Software:Lasergene ${ }^{\mathrm{TM}}$ ).

Durch die Sequenzanalysen zeigten sich in zwei Konstrukten jeweils eine Punktmutation (siehe Anhang Abb. 6.1 C und E), erkennbar an der Unterbrechung des schwarzen Konfliktbalkens. Im Fall von ERVEV-N, mit einer Punktmutation von CCC (Prolin) zu TCC (Serin), führte dies bei der Proteinexpression zum Austausch der hydrophoben (unpolaren) Aminosäure Prolin durch die hydrophil neutrale (polare) Aminosäure Serin. Im Fall von INKV-N kodierte sowohl das ursprüngliche Basentriplett AAC (Asparagin) als auch das nach Punktmutation entstandene AGC (Serin) für eine hydrophil neutrale (polare) Aminosäure. Mit beiden Konstrukten wurde weitergearbeitet und die bei der Expression entstandenen Proteine wurden entsprechend auf antikörperbindende Eigenschaften hin untersucht (siehe Kap. 3.5.4). 


\subsubsection{Transformation in kompetente $E$. coli Zellen}

Nach der Ligation erfolgte die Transformation in chemisch kompetente E. coli top 10 Zellen. Die positiven rekombinanten Bakterienklone wurden durch Blau-Weiß-Selektion (siehe Kap.2.2.3.3) identifiziert.

Anschließend wurden die Plasmide nach Minipräparation einzelner Klone (siehe Kap. 2.2.3.5) mittels spektrophotometrischer Messung auf Reinheit und Konzentration überprüft. Die Ergebnisse wurden in Tabelle 3.2 und Tabelle 3.3 zusammengefasst. Alle Konstrukte enthielten ausreichende Konzentrationen, um damit weiter zu arbeiten. Eine Ankonzentration war nicht erforderlich. Der Quotient aus $\mathrm{OD}_{260} / \mathrm{OD}_{280}$ lag bei allen Proben zwischen 1,8 und 2,0 - ein Indiz für relativ proteinfreie DNA- bzw. RNAPräparationen.

Tabelle 3.2: Übersicht aller hergestellten rekombinanten Donorplasmide

\begin{tabular}{lccc}
\hline Rekombinantes Plasmid & Klon Nr. & OD $_{\mathbf{2 6 0}} / \mathbf{O D}_{\mathbf{2 8 0}}$ & Konzentration [ng/ $\mathbf{\mu l}]$ \\
\hline BATV-N-pENTRY-IBA51 & 1 & 2,0 & 64,58 \\
BHAV-N-pENTRY-IBA51 & 2 & 1,9 & 43,54 \\
ERVEV-N-pENTRY-IBA51 & $4 \mathrm{~b}$ & 1,9 & 115,19 \\
EYAV-VP6-pENTRY-IBA51 & 8 & 2,0 & 158,01 \\
INKV-N-pENTRY-IBA51 & 2 & 2,0 & 29,72 \\
PALV-N-pENTRY-IBA51 & 3 & 1,8 & 23,11 \\
SFNV-N-pENTRY-IBA51 & 2 & 1,9 & 62,71 \\
SFSV-N-pENTRY-IBA51 & 1 & 1,9 & 65,43 \\
SFTV-N-pENTRY-IBA51 & 1 & 1,9 & 77,67 \\
TAHV-N-pENTRY-IBA51 & 1 & 1,9 & 56,25 \\
TBEV-NS1-pENTRY-IBA51 & 2 & 1,9 & 53,61 \\
TOSV-N-pENTRY-IBA51 & 1 & 2,0 & 65,72 \\
TRBV-VP7-pENTRY-IBA51 & 2 & 1,8 & 123,46 \\
UUKV-N-pENTRY-IBA51 & 3 & 1,8 & 106,72 \\
WNV-NS1-pENTRY-IBA51 & 2 & 1,9 & 97,03 \\
\hline
\end{tabular}


Tabelle 3.3: Übersicht aller hergestellten rekombinanten Expressionsplasmide

\begin{tabular}{lccc}
\hline Rekombinantes Plasmid & Klon Nr. & OD $_{\mathbf{2 6 0}} / \mathbf{O D}_{\mathbf{2 8 0}}$ & Konzentration [ng/ $\mathbf{l}]$ \\
\hline BATV-N-pASG-IBA5 & $1 \mathrm{~b}$ & 2,0 & 43,47 \\
BHAV-N-pASG-IBA5 & 5 & 2,0 & 56,42 \\
ERVEV-N-pASG-IBA5 & $1 \mathrm{~b}$ & 2,0 & 54,99 \\
EYAV-VP6-pASG-IBA5 & $8-1$ & 1,9 & 124,94 \\
INKV-N-pASG-IBA5 & 3 & 1,8 & 50,46 \\
PALV-N-pASG-IBA5 & 3 & 2,0 & 26,06 \\
SFNV-N-pASG-IBA5 & 12 & 1,9 & 89,90 \\
SFSV-N-pASG-IBA5 & 3 & 1,8 & 58,50 \\
SFTV-N-pASG-IBA5 & 11 & 1,9 & 57,65 \\
TAHV-N-pASG-IBA5 & 12 & 2,0 & 83,93 \\
TBEV-NS1-pASG-IBA5 & $2 \mathrm{~b}$ & 1,9 & 54,00 \\
TOSV-N-pASG-IBA5 & $4 \mathrm{~b}$ & 1,9 & 99,86 \\
TRBV-VP7-pASG-IBA5 & 2 & 1,9 & 96,97 \\
UUKV-N-pASG-IBA5 & 2 & 1,9 & 81,52 \\
WNV-NS1-pASG-IBA5 & $1 \mathrm{~b}$ & 1,8 & 57,15 \\
\hline
\end{tabular}

\subsection{Expression arboviraler Proteine}

\subsubsection{In vivo Proteinexpression in E. coli Bakterienkulturen}

Nach der Herstellung aller Expressionsplasmide (siehe Tabelle 3.3) erfolgte die Expression der viralen Proteine. Hierzu wurde jedes Konstrukt durch Transformation in BL21(DE3) E. coli Zellen gebracht (siehe Kap. 2.2.3.3), anschließend wurden die Proteine, wie in Abb. 3.5 dargestellt, exprimiert und zentrifugiert, um die löslichen von den unlöslichen Proteinen zu trennen. Die Proteine wurden entsprechend des viralen Ursprungs und des Proteingens benannt: BATV-N, BHAV-N, ERVEV-N, EYAV-VP6, INKV-N, PALV-N, SFNV-N, SFSV-N, SFTV-N, TAHV-N, TBEV-NS1, TOSV-N, TRBV-VP7, UUKV-N, WNV-NS1. Alle Transformationsplatten zeigten positive weiße Klone und führten zum Anwachsen der Vor- und Hauptkultur. Nach Zentrifugation enthielt das Pellet die intakten E. coli Zellen inklusive der exprimierten viralen Proteine. 
Um an die enthaltenen exprimierten rekombinanten Proteine $\mathrm{zu}$ gelangen, wurde das Zellpellet zuerst über Nacht bei $-20^{\circ} \mathrm{C}$ eingefroren und dann mittels Ultraschallbehandlung aufgeschlossen. Zuletzt wurden alle Ansätze zentrifugiert, die löslichen Proteine (im Überstand) wurden von den unlöslichen Proteinen und Zellresten (im Pellet) getrennt und separat gelagert.

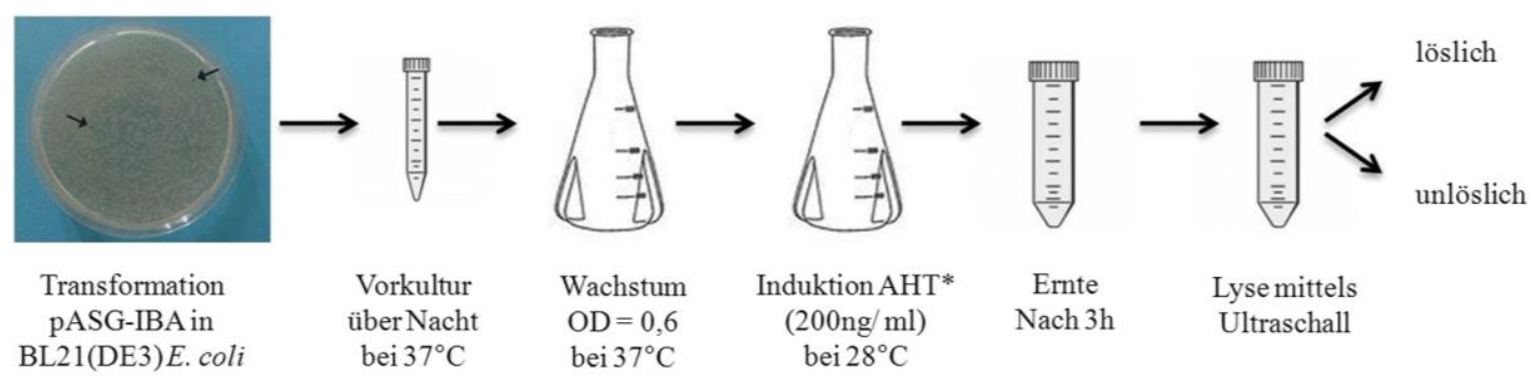

Abb. 3.5: Schematische Darstellung der Proteinexpression mit Expressionsvektor pASG-IBA. Nach der Transformation der rekombinanten Expressionsplasmide in BL21(DE3) E. coli Zellen wurde eine Vorkultur angelegt, damit eine Hauptkultur inokuliert und die Proteinexpression nach Erreichen einer optischen Dichte (OD) von etwa 0,6 durch Zugaben von Anhydrotetracyclin* (AHT) induziert. Nach drei Stunden wurden die Zellen geerntet, mittels Ultraschall lysiert und durch Zentrifugation die löslichen von den unlöslichen Bestandteilen getrennt.

Die Proben nach Lyse wurden auf ein SDS-Gel aufgetragen, mittels SDS-PAGE (siehe Kap. 2.2.4.2) der Größe nach aufgetrennt und auf eine PVDF-Membran transferiert (Western Blot) (siehe Kap. 2.2.4.3). Der Nachweis der Gesamtproteinmenge erfolgte durch Färbung der PVDF-Membran mit Amidoschwarz. Das Ergebnis wurde in Abb. 3.6 für alle exprimierten Proteine (BATV-N, ERVEV-N, TAHV-N, TBEV-NS1, TRBV-VP7, TOSV-N，UUKV-N，WNV-NS1，SFSV-N，SFNV-N，INKV-N，SFTV-N，BHAV-N, PALV-N, EYAV-VP6) zusammengefasst.

Sofern eine ausreichende Proteinkonzentration im Überstand enthalten war, wurde direkt mit dem Überstand weiter gearbeitet (siehe Kap. 3.3.2), ansonsten wurde das Pellet zuvor solubilisiert (siehe Kap. 2.2.4.5). Eine Solubilisierung erfolgte bei den Reoviren (TRBVVP7, EYAV-VP6), den Flaviviren (TBEV-NS1, WNV-NS1) und dem Nairovirus ERVEV-N. 

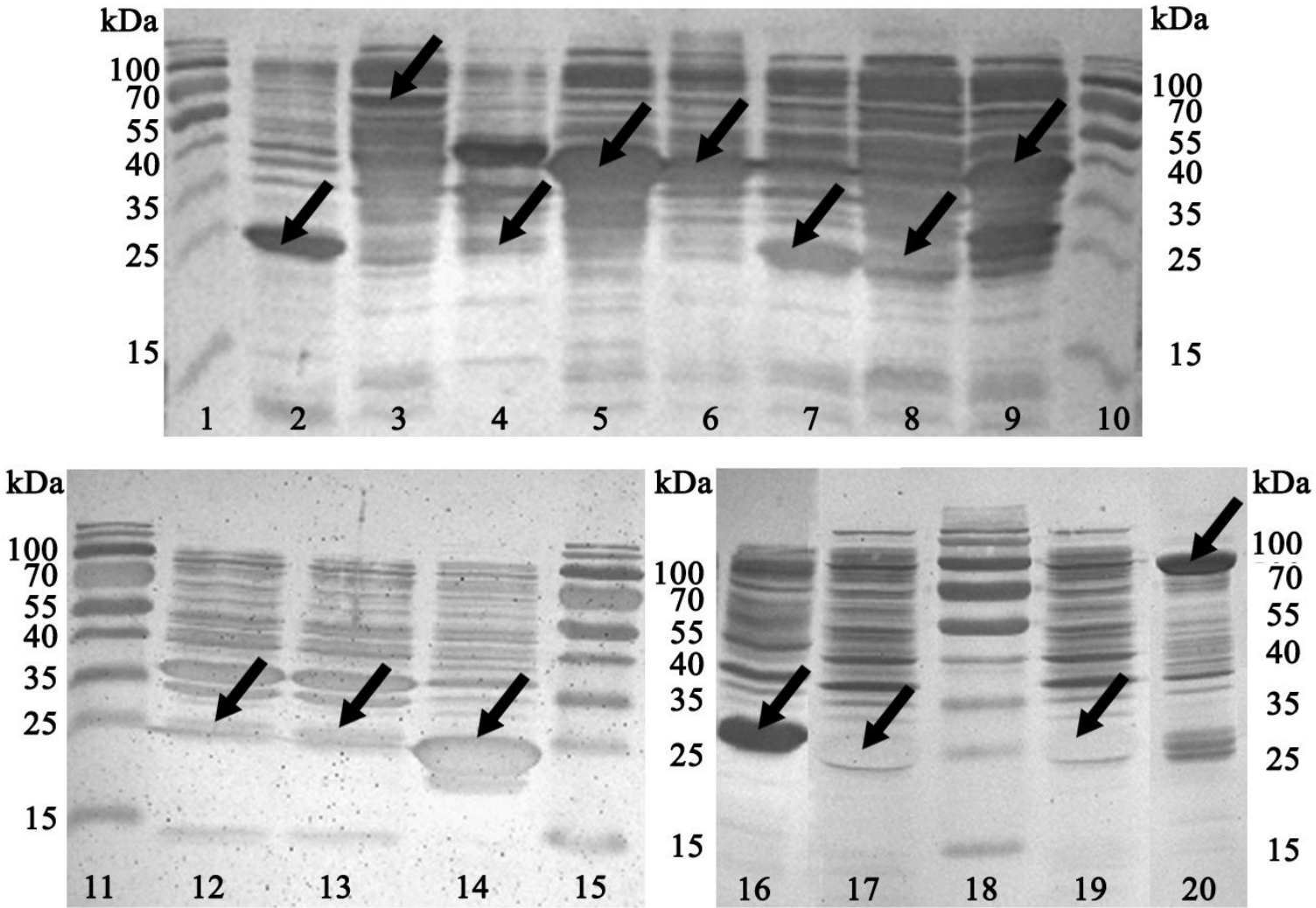

Abb. 3.6: Western Blot (Amidoschwarz) der exprimierten Proteine in BL21(DE3) E. coli Zellen. Dargestellt sind PVDF-Membranen gefärbt mit Amidoschwarz. Es wurden pro Spur jeweils 5 $\mu 1$ Molekulargewichtsmarker (15-170kDa) bzw. 10 $\mu$ l Probe nach Lyse aufgetragen. Spur 1: Molekulargewichtsmarker, Spur 2: BATV-N (28,2kDa), Spur 3: ERVEV-N (71,6kDa), Spur 4: TAHV-N (28,4kDa), Spur 5: TBEVNS1 (41,0kDa), Spur 6: TRBV-VP7 (41,7kDa), Spur 7: TOSV-N (29,4kDa), Spur 8: UUKV-N (30,2kDa), Spur 9: WNV-NS1 (40,7kDa), Spur 10: Molekulargewichtsmarker, Spur 11: Molekulargewichtsmarker, Spur 12: SFSV-N (29,2kDa), Spur 13: SFNV-N (29,6kDa), Spur 14: INKV-N (28,2kDa), Spur 15: Molekulargewichtsmarker, Spur 16: SFTV-N (29,2kDa), Spur 17: BHAV-N (29,1kDa), Spur 18: Molekulargewichtsmarker, Spur 19: PALV-N (29,2kDa), Spur 20: EYAV-VP6 (80,0kDa).

\subsubsection{Reinigung, Dialyse und Quantifizierung aller exprimierten Proteine}

Nachdem die Expression der rekombinanten Proteine (siehe Abb. 3.6) bestätigt wurde, wurde (wie in Kap. 2.2.4.6 beschrieben) die Reinigung durch Säulenchromatographie durchgeführt, die Proteinkonzentration der einzelnen Fraktionen ermittelt, positive Fraktionen vereint und anschließend in PBS [1X] dialysiert (Kap. 2.2.4.7).

In Tabelle 3.4 wurden alle Ergebnisse der Reinigung, Dialyse der Proteine und Quantifizierung der Fraktionen zusammengefasst. D steht für Durchfluss, W für Waschschritt, E für Eluatfraktion, grau unterlegte Eluatfraktionen wurden vereint, anschließend dialysiert und quantifiziert. Bei den in den Fraktionen D-W4 enthaltenen Proteinen, handelt es sich um Proteine ohne spezifischen Tag. 
Diese bei der Expression entstandenen Nebenprodukte (z.B. E. coli Proteine der Kultur) passierten die Säulenmatrix ohne an diese zu binden. In Fraktion W5 konnten in keinem Ansatz Proteine nachgewiesen werden, somit enthielten die Eluatfraktionen E größtenteils die exprimierten rekombinanten viralen Proteine mit Tag.

Tabelle 3.4: Zusammenfassung nach Reinigung und Konzentrationsermittlung

\begin{tabular}{lccccccccccccc}
\hline Protein & D & W1 & W2 & W3 & W4 & W5 & E1 & E2 & E3 & E4 & E5 & E6 \\
\hline BATV-N & + & + & + & $(+)$ & - & - & - & $(+)$ & $(+)$ & - & - & - \\
BHAV-N & + & + & $(+)$ & - & - & - & $(+)$ & + & + & + & $(+)$ & $(+)$ \\
ERVEV-N [S] & + & + & + & $(+)$ & - & - & - & $(+)$ & $(+)$ & $(+)$ & - & - \\
EYAV-VP6 [S] & + & + & $(+)$ & - & - & - & - & + & + & $(+)$ & $(+)$ & - \\
INKV-N & + & + & $(+)$ & - & - & - & - & + & + & $(+)$ & $(+)$ & - \\
PALV-N & + & + & + & $(+)$ & - & - & - & + & + & + & $(+)$ & $(+)$ \\
SFNV-N & + & + & $(+)$ & - & - & - & + & + & + & $(+)$ & $(+)$ & - \\
SFSV-N & + & + & $(+)$ & - & - & - & $(+)$ & + & + & + & $(+)$ & - \\
SFTV-N & + & + & $(+)$ & - & - & - & + & + & + & + & + & + \\
TAHV-N & + & + & $(+)$ & - & - & - & + & + & + & + & + & $(+)$ \\
TBEV-NS1 [S] & + & + & + & $(+)$ & - & - & $(+)$ & + & $(+)$ & $(+)$ & - & - \\
TOSV-N & + & + & + & $(+)$ & $(+)$ & - & + & + & + & + & + & $(+)$ \\
TRBV-VP7 [S] & + & + & + & $(+)$ & - & - & - & + & $(+)$ & - & - & - \\
UUKV-N & + & + & + & $(+)$ & $(+)$ & - & + & + & + & + & + & +
\end{tabular}

\subsubsection{Spezifischer Protein-Nachweis mittels Western-Blot}

Nach Reinigung und Dialyse wurden alle Proben auf SDS-Gele aufgetragen, mittels SDS-PAGE (Kap.2.2.4.2) aufgetrennt und durch Western-Blot auf PVDF-Membranen transferiert (Kap.2.2.4.3). Die Membranen wurden, wie in Kap. 2.2.4.4 beschrieben, gewaschen, unspezifische Bindungsstellen geblockt und mit Anti-Strep-tag ${ }^{\circledR}$ II-HRP Antikörper inkubiert, welcher spezifisch an den Strep-tag ${ }^{\circledR}$ II der exprimierten Proteine bindet. Der Strep-tag ${ }^{\circledR}$ II-Nachweis der exprimierten Proteine erfolgte durch Aufnahme der 
Chemilumineszenz nach ECL-Reaktion am Chemidoc XRS. Das Ergebnis wurde in Abb.

3.7 für alle Proben zusammengefasst. Alle Spuren zeigten die erwarteten Bandengrößen.

Die Ergebnisse der Konzentrationsbestimmungen aller vereinten und dialysierten Proteinproben sind aus der Tabelle 3.5 in Kapitel 3.5.1 abzulesen.
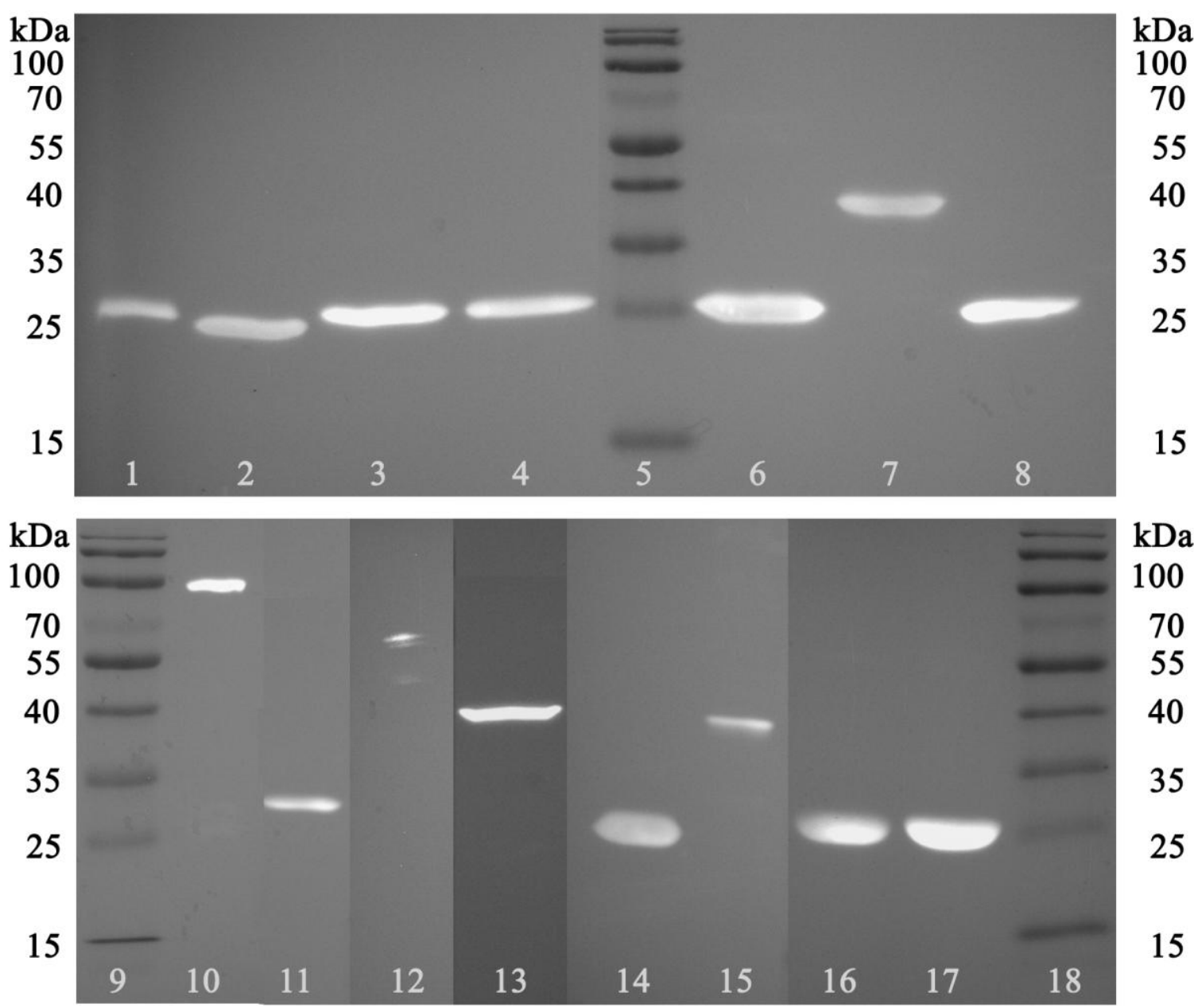

Abb. 3.7: Nachweis der exprimierten Proteine mit Strep-tag ${ }^{\circledR}$ II durch Anti-Strep-tag ${ }^{\circledR}$ II-HRP (ECL). Dargestellt sind Chemilumineszenz-Aufnahmen von PVDF-Membranen nach Western-Blot und Inkubation mit Anti-Strep-tag ${ }^{\circledR}$ II-HRP. Es wurden pro Spur jeweils $5 \mu 1$ Molekulargewichtsmarker (15-170kDa) bzw. $20 \mu 1$ Probe nach Reinigung und Dialyse aufgetragen. Spur 1: BATV-N (28,2kDa), Spur 2: INKV-N (28,2kDa), Spur 3: SFNV-N (29,6kDa), Spur 4: SFSV-N (29,2kDa), Spur 5: Molekulargewichtsmarker, Spur 6: TOSV-N (29,4kDa), Spur 7: TRBV-VP7 (41,7kDa), Spur 8: UUKV-N (30,2kDa), Spur 9: Molekulargewichtsmarker, Spur 10: EYAV-VP6 (80,0kDa), Spur 11: SFTV-N (29,2kDa), Spur 12: ERVEV-N (71,6kDa), Spur 13: WNV-NS1 (40,7kDa), Spur 14: TAHV-N (28,4kDa), Spur 15: TBEV-NS1 (41,0kDa), Spur 16: PALV-N (29,2kDa), Spur 17: BHAV-N (29,1kDa), Spur 18:Molekulargewichtsmarker. 


\subsection{Bestätigung verwendeter Positivseren durch Immunfluoreszenztest (IFT)}

Für die Entwicklung neuer Nachweismethoden sind Positivkontrollen unverzichtbar. Um sicherzustellen, dass es sich bei den zur Verfügung gestellten Seren (siehe Tabelle 2.14) tatsächlich um Seren mit viralem Antikörpertiter handelte, wurde jedes Serum in einem eigens entwickelten Immunfluoreszenztest (siehe Kap. 2.2.5.1) überprüft. Je Objektträger wurde ein Feld mit Negativserum inkubiert, weitere Felder des Objektträgers mit dem jeweiligen Positivserum in den Verdünnungen 1:20, 1:40, 1:80, 1:160, 1:320, 1:640, 1:1280, 1:2560, 1:5120. In Abb. 3.8 wurden Fluoreszenzmikroskopaufnahmen (600fache Vergrößerung) der infizierten Zellen nach Inkubation mit dem jeweiligen Positivserum und fluoreszenzmarkiertem Zweitantikörper zusammengefasst.
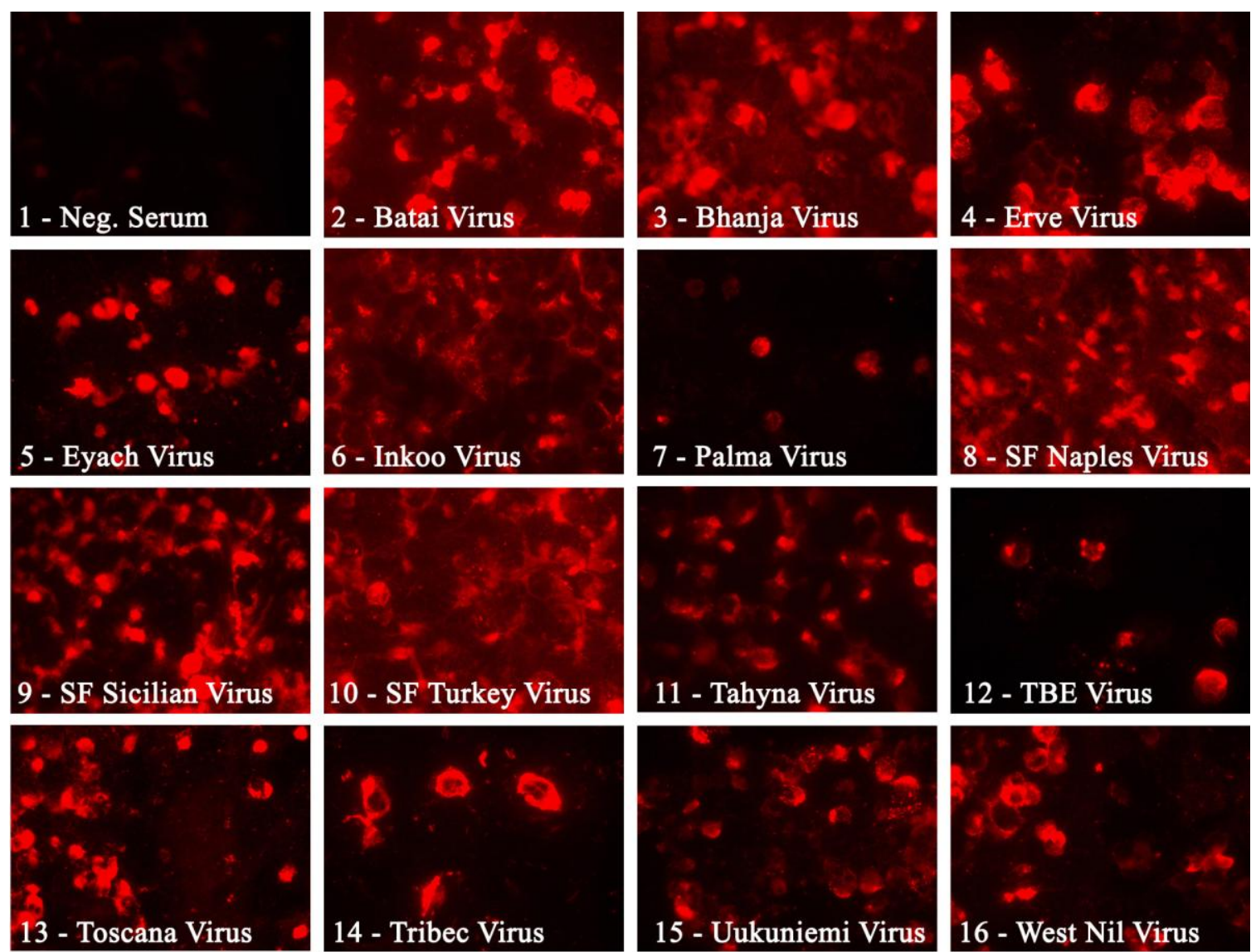

Abb. 3.8: Kontrolle der Positivseren durch Immunfluoreszenztest (IFT). Dargestellt sind die zusammengefassten Ergebnisse der Fluoreszenzmikroskopaufnahmen von infizierten Vero E6 bzw. Vero B4 Zellen nach Inkubation mit dem jeweiligen Positivserum und fluoreszenzmarkiertem (Cy3) Zweitantikörper in 600facher Vergrößerung. Die Bildbeschriftungen nennen jeweils das Virus, das zum Infizieren der Zellen verwendet wurde. Da für Inkoo Virus kein Positivserum vorhanden war, wurde wegen bekannter Kreuzreaktionen von Inkoo Virus und Tahyna Virus, für die Kontrolle das Tahyna Virus Serum mit Inkoo Virus infizierten Zellen verwendet. 
Alle Positivseren zeigten eine deutliche Reaktion mit den jeweiligen mit Virus infizierten Zellen. Die eingesetzte Negativkontrolle (siehe Abb. 3.8 - 1) zeigte jeweils eine deutlich schwächere bis gar keine Fluoreszenz und wurde nur einmalig in Abb. 3.8 dargestellt. In Tabelle 3.5 wurden die Ergebnisse der Fluoreszenzauswertung zusammengefasst. Bei den Positivseren handelte es sich eindeutig um Seren mit entsprechendem viralen Antikörpertiter. In der Tabelle wurde jeweils die maximale Nachweisgrenze, also die höchste positive Verdünnung des Serums aufgeführt. Alle Positivseren konnten zur Ermittlung der Sensitivität des CBA und zur Multiplex-CBA Entwicklung (siehe Kap.3.5.4) verwendet werden.

Tabelle 3.5: Zusammenfassung der IFT Ergebnisse

\begin{tabular}{lllc}
\hline Positivserum & IFT - Virus & Ursprung & IFT - Nachweisgrenze \\
\hline Anti-Calovo & Batai Virus & Maus & $1: 1280$ \\
Anti-Bhanja & Bhanja Virus & Maus & $1: 320$ \\
Anti-Erve & Erve Virus & Maus & $1: 2560$ \\
Anti-Eyach & Eyach Virus & Maus & $1: 160$ \\
Anti-Palma M4756 & Palma Virus & Maus & $1: 1280$ \\
Nap1 & SFN Virus & Human & $1: 80$ \\
S18 & SFS Virus & Human & $1: 80$ \\
SC1 & SFT Virus & Human & $1: 1280$ \\
Anti-Tahyna 181 & Inkoo Virus* & Maus & $1: 320$ \\
Anti-Tahyna 181 & Tahyna Virus & Maus & $1: 640$ \\
RSSE-AK IgG & TBE Virus & Maus & $1: 1280$ \\
T6 & Toscana Virus & Human & $1: 80$ \\
Anti-Tribec & Tribec Virus & Maus & $1: 1280$ \\
Anti Uuk & Uukuniemi Virus & Maus & $1: 2560$ \\
West Nil MIAF & West Nil Virus & Maus & $1: 1280$ \\
\hline *: Wegen bekannter Kreuzreaktionen konnte das Anti-Tahyna Virus Serum auch zum \\
Inkoo Virus Nachweis & verwendet werden. Ein Positivserum für das Inkoo Virus stand \\
nicht zur Verfügung. & & & \\
& & &
\end{tabular}




\subsection{Entwicklung des CBA als Multiplex-Test}

\subsubsection{Beweis der Kopplung spezifischer arboviraler Proteine an farbkodierte Populationen magnetischer carboxylierter Beads}

Nach erfolgreichem Abschluss der Expression, Reinigung, Dialyse und Quantifizierung aller arboviralen Proteine erfolgte die Kopplung an magnetische carboxylierte Beads

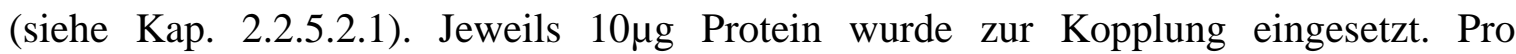
Expression wurde eine andere farbkodierte Beadpopulation verwendet (siehe Abb. 2.5). Die Ergebnisse der Konzentrationsermittlung, das zur Kopplung eingesetzte Volumen, die Beadpopulation und die Ergebnisse der Kopplungsüberprüfung wurden in Tabelle 3.6 für alle Viren zusammengefasst. Durch zu geringe Proteinkonzentrationen wurde das

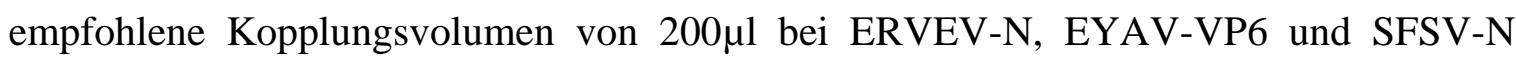
überschritten, die anschließende Kopplungsüberprüfung mit Strep-Tactin-R-PE (siehe Kap. 2.2.5.2.2) zeigte für alle Kopplungen deutliche Fluoreszenzsignale (MFI).

Tabelle 3.6: Zusammenfassung Kopplung der Proteine mit Beads und Kopplungsbeweis

\begin{tabular}{lcccc}
\hline Protein & $\begin{array}{c}\text { Konzentration } \\
{[\boldsymbol{\mu g} / \mathbf{~ m l}]}\end{array}$ & $\begin{array}{c}\text { Volumen } \\
{[\boldsymbol{\mu l}]}\end{array}$ & $\begin{array}{c}\text { Beadpopulation } \\
{[\text { Nummer] }}\end{array}$ & $\begin{array}{c}\text { Kopplungsbeweis } \\
{[\mathbf{M F I}] \mathbf{n}=\mathbf{2}}\end{array}$ \\
\hline BATV-N & 95,09 & 105,16 & 44 & $13854+12031$ \\
BHAV-N & 758,15 & 13,19 & 37 & $51911+50172$ \\
ERVEV-N & 24,86 & 402,25 & 35 & $12972+11283$ \\
EYAV-VP6 & 44,25 & 225,99 & 55 & $23901+23187$ \\
INKV-N & 89,31 & 111,97 & 34 & $22426+22386$ \\
PALV-N & 423,83 & 23,59 & 53 & $47316+45001$ \\
SFNV-N & 1499,10 & 6,67 & 27 & $43390+41002$ \\
SFSV-N & 43,03 & 232,40 & 29 & $26041+25054$ \\
SFTV-N & 538,70 & 18,56 & 63 & $39161+35335$ \\
TAHV-N & 1382,57 & 7,23 & 46 & $28621+27024$ \\
TBEV-NS1 & 156,21 & 64,02 & 36 & $19608+17664$ \\
TOSV-N & 912,03 & 10,96 & 54 & $43414+42486$ \\
TRBV-VP7 & 211,51 & 47,28 & 52 & $89678+92433$ \\
UUKV-N & 563,09 & 17,76 & 26 & $59747+58663$ \\
WNV-NS1 & 52,74 & 189,61 & 62 & $8047+8622$ \\
\hline
\end{tabular}




\subsubsection{Vermeidung falsch positiver Ergebnisse durch verbliebene $E$. coli Proteine}

Um falsch positive Signale zu vermeiden wurde von einer nicht absoluten Reinheit der Fusionsproteine nach Säulenchromatographie (siehe Kap.2.2.4.6) ausgegangen. Diese Annahme wurde durch zwei Versuche unterschiedlichen Ansatzes überprüft:

Erste Methode Immunoblot: Jeweils $1 \mu \mathrm{g}$ Proteinprobe, wie schon in Kap. 3.3.3 (nach Säulenchromatographie vereint und gegen PBS dialysiert) wurde mittels SDS-PAGE (siehe Kap. 2.2.4.2) und Western-Blot (siehe Kap. 2.2.4.3 ) aufgetrennt und auf eine PVDF-Membran transferiert. Die Proben wurden zum Nachweis von verbliebenen $E$. coli Proteinen zuerst mit einem polyklonalen Kaninchenserum mit hohem Anti-E. coli Antikörpertiter [Anti-Escherichia coli Polyclonal Rabbit 1:750] und anschließend mit AntiKaninchen-HRP Antikörper [Anti-Rabbit IgG 1:16000] inkubiert. Zusätzlich wurden zwei Positivkontrollen des E. coli Lysats (RTS100 und BL21DE3 Reinkultur) mitgeführt.

Die in Abb. 3.9 beispielhaft dargestellte Chemilumineszenz, nach ECL-Reaktion und Signalaufnahme am Chemidoc XRS der Proteinproben von INKV-N, SFNV-N, SFSV-N, TBEV-NS1, TOSV-N, TRBV-VP7, UUKV-N zeigte eine leichte Reaktion auf E. coli Antikörper. In allen untersuchten Proteinproben zeigte sich eine schwache E. coli spezifische Bande < $15 \mathrm{kDa}$.

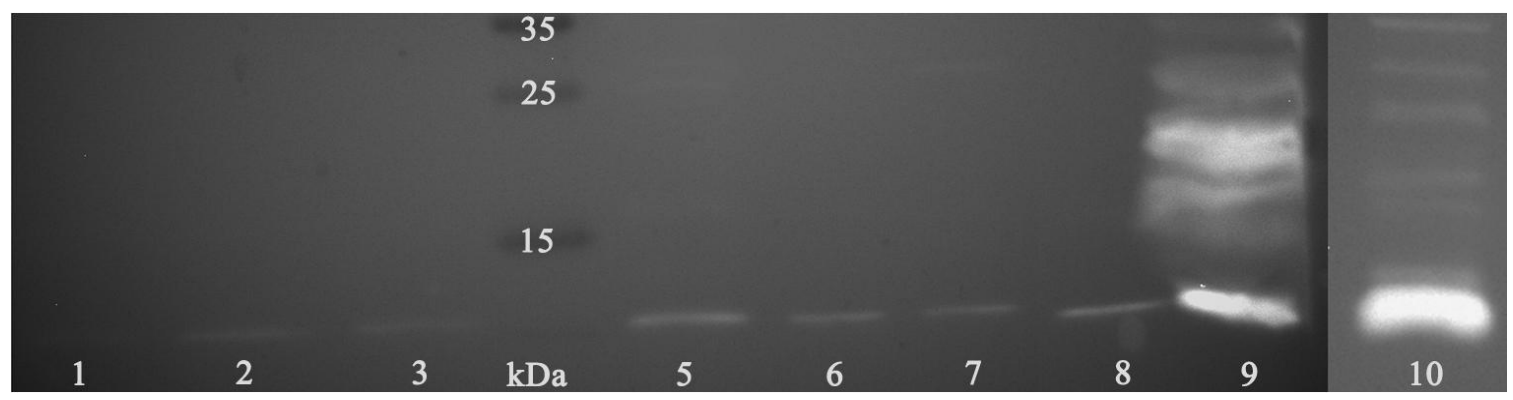

Abb. 3.9: Ausschnitt einer Chemilumineszenz-Aufnahme zum Nachweis verbliebener $E$. coli Proteine. Dargestellt sind Chemilumineszenz-Aufnahmen einer PVDF-Membran nach Western-Blot und Inkubation mit Anti-Escherichia coli Polyclonal Rabbit und Anti-Rabbit IgG-HRP Antikörper. Spur 1: INKV-N

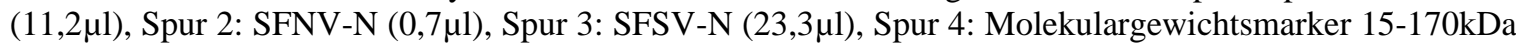
$(5 \mu 1)$, Spur 5: TBEV-NS1 $(6,4 \mu 1)$, Spur 6: TOSV-N $(1,1 \mu 1)$, Spur 7: TRBV-VP7 $(4,7 \mu 1)$, Spur 8: UUKV-N $(1,8 \mu 1)$, Spur 9: E. coli Lysat RTS $100(2 \mu 1)$, Spur 10: BL21(DE3) E. coli Lysat $(2 \mu 1)$. Die Proben in Spur 1-3 + 5-8 entsprechen einer Proteinkonzentration von ca. $1 \mu \mathrm{g}$ Gesamtprotein. 
Zweite Methode CBA: Überprüfung der bereits gekoppelten farbkodierten magnetischen Beads (siehe Kap. 2.2.5.2.1) durch eine aufeinander folgende Doppelinkubation mit polyklonalem Kaninchenserum mit hohem Anti-E.coli Antikörpertiter [Anti-E.coli Polyclonal

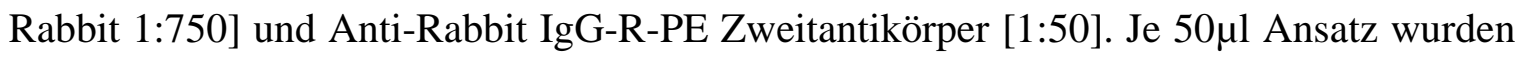
$1 \mu 1$ Proteinbead-Stock zugegeben. $1 \mu 1$ Stock entsprechen etwa 8000 Beads.

Die Ergebnisse wurden in Tabelle 3.7 zusammengefasst, pro Messung wurden mind. 100 Beads am MAGPIX ${ }^{\mathrm{TM}}$-System gemessen und daraus die MFI berechnet.

Tabelle 3.7: Nachweis auf verbliebene E. coli Proteine durch CBA

\begin{tabular}{lcc}
\hline Protein & Beadpopulation [Nummer] & Anti- E. coli $[$ MFI] n=1 \\
\hline BATV-N & 44 & 17072 \\
BHAV-N & 37 & 1244 \\
ERVEV-N & 35 & 11013 \\
EYAV-VP6 & 55 & 15284 \\
INKV-N & 34 & 4907 \\
PALV-N & 53 & 989 \\
SFNV-N & 27 & 8574 \\
SFSV-N & 29 & 9270 \\
SFTV-N & 63 & 3908 \\
TAHV-N & 46 & 8748 \\
TBEV-NS1 & 36 & 13636 \\
TOSV-N & 54 & 2003 \\
TRBV-VP7 & 52 & 11223 \\
UUKV-N & 26 & 913 \\
WNV-NS1 & 62 & 21898 \\
\hline
\end{tabular}

Sowohl Immunoblot, wie auch CBA-Methode belegen, dass eine geringe Menge verbliebener E. coli Proteine der Expressionskultur nach Reinigung mittels Säulenchromatographie und Dialyse in den Proteinproben vorlagen und somit ebenfalls an der Beadoberfläche der Proteinbeads gekoppelt wurden. 
Die in Abb. 3.10 zusammengefassten Ergebnisse zeigen die mediane Fluoreszenzintensität $[\mathrm{MFI}]$ für den spezifischen Protein-TAG (Strep-tag $\left.{ }^{\circledR} \mathrm{II}\right)$ Nachweis (siehe Kap. 3.5.1) je Beadpopulation, sowie die MFI für den E. coli Antikörper Nachweis, als Indiz für verbliebene $E$. coli Proteine.

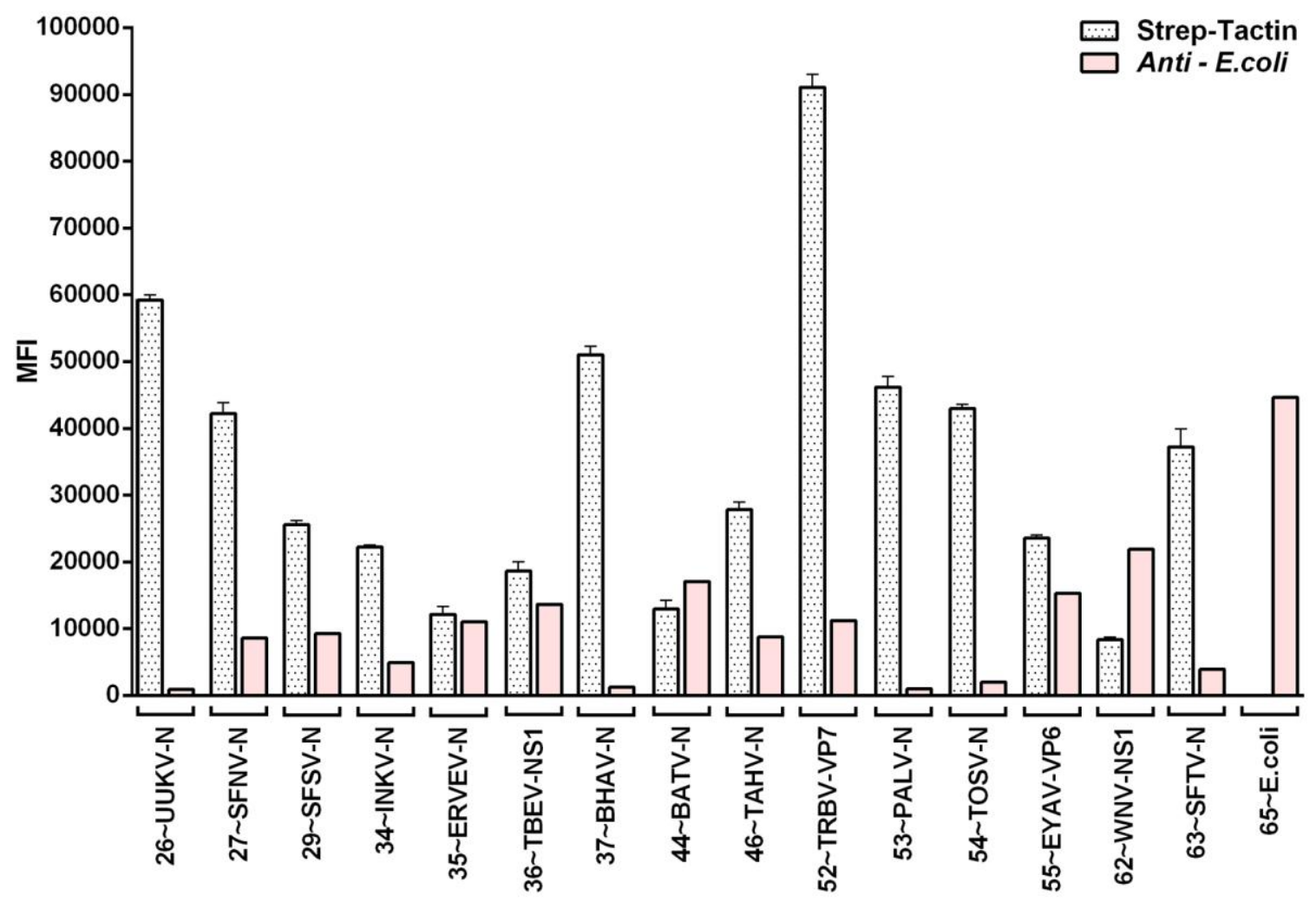

Abb. 3.10: Vergleich von MFI (Anti-E. coli) und MFI (Strep-Tactin-R-PE). Alle Proteinbeads (von links: UUKV-N, SFNV-N, SFSV-N, INKV-N, ERVEV-N, TBEV-NS1, BHAV-N, BATV-N, TAHV-N, TRBV-VP7, PALV-N, TOSV-N, EYAV-VP6, WNV-NS1, SFTV-N) zeigen ein deutliches Signal beim Nachweis des spezifischen Protein-TAGs (Strep-tag ${ }^{\circledR}$ II), ebenfalls zeigen alle Proteinbeads eine Reaktion auf E. coli Antikörper (Software: GraphPad Prism 6).

Seren mit einem hohen E. coli-Antikörpertiter könnten demnach zu einem Fluoreszenzsignal der Proteinbeads führen, obwohl keine viralen Antikörper im Serum vorhanden sind. Um diese falsch positiven Signale auszuschließen, wurde die Entwicklung einer internen Kontrolle des CBA auf E. coli Antikörper notwendig (in Abb. 3.10 als Beadpopulation 65 vorweggenommen dargestellt). Des Weiteren wurde eine Methode zum Abfangen der störenden E. coli-Antikörper aus Patientenmaterial und somit eine Reduktion der Reaktion aller Proteinbeads auf E. coli-Antikörper erarbeitet, welche im folgenden Kapitel behandelt wird. 


\subsubsection{Entwicklung interner Kontrollen und Notwendigkeit der Präadsorption}

\subsubsection{Entwicklung interner CBA Kontrollen}

Für die interne Kontrolle des CBAs wurde eine reine BL21(DE3) E. coli Expressionskultur (ohne Plasmidtransformation) verwendet. Hierzu wurde der Versuch der Proteinexpression und Lyse (siehe Kap.2.2.4.1) mit einer Reinkultur durchgeführt, die Gesamtmenge aller exprimierten E. coli Proteine nach Zellaufschluss ermittelt (BCA-Test: $8817,5 \mu \mathrm{g} / \mathrm{ml})$ und $10 \mu \mathrm{g}$ Gesamtprotein $(1,13 \mu \mathrm{l})$ an Beadpopulation \#65 gekoppelt. Eine

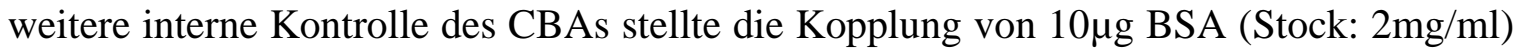
an Beadpopulation \#42 dar. Beide Kontrollen wurden, wie in Kap. 2.2.5.2.2 beschrieben, mit Strep-Tactin-R-PE inkubiert. Wie erwartet konnte kein Fluoreszenzsignal gemessen werden, da die Kontrollen und Strep-Tactin-R-PE nicht miteinander Kreuzreagieren und sich somit wie eine ungekoppelte Rohbeadpopulation verhalten.

Die aufeinander folgende Doppelinkubation mit polyklonalem Kaninchenserum mit hohem Anti- E. coli Antikörpertiter [Anti- E. coli Polyclonal Rabbit 1:750] und Anti-Rabbit IgG-R-PE Zweitantikörper [1:50] (siehe Kap.3.5.2) wurde ebenfalls mit beiden Kontrollen durchgeführt. Dies diente zur Kopplungsüberprüfung der internen E. coli Kontrolle (E. coli-Proteine an Beadpopulation \# 65 gekoppelt, siehe auch Abb. 3.10). Die Ergebnisse wurden in Tabelle 3.8 zusammengefasst, pro Messung wurden mind. 100 Beads am MAGPIX ${ }^{\mathrm{TM}}{ }_{-}$System gemessen und daraus die MFI berechnet.

Tabelle 3.8: Zusammenfassung der MFI der internen Kontrollen des CBA

\begin{tabular}{lccc}
\hline Protein & $\begin{array}{c}\text { Beadpopulation } \\
\text { [Nummer] }\end{array}$ & $\begin{array}{c}\text { Strep-Tactin-R-PE } \\
{[\mathbf{M F I}] \mathbf{n}=\mathbf{1}}\end{array}$ & $\begin{array}{c}\text { Anti- } \text { E. coli } \\
{[\mathbf{M F I}] \mathbf{n}=\mathbf{1}}\end{array}$ \\
\hline Kontrolle: BSA & 42 & 1 & 44 \\
Kontrolle: E. coli & 65 & 4 & 44624 \\
\hline
\end{tabular}

Starke Reaktionen der Kontrollen bei der Serentestung deuten auf einen erhöhten Hintergrund der Probe hin und könnten die Sensitivität des CBA beeinflussen. 


\subsubsection{Präadsorption der Seren zur Vermeidung falsch positiver Ergebnisse}

Um falsch positive Signale auf möglicherweise im Serum enthaltene E. coli-Antikörper von vorn herein auszuschließen, wurde eine vorangestellte Inkubation (Präadsorption) der Patientenprobe mit E. coli Lysat durchgeführt (siehe Kap.2.2.5.2.3).

Zur Ermittlung der optimalen E. coli Lysat-Verdünnung zur Präadsorption aller im Multiplex-CBA gemessenen Seren, wurde ein Negativserum eines gesunden Menschen mit intrinsisch hohem E. coli Antikörpertiter in den Verdünnungen 1:16, 1:32, 1:64 und 1:128 je einmal ohne Präadsorption und mit Präadsorption (mit den Lysatverdünnung 1:10, 1:20, 1:40, 1:80, 1:160 und 1:320) auf Fluoreszenzsignale beider Kontroll-Beads (E.coli und BSA) überprüft. Nach Inkubation der Ansätze mit der jeweiligen Verdünnung des Serums folgte eine zweite Inkubation mit Anti-Human-IgG-(R)-PE (siehe 2.1.10), wie in Kap. 2.2.5.2.4 beschrieben. Pro Messung wurden mind. 100 Beads am MAGPIX ${ }^{\mathrm{TM}}$ System gemessen und daraus die MFI berechnet. Die Ergebnisse wurden in Tabelle 3.9 und Tabelle 3.10 zusammengefasst.

Tabelle 3.9: Fluoreszenzsignal (MFI) des Präadsorptions-Tests für E. coli-Kontrolle

\begin{tabular}{lccccccc}
\hline & $\begin{array}{c}\text { ohne } \\
\text { Präadsorption }\end{array}$ & \multicolumn{5}{c}{ mit } \\
& & $\mathbf{( 1 : 1 0 )}$ & $\mathbf{( 1 : 2 0 )}$ & $\mathbf{( 1 : 4 0 )}$ & $\mathbf{( 1 : 8 0 )}$ & $\mathbf{( 1 : 1 6 0 )}$ & $\mathbf{( 1 : 3 2 0 )}$ \\
\hline Neg. S. (1:16) & 12226 & 633 & 1093 & 1172 & 891 & 1026 & 1387 \\
Neg. S. (1:32) & 6378 & 325 & 437 & 451 & 802 & 691 & 717 \\
Neg. S. (1:64) & 3101 & 222 & 234 & 286 & 317 & 363 & 460 \\
Neg.S. (1:128) & 2230 & 110 & 143 & 158 & 271 & 239 & 273 \\
\hline
\end{tabular}

Tabelle 3.10: Fluoreszenzsignal (MFI) des Präadsorptions-Tests für BSA- Kontrolle

\begin{tabular}{lccccccc}
\hline & $\begin{array}{c}\text { ohne } \\
\text { Präadsorption }\end{array}$ & \multicolumn{5}{c}{$\begin{array}{c}\text { mit } \\
\text { Präadsorption }\end{array}$} \\
& & $(\mathbf{1 : 1 0 )}$ & $\mathbf{( 1 : 2 0 )}$ & $\mathbf{( 1 : 4 0 )}$ & $\mathbf{( 1 : 8 0 )}$ & $\mathbf{( 1 : 1 6 0 )}$ & $\mathbf{( 1 : 3 2 0 )}$ \\
\hline Neg. S. (1:16) & 965 & 369 & 650 & 604 & 495 & 620 & 649 \\
Neg. S. (1:32) & 585 & 212 & 247 & 258 & 469 & 439 & 341 \\
Neg. S. (1:64) & 509 & 121 & 126 & 144 & 166 & 182 & 228 \\
Neg.S. (1:128) & 238 & 57 & 82 & 82 & 130 & 117 & 150 \\
\hline
\end{tabular}


In Abb. 3.11 ist das Beispiel für die Serenverdünnung von 1:128 mit und ohne Präadsorption gezeigt. Im Anhang in Abb. 6.3 wurden die Graphen aller PräadsorptionsTests (Serenverdünnung 1:16. 1:32, 1:64 und 1:128) angefügt.

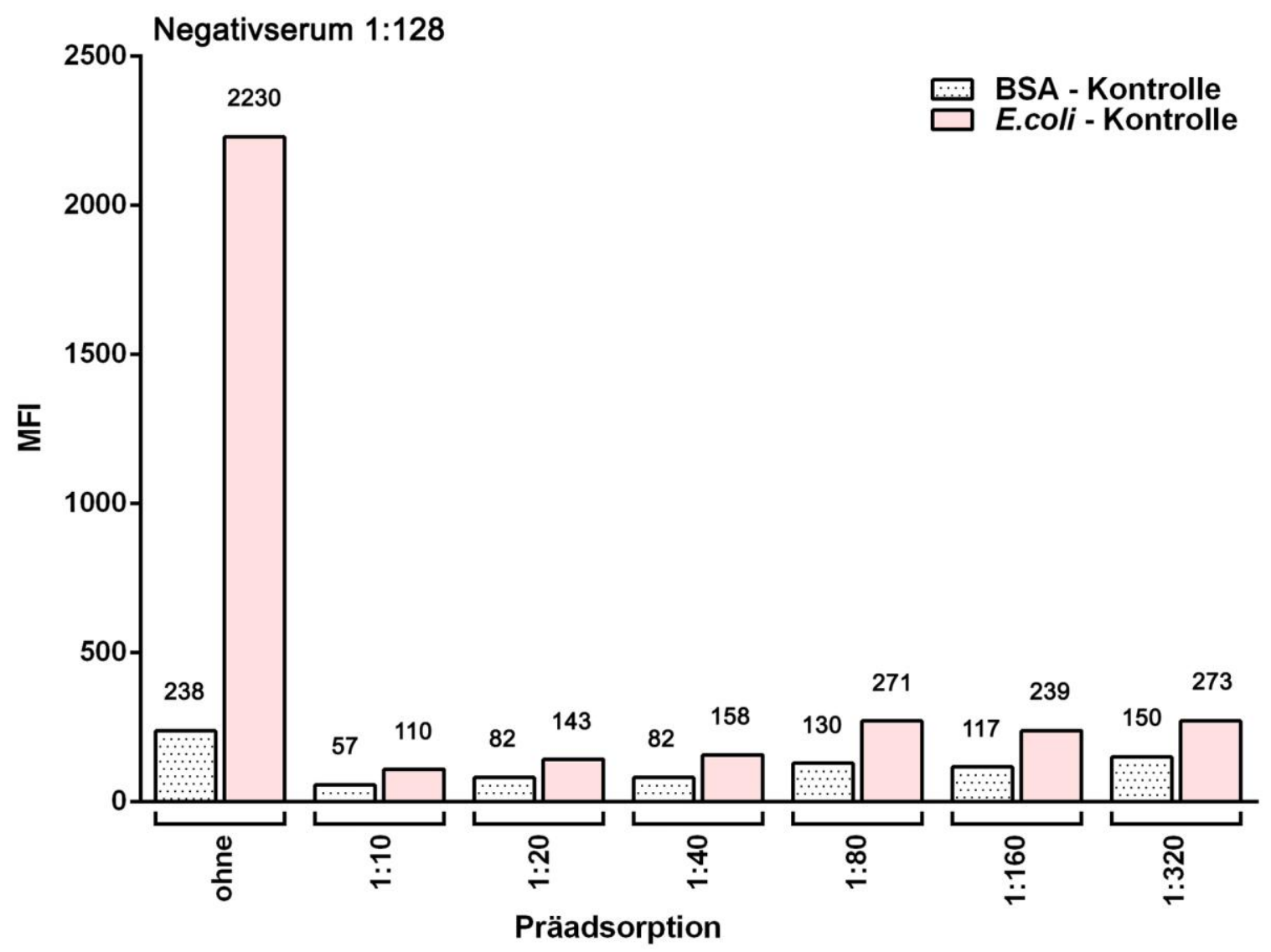

Abb. 3.11: Graphische Darstellung des Präadsorptions-Tests ohne und mit Präadsorption. Beispiel für das Negativserum mit der Verdünnung von 1:128 mit und ohne Präadsorption mit E. coli Lysat verschiedener Verdünnungsstufen (Software: GraphPad Prism 6).

Alle Versuche mit den Serenverdünnung 1:16, 1:32, 1:64 oder 1:128 zeigten ein starkes Fluoreszenzsignal der E. coli-Kontrolle und ein schwaches Hintergrundsignal der BSAKontrolle auf das Serum ohne Präadsorption.

Bei den Seren mit vorangestellter Inkubation mit E. coli Lysat zeigte sich eine deutliche Reduktion des Fluoreszenzsignals der E. coli-Kontrolle, die Fluoreszenzsignale der BSAKontrolle blieben im Vergleich durchgehend niedrig.

Als optimale E. coli Lysat-Verdünnung wurde eine Verdünnung zwischen 1:40 und 1:80 auf Grund der Reduktion des Fluoreszenzsignals der E. coli-Kontrolle auf ein zu vernachlässigendes Maß angesehen. Für den Multiplex-CBA-Test wurden alle Patientenproben daher zuerst einer vorangestellten Inkubation mit einem 1:60 verdünnten E. coli Lysat $\left(1 \mathrm{~h}, 37^{\circ} \mathrm{C}\right)$ unterzogen. 


\subsubsection{Sensitivität der gekoppelten Beadpopulationen und optimale Serenverdünnung für Multiplex-Ansätze}

Zur Ermittlung einer für den Multiplex-CBA optimalen Serenverdünnung zur Messung von Patientenproben wurde für jede gekoppelte Beadpopulation eine Sensitivitätsmessung (Kap. 2.2.5.2.3) mit dem zugehörigen Positivserum (siehe Tabelle 2.14) durchgeführt.

Pro Messung wurden mind. 100 Beads am MAGPIX ${ }^{\mathrm{TM}}$-System gemessen und daraus die MFI berechnet. Die Daten und eine Einzeldarstellung aller gemessenen Positivseren wurden im Anhang (Tabelle 6.1 und Abb. 6.4) angefügt. Abb. 3.12 zeigt die Zusammenfassung der Ergebnisse der Sensitivitätstests aller Positivseren.

Es zeigten sich dabei zwei Typen von Kurven: Die Messreihen mit hoher Sensitivität zeigten einen sigmoiden Kurvenverlauf, die Messreihen mit geringerer Sensitivität einen linearen Kurvenverlauf. Was auf unterschiedlich sensitiv bindende Proteinbeads und unterschiedlich hohe virale Antikörpertiter der Positivseren hindeutet.
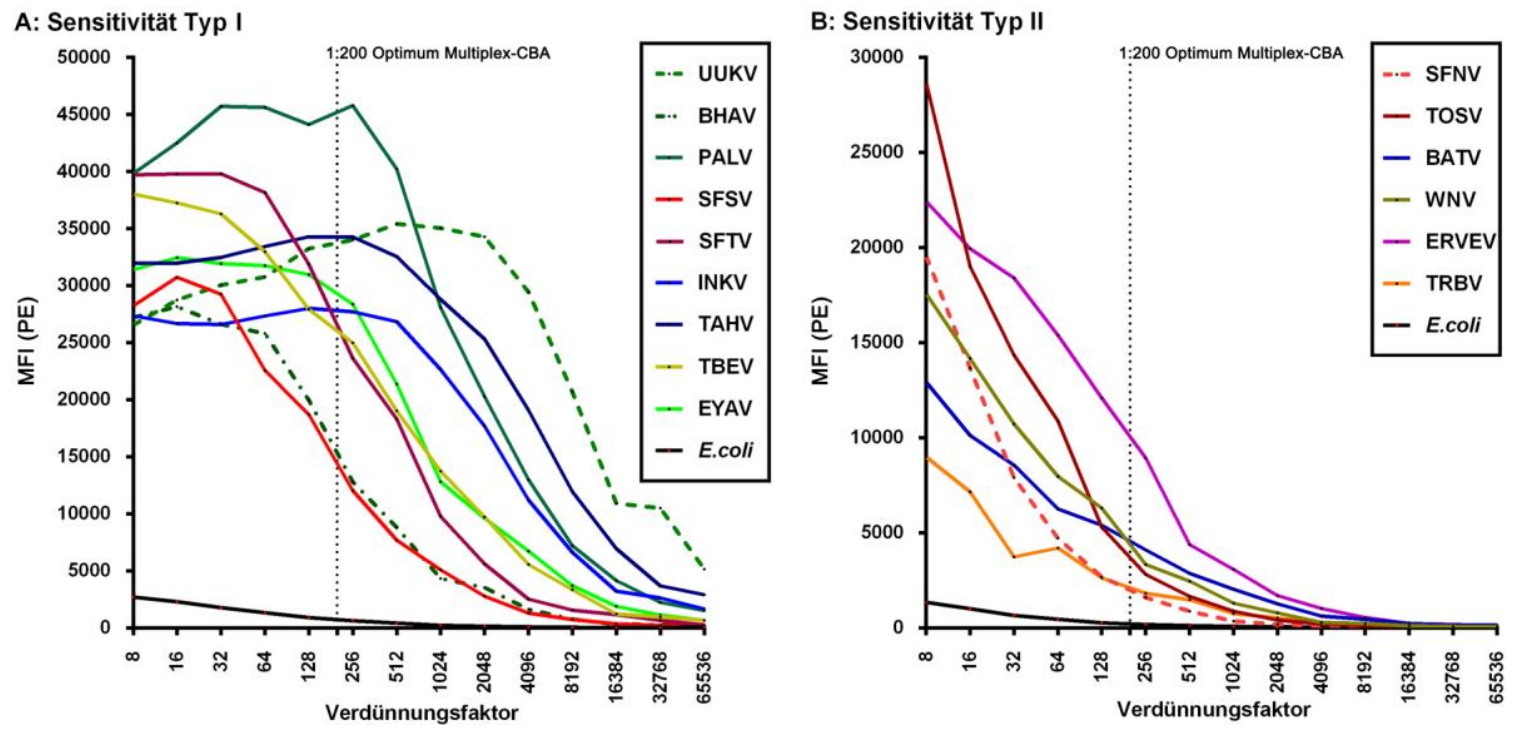

Abb. 3.12: Graphische Darstellung der Sensitivitätstests aller Positivseren als Zusammenfassung. Jedes Positivserum wurde in 14 Verdünnungsstufen beginnend mit 1:8 in zweier Schritten bis 1:65536 verdünnt und mit den zugehörigen gekoppelten Proteinbeads auf MFI überprüft. Zusätzlich wurde die CBA interne E. coli-Kontrolle mitgeführt. Die Zusammenfassung zeigt jeweils die Mittelwerte je Messpunkt aus drei voneinander unabhängigen Sensitivitätsmessungen. Fehlerbalken sind in den Einzeldarstellungen im Anhang dargestellt und wurden hier aus Gründen der Übersicht weggelassen. A: Zeigt die Zusammenfassung aller Seren mit sigmoidem Kurvenverlauf. B: Zeigt die Zusammenfassung aller Seren mit linearem Kurvenverlauf. Die gepunktete Linie deutet die optimale Serenverdünnung für einen Multiplex-CBA mit allen gekoppelten Proteinbeads an (Software: GraphPad Prism 6). 
Für den Multiplex-CBA wurde eine Serenverdünnung benötigt, in der möglichst viele Messreihen der Sensitivitätstests innerhalb ihres dynamischen Bereichs (linearer Kurvenverlauf) lagen und entsprechend wenig störende Wechselwirkungen der vorliegenden Antikörper miteinander vorlagen. Für die Typ I Proteinbeads zeigte sich eine hohe Sensitivität, der dynamische Bereich lag zwischen den Verdünnungen 1:128 und 1:2048. Für die Typ II Proteinbeads zeigte sich eine geringere Sensitivität, der dynamische Bereich lag zwischen den Verdünnungen 1:16 und 1:256. Somit ergab sich eine optimale Serenverdünnung für einen alle Proteinbeads enthaltenden Multiplex-CBA von 1:200.

Ein Vergleich der Nachweisgrenzen der Positivseren, die mittels CBA und IFT ermittelt wurden (siehe Tabelle 3.11) zeigte, dass der entwickelte CBA mindestens die doppelte Sensitivität im Vergleich zum IFT aufweist, teilweise sogar 100-fach sensitiver ist (siehe Tabelle 3.11 TAHV).

Tabelle 3.11: Vergleich der Nachweisgrenze von IFT und CBA

\begin{tabular}{llcc}
\hline Positivserum & Virus & $\begin{array}{c}\text { IFT - } \\
\text { Nachweisgrenze }\end{array}$ & $\begin{array}{c}\text { CBA - } \\
\text { Nachweisgrenze }\end{array}$ \\
\hline Anti-Calovo & Batai Virus & $1: 1280$ & $1: 2048$ \\
Anti-Bhanja & Bhanja Virus & $1: 320$ & $1: 8192$ \\
Anti-Erve & Erve Virus & $1: 2560$ & $1: 4096$ \\
Anti-Eyach & Eyach Virus & $1: 160$ & $1: 8192$ \\
Anti-Palma M4756 & Palma Virus & $1: 1280$ & $1: 8192$ \\
Nap1 & SFN Virus & $1: 80$ & $1: 128$ \\
S18 & SFS Virus & $1: 80$ & $1: 1024$ \\
SC1 & SFT Virus & $1: 1280$ & $1: 2048$ \\
Anti-Tahyna 181 & Inkoo Virus & $1: 320$ & $1: 8192$ \\
Anti-Tahyna 181 & Tahyna Virus & $1: 640$ & $1: 65536$ \\
RSSE-AK IgG & TBE Virus & $1: 1280$ & $1: 65536$ \\
T6 & Toscana Virus & $1: 80$ & $1: 128$ \\
Anti-Tribec & Tribec Virus & $1: 1280$ & $1: 2048$ \\
Anti Uuk & Uukuniemi Virus & $1: 2560$ & $1: 32768$ \\
West Nil MIAF & West Nil Virus & $1: 1280$ & $1: 2048$ \\
\hline
\end{tabular}




\subsubsection{Ermittlung der Kreuzreaktivität nah verwandter Arboviren}

Zu Ermittlung der Kreuzreaktivität der gekoppelten Proteinbeads auf andere virale Antikörper, wurden wie in Kap. 2.2.5.2.4 beschrieben alle Proteinbeads als Multiplex-Test vereint und je Ansatz mit einem der bereits mehrfach untersuchten Positivseren (siehe Tabelle 2.14) in einer Verdünnung von 1:200 (die ermittelte optimale Serenverdünnung für Multiplex-CBA siehe Kap. 3.5.4) gemessen. Pro Messung wurden mind. 100 Beads am MAGPIX ${ }^{\mathrm{TM}}$-System gemessen und daraus die MFI berechnet.

In Abb. 3.13 wurden als Beispiel zwei Kreuzreaktivitätstests graphisch dargestellt. Einmal ein Positivserum ohne Kreuzreaktion (A) und einmal ein Positivserum mit erwarteten Kreuzreaktionen von TAHV und INKV (B). Die gemessenen Daten (MFI) und alle weiteren graphisch dargestellten Ergebnisse der Kreuzreaktivitätstests aller getesteten Positivseren wurden im Anhang (Kap.6.4, Tabelle 6.2 und Abb. 6.5 - Abb. 6.8) angefügt.
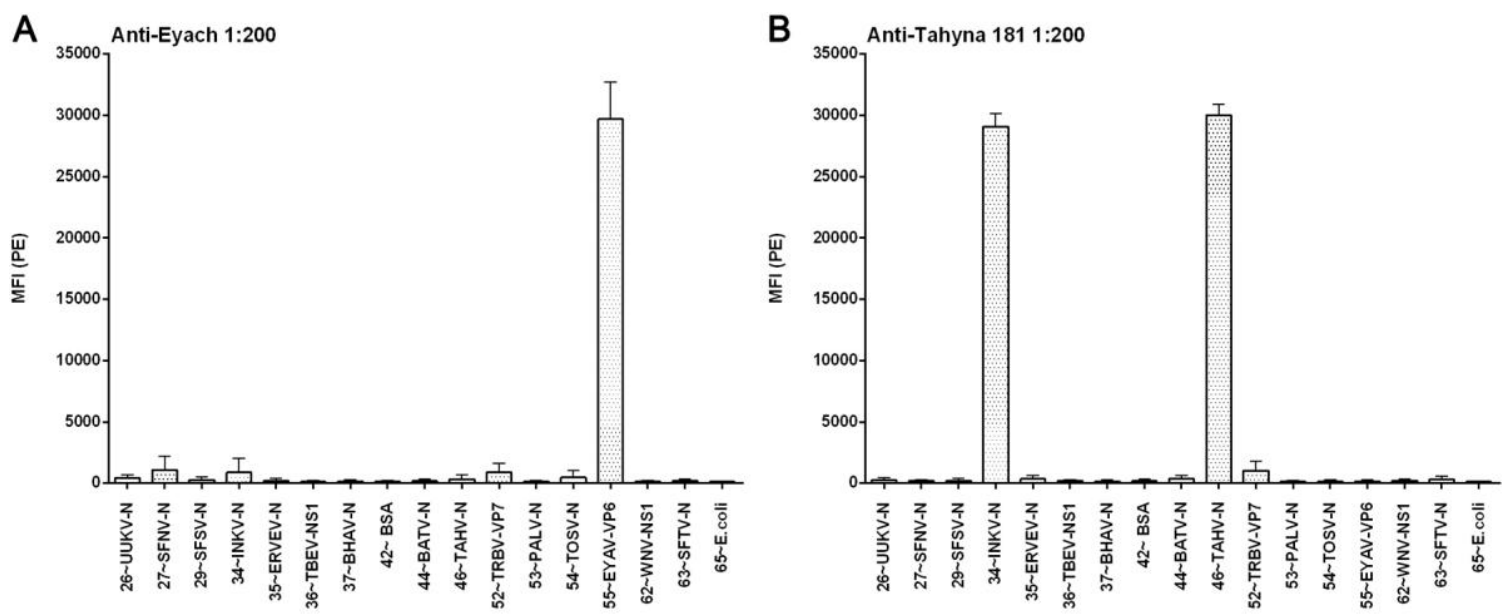

Abb. 3.13: Kreuzreaktivitätstests Multiplex-CBA für EYAV-Positivserum sowie TAHV- und INKVPositivserum. Dargestellt sind die MFI jeder gekoppelten Beadpopulation gemessen als Multiplex-CBA. A: Positivserum EYAV (Anti-Eyach) 1:200, n=3. B: Positivserum TAHV und INKV (Anti-Tahyna 181) 1:200, n=3 (Software: GraphPad Prism 6).

Die gekoppelten Proteinbeads EYAV-VP6 (Abb. 3.13 A) und UUKV-N, TRBV-VP7, BATV-N, ERVEV-N (siehe Anhang Abb. 6.8 A-D) zeigten, wie erwartet, keine oder nicht signifikant erhöhte Kreuzreaktionen $\mathrm{zu}$ anderen mit arboviralen Proteinen gekoppelten Proteinbeads. Die Kontrolle mit einem Negativserum zeigte keine falsch positiven Reaktionen im Multiplex-CBA.

Weitere Kreuzreaktionen zeigten sich, wie erwartet, zwischen den nah verwandten Viren: 
Die Proteinbeads von BHAV-N und PALV-N (beides nah-verwandte Zecken-übertragene Phleboviren) zeigten jeweils ein Fluoreszenzsignal auf das BHAV-Positivserum und das PALV-Positivserum (siehe Abb. 6.5 A und B).

Die Proteinbeads von WNV-NS1 und TBEV-NS1 (beides Flaviviren) zeigten jeweils ein Fluoreszenzsignal auf das WNV-Positivserum und das TBEV-Positivserum (siehe Abb. 6.6 A und B).

Bei den gekoppelten Proteinbeads der Sandmücken-übertragenen Phleboviren (SFNV, SFSV, SFTV und TOSV) konnten Kreuzreaktionen beim Messen der Positivseren ermittelt werden, allerdings nur zwischen den gekoppelten Proteinbeads von SFNV-N und TOSV-N (siehe Abb. 6.7: A und B) sowie zwischen SFSV-N und SFTV-N (siehe Abb. 6.7: C und D). Innerhalb der Sandmücken-übertragenen Phleboviren konnte somit zwischen zwei verschiedenen Gruppen unterschieden werden. In Tabelle 3.12 wurden alle Kreuzreaktivitäten der gekoppelten Proteinbeads mit den Positivseren zusammengefasst. Die im CBA erhaltenen Kreuzreaktionen entsprechen auch denen in anderen Testsystemen und sind in der Literatur beschriebenen (wwwn.cdc.gov/arbocat).

Tabelle 3.12: Zusammenfassung Kreuzreaktivität der gekoppelten Proteinbeads

\begin{tabular}{|c|c|c|c|c|c|c|c|c|c|c|c|c|c|c|c|c|}
\hline Beads & 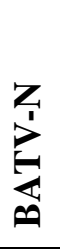 & $\begin{array}{l}Z \\
\mathbf{Z} \\
\mathbf{3} \\
\mathbf{3}\end{array}$ & 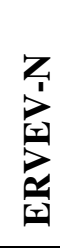 & 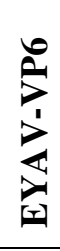 & $\begin{array}{l}z \\
\mathbf{z} \\
\bar{z} \\
z\end{array}$ & $\begin{array}{l}7 \\
3 \\
3 \\
3 \\
2\end{array}$ & $\frac{Z}{Z}$ & 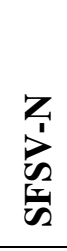 & $\begin{array}{l}Z \\
1 \\
2 \\
2 \\
2\end{array}$ & 忘 & 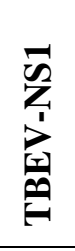 & $\begin{array}{l}7 \\
7 \\
8 \\
8 \\
0 \\
0\end{array}$ & 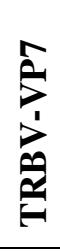 & $\begin{array}{l}z \\
z \\
3 \\
3 \\
3\end{array}$ & $\begin{array}{l}\bar{n} \\
\sum_{1} \\
z_{3}^{\prime} \\
z\end{array}$ & $\begin{array}{l}\ddot{8} \\
0 \\
0\end{array}$ \\
\hline BATV & + & - & - & - & - & - & - & - & - & - & - & - & - & - & - & - \\
\hline BHAV & - & ++ & - & - & - & ++ & - & - & - & - & - & - & - & - & - & - \\
\hline ERVEV & - & - & ++ & - & - & - & - & - & - & - & - & - & - & - & - & - \\
\hline EYAV & - & - & - & ++ & - & - & - & - & - & - & - & - & - & - & - & - \\
\hline PALV & - & ++ & - & - & - & ++ & - & - & - & - & - & - & - & - & - & - \\
\hline SFNV & - & - & - & - & - & - & ++ & - & - & - & - & + & - & - & - & - \\
\hline SFSV & - & - & - & - & - & - & - & ++ & ++ & - & - & - & - & - & - & - \\
\hline SFTV & - & - & - & - & - & - & - & ++ & ++ & - & - & - & - & - & - & - \\
\hline TAHV & - & - & - & - & ++ & - & - & - & - & ++ & - & - & - & - & - & - \\
\hline TBEV & - & - & - & - & - & - & - & - & - & - & ++ & - & - & - & + & - \\
\hline TOSV & - & - & - & - & - & - & ++ & - & - & - & - & ++ & - & - & - & - \\
\hline TRBV & - & - & - & - & - & - & - & - & - & - & - & - & + & - & - & - \\
\hline UUKV & - & - & - & - & - & - & - & - & - & - & - & - & - & ++ & - & - \\
\hline WNV & - & - & - & - & - & - & - & - & - & - & ++ & - & - & - & ++ & - \\
\hline Neg. & - & - & - & - & - & - & - & - & - & - & - & - & - & - & - & - \\
\hline
\end{tabular}




\subsubsection{Grenzwertberechnung Multiplex-CBA}

Wie schon in Kap. 2.2.5.2.6 beschrieben wurde der Grenzwert an Hand der Ergebnisse des Multiplex-CBA von 45 gut charakterisierten humanen Negativseren (1:200 verdünnt) auf zwei Methoden berechnet:

Grenzwert $(\mathrm{A})=\mathrm{MW}(\mathrm{MFI})+6 \mathrm{x}$ SD und Grenzwert $(\mathrm{B})=\mathrm{MW}(\mathrm{MFI})+\mathrm{SD} \times f$ nach (Frey et al., 1998), jeweils pro Beadpopulation einmal für IgG-Antikörper und einmal für IgM-Antikörper.

Pro Messung wurden mind. 30 Beads am MAGPIX ${ }^{\mathrm{TM}}$-System gemessen und daraus die MFI berechnet. Die Daten, sowie die Grenzwert-Berechnungen wurden in Tabellenform dem Anhang hinzugefügt (siehe Kapitel 6.5, Tabelle 6.3,Tabelle 6.4, Tabelle 6.5 und Tabelle 6.6), die Ergebnisse wurden in Tabelle 3.13 und Tabelle 3.14 zusammengefasst:

Tabelle 3.13: Zusammenfassung der Grenzwert-Berechnungen für IgG-Antikörper, $\mathrm{n}=45$

\begin{tabular}{lcc}
\hline Beadpopulation & (A) IgG: MW (MFI) +6 x SD & (B) IgG: MW (MFI) + SD x $f$ \\
\hline BP26 - UUKV & 953 & 887 \\
BP27 - SFNV & 1199 & 1115 \\
BP29 - SFSV & 1403 & 1313 \\
BP 34 - INKV & 2751 & 2577 \\
BP35 - ERVEV & 1566 & 1465 \\
BP36 - TBEV & 1805 & 1686 \\
BP37 - BHAV & 2401 & 2233 \\
BP42 - BSA & 1649 & 1539 \\
BP44 - BATV & 2048 & 1912 \\
BP46 - TAHV & 1684 & 1574 \\
BP52 - TRBV & 2292 & 2148 \\
BP53 - PALV & 2694 & 2505 \\
BP54 - TOSV & 1923 & 1787 \\
BP55 - EYAV & 1630 & 1531 \\
BP62 - WNV & 1428 & 1337 \\
BP63 - SFTV & 1078 & 1010 \\
BP65 - E. coli & 1965 & 1837 \\
\hline
\end{tabular}


Tabelle 3.14: Zusammenfassung der Grenzwert-Berechnungen für IgM-Antikörper, $n=45$

\begin{tabular}{lcc}
\hline Beadpopulation & (A) IgM: MW (MFI) +6 x SD & (B) IgM: MW (MFI)+ SD x $f$ \\
\hline BP26 - UUKV & 1529 & 1438 \\
BP27 - SFNV & 3282 & 3075 \\
BP29 - SFSV & 2620 & 2463 \\
BP 34 - INKV & 2621 & 2463 \\
BP35 - ERVEV & 1290 & 1215 \\
BP36 - TBEV & 950 & 895 \\
BP37 - BHAV & 2925 & 2747 \\
BP42 - BSA & 1010 & 944 \\
BP44 - BATV & 1232 & 1159 \\
BP46 - TAHV & 3284 & 3084 \\
BP52 - TRBV & 2600 & 2452 \\
BP53 - PALV & 2962 & 2781 \\
BP54 - TOSV & 3589 & 3370 \\
BP55 - EYAV & 2231 & 2096 \\
BP62 - WNV & 960 & 904 \\
BP63 - SFTV & 3539 & 3326 \\
BP65 - E. coli & 572 & 539 \\
\hline
\end{tabular}

\subsubsection{IgM- und IgG- Antikörpernachweis gegen europäische humanpathogene Arboviren (Multiplex-CBA)}

Der Multiplex-CBA wurde wie in Kap. 2.2.5.2.5 beschrieben durchgeführt. Alle Proben der Studie (111 Patienten, teils mehrere Proben verschiedener Zeitpunkte vorhanden) wurden sowohl auf anti-arbovirale IgG-Antikörper, wie auch anti-arbovirale IgM-Antikörper im Multiplex-CBA getestet. Bei unauffälligem Befund wurden die Proben einmalig, bei auffälligem Befund doppelt $(n=2)$, teilweise in Triplika-Messung $(n=3)$ in einer 1:200 Verdünnung getestet. Pro Messung wurden mind. 30 Beads am MAGPIX ${ }^{\mathrm{TM}}$ System gemessen und daraus die MFI berechnet. Die Daten wurden in Tabellenform dem Anhang (siehe Kap.6.6) hinzugefügt, Werte oberhalb des Grenzwertes wurden farblich hervorgehoben (siehe Tabelle 6.7 - Tabelle 6.12). Grenzwert (A) und (B) lieferten nahezu die gleiche Anzahl positiver Seren. 


\subsubsection{Auswertung Multiplex-CBA}

Wie schon in Kap. 2.2.5.2.6 beschrieben, wurden alle getesteten Seren den Fällen 1 - 4 zugeordnet. Alle Seren unterhalb des berechneten beadspezifischen Grenzwertes (siehe Kap. 3.5.6) wurden zunächst Fall 1 (unauffälliges Serum ohne arbovirale Infektion) zugeordnet. Standen von einem Patienten mehr als eine Probe (beide Abnahmen innerhalb von zwei Wochen) zur Verfügung, kann von einem bestätigten Ergebnis ausgegangen werden. Dies war bei sechs Patienten der Fall (siehe Tabelle 6.9 und Tabelle 6.10 im Anhang bzw. Kap. 3.5.7.3). Die Multiplex-CBA-Ergebnisse aller anderen Patienten lieferten durch die einmalige Abgabe eines Serums lediglich einen ungesicherten Hinweis auf eine vorliegende Infektion (siehe Tabelle 6.7 und Tabelle 6.8). Auf die Problematik des falschen Zeitpunktes der Probenabnahme bei einmaliger Abgabe eines Serums und dem daraus möglicherweise resultierendem, unter dem Grenzwert liegenden Ergebnis wird in der Diskussion (siehe Kap. 4) weiter eingegangen. Bei vier Patienten wird eine akute Infektion (Fall 4 siehe Abb. 6.12) vermutet, obwohl die gemessene MFI gegen IgMAntikörper knapp unterhalb des Grenzwertes lag, der IgG-Antikörper Grenzwert jedoch überschritten wurde.

\subsection{Fall 1: Keine arbovirale Infektion: IgM und IgG negativ.}

Die Seren von 61 der 111 Patienten zeigten keine Auffälligkeiten bei der Überprüfung auf anti-arbovirale IgM- und IgG-Antikörper im Multiplex-CBA. Alle Werte lagen unterhalb des berechneten beadspezifischen Grenzwertes. Der Auslöser der Krankheitssymptome dieser Patienten bleibt weiterhin unklar, lediglich die 15 in dieser Arbeit untersuchten Arboviren konnten ausgeschlossen werden.

\subsection{Fall 2: Verdacht auf arbovirale Infektion, die Wochen oder Monate zurückliegt: IgM negativ, IgG positiv}

Die Seren von 11 der 111 Patienten zeigten Auffälligkeiten bei der Überprüfung auf antiarbovirale IgG-Antikörper im Multiplex-CBA, blieben jedoch IgM negativ (unterhalb des berechneten beadspezifischen Grenzwertes). Eine zweite Probe mit gleichem Ergebnis würde eine akute Infektion ausschließen. Lediglich bei einem Patienten lag eine zweite Probe vor. Die Ergebnisse der ersten Messung $(n=1)$ wurden in Tabellenform dem Anhang hinzugefügt (siehe Tabelle 6.7 und Tabelle 6.8). Zur Bestätigung wurden alle auffälligen Seren erneut gemessen (siehe Kap. 3.5.7.2). 


\subsection{Fall 3: Verdacht auf akute arbovirale Infektion: IgM positiv, IgG negativ}

Die Seren von 21 der 111 Patienten zeigten Auffälligkeiten bei der Überprüfung auf antiarbovirale IgM-Antikörper im Multiplex-CBA, blieben jedoch IgG negativ (unterhalb des berechneten beadspezifischen Grenzwertes). Eine zweite Probe (Abnahme innerhalb von zwei Wochen) müsste eine Serokonversion zeigen und IgG positiv ausfallen.

Bei keinem dieser 21 Patienten lag eine zweite Probe vor. Die Ergebnisse der ersten Messung ( $\mathrm{n}=1)$ wurden in Tabellenform dem Anhang hinzugefügt (siehe Tabelle 6.7 und Tabelle 6.8). Zur Bestätigung wurden alle auffälligen Seren erneut gemessen (siehe Kap. 3.5.7.2).

\subsection{Fall 4: Verdacht auf akute arbovirale Infektion: IgM positiv, IgG positiv}

Die Seren von 10 der 111 Patienten zeigten Auffälligkeiten bei der Überprüfung auf antiarbovirale IgM- und IgG-Antikörper im Multiplex-CBA. Eine zweite Probe mit IgG positivem Ergebnis würde die Diagnose sichern. Dies ist bei zwei Patienten der Fall, es handelt sich demnach um eine akute Infektion in der späten Phase, in der bereits weitgehend ein Antikörpertiter gegen das entsprechende Virus ausgebildet wurde.

Die Ergebnisse der ersten Messung $(n=1)$ wurden in Tabellenform dem Anhang hinzugefügt (siehe Tabelle 6.7 und Tabelle 6.8). Zur Bestätigung wurden alle auffälligen Seren erneut gemessen (siehe Kap. 3.5.7.2).

\subsubsection{Bestätigung der Multiplex-CBA Ergebnisse durch Mehrfachmessung auffälliger Seren}

\section{Fall 2: IgM negativ, IgG positiv (11 Patienten)}

Die Ergebnisse der 11 Patientenproben unter Betrachtung beider berechneter Grenzwerte (A) und (B) wurden in Tabelle 3.15 und Tabelle 3.16 zusammengefasst. Eine graphische Darstellung wurde dem Anhang Abb. 6.9 hinzugefügt. Jedes Serum wurde doppelt auf IgM-Antikörper $(n=2)$ und dreifach auf IgG-Antikörper $(n=3)$ getestet. 9 Seren zeigten einen positiven Wert jeweils auf ein Virus oder ein kreuzreagierendes Virenpaar (Kreuzreaktivitätstest auf IgG-Antikörper: BHAV/PALV, INKV/TAHV, SFNV/TOSV, SFSV/ SFTV siehe Kap. 2.2.5.2.4, Tabelle 3.12). 
Tabelle 3.15: Ergebnisse Einzelinfektion, Multiplex-CBA, n=3, Fall 2 (IgM: -, IgG: +)

\begin{tabular}{llc}
\hline Vektor & Virus & Grenzwert (A) und (B) \\
\hline Zecke & BHAV / PALV & 0 \\
ERVEV & 0 \\
EYAV & 3 (bestätigt) \\
UUKV & 0 \\
TBEV & 0 \\
TRBV & 1 (unbestätigt) \\
BATV & 0 \\
Stechmücke & INKV / TAHV & 0 \\
INKV (ohne TAHV) & 1 (bestätigt) \\
TAHV (ohne INKV) & 2 (bestätigt) \\
WNV & 0 \\
\hline Sandmücke & SFNV / TOSV & 1 (bestätigt) \\
& SFSV / SFTV & 0 \\
& SFNV/TOSV + SFSV/SFTV & 1 (bestätigt) \\
\hline
\end{tabular}

Tabelle 3.16: Ergebnisse Mehrfachinfektion, Multiplex-CBA, n=3, Fall 2 (IgM: -, IgG: +)

\begin{tabular}{lll}
\hline Serumnummer & Grenzwert (A) & Grenzwert (B) \\
\hline 653731 & INKV/TAHV + & INKV/TAHV + \\
& TOSV $($ ohne SFNV $)+$ & TOSV $($ ohne SFNV) + \\
& EYAV $(+)$ & EYAV + \\
\hline 584297 & SFNV/TOSV + & SFNV/TOSV + \\
& EYAV (+) & EYAV $(+)$ \\
& INKV (ohne TAHV) & INKV (ohne TAHV) \\
\hline
\end{tabular}

(+) unbestätigt, nur eine von 3 Messungen positiv, aber IFT positiv

Das Serum mit der Nummer 653731 (Tabelle 3.16) zeigte positive Werte für EYAV, INKV/TAHV und TOSV (ohne SFNV), eine Mehrfachinfektion verschiedener Viren über die Zeit ist nicht auszuschließen, eine zweite Probe (Abnahme nach zwei Wochen) stand nicht zur Verfügung. Erneute Multiplex-CBA Messungen (IgG: n=3) bestätigten einen deutlich erhöhten IgG-Antikörpertiter gegen INKV/TAHV, der Wert für TOSV war in allen drei Messungen erhöht, zeigte aber nicht die zu erwartende Kreuzreaktion mit SFNV. EYAV konnte nicht in allen drei Messungen bestätigt werden und lag teilweise knapp unterhalb des Grenzwertes. 
Bei dem Patienten mit der Serumnummer 584297 (positiv auf SFNV/TOSV, INKV (ohne TAHV), EYAV) lag eine zweite Probe (Abnahme nach zwei Wochen) mit Nr. 585668 vor (siehe Tabelle 6.9). Dieses Serum zeigte IgG positive Ergebnisse gegen SFNV/TOSV und INKV (ohne die zu erwartende Kreuzreaktion mit TAHV). Die zweite Probe blieb EYAV negativ.

\section{Fall 3: IgM positiv, IgG negativ (21 Patienten)}

Die Ergebnisse der 21 Patientenproben unter Betrachtung beider berechneter Grenzwerte (A) und (B) wurden in Tabelle 3.17 und Tabelle 3.18 zusammengefasst. 10 Seren zeigten einen positiven Wert jeweils auf ein Virus bzw. kreuzreagierendes Virenpaar, bei zwei Seren wurde das Ergebnis durch eine zweite Messung nicht bestätigt (Serumnr. 587182 EYAV und 634605 WNV). Bei vier Seren konnte eine deutlich erhöhte MFI für ein Virus gemessen werden, eine akute Mehrfachinfektion wurde ausgeschlossen (Serumnr. 584537, 630539, 640296, 654198). Eine graphische Darstellung wurde dem Anhang (Abb. 6.10 und Abb. 6.11) hinzugefügt. Die Seren wurden doppelt auf IgM-Antikörper $(n=2)$ getestet, bei zwei Seren erfolgte wegen zu geringem Probevolumen nur eine Messung.

Die Seren mit den Nummern 653039 und 1163451 zeigten in der ersten Messung keine eindeutigen Ergebnisse, eine zweite Messung fiel IgM negativ aus. Da zu beiden Seren keine zweite Probe zur Messung zur Verfügung stand, wurde zuerst von einem falsch positiven Signal in der ersten Messung ausgegangen, eine spätere IFT-Überprüfung des Serums 1163451 bestätigt den Hinweis der ersten CBA-Messung auf eine vorliegende akute EYAV-Infektion (siehe Tabelle 3.20).

Die Seren mit den Nummern 532655, 567544 und 587131 zeigten keine eindeutigen Ergebnisse und eine Reaktion auf die E. coli-Kontrolle. Ein erhöhter Anti-E.coli-Antikörpertiter (auch nach Präadsorption noch erhöht) führt zu falsch positiven Ergebnissen, eine eindeutige Auswertung der drei Seren ist nicht möglich. Eine zweite Probe stand zur Messung nicht zur Verfügung.

Das Serum mit der Nummer 1155523 zeigte keine eindeutigen Ergebnisse, die MFI für verschiedene Viren war erhöht, eine zweite Probe stand nicht zur Verfügung. Eine eindeutige Auswertung ist nicht möglich. 
Tabelle 3.17: Ergebnisse Einzelinfektion, Multiplex-CBA, n=3, Fall 3 (IgM: +, IgG: -)

\begin{tabular}{llc}
\hline Vektor & Virus & Grenzwert (A) und (B) \\
\hline Zecke & BHAV (ohne PALV) & 1 (bestätigt) \\
ERVEV & 0 \\
EYAV & 1 (bestätigt) +1 (unbestätigt) \\
UUKV & 0 \\
TBEV & 0 \\
TRBV & 3 (bestätigt) \\
BATV & 0 \\
\hline Stechmücke & INKV / TAHV & 2 (bestätigt) \\
& WNV & 1 (unbestätigt) \\
\hline Sandmücke & SFNV / TOSV & 1 (bestätigt) \\
SFNV (ohne TOSV) & 1 (bestätigt) \\
& SFSV / SFTV & 1 (bestätigt) \\
SFTV (ohne SFSV) & 3 (bestätigt) \\
\hline
\end{tabular}

Das Serum mit der Nummer 618439 zeigte deutlich erhöhte MFI für zwei verschiedene Viren, eine akute Mehrfachinfektion mit INKV/TAHV und TRBV kann nicht ausgeschlossen werden. Eine zweite Probe stand zur Messung nicht zur Verfügung.

Tabelle 3.18: Ergebnisse Mehrfachinfektion, Multiplex-CBA, n=3, Fall 3 (IgM: +, IgG: -)

\begin{tabular}{lcc}
\hline Serumnummer & Grenzwert (A) & Grenzwert (B) \\
\hline 618439 & INKV/TAHV + & INKV/TAHV + \\
& TRBV & TRBV \\
\hline
\end{tabular}

\section{Fall 4: IgM positiv, IgG positiv (10 Patienten)}

Da in diesem Fall sowohl anti-arbovirale IgM-, wie auch IgG-Antikörper nachgewiesen wurden handelt es sich um Patienten mit einer arboviralen Infektion in der späten akuten Phase, in der bereits ein IgG-Antikörpertiter ausgebildet wurde. Die Ergebnisse der 10 Patientenproben wurden in Tabelle 3.19 zusammengefasst. Eine graphische Darstellung wurde dem Anhang (Abb. 6.12) hinzugefügt.

Bei 4 von 10 Patientenproben lagen die MFI Werte nur knapp unterhalb des Grenzwertes für IgM-Antikörper, bedingt durch das Fehlen einer zweiten Probe nach zwei Wochen, aber dem passenden Muster (gleiche auffällige Beadpopulation IgG und IgM) wurden diese Seren Fall 4 und nicht Fall 2 (beschreiben beide akute Infektionen) zugeordnet. 
Tabelle 3.19: Ergebnisse Einzelinfektion, Multiplex-CBA, Fall 4 (IgM: + , IgG: +)

\begin{tabular}{llc}
\hline Vektor & Virus & Grenzwert (A) und (B) \\
\hline Zecke & BHAV / PALV & 1 (bestätigt) \\
ERVEV & 1 (bestätigt) \\
EYAV & 1 (bestätigt) \\
UUKV & 0 \\
TBEV & 1 (bestätigt) \\
TRBV & 0 \\
\hline Stechmücke & BATV & 0 \\
INKV / TAHV & 1 (bestätigt) \\
WNV & 0 \\
\hline Sandmücke & SFNV / TOSV & 0 \\
TOSV (ohne SFNV) & 2 (bestätigt) \\
& SFSV / SFTV & 1 (bestätigt) \\
& SFTV (ohne SFSV) & 2 (bestätigt) \\
\hline
\end{tabular}

Das Serum mit der Nummer 555627 zeigte neben der akuten ERVEV-Infektion zusätzlich einen Hinweis auf eine bereits zurückliegende EYAV-Infektion.

Das Serum mit der Nummer 635188 zeigte neben der akuten TOSV-Infektion zusätzlich einen Hinweis auf eine bereits zurückliegende TRBV- und EYAV-Infektion.

\subsubsection{Bestätigung der Multiplex-CBA Ergebnisse durch Doppelproben}

Bei sechs Patienten erfolgte eine weitere Probenabnahme innerhalb von zwei Wochen. Durch die erste Probe ergab sich der Verdacht auf zwei akute arbovirale Infektionen, eine zurïckliegende arbovirale Infektion und drei Patienten waren Multiplex-CBA unauffällig. Bei allen sechs Patienten wurde durch die zweite Probe der Verdacht bestätigt. Die Ergebnisse wurden in Tabelle 6.9 und Tabelle 6.10 dem Anhang hinzugefügt. Eine graphische Darstellung aller Patientenseren (Fall 2 in Abb. 6.9 und Fall 4 in Abb. 6.12) wurde dem Anhang hinzugefügt. Die Patienten mit zwei zur CBA-Messung zur Verfügung stehenden Proben wurden mit * (1. Probe) und * (2. Probe) gekennzeichnet.

In Abb. 3.14 und Abb. 3.15 wurden als Beispiel eine akute arbovirale SFNV/SFTVInfektion und eine zurückliegende SFNV/TOSV-Infektion dargestellt. Jeweils mehrfach getestet auf IgM- und IgG- Antikörper. 

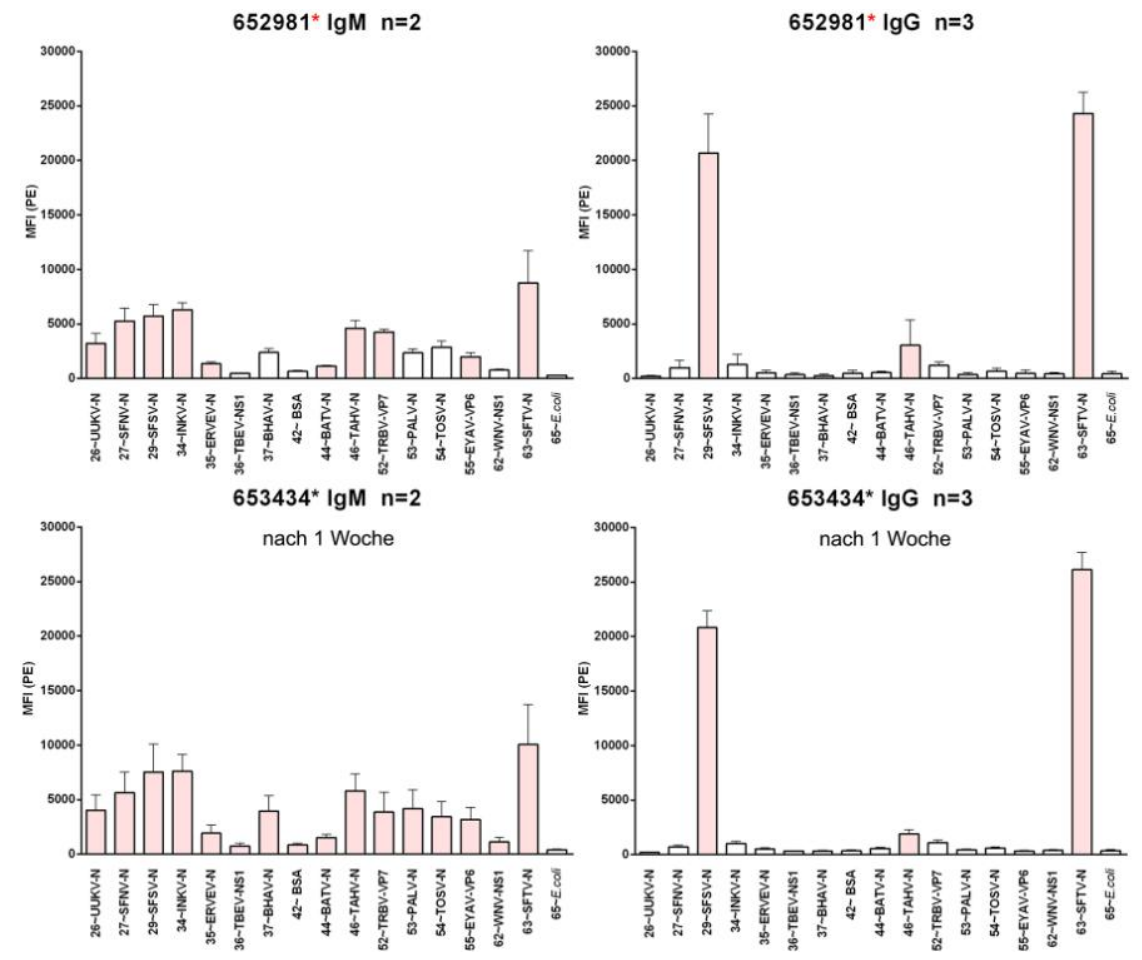

Abb. 3.14: Gesicherte akute SFSV/SFTV-Infektion (Multiplex-CBA). Dargestellt sind die MFI jeder gekoppelten Beadpopulation. Links die IgM-, rechts die IgG-Ergebnisse, oben die erste Patientenprobe, unten die zweite Patientenprobe (Software: GraphPad Prism 6).
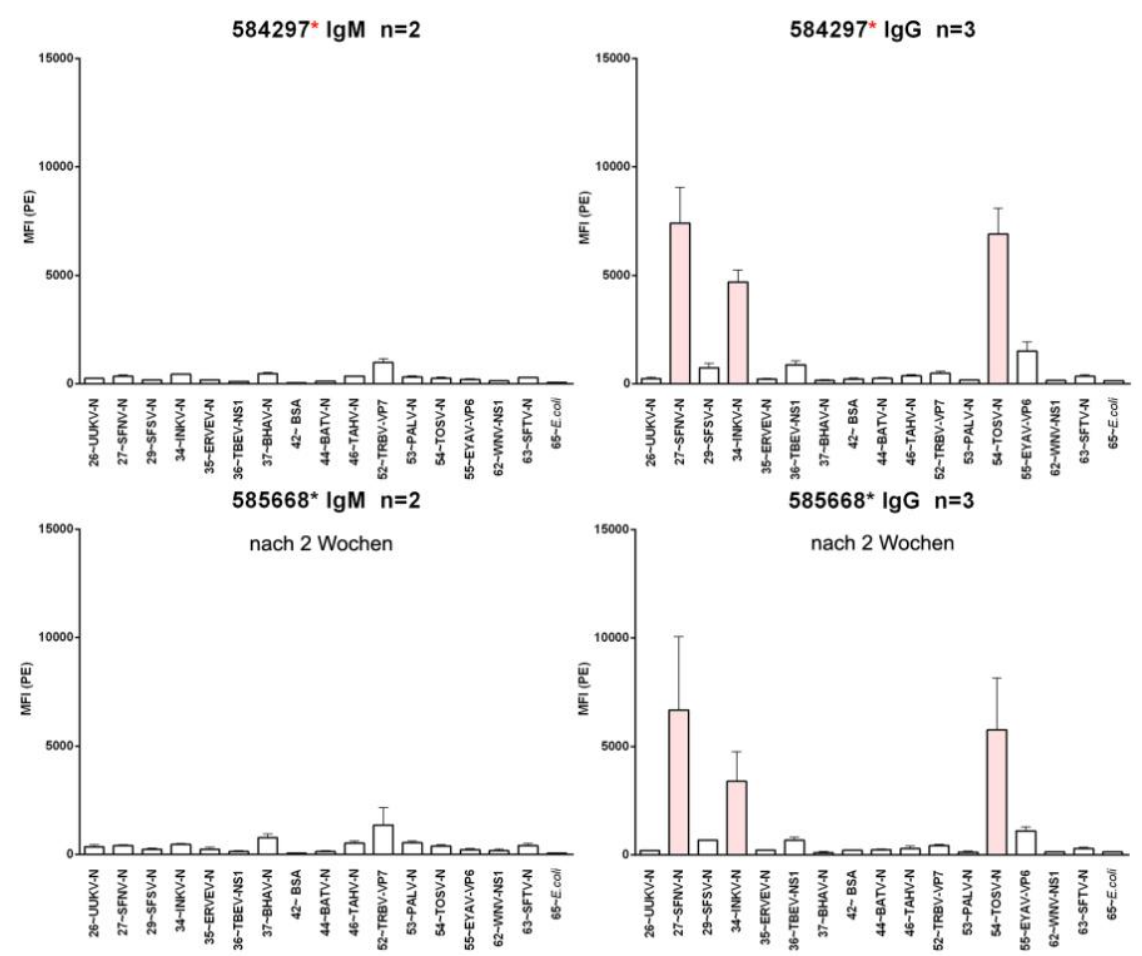

Abb. 3.15: Gesicherte zurückliegende SFNV/TOSV-Infektion, Verdacht auf Mehrfachinfektion mit INKV + evtl. EYAV (Multiplex-CBA). Dargestellt sind die MFI jeder gekoppelten Beadpopulation. Links die IgM-, rechts die IgG- Ergebnisse, oben die erste Patientenprobe, unten die zweite Patientenprobe (Software: GraphPadPrism6). 


\subsubsection{Zusammenfassung Multiplex-CBA und IFT-Bestätigung}

Alle Seren der 111 Patienten wurden im Multiplex-CBA getestet und den Fällen 1 - 4 zugeordnet. Eine graphische Darstellung jedes Serums Fall 2 - 4 (zurückliegende und akute Infektionen) getestet gegen anti-arbovirale IgM-Antikörper und IgG-Antikörper wurde dem Anhang (siehe Kap. 6.6.6 - 6.6.8) hinzugefügt. Alle durch Mehrfachmessung bestätigten Ergebnisse wurden in Tabelle 3.21 und Tabelle 3.22 zusammengefasst. Zusätzlich wurden alle IgG auffälligen Seren mit dem in Kap. 2.2.5.1 bereits beschriebenen IFT getestet. Eine Zusammenfassung ist in Tabelle 3.20 dargestellt.

Tabelle 3.20: Ergebnisse Multiplex-CBA und IFT (IgG auffälliger Seren)

\begin{tabular}{|c|c|c|c|}
\hline Serumnr. & Fall & Multiplex-CBA (1:200) & IFT $(1: 100)$ \\
\hline 482163 & 2 & SFNV / TOSV + & SFNV,+ TOSV + \\
\hline 554005 & 2 & TRBV (+) & TRBV - \\
\hline 562900 & 2 & INKV +, TAHV - & TAHV + \\
\hline 583091 & 2 & EYAV + & EYAV + \\
\hline $584297^{*}$ & 2 & $\begin{array}{l}\text { SFNV/TOSV +, SFSV/SFTV -, } \\
\text { EYAV (+), INKV + }\end{array}$ & $\begin{array}{l}\text { SFNV }+, \text { TOSV }+, \text { SFSV }+, \text { SFTV }+ \text {, } \\
\text { EYAV }+, \text { TAHV - }\end{array}$ \\
\hline $585668^{*}$ & 2 & SFNV/TOSV +, INKV +, EYAV - & SFNV +, TOSV +, EYAV + \\
\hline 600518 & 2 & $\mathrm{EYAV}+$ & EYAV + \\
\hline 605741 & 2 & TAHV + & TAHV - \\
\hline 644558 & 2 & TAHV + & TAHV + \\
\hline 651426 & 2 & EYAV +, BHAV/PALV - & EYAV +, BHAV -, PALV - \\
\hline 653731 & 2 & INKV/TAHV +, TOSV +, EYAV(+) & TAHV +, TOSV +, EYAV + \\
\hline 120116 & 2 & SFNV/TOSV +, SFSV/SFTV + & $\mathrm{SFNV}+, \mathrm{TOSV}+, \mathrm{SFSV}+, \mathrm{SFTV}+$ \\
\hline 653039 & 3 & SFTV (+), SFSV -, EYAV - & SFTV -, SFSV -, EYAV - \\
\hline 528149 & 4 & BHAV/PALV +, SFNV +, TOSV - & BHAV +, PALV +, SFNV -, TOSV - \\
\hline 545809 & 4 & $\mathrm{SFTV}+, \mathrm{SFSV}-$ & $\mathrm{SFTV}+, \mathrm{SFSV}-$ \\
\hline 555627 & 4 & ERVEV +, EYAV (+) & $\operatorname{EYAV}(+)$ \\
\hline $578045^{*}$ & 4 & $\mathrm{EYAV}+, \mathrm{BHAV} / \mathrm{PALV}-$ & EYAV (+), BHAV -, PALV - \\
\hline $578586^{*}$ & 4 & EYAV +, BHAV/PALV - & EYAV (+), BHAV -, PALV - \\
\hline 598313 & 4 & TOSV,+ SFNV - & TOSV,+ SFNV + \\
\hline 604152 & 4 & $\mathrm{SFTV}+, \mathrm{SFS}-$ & SFTV -, SFSV - \\
\hline 608929 & 4 & INKV/TAHV +, PALV (+) & TAHV,+ BHAV $(+)$, PALV + \\
\hline 635188 & 4 & $\begin{array}{l}\text { TOSV +, SFNV (+), EYAV +, } \\
\text { TRBV +, INKV (+) }\end{array}$ & TOSV (+), SFNV +, EYA + \\
\hline 635306 & 4 & $\mathrm{TBEV}+, \mathrm{WNV}-$, INKV (+) & $\mathrm{TBEV}+, \mathrm{WNV}-$ \\
\hline $652981^{*}$ & 4 & $\begin{array}{l}\text { SFSV/SFTV }+, \text { SFNV }(+), \text { TOSV }- \text {, } \\
\text { TAHV + }\end{array}$ & $\begin{array}{l}\mathrm{SFSV}+, \mathrm{SFTV}+, \mathrm{SFNV}+, \mathrm{TOSV}+ \\
\mathrm{TAHV}+\end{array}$ \\
\hline $653434^{*}$ & 4 & SFSV/SFTV +, TAHV + & SFSV +, SFTV + \\
\hline
\end{tabular}


Nach der zusätzlichen IFT-Testung des Patientenserums mit der Nummer 1163451 (CBA nicht eindeutig) wird von einer weiteren akuten EYAV-Infektion ausgegangen.

Die IFT-Überprüfung des Serums mit der Nummer 653039, das im Multiplex-CBA nicht eindeutig und somit nicht auswertbar war, führte zum Ausschluss einer Infektion mit SFSV, SFTV und EYAV.

Die Seren mit den Nummern 528149 (akut BHAV/PALV), 608929 (akut INKV/TAHV), 635306 (akut TBEV), 652981 (akut SFSV/SFTV) zeigen eine deutlich (signifikant) erhöhte MFI für ein Virus / ein Viruspaar, eine akute Mehrfachinfektion wurde ausgeschlossen.

Tabelle 3.21: Zusammenfassung bestätigter Einzelinfektionen

\begin{tabular}{|c|c|c|c|}
\hline Vektor & Virus & $\begin{array}{c}\text { akute } \\
\text { arbovirale Infektion }\end{array}$ & $\begin{array}{l}\text { zurückliegende } \\
\text { arbovirale Infektion }\end{array}$ \\
\hline \multirow{6}{*}{ Zecke } & BHAV / PALV & $2(1,8 \%)$ & 0 \\
\hline & ERVEV & $1^{*}(0,9 \%)$ & 0 \\
\hline & EYAV & $2+1^{\circ}(2,7 \%)$ & $4^{*}(3,6 \%)$ \\
\hline & UUKV & 0 & 0 \\
\hline & TBEV & $1(0,9 \%)$ & 0 \\
\hline & TRBV & $3(2,7 \%)$ & $1(0,9 \%)$ \\
\hline \multirow[t]{3}{*}{ Stechmücke } & BATV & 0 & 0 \\
\hline & INKV / TAHV & $3(2,7 \%)$ & $3(2,7 \%)$ \\
\hline & WNV & $1^{\circ}(0,9 \%)$ & 0 \\
\hline \multirow[t]{3}{*}{ Sandmücke } & SFNV / TOSV & $3(2,7 \%)$ & $1(0,9 \%)$ \\
\hline & SFSV / SFTV & $7(6,3 \%)$ & 0 \\
\hline & SFNV/TOSV+SFSV/SF & TV & $1(0,9 \%)$ \\
\hline \multicolumn{4}{|c|}{$\begin{array}{l}\text { "Serum } 555627 \text { (akut ERVEV, Hinweis auf zurückliegende EYAV-Infektion) } \\
\text { unbestätigt, nur } 1 \text { Messungen CBA positiv und nicht IFT bestätigt }\end{array}$} \\
\hline Serumnr. & Status & \multicolumn{2}{|l|}{ Mehrfachinfektion Virus } \\
\hline 618439 & akute Infektion & \multicolumn{2}{|l|}{ INKV/TAHV + TRBV } \\
\hline 584297 & zurückliegende Infektion & \multicolumn{2}{|c|}{ SFNV/TOSV + INKV (ohne TAHV) + EYAV } \\
\hline 653731 & zurückliegende Infektion & \multicolumn{2}{|c|}{ INKV/TAHV + TOSV(ohne SFNV) + EYAV } \\
\hline 635188 & $\begin{array}{l}\text { akute Infektion und } \\
\text { zurückliegende Infektion }\end{array}$ & \multicolumn{2}{|l|}{ TRBV + EYAV } \\
\hline
\end{tabular}




\section{Diskussion}

Neben dem TBE-Virus steht eine Reihe von seltenen europäischen Arboviren im Verdacht aseptische Meningitiden oder Enzephalitiden zu verursachen. Sie wären somit bei diesen Erkrankungen für einen Teil der in 50\% der Fälle unklar bleibenden Ätiologie verantwortlich. Um hier eine innovative Problemlösung anzubieten wurde in dieser Arbeit das Ziel verfolgt ein serologisches Multiparameterdiagnostiksystem zum Nachweis von IgM-, und IgG-Antikörpern für diese vernachlässigten Viren zu entwickeln. Für den Aufbau eines solchen Diagnosesystems wurde ein Multiplex-CBA (,Cytometric Bead Array") auf Basis von antigengekoppelten Mikrokugeln (Beads) etabliert. Dieses Verfahren erlaubt erstmals einen simultanen Antikörpernachweis gegen 15 verschiedene europäische humanpathogene Arboviren. Das Testverfahren kann zum Nachweis von IgM- und IgG-Antikörpern verwendet werden.

Die Routinediagnostik erfolgte bislang üblicherweise durch ELISA- bzw. IFT- Techniken, wie in Kap.1.2.1 beschrieben, die jedoch die meisten dieser europäischen Arboviren gar nicht abbilden. Diese zum Nachweis von anti-viralen Antikörpern (IgM und $\mathrm{IgG}$ ) verwendeten Methoden benötigen ein relativ großes Serumvolumen. Sowohl ELISA wie auch IFT eignen sich eher für Einzelanalysen, bei denen pro Testansatz in der Regel der Nachweis von Antikörpern gegen einen Erreger untersucht wird. Entsprechend zeitintensiv und aufwendig gestaltet sich die Überprüfung eines Serums auf ein ganzes Spektrum verschiedener Antikörper gegen unterschiedliche Viren (Khan et al., 2005).

Die Entwicklung eines geeigneten Testsystems, das schnell Ergebnisse liefert, einfach handhabbar und verlässlich ist, nur ein geringes Probenvolumen benötigt und den simultanen Nachweis mehrerer anti-arboviraler Antikörper zulässt ist zielführend, schnell durchführbar und kostensparend. Aussagen über Vorkommen und Verbreitung von Arboviren in Europa wären mit einem Multiplex-Test ebenso möglich, wie die Datenerhebung auf den Gebieten der Diagnostik, Epidemiologie und Pathogenese arboviraler Infektionen. Auch ließe sich so künftig eine datenbasierte Risikobewertung bezüglich des Auftretens arboviraler ZNS-Erkrankungen im öffentlichen Gesundheitswesen durchführen. 
In dieser Arbeit wurde ein Multiplex-CBA gegen die in Tabelle 1.1 aufgelisteten europäischen Arboviren entwickelt, der Antikörper gegen die viralen Antigene Nukleoprotein N der Bunyaviren, Nichtstrukturprotein NS1 der Flaviviren und das Oberflächenprotein VP6 bzw. VP7 der Reoviren detektieren kann.

Die Bunyaviren (siehe Kap. 1.1.4.2) bestehen aus drei Genomsegmenten (S, M und L), die von einer Hüllmembran mit eingelagerten Glykoproteinen umgeben sind (siehe Abb. 1.5). Die drei einzelsträngigen RNA-Segmente sind mit einer Vielzahl von Nukleokapsidproteinen (N-Proteinen) komplexiert und bilden so die helikalen Ribonukleokapside. Diese Ummantelung der RNA-Segmente schützt die virale RNA vor Degradierung. Das N-Protein ist demnach das am häufigsten vorkommende virale Produkt in den Viruspartikeln der Bunyaviren, bzw. ihrer infizierten Zellen. Ferner wird vermutet, dass das N-Protein mit den L, Gn und Gc Proteinen interagiert und so eine Rolle bei der Replikation einnimmt. Aufgrund der hohen Anzahl der N-Proteine wird davon ausgegangen, dass nach der Infektion Antikörper gegen das N-Protein gebildet werden (Fields, Knipe \& Howley, 2007). Grundlegend gilt, dass häufig virale Proteine, die nicht Ziel der neutralisierenden humoralen Immunantwort sind, eine hohe Antigenität aufweisen. Für die serologische Detektion von Antikörpern gegen Bunyaviren kommt das N-Protein als virales Antigen demnach in Frage. Gezeigt wurde dies mitunter für TOSVN (Schwarz, Gilch \& Schatzl, 1998). Im Rahmen dieser Arbeit wurde das N-Protein der Viren ERVEV, BHAV, PALV, UUKV, TAHV, BATV, INKV, SFNV, SFSV, SFTV und TOSV rekombinant hergestellt.

Bisher entwickelte serologische Testverfahren für Flaviviren hingegen basieren größtenteils auf dem Nachweis von Antikörpern gegen das Glykoprotein E der Virushülle. Wie schon in Kap. 1.1.4.3 beschrieben besteht das Genom der Flaviviren aus einem linearen, einzelsträngigen RNA-Segment, das ein Polyprotein kodiert, welches durch wirtseigene Proteasen prozessiert wird. Teile dieses Polyproteins kodieren für die Strukturproteine $\mathrm{C}$ (englisch: core), M (englisch: membrane) und E (englisch: envelope), sowie die Nichtstrukturproteine NS1, NS2A, NS2B, NS3, NS4A, NS4B und NS5. Durch die antigenen Verwandtschaften der einzelnen Epitope des E- Proteins der Flaviviren konnten hohe Kreuzreaktivitäten bei der Testung verschiedener Seren beobachtet werden (Crill, Trainor 
\& Chang, 2007; Kimurakuroda \& Yasui, 1986; Liu et al., 2008). Um diese Kreuzreaktionen zu vermeiden wurde im Rahmen dieser Arbeit versucht das NS1-Protein und das C-Protein rekombinant $\mathrm{zu}$ exprimieren. In früheren Arbeiten konnten die antigenen Eigenschaften des NS1-Proteins und des C-Proteins bereits gezeigt werden (Alcon et al., 2002; PupoAntunez et al., 1997). Antikörper gegen das NS1-Protein von TBEV sind bereits acht Tage nach Infektion nachweisbar (Matveeva et al., 1995), demnach wird eine frühe Antikörperantwort gegen das NS1-Protein induziert (Bugrysheva et al., 2001).

Die viralen Gensequenzen von TBEV-C, TBEV-NS1, WNV-C und WNV-NS1 konnten mittels PCR amplifiziert und erfolgreich in den Donorvektor pENTRY-IBA51 bzw. den Expressionsvektor pASG-IBA ligiert werden. Die Expression des C-Proteins von TBEV und WNV war nicht erfolgreich, die Expression des NS1-Proteins von TBEV und WNV hingegen gelang. Bei dem NS1-Protein handelt es sich um ein Protein mit bislang unklarer Funktion (Brinton, 2002), das während der akuten Phase aus den infizierten Zellen durch Sekretion ins Serum abgegeben wird (Macdonald et al., 2005). NS1-Proteine konnten im Serum nach drei bis acht Tagen nach Infektion nachgewiesen werden, IgMAntikörper gegen NS1-Protein bereits fünf Tage nach Infektion. Ferner konnte gezeigt werden, dass das NS1-Protein in mehreren Formen vorliegen kann, membrangebunden wahrscheinlich als Dimer, sezerniert als Hexamer. Es wird vermutet, dass das NS1Protein des Gelbfiebervirus am Replikationszyklus mitwirkt (Lindenbach \& Rice, 1997). Dem NS1-Protein von West Nil Virus konnte eine essentielle Co-Faktor Rolle in der Regulation des Replikationskomplexes und der viralen RNA-Synthese zugeordnet werden (Youn et al., 2013). Nach (Youn et al., 2012) ist das NS1-Protein von WNV nach Bindung mit NS4B-Protein an der frühen viralen RNA-Replikation beteiligt. Weitere Studien lassen vermuten, dass das NS1-Protein am intrazellulären Transport der viralen Strukturproteine und an der Virusfreisetzung beteiligt ist, die Funktionen der Nichtstrukturproteine konnten bislang nicht vollständig aufgeklärt werden (Brinton, 2014). Je Flavivirus wurde eine Beadpopulation (jeweils mit NS1-Protein gekoppelt) im MultiplexCBA eingesetzt. Alle Daten die das C-Protein betreffen wurden nicht weiter in dieser Arbeit erwähnt. 
Bei den Orbiviren und Coltiviren (Familie Reoviridae) (siehe Kap. 1.1.4.1) handelt es sich um nicht-umhüllte Viruspartikel, die aus drei Kapsidschichten aufgebaut sind, dem inneren, mittleren und äußeren Kapsid. Eine cryoelektronische Mikroskopie (CryoEM) des Broadhaven Virus (BRDV), ein wie Tribec-Virus von Zecken übertragenes Orbivirus (Gorman, 1983), gab bereits 1997 Aufschluss über die dreidimensionale Anordnung der Proteine der einzelnen Kapsidschichten (Schoehn et al., 1997). Es konnte gezeigt werden, dass die äußere Kapsidschicht aus zwei Proteinen (VP2 und VP5) und die mittlere Kapsidschicht aus VP7-Proteinen aufgebaut ist. Hierbei sind die Proteine des äußeren Kapsids so angeordnet, dass sie als Hülle um die VP7-Proteine kreisförmig herum liegen (Abb. 1.4).

Im Falle von Bluetongue Virus (BTV), dem bislang am besten untersuchten Orbivirus, konnte gezeigt werden, dass gereinigtes VP2-Protein eine Antikörperreaktion auslösen kann, die das Virus neutralisiert, die Bindung an Zellen verhindert und Schafe gegen eine BTV-Infektion schützt (Inumaru \& Roy, 1987). Untersuchungen an Broadhaven Virus zeigten jedoch, dass hier VP5 die Haupt-Serotyp-Determinante ist (Moss, Ayres \& Nuttall, 1987), vermutlich da VP5 auf der Oberfläche des äußeren Kapsids von BRDV besser für Antikörper zugänglich ist als bei BTV.

Die Expression von VP2 und VP5-Protein des TRBV war nicht erfolgreich, daher wurde auf das VP7-Protein zurückgegriffen. Die viralen Gensequenzen von VP2 und VP5 konnten mittels PCR amplifiziert und erfolgreich in den Donorvektor pENTRY-IBA51 ligiert werden, der Transfer der Gensequenzen in den Expressionsvektor pASG-IBA5 führte nach mehreren Versuchen zu keinem Expressionsplasmid mit vollständiger viraler Gensequenz. Die Sequenzierung von TRBV-VP2-pASG-IBA5 zeigte, dass nur 1130bp der ursprünglichen 1659bp (ohne Start- und Stopp-Kodon) in den Expressionsvektor transferiert wurden. Vermutlich ist die rekombinante Schnittstelle des Vektors der VP2Sequenz so ähnlich, dass die hinteren 529bp abgeschnitten und nicht mit in das Plasmid integriert werden. Die Sequenzierung von TRBV-VP5-pASG-IBA5 zeigte ausschließlich Vektorsequenzen, das Insert ging beim Transfer vollständig verloren. Eine Expression der Proteine war nicht möglich, die Teilsequenz von VP2 führte $\mathrm{zu}$ keiner messbaren Expression. 
Da allein die Expression des VP7-Proteins für TRBV erfolgreich verlief, wurden alle Daten die das VP2-Protein und das VP5-Protein betreffen nicht weiter in dieser Arbeit berücksichtigt. Das VP7-Protein ist auf Grund der Anordnung der äußeren Kapsidschicht, zumindest im Falle von BRDV, ebenfalls für Antikörper zugänglich (Schoehn et al., 1997) und lässt antigene Eigenschaften für VP7 von TRBV erwarten. Ferner existiert für das verwandte BTV ein VP7-basierter kompetitiver ELISA (Wang, 1992).

Für das Coltivirus EYAV wurde das VP6-Protein (auf Segment 6 lokalisiert) exprimiert. In einem von Jaafar et al. entwickelten ELISA zur Detektion von IgG-Antikörpern gegen das EYAV, in dem die Proteine VP6, VP7 und VP12 verglichen wurden, zeigte das VP6 die stärkste Reaktivität mit einer Spezifität von 100\% (kein falsch-positives Ergebnis bei der Untersuchung von 340 Seren französischer Blutspender) (Mohd Jaafar et al., 2004).

Die viralen Gensequenzen ERVEV-N, BHAV-N, PALV-N, UUKV-N, TAHV-N, BATV-N, INKV-N, SFNV-N, SFSV-N, SFTV-N, TOSV-N (Bunyaviren), TBEV-NS1, WNV-NS1 (Flaviviren), EYAV-VP6, TRBV-VP7 (Reoviren) konnten mittels PCR amplifiziert (siehe Agarosegel Abb. 3.1) und erfolgreich in den Donorvektor pENTRYIBA51 bzw. den Expressionsvektor pASG-IBA5, mit N-terminal gelegener Strep-tag ${ }^{\circledR}$ II Affinitätssequenz (Terpe, 2003), ligiert werden.

Durch die Sequenzanalysen zeigte sich in zwei Konstrukten jeweils eine Punktmutation im Vergleich zu der Originalsequenz (siehe Kap. 3.2.2), die unter diesen Umständen exprimierten Proteine zeigten trotz Mutation antigene Eigenschaften (siehe Kap. 3.5.4) und wurden für die Multiplex-CBA-Entwicklung verwendet.

Für die Expression der arboviralen Proteine wurde ein in vivo Expressions-System in E. coli BL21 (DE3) Zellen gewählt in Verbindung mit einem Anhydrotetracyclin induzierbaren tet-Promotor (Terpe, 2006), unter Verwendung des Expressionsvektors pASG-IBA.

Vorversuche mit dem pPSG-IBA Vektor (IPTG-induzierbare Proteinexpression durch T7Promotor) zeigten für die exemplarisch verwendeten TRBV-VP7 und UUKV-N eine sogenannte nicht induzierte Spontanexpression. Bereits vor Induktion durch IPTGZugabe wurden die Proteine exprimiert, die Zellen zeigten ein verlangsamtes Wachstum 
der Hauptkultur bis zur OD = 0,5 (optimale Wachstumsphase zur Induktion). Verantwortlich dafür könnten die möglicherweise für die Zellen leicht toxischen viralen Proteine sein.

Die Spontanexpression bereits in der Vorkultur noch vor IPTG-Induktion verbunden mit einer zeitlichen Verlängerung der Zellwachstumsphase und einer verringerten Expressionseffizienz wurde bereits mehrmals bei Proteinexpressionen mit verschiedenen T7 RNA Polymerase/ T7 Promotor basierten Expressionssystemen beschrieben (Mertens, Remaut \& Fiers, 1995). Da jedes rekombinante Protein anders auf seine Umgebung einwirken kann, ist eine Voraussage der Expressionseffizienz nie möglich und muss individuell ausgetestet werden. In kleinem Maßstab, um einen Überblick zu erhalten, eignen sich in vitro Expressionssysteme. Für größere Proteinmengen eignen sich, nicht zuletzt auch aus Kostengründen, in vivo Expressionssysteme, in denen Wirtszellen und Expressionsvektoren aufeinander abgestimmt werden können (z.B. StarGate ${ }^{\circledR}$-System, IBA).

Vergleichsexperimente von Proteinexpressionen mit pPSG-IBA und pASG-IBA Expressionsvektoren zeigten eine deutlich höhere Proteinkonzentration für die Proteine der Arboviren TRBV und UUKV nach Expressionsversuchen mit dem pASG-IBA Vektor. Die Versuchsdauer auf Grund der Wachstumsgeschwindigkeit der Vorkultur war bei Verwendung des pASG-IBA Vektors kürzer. Die pASG Vektoren zeichnen sich durch ihre dichte Expression (keine Proteinexpression vor Induktion durch Anhydrotetracyclin) aus, laut Hersteller wird dieser Vektor bei der Expression vermeintlich toxischer Proteine empfohlen. Die Vorversuche wurden in dieser Arbeit nicht dargestellt, sie decken sich mit den Angaben zu den Vektoren des StarGate ${ }^{\circledR}$ - Handbuches des Herstellers (www.ibalifesciences.com/technical-support.html) und den Expressionstests von Skerra mit pASK Expressionsvektor, einem dem pASG sehr ähnlichen Vektor (Skerra, 1994).

Wie in Kap. 2.2.4.6 beschrieben, wurde durch Verwendung der pASG-IBA5 Vektoren den rekombinanten viralen Proteinen bei der Expression N-terminal eine Strep-tag ${ }^{\circledR} \mathrm{II}$ Affinitätssequenz angehängt. Dieser acht Aminosäuren lange Strep-tag ${ }^{\circledR}$ II (Trp-Ser-HisPro-Gln-Phe-Glu-Lys) beeinflusst dabei weder die Proteinstruktur noch die biologische 
Aktivität des Proteins als Antigen (Schmidt \& Skerra, 2007). Der spezifische Nachweis im Western Blot mit Anti-Strep-tag ${ }^{\circledR}$ II-HRP durch ECL-Reaktion (Abb. 3.7) zeigte, dass alle Proteine erfolgreich exprimiert und gereinigt durch Säulenchromatographie vorlagen. Die unlöslichen Proteine ERVEV-N, EYAV-VP6, TRBV-VP7, TBEV-NS1 und WNV-NS1 (siehe Tabelle 3.4 [S]) wurden zuvor durch Solubilisierung in ihre lösliche Form überführt.

In der Literatur wurde beschrieben, dass eine Solubilisierung mit 1,5\% Sarkosyl zwar den größten Teil ungelöster Proteine in eine lösliche Form überführt, dass dadurch aber ihre Aktivität stark herabgesetzt werden kann (Zhuo et al., 2005). Eine Solubilisierung mit 0,3\% Sarkosyl hingegen wird als ausreichend für die Solubilisierung von funktionstüchtigen Proteinen beschrieben (R.R. Burgess, 1996). Für die Solubilisierung wurde in dieser Arbeit in einer Versuchsreihe eine Sarkosyl-Konzentration von 0,4\% als ideal ermittelt und verwendet. Alle unlöslichen Proteine konnten solubilisiert werden und zeigten nach Kopplung an Beads antigene Eigenschaften (siehe Sensitivität).

Für die Kopplung von 1,25 x $10^{6}$ Beads wird durch den Hersteller (BioRad) eine Proteinkonzentration von 5-12 $\mu$ g Protein empfohlen. Um diese Proteinmenge zu erhalten, wurden die rekombinanten Proteine in vivo in 100ml E. coli BL21 (DE3) Kulturen exprimiert.

Die Kopplung der 15 arboviralen Proteine an unterschiedliche farbkodierte Beads konnte nach Inkubation mit Strep-Tactin-R-PE durch Fluoreszenzdetektion (MAGPIX $^{\mathrm{TM}}$ System) nachgewiesen werden. Das mit dem Fluoreszenzfarbstoff Phycoerythrin markierte Strep-Tactin bindet dabei an die Affinitätssequenz (Strep-tag ${ }^{\circledR}$ II) des rekombinanten Proteins. Als Negativkontrolle wurden Beads verwendet, die zuvor mit BSA bzw. E. coli Proteinen gekoppelt wurden (siehe Kap. 3.5.3.1). Pro Messung wurden mind. 100 Beads am MAGPIX ${ }^{\mathrm{TM}}$-System gemessen und daraus die mediane Fluoreszenzintensität (MFI) berechnet. Abb. 3.10 zeigt die graphische Auftragung des Kopplungssignals und die Ergebnisse des E. coli Protein Nachweises je Beadpopulation. Ein signifikant erhöhtes Fluoreszenzsignal der Kopplungsmessungen der Beadpopulationen mit arboviralen Proteinen (2000-fach bis 20000-fach höher) im Vergleich zu den beiden internen Negativkontrollen bestätigen die Kopplungen für alle Proteinbeads. 
Die ebenfalls in Abb. 3.10 dargestellten Ergebnisse der E. coli Protein Nachweismessung bestätigen die Vermutung, dass nach Säulenchromatographie (siehe Kap. 3.3.2) die Eluate der rekombinanten Proteine nicht vollständig von allen (als Nebenprodukt der Expression entstandenen) E. coli Proteinen gereinigt vorlagen. Der in Abb. 3.9 dargestellte Western Blot mit spezifischem Nachweis durch Anti-E.coli Antikörper bekräftigt diesen Verdacht. Bei späteren Expressionen wie BHAV und PALV wurden die Proben doppelt (nach vorheriger Dialyse) über die zuvor regenerierte Säule gegeben.

Es muss demnach davon ausgegangen werden, dass eine geringe Menge verbliebener E. coli Proteine der Expressionskultur ebenfalls an die Beadoberfläche der Proteinbeads gekoppelt wurde. Seren mit intrinsisch hohem E. coli-Antikörpertiter könnten demnach zu einem Fluoreszenzsignal führen, obwohl keine anti-viralen Antikörper im Serum vorhanden sind.

Bei der Annahme, dass: (i) bei einer Kopplung von 10 $\mu$ g Protein alle Bindungsstellen der Beads besetzt werden, (ii) alle arboviralen Oberflächenproteine nicht mit anti-E. coli Antikörpern kreuzreagieren (keine Reaktion der rekombinanten Proteine im WesternBlot/Chemilumineszenz auf anti-E. coli Antikörper Abb. 3.9, nur spezifische E. coliProteinbande) und (iii) bei der Kopplung der E. coli-Kontrolle (BP-65) 100\% E. coli Proteine an die Beadpopulation gekoppelt wurden, kann man davon ausgehen, dass der Wert (MFI) von 44624 der CBA-Messung (Tabelle 3.8) als Absolutwert (100\%) interpretiert werden kann.

Daraus ergibt sich, dass bei 11 von 15 Kopplungen mind. $75 \%$ der Bindungsstellen mit arboviralen Proteinen und maximal 25\% der Bindungsstellen mit E. coli Proteinen gekoppelt vorlagen (UUKV 98\%, PALV 98\%, BHAV 97\%, TOSV 95\%, SFTV 91\%, INKV 89\%, SFNV 81\%, TAHV 80\%, SFSV 79\%, ERVEV 75\%, TRBV 75\%).

Ferner wurden bei 3 Kopplungen $60-70 \%$ der Bindungsstellen mit arboviralen Proteinen und 30-40\% mit E. coli Protein besetzt (TBEV 69\%, EYAV 66\%, BATV 62\%).

Lediglich bei 1 Kopplung (WNV) lag das Verhältnis arboviraler Proteine zu E. coli Proteinen bei $51 \%$ zu $49 \%$.

Die Kopplungsergebnisse durch Tag-Nachweis eignen sich nicht für derartige Rückschlüsse, da zum einen keine zu 100\% mit Strep-tag ${ }^{\circledR}$ II gekoppelte Beadpopulation als 
Absolutwert vorliegt und zum anderen jedes Protein durch Faltung und Größe eine unterschiedliche Zugänglichkeit des Strep-tag ${ }^{\circledR}$ IIs aufweist. Dennoch beweisen die gemessenen Fluoreszenzsignale nach Strep-Tactin-R-PE Inkubation (Tabelle 3.6), dass die Kopplung jeder Beadpopulation mit entsprechendem Strep-tag ${ }^{\circledR}$ II tragenden arboviralen Proteinen erfolgreich stattgefunden hat (siehe Kopplung).

Um falsch positive Signale in den Patientenseren durch Antikörper gegen E. coli auszuschließen, wurde eine Präadsorption des zu untersuchenden Materials durchgeführt (siehe Kap.2.2.5.2.3 und Kap.3.5.3.2), um die in den Patientenproben enthaltenen E. coli-Antikörper noch vor Kontakt mit den Proteinbeads abzufangen. Wie in Abb. 3.11 gezeigt, senkt eine Präadsorption das E. coli Signal auf ein zu vernachlässigendes Maß.

Auch wenn eine 1:10 Verdünnung des E. coli Lysats das E. coli Signal noch stärker reduziert hätte (siehe Abb. 3.11), wurde die Verdünnung so hoch wie möglich gewählt, um die Ursprünglichkeit des Probenmaterials weitestgehend $\mathrm{zu}$ wahren. Es zeigte sich, dass eine 1:60 Verdünnung das E. coli Signal auf ein zu vernachlässigendes Maß reduzierte. Solange der Wert unterhalb des E. coli spezifischen Grenzwertes (siehe Kap.3.5.6) liegt, ist ein falsch positives Ergebnis durch E. coli-Antikörper auszuschließen.

Die zur Verfügung stehenden Positivseren wurden zur Sensitivitätsmessung (siehe Kap.3.5.4) verwendet. Wie in Abb. 3.12 A und B zusammengefasst und in Abb. 6.4 einzeln dargestellt, konnten IgG-Antikörper gegen alle 15 Arboviren eindeutig nachgewiesen werden. Die medianen Fluoreszenzintensitäten (MFI) sind je Versuch signifikant höher als ihre vergleichbare Negativkontrolle. Es zeigten sich zwei Typen von Kurvenverläufen bei der Auftragung der MFI gegen die verschiedenen Verdünnungen (1:8 bis zu 1:65536): sigmoider Kurvenverlauf bei hoher Sensitivität (Typ I), linearer Kurvenverlauf bei geringerer Sensitivität (Typ II), was zum einen durch unterschiedlich fest bindende Antikörper an die Proteinbeads und zum anderen durch unterschiedliche anti-arbovirale Antikörpertiter der Positivseren zu erklären ist.

Der Kurvenverlauf von SFNV-N und TOSV-N (Typ II) lässt sich durch das verwendete humane Positivserum erklären, welches schon im IFT mit einer Nachweisgrenze von 1:80 auf ein nicht hochtitriges Serum hindeutet. Ein polyklonales Mausserum stand leider nicht 
zur Verfügung, würde aber wahrscheinlich durch einen höheren Antikörpertiter zu einer Typ I Sensitivität mit sigmoidem Kurvenverlauf führen.

Bei der Kopplung der Proteine BATV-N und ERVEV-N (Typ II) betrug der Anteil der gekoppelten E. coli Proteine ca. 38\% und 25\%. Eine doppelte Reinigung der Proteine über Strep-Tactin Säulen könnte zu einer höheren Reinheit der gekoppelten viralen Proteine und einer damit verbundenen höheren Nachweissensitivität im CBA führen. Im Rahmen dieser Arbeit wurde eine solche Doppelreinigung für BATV-N und ERVEV-N nicht durchgeführt.

Bei TRBV-VP7 werden zum einen die $25 \%$ durch E. coli Protein blockierten BeadBindungsstellen ein Grund für die mit allen anderen Proteinbeads vergleichbar geringste Sensitivität sein. Ferner wird die bereits erwähnte strukturelle Lokalisation des VP7 auf der Virusoberfläche (versenkt und möglicherweise von VP2 und VP5 überdeckt) und die damit verbundene geringere Zugänglichkeit für Antikörper ein weiterer Grund für die beobachtete geringere Sensitivität sein. Da die Expression von VP2 und VP5 im Rahmen dieser Arbeit nicht zu den zur Kopplung notwendigen Proteinmengen geführt hat, muss die Expression dieser Proteine optimiert werden. Zur Verbesserung der Sensitivität zum Nachweis von TRBV wird die zusätzliche Aufnahme von VP2 und VP5 in den MultiplexTest empfohlen. Die Sensitivität des VP7 reichte dennoch aus, um bei einer 1:200 Verdünnung von Patientenseren einen signifikanten Unterschied der MFI zum Negativserum zu erkennen und so Rückschlüsse auf vorliegende TRBV-Infektionen zu erhalten.

WNV-NS1 zeigt, obwohl wahrscheinlich nur die Hälfte der Bead-Bindungsstellen durch virales NS1 Protein gekoppelt wurde, eine signifikant erhöhte MFI im Vergleich zur Negativkontrolle. Eine doppelte Reinigung über Strep-Tactin Säulen würde zu einer höheren Sensitivität führen. Ein weiterer Ansatzpunkt zur Verbesserung der Sensitivität wäre statt der Kopplung der löslichen Monomere des NS1-Proteins die Kopplung der bereits erwähnten hexameren Form des NS1-Proteins.

Für die Typ I Proteinbeads zeigte sich eine hohe Sensitivität (Abb. 3.12 A), der gemeinsame dynamische Bereich lag zwischen den Serenverdünnungen von 1:128 und 
1:2048. Für die bereits erwähnten Typ II Proteinbeads zeigte sich eine geringere Sensitivität (Abb. 3.12 B), der gemeinsame dynamische Bereich lag zwischen den Serenverdünnungen von 1:16 und 1:256.

Die Ergebnisse zeigen, dass es möglich ist durch das entwickelte CBA-System Antikörper gegen Arboviren in Positivseren nachzuweisen. Als optimale Serumverdünnung zur Multiplex-CBA Entwicklung, bei der alle Proteinbeads signifikant erhöhte Werte im Vergleich zu ihrer Negativkontrolle zeigen, wurde eine Serenverdünnung von 1:200 standardmäßig festgelegt.

Höher konzentrierte Patientenseren mit hohem Antikörpertiter könnten bei den Proteinbeads mit hoher Sensitivität dazu führen, dass der Multiplex-CBA nicht für alle Proteinbeads in seinem dynamischen Bereich (siehe Kap.3.5.4) liegt und sich ggf. die vorhandenen Antikörper gegenseitig behindern. Stärker verdünnte Seren hingegen könnten bei den Proteinbeads mit etwas geringerer Sensitivität zu falsch negativen Ergebnissen führen.

Im Vergleich der Nachweisgrenze der Positivseren, die mittels CBA und IFT ermittelt wurden (siehe Tabelle 3.11) zeigte sich, dass der entwickelte CBA mindestens die doppelte Sensitivität im Vergleich zum IFT aufweist, teilweise sogar 100-fach sensitiver ist (siehe Tabelle 3.11 TAHV).

Der Kreuzreaktivitätstest des CBA als Multiplex-Test (siehe Kap. 3.5.5) ermöglicht Aussagen zur Spezifität der 15 einzelnen viralen Proteinbeads.

Zum Vergleich wurde eine phylogenetische Analyse der 15 arboviralen Proteinsequenzen durch ClustalW Multiple Sequence Alignment (Lasergene ${ }^{\mathrm{TM}}$ : DNASTAR Inc.) durchgeführt. Die Homologien der Proteine zueinander sind in Abb. 4.1 dargestellt und spiegeln im Wesentlichen die im Multiplex-CBA gezeigten Kreuzreaktivitäten (BHAV-N/PALV-N，INKV-N/TAHV-N，SFNV-N/TOSV-N，SFSV-N/SFTV-N und WNV-NS1/TBEV-NS1) wieder. 
Identität [\%]

\begin{tabular}{|c|c|c|c|c|c|c|c|c|c|c|c|c|c|c|c|c|c|}
\hline & 1 & 2 & 3 & 4 & 5 & 6 & 7 & 8 & 9 & 10 & 11 & 12 & 13 & 14 & 15 & & \\
\hline 1 & & 10.2 & 9.4 & 6.9 & 42.9 & 10.6 & 12.2 & 11.1 & 11.1 & 42.9 & 9.4 & 13.1 & 6.5 & 13.7 & 9.0 & 1 & BATV-N \\
\hline 2 & 504.0 & & 11.4 & 10.9 & 9.7 & 97.6 & 32.1 & 34.6 & 35.4 & 9.3 & 8.9 & 32.1 & 10.6 & 26.1 & 5.3 & 2 & BHAV-N \\
\hline 3 & 553.0 & 442.0 & & 8.3 & 6.0 & 11.4 & 9.5 & 8.6 & 9.4 & 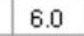 & 5.4 & 8.8 & 6.3 & 10.3 & 6.7 & 3 & ERVEV-N \\
\hline 4 & 1000.0 & 461.0 & 661.0 & & 8.5 & 10.5 & 9.9 & 11.8 & 11.0 & 8.9 & 10.8 & 9.1 & 7.0 & 10.2 & 11.6 & 4 & EYAV-VP6 \\
\hline 5 & 101.1 & 538.0 & 1000.0 & 637.0 & & 9.7 & 6.5 & 8.8 & 9.3 & 83.8 & 6.8 & 7.4 & 6.0 & 9.7 & 8 & & INKKV-N \\
\hline 6 & 476.0 & 2.5 & 442.0 & 482.0 & 538.0 & & 32.1 & 34.1 & 35.0 & 9.3 & 9.3 & 32.1 & 11.0 & 26.1 & 5.3 & 6 & PALV-N \\
\hline 7 & 407.0 & 147.4 & 545.0 & 524.0 & 1000.0 & 147.4 & & 44.3 & 45.1 & 6.1 & 11.1 & 89.3 & 8.8 & 29.6 & 10.7 & 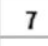 & SFNV-N \\
\hline 8 & 451.0 & 134.8 & 637.0 & 426.0 & 605.0 & 136.8 & 96.5 & & 97.2 & 8.8 & 12.7 & 43.5 & 8.2 & 34.3 & 8.9 & 8 & SFSV-N \\
\hline 9 & 451.0 & 130.9 & 560.0 & 461.0 & 569.0 & 132.8 & 93.9 & 2.9 & & 9.3 & 13.1 & 43.9 & 8.2 & 34.3 & 9. & 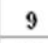 & SFTV-N \\
\hline 10 & 101.1 & 569.0 & 1000.0 & 595.0 & 18.3 & 569.0 & 1000.0 & 605.0 & 569.0 & & 7.2 & 7.0 & 6.4 & 8.4 & 8.9 & 10 & TAHV-N \\
\hline 11 & 553.0 & 595.0 & 1000.0 & 471.0 & 1000.0 & 560.0 & 451.0 & 393.0 & 380.0 & 874.0 & & 11.0 & 5.5 & 9.1 & 43.1 & 11 & TBEV-NS1 \\
\hline 12 & 377.0 & 147.4 & 615.0 & 577.0 & 845.0 & 147.4 & 11.5 & 99.1 & 97.8 & 1000.0 & 461.0 & & 8.5 & 29.5 & 9.8 & 12 & TOSV-N \\
\hline 13 & 1000.0 & 482.0 & 1000.0 & 945.0 & 1000.0 & 461.0 & 615.0 & 688.0 & 688.0 & 1000.0 & 1000.0 & 649.0 & & 7.3 & 7.3 & 13 & TRBV-VP7 \\
\hline 14 & 360.0 & 188.3 & 493.0 & 498.0 & 538.0 & 188.3 & 162.5 & 136.1 & 136.1 & 661.0 & 586.0 & 163.3 & 874.0 & & 11.8 & 14 & UUKV-N \\
\hline \multirow[t]{2}{*}{15} & 586.01 & 1000.0 & 11000.0 & 434.0 & 595.0 & 1000.0 & 476.0 & 595.0 & 531.0 & 595.0 & 100.3 & 531.0 & 845.0 & 422.0 & & 15 & MNV-NS1 \\
\hline & 1 & 2 & 3 & 4 & 5 & 6 & 7 & 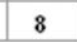 & 9 & 10 & 11 & 12 & 13 & 14 & 15 & & \\
\hline
\end{tabular}

Abb. 4.1: Phylogenetische Analyse der 15 arboviralen Proteinsequenzen. Dargestellt sind die einzelnen prozentualen Identitäten und Divergenzen der Proteinsequenzen zueinander. Farblich hervorgehoben sind die im Multiplex-CBA auftretenden Kreuzreaktivitäten von BHAV-N/PALV-N (97,6\%),INKV-N/TAHV-N $(83,8 \%)$, SFNV-N/TOSV-N (89,3\%), SFSV-N/SFTV-N $(97,2 \%)$ und WNV-NS1/TBEV-NS1 $(43,1 \%)$. (ClustalW Multiple Sequence Alignment, MegAlign, Lasergene ${ }^{\mathrm{TM}}$ : DNASTAR Inc.)

Die Reoviren (EYAV-VP6 und TRBV-VP7), sowie die Bunyaviren UUKV-N, BATV-N, ERVEV-N zeigten keine signifikanten Kreuzreaktionen zu anderen Proteinbeads. Mit Homologie von unter $12 \%$ zu den jeweils 14 anderen Aminosäuresequenzen bestätigen die phylogenetischen Analysen für EYAV-VP6, TRBV-VP7 und ERVEV-N die Ergebnisse. Ebenfalls lässt sich aus Multiplex-CBA und phylogenetischer Analyse schließen, dass im Falle von UUKV-N eine maximale Homologie $\mathrm{zu}$ den anderen Proteinen von $34,3 \%$ ebenfalls nicht zu einer messbaren signifikanten Kreuzreaktion führt.

Innerhalb der von Zecken-übertragenen Phleboviren zeigte sich neben dem erwähnten UUKV (keine Kreuzreaktion im Multiplex-CBA) eine Kreuzreaktion von BHAV-N und PALV-N. Beide Positivseren führten zu einem Fluoreszenzsignal jeweils beider Beadpopulationen, blieben jedoch im Multiplex-CBA für alle anderen Beads negativ (Tabelle 3.12). Durch die auf Nukleotidebene 86\%ige Homologie des S-Segmentes von BHAV und PALV (Dilcher et al., 2012a) war diese Kreuzreaktion zu erwarten. Das S-Segment von UUKV weist im Vergleich lediglich eine 35,8\%ige Homologie auf Nukleotidebene zu BHAV auf (Dilcher et al., 2012a). Diese Ergebnisse decken sich mit der phylogenetischen Analyse auf Proteinebene, BHAV-N und PALV-N zeigen eine 97,6\%ige 
Homologie (siehe Abb. 4.1 roter Kasten) und bestätigen dadurch letztlich die serologischen Ergebnisse bei der Erstbeschreibung des PALV (Filipe et al., 1994).

Innerhalb der von Stechmücken-übertragenen Orthobunyaviren zeigten nur INKV-N und TAHV-N eine Kreuzreaktion. Es kam zu keiner Kreuzreaktion mit BATV-N. Das TAHVPositivserum führte zu einem Fluoreszenzsignal beider Beadpopulationen, blieb jedoch sonst im Multiplex-CBA negativ. INKV und TAHV sind auf Nukleotidebene für das S-Segment zu 79,7\% homolog (Vapalahti et al., 1996) und zeigen für das N-Protein auf Aminosäureebene nach ClustalW Alignment sogar 83,8 \%ige Homologie (siehe Abb. 4.1 roter Kasten). TAHV und INKV werden der California Serogruppe und BATV der Bunyamwera Serogruppe der Bunyaviren zugeordnet (Lundstrom, 1999).

Wegen der antigenen Verwandtschaften der einzelnen Epitope des E-Proteins der Flaviviren werden hohe Kreuzreaktivitäten bei der Testung verschiedener Seren beobachtet (Crill et al., 2007; Dobler et al., 1997; Kimurakuroda \& Yasui, 1986; Liu et al., 2008). Die Kopplung des NS1-Proteins der Flaviviren WNV und TBEV (zu 43,1\% homolog siehe Abb. 4.1 roter Kasten) führte nicht $\mathrm{zu}$ der erhofften verbesserten und eindeutigeren Differenzierung, WNV-NS1 und TBEV-NS1 zeigten eine Kreuzreaktion im Multiplex-CBA, blieben jedoch für Bunyaviren und Reoviren unauffällig.

Die europäischen Sandmücken-übertragenen Phleboviren werden in zwei Serogruppen eingeteilt (Hubálek, 1996). Wie erwartet zeigten sich Kreuzreaktionen der Proteinbeads SFNV-N mit TOSV-N, sowie SFSV-N mit SFTV-N. Alle anderen Proteinbeads blieben bei den Kreuzreaktivitätstests der Positivseren der Phleboviren im Multiplex-CBA unauffällig. SFTV-N und SFSV-N zeigen auf Nukleotidebene für das S-Segment eine 91,8\%ige Homologie (Carhan et al., 2010), auf Aminosäureebene sind SFSV-N und STFV-N zu 97,2\% homolog und SFNV-N und TOSV-N zu 89,3\% (siehe Abb. 4.1 roter Kasten). Beide Gruppen zueinander zeigen jedoch nur Homologien von 43,5 - 45,1\% und führen zu keinen signifikanten Kreuzreaktionen im Multiplex-CBA.

Kurz gesagt konnten Kreuzreaktionen für BHAV/PALV, INKV/TAHV, TBEV/WNV, SFNV/TOSV, SFSV/SFTV gezeigt werden. 
Es ist demnach möglich Patientenseren mit dem Multiplex-CBA zu testen und anschließend die Ergebnisse zehn verschiedenen Kategorien zuzuordnen. Fünf Kategorien sind dabei eindeutig einem Arbovirus zuzuordnen (BATV, ERVEV, EYAV, UUKV, TRBV), die anderen fünf Kategorien ermöglichen durch Kreuzreaktion zueinander die Eingrenzung auf je zwei Viren (BHAV/PALV, INKV/TAHV, TBEV/WNV, SFNV/ TOSV, SFSV/SFTV).

Die Evaluation des neu entwickelten Multiplex-CBA erfolgte an Hand der bereits in Kap. 2.2.5.2.5 beschriebenen Proben erkrankter Patienten mit Symptomen einer aseptischen Meningitis oder aseptischen Meningoenzephalitis. Als Kernuntersuchung der vorliegenden Arbeit soll somit die Frage beantwortet werden, ob es möglich ist, anhand der in dieser Arbeit exprimierten, gereinigten und an Beads gekoppelten arboviralen Proteine, anti-arbovirale Antikörper in Seren nachzuweisen.

Hierzu wurden die Beads im Multiplex-Ansatz (siehe Kap. 2.2.5.2.5) mit Patientenseren (1:200 verdünnt) inkubiert, gefolgt von einer Zweitantikörperinkubation. Nach Messung am MAGPIX ${ }^{\mathrm{TM}}$-System wurde die mediane Fluoreszenzintensität (MFI) ermittelt. Bei dem Probenmaterial handelt es sich um Humanseren, der Zweitantikörper wurde entsprechend des Ursprungs und Immunglobulin-Typs gewählt (PE-Anti-Human IgM bzw. PE-Anti-Human IgG). Als Negativkontrolle wurden beide Kontrollbeads (BSA und E.coli) mitgeführt.

Der Grenzwert (siehe Kap. 2.2.5.2.6) wurde auf Grund nicht vorhandener humaner Positivseren an Hand der Messung von 45 bestätigten Negativseren für jede Beadpopulation unabhängig berechnet. Für die IgM-Antikörperdetektion und die IgG-Antikörperdetektion wurde jeweils ein Grenzwert für jede Beadpopulation berechnet. Verglichen wurden zwei Methoden: Die aus Erfahrungsberichten stammende Standardformel (A): Mittelwert addiert mit der sechsfachen Standardabweichung und die nach (Frey et al., 1998) statistisch definierte Endpunkt Titer Bestimmung für Immuntests (B): Mittelwert addiert mit dem Produkt aus Standardabweichung und Multiplikator $f$. Zur Vermeidung falsch positiver Signale wurde der t-Wert einer einseitigen $t$-Verteilung mit einer Wahrscheinlichkeit von 99,9999\% ( $P=0$,999999) möglichst hoch gewählt. Zur Bestätigung des ersten Befundes würde einem Patienten innerhalb von zwei Wochen 
erneut eine Probe entnommen werden, wäre der Patient wirklich akut infiziert müsste die zweite Probe deutlich oberhalb des IgG-Grenzwertes liegen (Serokonversion). Um unnötige, kostenintensive und möglicherweise risikoreiche Behandlungen eines Patienten mit nicht bestätigtem Befund zu vermeiden, ist der Grenzwert vertretbar größer zu wählen, als es die Sensitivitätsmessungen erlauben. Eine endgültige Evaluation des Multiplex-CBA ist erst mit der Zeit möglich, wenn auf Grund mehrerer Studien genug bestätigte humane Positivseren vorliegen. An Hand gut charakterisierter Positiv- und Negativseren könnten weitere Grenzwertberechnungen (Greiner \& Gardner, 2000; Greiner, Sohr \& Gobel, 1995) erstellt werden, was z.B. die Einteilung in drei Kategorien (positiv, grenzwertig, negativ) ermöglichen würde. Da zurzeit bundesweit keine definierten Humanseren in ausreichender Zahl vorliegen ist eine solche Untersuchung nicht möglich.

Beide in dieser Arbeit in Kap. 2.2.5.2.6 beschriebenen und in Kap. 3.5.6 berechneten Grenzwerte führen zu nahezu der gleichen Anzahl positiver Seren, so dass im Folgenden die Auswertung an Hand des etwas geringeren Grenzwertes (Methode B) diskutiert wurde, um alle auffälligen Seren zu erfassen.

Die internen CBA-Kontrollen, in Form von an Beads gekoppelten BSA und E.coli Proteinen, konnten erfolgreich hergestellt werden. Durch das standardmäßige Mitführen der E. coli Kontrolle (BP 65) können falsch positive Seren, die auch nach Präadsorption einen störenden anti-E. coli Antikörpertiter aufweisen, schnell und einfach identifiziert werden.

23 Seren zeigten Auffälligkeiten mindestens einer Beadpopulation für anti-arbovirale IgG-Antikörper (siehe Kap. 3.5.6) nach erster Messung aller 111 Patientenseren. Auffällig bedeutet, dass die ermittelte MFI oberhalb des errechneten Grenzwertes lag, alle auffälligen Ergebnisse wurden in Tabelle 6.7 farblich hervorgehoben. Ein Patientenserum (558123) zeigte trotz Präadsorption (siehe Kap.2.2.5.2.4) eine erhöhte MFI der E.coli Kontrolle. Die ebenfalls messbare MFI für TAHV dieses Serums wird als falsch positiv auf Grund störender E.coli-Antikörper im Serum eingestuft. Alle anderen Seren zeigten keine Auffälligkeiten der internen Kontrollen. 
Alle 23 IgG-Antikörper auffälligen Patientenseren wurden drei Mal (in voneinander unabhängigen Testläufen) gemessen (Tabelle 6.11). Bei 91\% der Seren (21 von 23) konnten die Ergebnisse der ersten Messung in beiden folgenden Messungen bestätigt werden.

27 Seren zeigten Auffälligkeiten mindestens einer Beadpopulation für anti-arbovirale IgM-Antikörper (siehe Kap.3.5.6) nach erster Messung aller 111 Patientenseren und liegen oberhalb des errechneten Grenzwertes (siehe Tabelle 6.8). Das Patientenserum (653731) zeigte Reaktion auf die BSA-Kontrolle, blieb aber für alle anderen Proteinbeads unauffällig. 26 der 28 IgM-Antikörper auffälligen Patientenseren wurden zur Bestätigung der Ergebnisse erneut mit dem Multiplex-CBA gemessen, zwei Patientenseren standen zur erneuten Messung nicht mehr zur Verfügung (495922, 612490). Die positiven Multiplex-CBA Ergebnisse konnten bei $77 \%$ der Seren (20 von 26) bestätigt werden (siehe Tabelle 6.12). Ein möglicher Grund für die niedrigere Reproduktionsrate der Ergebnisse im Vergleich zu den Multiplex-CBA Messungen der anti-arboviralen IgG-Antikörper könnte die Tatsache sein, dass IgM-Antikörper anfälliger gegenüber dem mehrfachen Auftauen und Einfrieren sind (Truszkiewicz, 2011). Die zweite Messung zeigte tendenziell etwas geringere MFI der Proteinbeads.

Für die Zuordnung der Multiplex-CBA Ergebnisse in zurückliegende Infektionen (Fall 2, siehe Kap. 3.5.7.1.2) und akute Infektionen (Fall 3-4, siehe Kap. 3.5.7.1.3 und 3.5.7.1.4), wie in Kap. 2.2.5.2.6 ausführlich beschrieben, wurden 22 der 23 IgG-Antikörper auffälligen Seren zur Absicherung im IFT (Verdünnung 1:100) getestet. Das Serum mit der Nummer 654198 stand zur IFT Überprüfung nicht mehr zur Verfügung. Von 3 der 22 Patienten standen jeweils zwei Proben (Abnahme innerhalb von zwei Wochen) zur Messung zur Verfügung. Diese mit *gekennzeichneten Seren wurden ebenfalls im IFT überprüft. Eine Zusammenfassung beider Auswertungen ist in Tabelle 3.20 dargestellt. Von den insgesamt 25 überprüften Patientenseren konnten 21 Patientenseren (84\%) durch Immunfluoreszenzmikroskopie der IFTs als auffällig bewertet werden. Bei 35 positiven CBA Ergebnissen konnten 29 im IFT (83\%) positiv bestätigt werden und bei 13 negativen CBA Ergebnissen konnten 9 im IFT (70\%) negativ bestätigt werden. 
Im Anhang wurden die Multiplex-CBA Ergebnisse aller auffälligen Patientenseren nach Fallzuordnung graphisch dargestellt (Fall 2 siehe Kap. 6.6.6, Fall 3 siehe Kap. 6.6.7, Fall 4 siehe Kap. 6.6.8). Gezeigt werden die MFI je Beadpopulation einmal gegen antiarbovirale IgM- und einmal gegen anti-arbovirale IgG-Antikörper. Mit nur einer abgegeben Patientenprobe können keine den Verdacht der ersten Probe bestätigenden Aussagen getroffen werden, eine zweite Probe (Abgabe innerhalb von zwei Wochen) hätte die Diagnose zweifelsfrei bewiesen. Bei nur 6 von 111 Patienten stand eine zweite Probe zur Messung zur Verfügung (Tabelle 6.9 und Tabelle 6.10), für alle anderen Patienten kann der Multiplex-CBA nur einen Hinweis auf die vermeintlich vorliegende arbovirale Infektion geben.

Die Fallzuordnung der 111 erkrankten Patienten mit Hilfe des in dieser Arbeit entwickelten Multiplex-CBA wird im Folgenden ausführlich beschrieben.

Fall 1 (IgM negativ, IgG negativ): 69 von 111 Patienten (62\%) zeigen keine Anzeichen für eine akute oder Wochen bis Monate zurückliegende arbovirale Infektion der in dieser Arbeit untersuchten 15 Arboviren (IgM-Antikörper und IgG-Antikörper unauffällig). Der Auslöser der Krankheitssymptome bleibt weiterhin unklar, eine BATV-, BHAV-, ERVEV-, EYAV-, INKV-, PALV-, SFNV-, SFSV-, SFTV-, TAHV-, TBEV-, TOSV-, TRBV-, UUKV-, oder WNV-Infektion konnte als Krankheitsursache ausgeschlossen werden.

42 von 111 Patienten (38\%) zeigen Anzeichen für eine akute oder Wochen bis Monate zurückliegende arbovirale Infektion:

Fall 2 (IgM negativ, IgG positiv): Von den 42 Patienten weisen 11 Patienten (10\% aller getesteten Patienten) Anzeichen einer zurückliegenden arboviralen Infektion auf. Auf Grund der spezifischen MFI, bzw. signifikant erhöhter MFI bestimmter Proteinbeads (siehe Kreuzreaktivitätstest Kap. 3.5.5) konnten den Patienten Einzelinfektionen (siehe Tabelle 3.15) oder Mehrfachinfektionen (siehe Tabelle 3.16) zugeordnet werden.

Hinweise für Einzelinfektionen konnten für INKV/TAHV=3 (2,7\%), EYAV=3 (2,7\%), SFNV/TOSV $=1(0,9 \%)$ und TRBV-Infektion $(0,9 \%)(\mathrm{Nr} .554005)$ gezeigt werden. 
Das Patientenserum mit der Nr. 554005 konnte weder mit weiteren CBA-Messungen, noch mit dem IFT bestätigt werden. Es muss als unbestätigter Verdacht auf eine zurückliegende TRBV-Infektion behandelt werden.

Das Patientenserum mit der Nummer 120116 ist für alle vier Sandmückenfieberviren (SFSV, SFNV, SFTV, TOSV) positiv. Es kann sich entweder um eine Mehrfachinfektion mit jeweils einem Virus jeder Kategorie (SFSV/SFTV, SFNV/TOSV) handeln oder es liegt eine Infektion mit einem diesen Viren verwandten, aber nicht im Multiplex-CBA erfassten Sandmückenfiebervirus vor, das eine ausreichende Homologie des Nukleokapsids aufweist, um eine Kreuzreaktivität hervorzurufen.

Wie in Kap. 3.5.7.2 beschrieben führte die Untersuchung von 2 Patientenseren mittels Multiplex-CBA und IFT zum Verdacht auf zurückliegende Mehrfachinfektionen (siehe Tabelle 3.16):

Hinweis auf Mehrfachinfektion bei dem Patientenserum 653731 mit zurückliegender INKV/TAHV-, sowie TOSV-Infektion und IFT-begründetem Verdacht einer EYAVInfektion.

Hinweis auf Mehrfachinfektion bei dem Patientenserum 584297 (mit zurückliegender SFNV/TOSV-Infektion und dem Verdacht einer zusätzlichen zurückliegenden INKVund EYAV-Infektion). Von diesem Patienten stand eine weitere Probe zur Messung zur Verfügung, die Ergebnisse bestätigen den Verdacht auf eine vorliegende Mehrfachinfektionen (siehe Abb. 3.15).

Fall 3 und Fall 4: Von den 42 Patienten weisen 31 Patienten (28\% aller getesteten Patienten) Anzeichen einer akuten arboviralen Infektion auf. Hierbei kann zwischen einer akuten Infektion ohne Serokonversion (Fall 3: IgM positiv, IgG negativ) und einer Infektion in der späten akuten Phase mit Serokonversion (Fall 4: IgM positiv und IgG positiv) unterschieden werden.

Nur von zwei Patienten stand eine weitere Probe (Abnahme innerhalb von zwei Wochen) zur Messung zur Verfügung (siehe Tabelle 6.9 und Tabelle 6.10 ). Bei dem einen Patienten $(578045+578586)$ konnte so eine akute EYAV-Infektion bestätigt werden, bei dem anderen Patienten $(652981+653434)$ eine akute SFSV/SFTV-Infektion (siehe Kap. 3.5.7.3) jeweils mit Serokonversion. 
Hinweise für akute arbovirale Einzelinfektionen konnten für BHAV/PALV=2 (1,8\%), ERVEV=1 (0,9\%), EYAV=3 (2,7\%) (davon eine unbestätigt), TBEV=1 (0,9\%), TRBV=3 $(2,7 \%), \mathrm{INKV} / \mathrm{TAHV}=3(2,7 \%), \mathrm{WNV}=1(0,9 \%)$ (unbestätigt), SFNV/TOSV=3 $(2,7 \%)$, SFSV/SFTV=7 $(6,3 \%)$ gezeigt werden.

Hinweise auf eine akute arbovirale Mehrfachinfektion (siehe Tabelle 3.18) konnten für ein Serum (618439) für INKV/TAHV und TRBV gezeigt werden. Das Patientenserum (635188) zeigte Hinweise auf akute TOSV-Infektion und eine zurückliegende Infektion mit TRBV und EYAV.

Fall 3 (IgM positiv, IgG negativ): Drei Patientenseren (532655, 567544, 587131) waren zwar auffällig in der IgM-Antikörper Detektionsmessung, konnten aber wegen erhöhter MFI der E.coli Kontrolle auf Grund von störenden E.coli-Antikörpern im Serum (trotz Präadsorption) und der daraus möglicherweise resultierenden falsch positiven Fluoreszenzsignale nicht ausgewertet werden. Bei zwei weitere Seren (584537 und 630539) lag das Fluoreszenzsignal der E-coli-Kontrolle zwar oberhalb des Grenzwertes, die Proteinbeads zeigten jedoch einen signifikanten Unterschied, so dass von einer akuten TRBV-Infektion (584537) beziehungsweise einer akuten SFNV/TOSV-Infektion (630539) ausgegangen werden kann. Das Patientenserum 653039 ohne signifikant erhöhte MFI der IgM-Antikörpermessung, war IgG-Antikörper auffällig für SFTV-N, dies konnte allerdings im IFT nicht bestätigt werden.

Fall 4 (IgM positiv, IgG positiv): Die Ergebnisse des Patientenserums 528149 wurden zur Absicherung im IFT getestet (BHAV und PALV positiv, SFNV negativ). Dieses Serum wurde durch die IFT-Bestätigung als BHAV und PALV IgG positiv eingestuft.

Fünf Seren $(545809,578586,598313,604152$ und 635188) einzeln graphisch dargestellt im Anhang Abb. 6.12 zeigten eine MFI (IgM-Antikörper Messung) unterhalb des berechneten Grenzwertes, geht man aber davon aus, dass in diesen Fällen die erste Probenentnahme zu spät erfolgte (eine zweite zum Vergleich lag nicht vor) und es bereits zu einer Serokonversion von IgM-Antikörpern zu IgG-Antikörpern gekommen ist, sind diese Seren Fall 4 zuzuordnen. Die Patienten befinden sich in der sehr späten akuten Phase einer viralen Infektion. 
Alle Multiplex-CBA Ergebnisse wurden in akute und zurückliegende Einzelinfektionen (siehe Tabelle 3.21) und Mehrfachinfektionen (siehe Tabelle 3.22) zusammengefasst.

Mit dem Multiplex-CBA war es möglich durch die Untersuchung der 111 Patientenseren (Proben erkrankter Patienten mit Symptomen einer aseptischen Meningitis oder aseptischen Meningoenzephalitis, siehe Kap. 2.2.5.2.5) bei 42 Patienten einen erhöhten anti-arboviralen Antikörpertiter zu detektieren.

An Hand von sechs Fallbeispielen (sechs Personen von denen eine weitere Probe zur Untersuchung vorlag) konnten zwei akute arbovirale Infektionen zum einen mit dem von Zecken übertragenen Eyach Virus (EYAV) und zum anderen mit einem der beiden Sandmückenfieberviren SFSV/SFTV, sowie eine Wochen oder Monate zurückliegende arbovirale Infektion mit einem der beiden Sandmückenfieberviren SFNV/TOSV als Auslöser der Krankheitssymptome eindeutig identifiziert werden.

Mit dem Multiplex-CBA war es erstmals möglich Patientenseren mit relativ geringem Zeitaufwand auf Mehrfachinfektionen mit unterschiedlichen Arboviren zu testen. Die bei den Mehrfachinfektionen auftretenden Arboviren (siehe Tabelle 3.22) INKV/TAHV, TRBV, EYAV, SFSV/SFTV und SFNV/TOSV spiegeln dabei die fünf häufigsten Fälle der Einzelinfektionen wieder.

Beziehen wir die Erkenntnisse der Fallzuordnungen aller Patienten nach Multiplex-CBA Messungen auf die jeweiligen Vektoren der Viren, um die teilweise spärliche Literatur der wenig untersuchten Arboviren in den Kontext zu den CBA-Ergebnissen zu stellen, lassen sich folgende Aussagen treffen:

15 Patienten zeigten Hinweise auf eine akute oder zurückliegende von Zeckenübertragene arbovirale Infektion: 7 Fälle von EYAV (6,3\%), 4 Fälle von TRBV (3,6\%), 2 Fälle von BHAV/PALV (1,8\%) und je 1 Fall von TBEV $(0,9 \%)$ und ERVEV $(0,9 \%)$. Es gab keine Hinweise auf eine UUKV-Infektion.

Der Vektor dieser Arboviren Ixodes ricinus ist seit Jahren in Deutschland heimisch (siehe Abb. 1.1). Die kürzlich neu im April 2014 erschienene Auflistung des Robert-KochInstituts (Seedat, Altmann \& Hellenbrand, 2014) der TBE-Risikogebiete, beruhend auf 
gemeldeten Fällen von TBE-Erkrankungen in Deutschland von 2002-2013 macht deutlich, wie (aktuell 142 Kreise) diese Zecke fast flächendeckend in Deutschland vorkommt. Dass in dieser Arbeit lediglich ein TBEV Fall gezeigt wurde erklärt sich dadurch, dass alle Seren der Studie zuvor auf TBEV-Infektion geprüft und nicht zum Pool der 111 in dieser Arbeit untersuchten Patientenseren hinzugefügt wurden. Mit dem Multiplex-CBA war es somit möglich bei einem als zuvor enzephalitischen Patienten mit unklarer Ätiologie eingestuften Patienten eine akute TBEV-Infektion nachweisen zu können.

Bei der Untersuchung von Patienten mit neuropathologischen Störungen in Tschechien wurden 12\% EYAV positiv getestet (Malkova et al., 1980). Im Rahmen dieser Arbeit wurden $6,3 \%$ der Patienten EYAV positiv getestet, ein Zeichen dafür, dass EYAV weiterhin in Deutschland vorkommt. Nach neusten Erkenntnissen konnte mitunter EYAV, TRBV und UUKV in Zecken in Deutschland nachgewiesen werden (Dobler et al., 2014). Im Fall von TRBV konnten diese Erkenntnisse durch die vier TRBV auffälligen Patientenseren bestätigt werden. Eine weitere Studie von 2006, in der Proben von Hasen als mögliches Reservoir für Viren untersucht wurden, zeigte 1 von 22 Proben aus Schleswig-Holstein (Deutschland) einen positiven Fall von TRBV (Dobler et al., 2006).

Hinweise auf eine UUKV-Infektion gab es im Rahmen der Multiplex-CBA Auswertungen nicht. Es lässt sich allerdings vermuten, dass auf Grund der zuvor erwähnten Detektion von UUKV in Zecken (Dobler et al., 2014) eine Untersuchung von Patientenseren des aktuellen Jahres sehr wahrscheinlich UUKV positiv ausfallen würde. Nach (Hubalek, 2009) kam BHAV 2009 in Europa in Italien, Kroatien, Bulgarien und der Slowakei vor. Die zwei positiven Fälle von BHAV/PALV im Multiplex-CBA lassen dies nun auch für Deutschland vermuten.

Bereits vor 1989 lag die Seroprävalenz der Bevölkerung rund um Saulges (Frankreich) gegen ERVEV bei 2,7\% (Chastel et al., 1989). 1998 konnten in einer Blindstudie 13,9\% der Patienten mit Donnerschlag Kopfweh (,thunderclap headache“) ERVEV Antikörper nachgewiesen werden. Die Seroprävalenz einer Kohorte von unauffälligen Blutspendern lag bei 1\% (Treib et al., 1998). Der eine Fall von EYAV unter Patienten mit aseptischer Meningitis und aseptischer Meningoenzephalitis stehen nicht im Widerspruch zu den bislang veröffentlichten Ergebnissen. 
7 Patienten zeigten Hinweise auf eine akute oder zurückliegende von Stechmückenübertragene arbovirale Infektion: 6 Fälle von INKV/TAHV (5,4\%), 1 unbestätigter Fall von WNV $(0,9 \%)$, für eine BATV-Infektion gab es keine Hinweise.

Ein WNV Ausbruch 1999 in Nord-Amerika führte zu 1,8 Millionen infizierten Menschen mit 12852 gemeldeten Meningoenzephalits Fällen und 1308 Toten (Kilpatrick, 2011). Ferner wurden 3827 WNV-Infektionen von Menschen innerhalb von fünf Jahren (2003 2007) in Colorado gemeldet (Kilpatrick \& Pape, 2013). Auch wenn in dieser Arbeit eine WNV-Infektion in Deutschland nicht eindeutig bewiesen werden konnte, so ist es nur noch eine Frage der Zeit.

Die den Erreger tragenden Stechmücken (siehe Abb. 1.2) wurden bereits mehrfach in Deutschland gesichtet (Becker et al., 2014), eine aktuelle Studie belegt Funde verschiedener Stechmückenarten, die von 2010-2014 in Hamburg gefangen wurden (Kruger et al., 2014). Bei der Untersuchung von 16057 Stechmücken, die in SüdwestDeutschland gefangenen wurden, zeigten sich Hinweise auf BATV in den Vektoren (Jost et al., 2011). Auf Grund phylogenetischer Analysen ist es wahrscheinlich, dass das BATV aus der Slowakei, Ukraine oder Russland nach Deutschland eingewandert ist. Dies konnte mit den von 2003-2009 gesammelten Patientenproben jedoch nicht bestätigt werden.

Die Verbreitung des INKV ist auf Nordeuropa und Russland beschränkt (siehe Abb. 1.2), in den 1960er Jahren betrug die Seroprävalenz in Finnland etwa 24\% (BrummerKorvenkontio et al., 1973) und verdoppelte sich mit 51\% nahezu bis 2007 (Putkuri, Vaheri \& Vapalahti, 2007). Das TAHV konnte erstmals im Oberrheintal aus Stechmücken, die von 1979-1981 gefangen wurden, isoliert werden (Pilaski \& Mackenstein, 1985). Darüber hinaus wurde TAHV im Rahmen einer Dissertationsarbeit im Oberrheingebiet in Stechmücken mit einer nested RT-PCR nachgewiesen (Schüßler, 2000). Aktuellen Studien zufolge konnte TAHV nördlich der Alpen in Tirol in humanen Patientenproben nachgewiesen werden, 2,6\% waren TAHV positiv (Sonnleitner et al., 2014). Die ermittelten positiven Seren bestätigen, dass es tatsächlich auch im Oberrheingraben zu TAHV-Infektionen kommt. 
12 Patienten zeigten Hinweise auf eine akute oder zurückliegende von Sandmückenübertragene arbovirale Infektion: 4 Fälle von SFNV/TOSV (3,6\%), 7 Fälle von SFSV/SFTV $(6,3 \%)$ und 1 Fall, bei dem die MFI aller Proteinbeads der Sandmückenfieberviren (SFSV+SFTV+SFNV+TOSV) oberhalb des Grenzwertes lagen. Bei diesem Fall konnte nicht geklärt werden, ob es sich um eine Mehrfachinfektion mit mehreren Sandmückenfieberviren handelt oder um ein in dieser Arbeit nicht untersuchtes Virus, das nah verwandt mit SFSV, SFNV, SFTV und TOSV ist.

Die Seroprävalenz für SFNV und SFSV der Bevölkerung Athens (Griechenland), die vor dem extremen Einsatz von Insektenschutzmitteln als Malariaprophylaxe 1946 bereits gelebt hat, liegt zwischen 13 - 36\% (Tesh \& Papaevangelou, 1977). Eine weitere Studie in Griechenland zeigte 11,26\% TOSV positive Menschen im Alter von 1-87 Jahren (Anagnostou \& Papa, 2013). Die Seroprävalenz für TOSV im südlichen Europa liegt zwischen 16-72\% (Charrel et al., 2005).

Alarmierend sind die insgesamt 10 Fälle (3 SFNV/TOSV, 7 SFSV/SFTV) einer akuten Sandmückenfieberviren-Infektion. Anders als bisher bekannt (siehe Abb. 1.3) konnten seit 2000 Sandmücken in Deutschland gefangen werden (Naucke et al., 2008; Naucke \& Pesson, 2000). Die durch sie übertragenen Viren wurden nur bislang, bedingt durch fehlende Studien, fälschlicherweise nicht als Risiko in Deutschland angesehen. Im Rahmen dieser Arbeit wurden Infektionen mit Sandmückenfieberviren beobachtet, was die Vermutung nahe legt, dass die Sandmücken den Sprung von südlich der Alpen in unsere Breitengrade vollzogen haben. Dies deckt sich mit der Hypothese von (Semenza \& Menne, 2009), dass eine mögliche Ausbreitung der Sandmücken in Europa besteht, sofern es die Umweltbedingungen ermöglichen.

Durch die Entwicklung des Multiplex-CBA für humanpathogene Arboviren war es erstmals möglich Einzelinfektionen in solch einem Umfang nachzuweisen. Dabei ist das Vorkommen von Mehrfachinfektionen gleichsam erstaunlich, wie ebenfalls alarmierend.

Die in dieser Arbeit untersuchten Patienten stammen aus der Region rund um den Schwarzwald (Oberrheintal) und waren die letzten drei Jahre nicht im Mittelmeerraum im Urlaub (Meyer-König et al., 2014 in preparation). Demnach kommen solche arboviralen Infektionen mittlerweile in Deutschland vor und müssen in Zukunft bei aseptischer Meningoenzephalitis mit berücksichtigt werden. 


\section{$5 \quad$ Zusammenfassung}

Im Rahmen dieser Arbeit wurde ein zytometrisches Kugel-Test-Verfahren (englisch: Cytometric-Bead-Array „CBA“) als serologischer Simultannachweis (Multiplex-Test) von Antikörpern gegen ein Spektrum von 15 durch Zecken, Stechmücken und Sandmücken übertragene europäische humanpathogene Arboviren entwickelt.

Bei diesem auf Beads basierenden Flüssigphasen-Immunadsorptionstest wurden 15 rekombinante virale Proteine: Nukleoprotein N der Bunyaviren, Nichtstrukturprotein NS1 der Flaviviren und die Oberflächenproteine VP6 bzw. VP7 der Reoviren mit antigenen Eigenschaften exprimiert, gereinigt, quantifiziert und an magnetische Beads gekoppelt. Des Weiteren wurden zwei interne CBA-Kontrollen (BSA-Kontrolle: Nachweis unspezifischer Hintergrundreaktion, E. coli-Kontrolle: Nachweis intrinsisch erhöhter E. coli Antikörpertiter) entwickelt, die schnell und verlässlich Hinweise auf falsch positive Ergebnisse geben konnten. Die Messungen erfolgten durch Fluoreszenzdetektion am MAGPIX ${ }^{\mathrm{TM}}-$ System.

Als Kontrolltest wurde parallel ein Immunfluoreszenztest (IFT) aufgebaut um so die zur Verfügung gestellten sehr seltenen Positivseren zu bestätigen. Die CBA-Austestung der Positivseren ergab eine optimale Serenverdünnung für den Multiplex-Test von 1:200, hier lag jeder Antikörpernachweis in seinem dynamischen Testbereich.

Die bei den Arboviren bekannten Kreuzreaktionen zeigten sich auch im CBA. In Folge war es möglich bei fünf Arboviren (BATV, ERVEV, EYAV, UUKV, TRBV) eine eindeutige serologische Diagnose zu stellen und die Viren als Krankheitsursache zu bestimmen. Bei den restlichen zehn Arboviren war, bedingt durch die Kreuzreaktionen, eine Eingrenzung auf je zwei Viren (BHAV/PALV, INKV/TAHV, TBEV/WNV, SFNV/TOSV, SFSV/SFTV) als Krankheitsursache möglich.

Basierend auf der Messung von 45 gut charakterisierten humanen Negativseren wurde ein Grenzwert je Virus bestimmt und der Multiplex-CBA mit Patientenseren evaluiert.

Von 111 Patienten (mit aseptischen Meningitis oder aseptischen Meningoenzephalitis Symptomen) konnte der Multiplex-CBA bei 42 Patienten (38\%) einen Hinweis auf eine vorliegende virale Infektion liefern. Es konnte durch IgM-Antikörper und IgG-Antikörper Messungen zwischen dem Verdacht auf eine akute Infektion (bei 31 Patienten $=28 \%$ ) 
und dem Verdacht auf eine Wochen oder Monate zurückliegende Infektion (bei 11 Patienten $=10 \%$ ) unterschieden werden.

Die Reproduzierbarkeit der Multiplex-CBA Ergebnisse lag bei 91\% (IgG-AntikörperDetektion) und bei 77\% (IgM-Antikörper-Detektion).

Der entwickelte Multiplex-CBA spart wertvolle Zeit im Labor durch den simultanen Antikörpernachweis und benötigt nur ein sehr geringes Probenvolumen. Sind die Proteinbeads erst einmal gekoppelt sind diese mindestens ein Jahr haltbar und liefern bei gleichbleibender Qualität der Proben identische Fluoreszenzsignale.

Der Multiplex-CBA hat das Potential, erfolgreich als Labor-Standard für die Diagnostik von aseptischen Meningoenzephalitiden etabliert zu werden. Die Verwendung des neu entwickelten Multiplex-CBAs erlaubt eine Eingrenzung eines Pathogens und gibt Aufschluss darüber, ob eine akute oder eine bereits zurückliegende arbovirale Infektion vorliegt. Durch die Identifizierung akuter arboviraler Infektionen könnte der Krankheitsverlauf und die Epidemiologie einzelner europäischer Arboviruserkrankungen genauer beschrieben werden.

Ferner könnte der Multiplex-CBA klären, welchen Anteil einzelne europäische Arboviruserkrankungen an den bis zu 50\% ungeklärten aseptischen Meningoenzephalitiden in Europa haben.

Im Rahmen dieser Arbeit wurden zum Teil erstmals zurückliegende Infektionen (IgM negativ / IgG positiv) mit EYAV, TRBV, INKV/TAHV, SFNV/TOSV und akute Infektionen (IgM positiv / IgG negativ oder IgM positiv / IgG positiv) mit EYAV, TRBV, ERVEV, TBEV, WNV, INKV/TAHV, BHAV/PALV, SFSV/SFTV, SFNV/TOSV bei Patienten mit aseptischer Meningoenzephalitis aus Südwest-Deutschland nachgewiesen.

Es konnten somit erstmals in solch einem Umfang Patientenseren getestet werden und so gezeigt werden, dass in Südwest-Deutschland neben Zecken und Stechmücken auch Sandmücken als Virusüberträger fungieren und diese damit eine Gefahr für das Auftreten von Meningitis- und Enzephalitisfällen darstellen.

Eine zunehmende Verbreitung virusübertragender Vektoren mit Ausdehnung nach Norden ist, wahrscheinlich auf Grund der Klimaerwärmung, bereits eingetreten, sodass bei dem klinischen Verdacht auf aseptische Meningitis diese europäischen Arboviren in der Routinediagnostik mit zu berücksichtigen sind. 


\section{$6 \quad$ Anhang}

\subsection{Zusammenfassung: Sequenzanalyse Lasergene ${ }^{\mathrm{TM}}$}

\subsubsection{Sequenzanalyse aller rekombinanten Donorplasmide (Strategy View)}
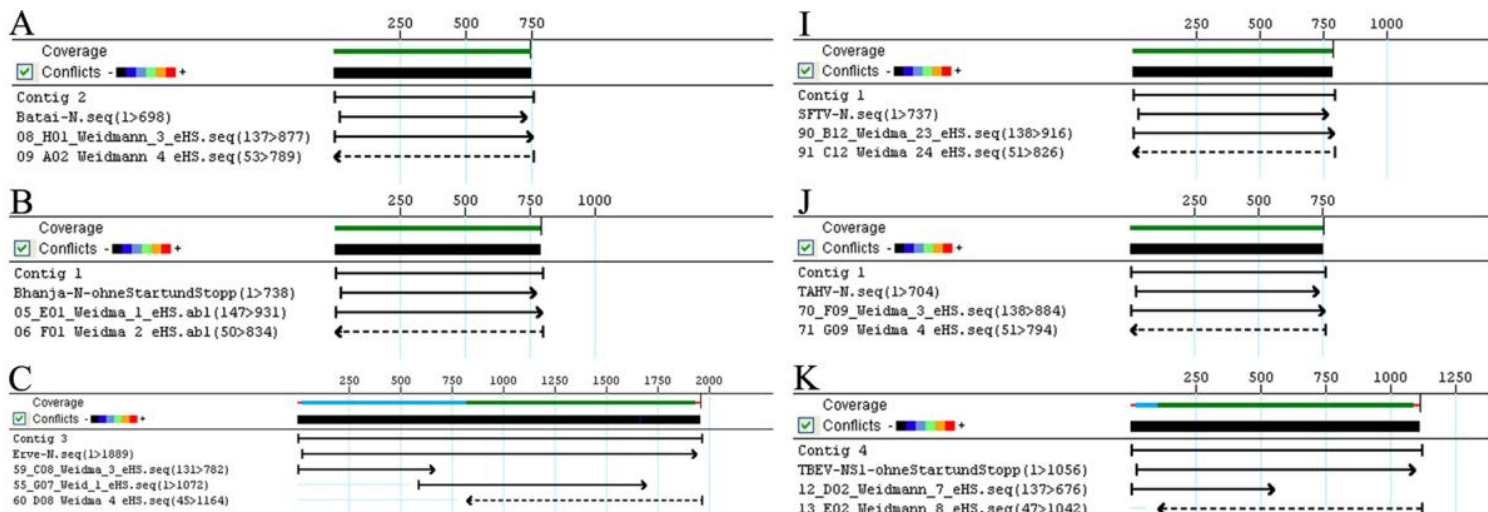

$\mathrm{D}$
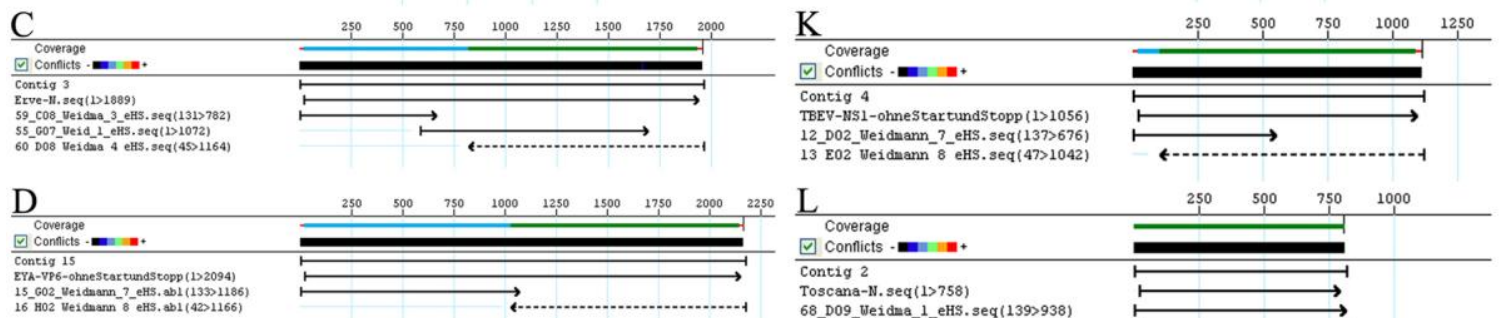

年 8 eHs.

$\begin{array}{llll}250 & 500 \quad 750 \quad 1000\end{array}$

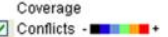

contig 2

Toscana-N. seq (1>75)

8_D09_Weidac___eHS. $\operatorname{seq}(139>938)$

M

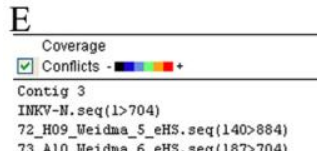

$250 \quad 500 \quad 750$

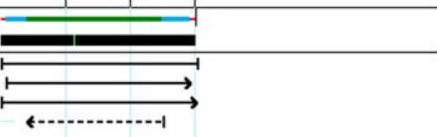

Coverage

Contig 3

TRBV-VP7-ohneStartun 75-C10 Weidas 1 - eHS. seq(135>1011)

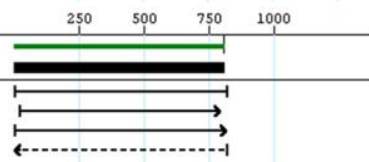

F

$250 \quad 500 \quad 750 \quad 1000$

$\underline{\mathrm{N}}$
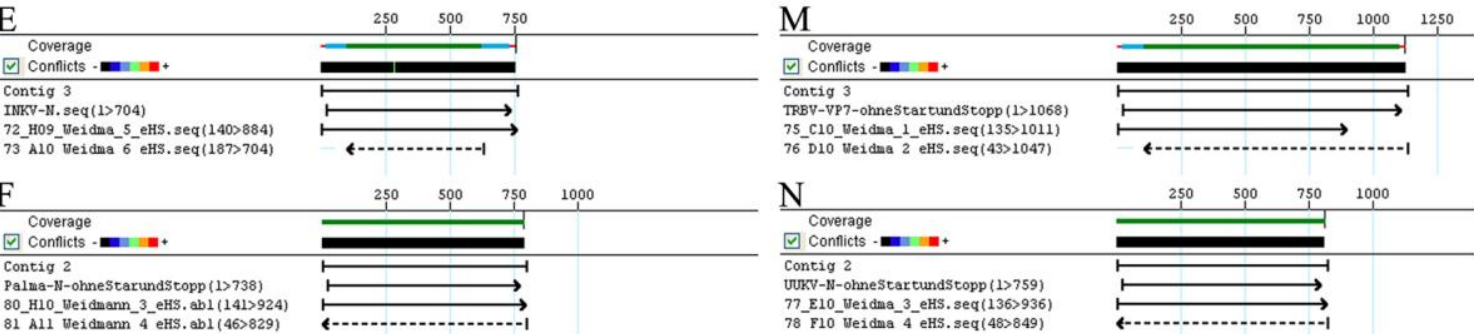

G
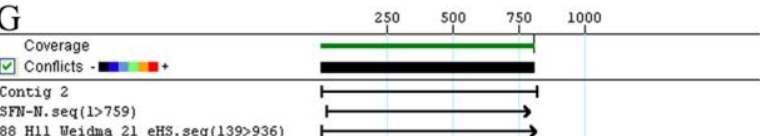

$\mathrm{O}$

88_H11_Weidma_21_eHS. seq(139>936)
89 A12 Weidima 22 eHS. seq(49>847)
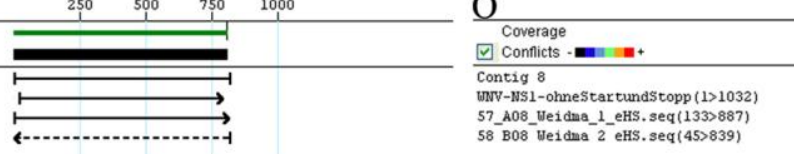

WNV-WS1-ohneStartundStopp (1>1032)
57_A08_Weidana_1_eHS. seq(133>887)

58 B08 Weidma 2 eHS. seq(45>839)

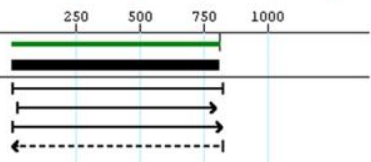

$\underline{\mathrm{H}}$

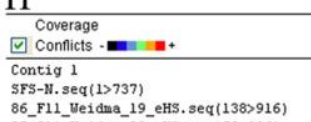

$\begin{array}{rrrr}250 & 500 & 750 & 1000\end{array}$

SFS-N. seq(1>737)

66_F11_Weidana_19_eHS. seq(138>9)
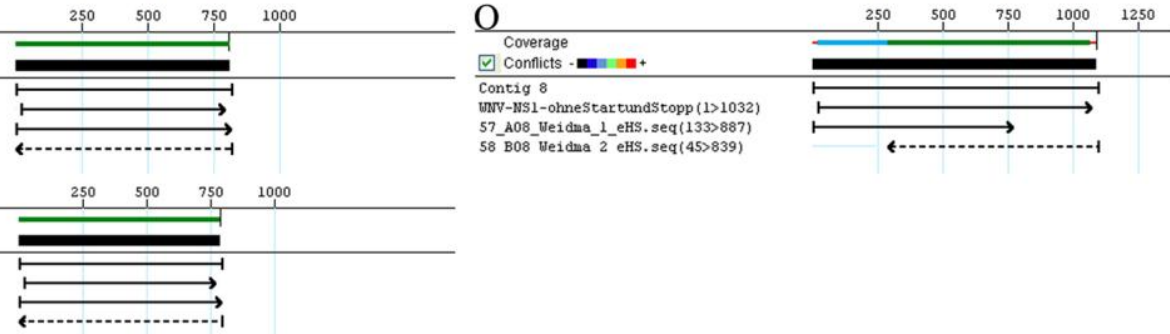

Abb. 6.1: Sequenzanalyse aller hergestellten rekombinanten Donorplasmide. A: BATV-N-pENTRYIBA51\#1， B: BHAV-N-pENTRY-IBA51\#2, C: ERVEV-N-pENTRY-IBA51\#4b die Sequenzanalyse zeigt eine Punktmutation von Prolin (CCC) zu Serin (TCC), D: EYAV-VP6-pENTRY-IBA51\#8, E: INKV-NpENTRY-IBA51\#2 die Sequenzanalyse zeigt eine Punktmutation von Asparagin (AAC) zu Serin (AGC), F: PALV-N-pENTRY-IBA51\#3， G: SFNV-N-pENTRY-IBA51\#2， H: SFSV-N-pENTRY-IBA51\#1, I: SFTV-N-pENTRY-IBA51\#1， J: TAHV-N-pENTRY-IBA51\#1， K：TBEV-NS1-pENTRY-IBA51\#2, L: TOSV-N-pENTRY-IBA51\#1, M: TRBV-VP7-pENTRY-IBA51\#2, N: UUKV-N-pENTRY-IBA51\#3, O: WNV-NS1-pENTRY-IBA51\#2. (Software:Lasergene ${ }^{\mathrm{TM}}$ ) 


\subsubsection{Beispiel: BATV-N-pENTRY (Alignment)}

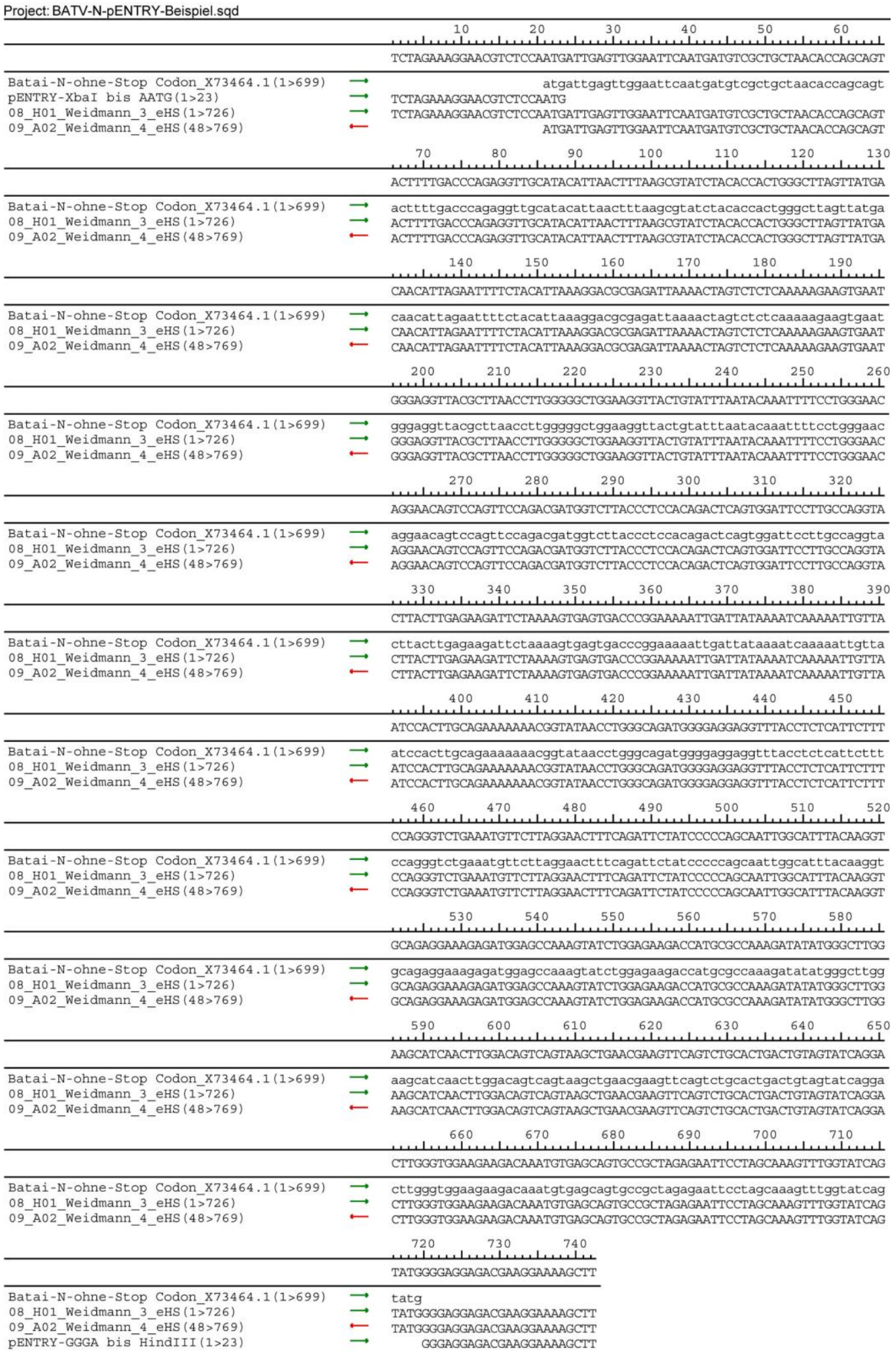

Abb. 6.2: Sequenzanalyse von BATV-N. Vergleich BATV-N-pENTRY-IBA51-\#1 (08 Sequenzierung mit Vorwärts-Primer und 09 mit Rückwärtsprimer) mit der Referenzsequenz der Datenbank und den flankierenden pENTRY-Sequenzen (Software:Lasergene ${ }^{\mathrm{TM}}$ ). 


\subsection{Zusammenfassung: Ergebnisse CBA Präadsorptions-Test}
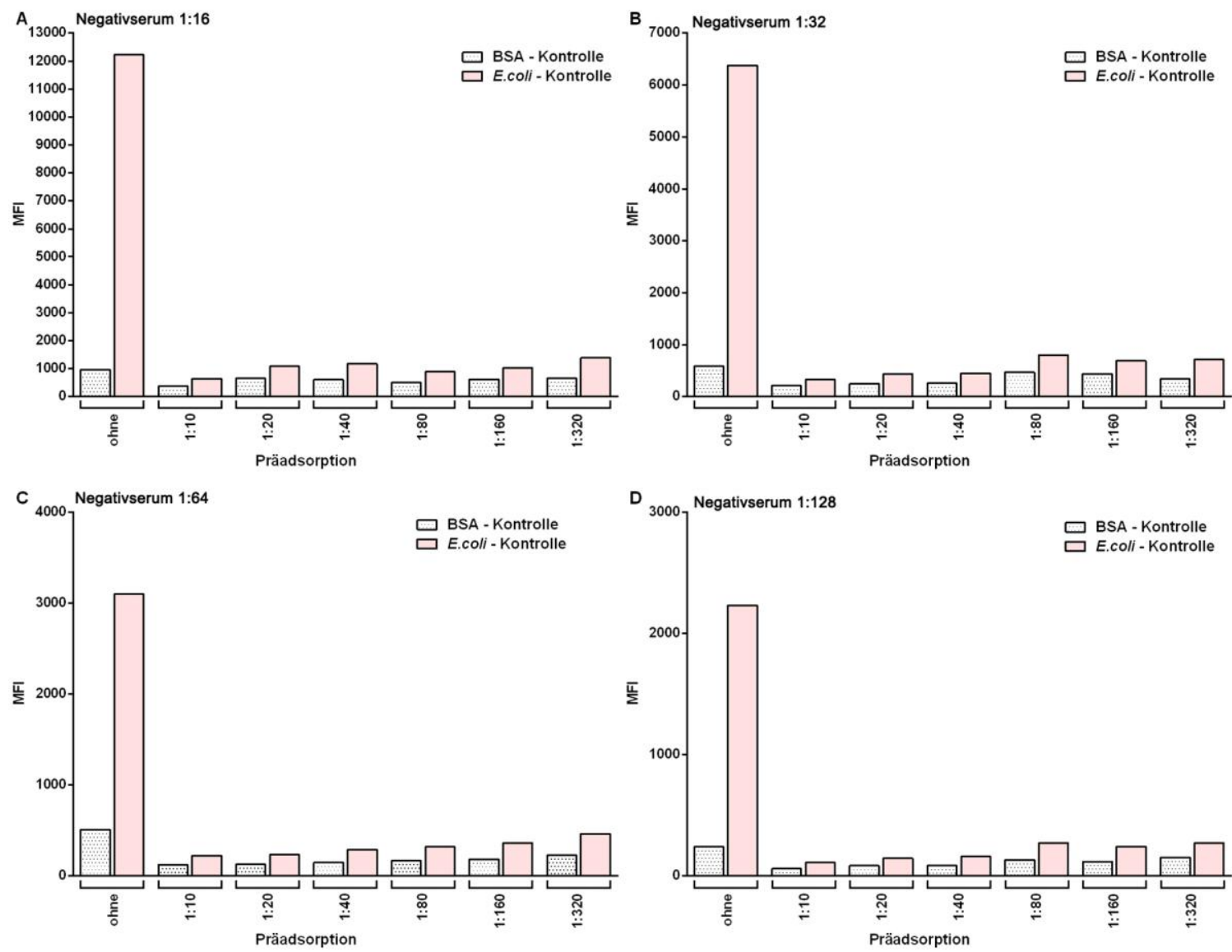

Abb. 6.3: Graphische Darstellung des Präadsorptions-Tests mit E. coli Lysat. A: Negativserum Verdünnung 1:16 mit und ohne Präadsorption mit E. coli Lysat, B: Negativserum Verdünnung 1:32 mit und ohne Präadsorption mit E. coli Lysat, C: Negativserum Verdünnung 1:64 mit und ohne Präadsorption mit E. coli Lysat, D: Negativserum Verdünnung 1:128 mit und ohne Präadsorption mit E. coli Lysat (Software: GraphPad Prism 6).

\subsection{Zusammenfassung: Ergebnisse CBA Sensitivitätstest}

\subsubsection{MFI (PE) aller Sensitivitätstests, IgG-Antikörper, $\mathbf{n = 3}$ (Daten)}

Tabelle 6.1: Daten (MFI) nach Messung verschiedener Verdünnungen aller Positiveren

\begin{tabular}{|c|c|c|c|c|c|c|c|c|c|c|c|c|c|c|c|}
\hline & & \multicolumn{14}{|c|}{ Verdünnung } \\
\hline & & $1: 8$ & $1: 16$ & $1: 32$ & $1: 64$ & $1: 128$ & $1: 256$ & 1:512 & $1: 1024$ & $1: 2048$ & 1:4096 & $1: 8192$ & $1: 16384$ & $1: 32768$ & 1:65536 \\
\hline \multirow{2}{*}{ Anti-TAHYNA 181} & $\mathrm{n}=1$ & 31970 & 33407 & 34057 & 34681 & 36024 & 35783 & 32213 & 28983 & 23935 & 15277 & 11184 & 5159 & 2574 & 2652 \\
\hline & & 302 & 294 & 280 & 218 & 114 & 141 & 79 & 55 & 49 & 36 & 30 & 27 & 26 & 54 \\
\hline \multirow[t]{4}{*}{ (Für: TAHV-N) } & $n=2$ & 33638 & 33254 & 34057 & 35344 & 36581 & 36438 & 34702 & 30405 & 26794 & 22518 & 12519 & 9834 & 4783 & 3241 \\
\hline & & 430 & 358 & 326 & 246 & 234 & 190 & 170 & 82 & 74 & 61 & 57 & 38 & 38 & H4 \\
\hline & $n=3$ & 30312 & 29316 & 29343 & 30310 & 30296 & 30622 & 30769 & 27076 & 25265 & 19458 & 12179 & 5872 & 3735 & 2886 \\
\hline & &. .254. & .181 & 124 & .144 & 115 & $7 !$ & 45 & 48 & & & & & & \\
\hline \multirow[t]{2}{*}{$\overline{\mathrm{RSSE}} \overline{\mathrm{A}} \overline{\mathrm{AK}} \overline{\mathrm{lg}} \overline{\mathrm{lg}}$} & $n=1$ & $362 \overline{09}$ & 36220 & 39084 & $341 \overline{12}$ & $297 \overline{47}$ & $253 \overline{26}$ & 18822 & 13282 & $\overline{9434}$ & 5085 & 2853 & 1161 & $\overline{9} 5 \overline{9}$ & $\overline{6} \overline{3} \overline{6}$ \\
\hline & & 362 & 379 & 337 & 226 & 158 & 99 & 27 & 48 & 38 & 24 & 24 & 20 & 16 & 22 \\
\hline \multirow[t]{4}{*}{ (Für: TBEV-NSI) } & $n=2$ & 42293 & 39425 & 36599 & 32689 & 23866 & 22558 & 19275 & 11310 & 7489 & 3735 & 2336 & 817 & 636 & 578 \\
\hline & & 249 & 92 & 110 & 78 & 60 & 55 & 44 & 35 & 41 & 33 & 27 & 30 & 29 & 31 \\
\hline & $n=3$ & 35597 & 36157 & 33202 & 32160 & 30236 & 27091 & 19032 & 16682 & 12309 & 7885 & 4890 & 1708 & 1348 & 840 \\
\hline & & 800. & .794 & 416 & 349 & 265 & 192 & 88 & & & $4 !$ & 37 & 3 & 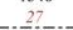 & 20 \\
\hline \multirow[t]{2}{*}{ Anti Uúk } & $\mathrm{n}=1$ & $25640^{\circ}$ & 29332 & 30917 & $292 \overline{8}$ & 34015 & $32 \overline{14}$ & 33451 & 31753 & $311 \overline{36}$ & $23 \overline{4} 48$ & $230 \overline{40}$ & $10 \overline{4} \overline{4} \overline{3}^{\circ}$ & 7961 & $46 \bar{i}$ \\
\hline & & 1024 & 996 & 828 & $6+2$ & 492 & 314 & 211 & 129 & 122 & 60 & 64 & 49 & 33 & 26 \\
\hline \multirow[t]{4}{*}{ (Für: UUKV-N) } & $\mathrm{n}=2$ & 24265 & 25193 & 26373 & 29345 & 30328 & 32335 & 31816 & 32446 & 30618 & 27182 & 16897 & 10201 & 10492 & 2557 \\
\hline & & 903 & 894 & 741 & 564 & 379 & 279 & 181 & 129 & 109 & 78 & 61 & 41 & 45 & 525 \\
\hline & $n=3$ & 29773 & 31767 & 32863 & 33683 & 35462 & 37310 & 41023 & 41000 & 41120 & 37725 & 22192 & 12139 & 13101 & 8289 \\
\hline & & 917. & 794. & 662 & 461 & 360. & 287. & 208 & 146 & .125 & 94 & 54 & 48 & .54 & 9! \\
\hline
\end{tabular}




\begin{tabular}{|c|c|c|c|c|c|c|c|c|c|c|c|c|c|c|c|}
\hline & & & & & & & & Vers & nung & & & & & & \\
\hline & & $1: 8$ & $1: 16$ & $1: 32$ & $1: 64$ & $1: 128$ & $1: 256$ & 1:512 & 1:1024 & $1: 2048$ & 1:4096 & $1: 8192$ & $1: 16384$ & $1: 32768$ & $1: 65536$ \\
\hline Anti-Eyach & $\mathrm{n}=1$ & 33587 & 33865 & 33792 & 33909 & 32756 & 30042 & 23402 & 14587 & 10290 & 6592 & 3866 & 1728 & 1206 & 621 \\
\hline & & 526 & 290 & 204 & 139 & 94 & 73 & 49 & 41 & 42 & 34 & 23 & 27 & 29 & 27 \\
\hline (Für: EYAV-VP6) & $\mathrm{n}=2$ & 30678 & 32987 & 31572 & 31470 & 30984 & 28655 & 19622 & 12338 & 10433 & 6426 & 4011 & 2110 & 1129 & 705 \\
\hline & & 404 & 263 & 205 & 126 & 99 & 75 & 58 & 45 & 42 & 38 & 31 & 29 & 35 & 34 \\
\hline & $n=3$ & 29991 & 30570 & 30498 & 29891 & 29230 & 26478 & 21122 & 11565 & 8165 & 7159 & 3288 & 1869 & 1104 & 672 \\
\hline & & 258 & 191 & & 114 & 75 & 56 & 53 & 46 & 39 & 39 & & & & \\
\hline Anti-Bhanja & $n=1$ & $263 \overline{24}$ & $266 \overline{42}$ & 26632 & 25102 & 19509 & 15348 & 8418 & 4550 & 3752 & 1772 & $81 \overline{7}$ & 267 & 204 & 262 \\
\hline & & 1186 & 885 & 733 & 525 & 371 & 322 & 155 & 94 & 82 & 64 & 45 & 35 & 27 & 35 \\
\hline (Für:BHAN-N) & $n=2$ & 21632 & 22786 & 25057 & 23399 & 18229 & 12647 & 8556 & 4376 & 3280 & 1731 & 974 & 420 & 322 & 158 \\
\hline & & 785 & 651 & 528 & 384 & 273 & 216 & 116 & 75 & 82 & 59 & 54 & 41 & 41 & 44 \\
\hline & $n=3$ & 33701 & 35066 & 28210 & 28920 & 22218 & 10456 & 9434 & 4115 & 3618 & 1428 & 511 & 298 & 317 & 165 \\
\hline & & 858 & 766 & 467 & 405 & 349 & 173 & 152 & 113 & & & & & 36 & \\
\hline Anti-Palma & $\mathrm{n}=1$ & 39173 & $394 \overline{78}$ & $425 \overline{16}$ & 45735 & 45863 & 51324 & 45176 & 29839 & $29 i 51$ & 16214 & 10818 & 5940 & 3376 & 2145 \\
\hline M4746 & & 297 & 212 & 192 & 152 & 107 & 95 & 63 & 35 & 37 & 39 & 27 & 24 & 27 & 24 \\
\hline & $\mathrm{n}=2$ & 39758 & 43886 & 48134 & 46284 & 47115 & 45168 & 41579 & 28555 & 19368 & 12228 & 6201 & 3776 & 1962 & 1326 \\
\hline (Für: PALV-N) & & 185 & 169 & 143 & 94 & 88 & 54 & 44 & 43 & 37 & 37 & 21 & 38 & 39 & 61 \\
\hline & $n=3$ & 40612 & 44214 & 46562 & 44906 & 39447 & 40895 & 33952 & 25889 & 12377 & 10530 & 4636 & 2740 & 1389 & 1091 \\
\hline & & & & & 75 & 53 & 58 & 45 & & & & & & & \\
\hline 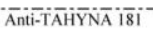 & $n=1$ & 26549 & 25949 & $-\frac{1}{25025}$ & 26843 & 26837 & 26136 & 25564 & 21935 & 17396 & $\frac{1}{12282}$ & 5042 & -2638 & -2448 & $-\frac{15}{1512}$ \\
\hline & & 266 & 231 & 137 & 144 & 109 & 87 & 59 & 48 & 30 & 29 & 39 & 24 & 16 & 26 \\
\hline (Für: INKV-N) & $n=2$ & 25811 & 25102 & 25466 & 26139 & 26899 & 26986 & 25646 & 22114 & 17722 & 11060 & 6382 & 3847 & 2368 & 1259 \\
\hline & & 216 & 173 & 135 & 117 & 82 & 75 & 72 & 36 & 52 & 45 & 35 & 38 & 31 & 41 \\
\hline & $n=3$ & 29734 & 29024 & 29352 & 29103 & 30317 & 30074 & 29322 & 23950 & 17964 & 10296 & 8488 & 3231 & 3081 & 2268 \\
\hline & & 276 & 183 & 154 & 114 & 92 & 83 & 72 & 58 & 50 & 46 & 34 & 34 & 33 & 355 \\
\hline $\sin ^{-1}$ & $n=1$ & 32288 & 32213 & 30097 & 22179 & 18915 & 10305 & 7515 & 5220 & 2604 & 1182 & 587 & 249 & $2 i 7$ & 136 \\
\hline & & 1719 & 1614 & 1163 & 651 & 479 & 251 & 158 & 122 & 81 & 56 & 41 & 34 & 27 & 34 \\
\hline (Für: SFSV-N) & $\mathrm{n}=2$ & 21804 & 29818 & 29418 & 22609 & 19137 & 11972 & 7793 & 5335 & 3117 & 1424 & 884 & 411 & 270 & 208 \\
\hline & & 1616 & 2710 & 1703 & 1024 & 740 & 532 & 361 & 280 & 181 & 110 & 75 & 58 & 46 & 45 \\
\hline & $\mathrm{n}=3$ & 30638 & 30184 & 28289 & 1058 & 18104 & 13873 & 7798 & 4729 & 2636 & 1325 & 763 & 426 & 209 & 163 \\
\hline & & 3127 & 2946 & 1174 & 22949 & 706 & 503 & 352 & 239 & 162 & 103 & 83 & 56 & & 46 \\
\hline$\overline{\mathrm{SCI}}^{-}$ & $n=1$ & 41285 & 43840 & -42228 & 41929 & 36418 & 29239 & 22365 & 14714 & 6917 & $\frac{1}{3167}$ & 2487 & $205 \overline{5}$ & $102 \overline{8}$ & $3 i \overline{4}$ \\
\hline & & 22303 & 19521 & 13757 & 10917 & 7651 & 5421 & 3095 & 1953 & 894 & 597 & 340 & 256 & 158 & 113 \\
\hline (Für: SFTV-N) & $n=2$ & 38950 & 38050 & 38936 & 37222 & 33442 & 21076 & 17983 & 8122 & 6047 & 2897 & 1428 & 792 & 719 & 254 \\
\hline & & 17504 & 14158 & 12663 & 9550 & 6708 & 4067 & 3076 & 1480 & 951 & 471 & 291 & 167 & 121 & 71 \\
\hline & $n=3$ & 38956 & 37515 & 38316 & 35353 & 25787 & 20648 & 14605 & 6517 & 3920 & 1510 & 805 & 681 & 290 & 243 \\
\hline & & $16 ! 39$ & .12173 & 10993 & .7586 & 4751. & .3634 & .2496 & 990. & 483 & 280. & 154 & 143 & 83 & -73- \\
\hline Anti-Ërve & $n=1$ & 19160 & 15305 & -13182 & 11390 & $-\frac{7}{8223}$ & $\frac{5629}{562}$ & $-\frac{37}{3146}$ & 1806 & 631 & 554 & 298 & 119 & 116 & 73 \\
\hline & & 267 & 201 & 128 & 100 & 64 & 63 & 39 & 33 & 24 & 24 & 23 & 26 & 23 & 22 \\
\hline (Für: ERVEV-N) & $n=2$ & 18580 & 16940 & 15344 & 11294 & 8227 & 6074 & 3378 & 1635 & 1029 & 559 & 294 & 163 & 99 & 78 \\
\hline & & 273 & 189 & 159 & 105 & 79 & 67 & H4 & 39 & 33 & 27 & 31 & 33 & 29 & 33 \\
\hline & $\mathrm{n}=3$ & 29553 & 27591 & 26698 & 23496 & 19849 & 15129 & 6632 & 5798 & 3453 & 1986 & 1064 & 387 & 341 & 213 \\
\hline & & 209 & 181 & 140 & 86 & 78 & 59 & 33 & 30 & 27 & 22 & 22 & 10 & 15 & 24 \\
\hline West Nil MiĀ & $n=1$ & 16619 & $144 \overline{40}$ & 9497 & 5915 & 5384 & 2351 & 1856 & 1136 & 558 & 392 & 126 & 87 & $67^{-}$ & 53 \\
\hline MG61369 & & 114 & 131 & 72 & 61 & 55 & 40 & 27 & 27 & 27 & 24 & 23 & 20 & 20 & 22 \\
\hline & $\mathrm{n}=2$ & 17756 & 14809 & 11066 & 9015 & 6542 & 3698 & 2585 & 1431 & 830 & 102 & 260 & 136 & 105 & 65 \\
\hline (Für: WNV-NSI) & & 152 & 116 & 101 & 78 & 67 & 51 & 40 & 39 & 37 & 31 & 37 & $3 I$ & 24 & 30 \\
\hline & $\mathrm{n}=3$ & 18332 & 13265 & 11627 & 8978 & 6977 & 3975 & 2945 & 1341 & 985 & 378 & 335 & 140 & 79 & 69 \\
\hline & & 202 & 167 & .141 & 78 & 68 & 39 & 38 & 29 & 30 & 25 & $\ldots$ & 26 & 14 & 24 \\
\hline Anti-Calovo & $n=1$ & $14 i 24$ & 11640 & 10169 & 7023 & 6531 & 5080 & 3525 & 2422 & 1419 & $740-$ & 424 & 287 & 186 & 196 \\
\hline & & 1659 & 1530 & 1338 & 721 & 669 & 354 & 273 & 197 & 102 & 83 & 61 & 50 & 42 & 48 \\
\hline (Für:BATV-N) & $n=2$ & 14687 & 11074 & 10032 & 8153 & 6557 & 5164 & 4046 & 2947 & 2013 & 955 & 767 & 358 & 218 & 208 \\
\hline & & 1843 & 1492 & 1255 & 917 & 736 & 558 & 420 & 252 & 207 & 133 & 97 & 75 & 48 & +2 \\
\hline & $\mathrm{n}=3$ & 9987 & 7658 & 5479 & 3594 & 3127 & 2073 & 1040 & 736 & 373 & 191 & 176 & 75 & 84 & 60 \\
\hline & & 1034 & 831 & 649 & 422 & 337 & 257 & 145 & 106 & 78 & 53 & 42 & 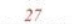 & 29 & 34 \\
\hline Anti-Tribec & $n=1$ & 13929 & 10340 & 4495 & 5966 & 3950 & 2505 & 2063 & 1206 & 688 & 388 & 151 & 137 & 88 & 108 \\
\hline & & 262 & 209 & 162 & 118 & 98 & 63 & 50 & 34 & 32 & 23 & 19 & 20 & 23 & 22 \\
\hline (Für: TRBV-VP7) & $\mathrm{n}=2$ & 4438 & 6615 & 3550 & 4186 & 2936 & 1726 & 1707 & 710 & 491 & 280 & 160 & 118 & 128 & 87 \\
\hline & & 197 & 193 & 121 & 118 & 87 & 68 & 37 & 45 & 29 & 38 & 24 & 30 & 31 & 29 \\
\hline & $n=3$ & 8627 & 4515 & 3162 & 2481 & 1027 & 1263 & 671 & 381 & 388 & 116 & 87 & 79 & 42 & 71 \\
\hline & & 129 & 124 & & 80 & 50 & 52 & 38 & 3 & & & & 26 & 24 & 26 \\
\hline Тั0 & $n=1$ & 31296 & 20522 & 16369 & 11431 & 7139 & 3823 & 1961 & 1009 & 625 & 307 & 177 & 103 & 48 & 38 \\
\hline & & 5513 & 3936 & 2802 & 1724 & 1088 & 722 & 423 & 260 & 177 & 126 & 83 & 60 & $\begin{array}{l}480 \\
61\end{array}$ & $\begin{array}{l}30 \\
41\end{array}$ \\
\hline (Für: TOSV-N) & $n=2$ & 28476 & 18864 & 13984 & 11420 & 4895 & 2704 & 1844 & 874 & 372 & 220 & 105 & 109 & 29 & 23 \\
\hline & & 5014 & 3501 & 2287 & 1512 & 872 & 429 & 415 & 195 & 160 & 107 & 78 & 49 & 42 & 30 \\
\hline & $\mathrm{n}=3$ & 26232 & 17699 & 12692 & 9811 & 3873 & 1910 & 1163 & 755 & 257 & 135 & 86 & 52 & 23 & 30 \\
\hline & & 4459 & 3263 & 1971 & 1345 & 473 & 354 & 256 & 182 & 128 & 90 & 63 & 44 & 34 & 48 \\
\hline Napi & $n=1$ & 14174 & 12556 & 6225 & 3271 & 2047 & 1182 & 532 & 171 & 155 & 83 & $31^{-}$ & 26 & 18 & 24 \\
\hline & & 957 & 911 & 587 & 389 & 236 & 181 & 116 & 61 & 69 & 64 & 42 & 27 & 39 & 61 \\
\hline & $n=2$ & 21750 & 13479 & 8023 & 5462 & 3291 & 1971 & 1108 & 367 & 188 & 112 & 75 & 34 & 27 & 29 \\
\hline & & 1654 & 946 & 555 & 426 & 265 & 204 & 135 & 101 & 80 & 63 & 57 & 46 & 45 & 50 \\
\hline & $n=3$ & 22737 & 14982 & 9459 & 5420 & 2740 & 1667 & 1004 & 546 & 243 & 162 & 64 & 38 & 29 & 37 \\
\hline & & 1069 & 894 & 575 & 347 & 231 & 158 & 128 & 81 & 66 & 61 & 52 & 42 & 41 & 66 \\
\hline
\end{tabular}

\subsubsection{Einzeldarstellung Sensitivität Typ I und Typ II (GraphPad Prism 6)}

A: Sensitivität Typ I
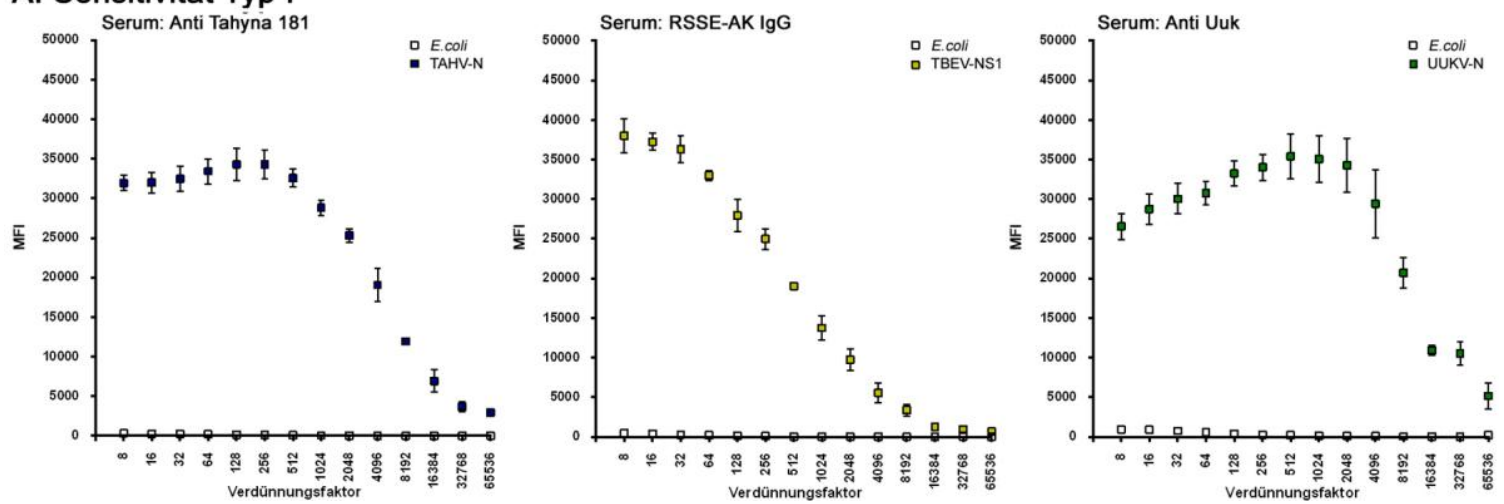

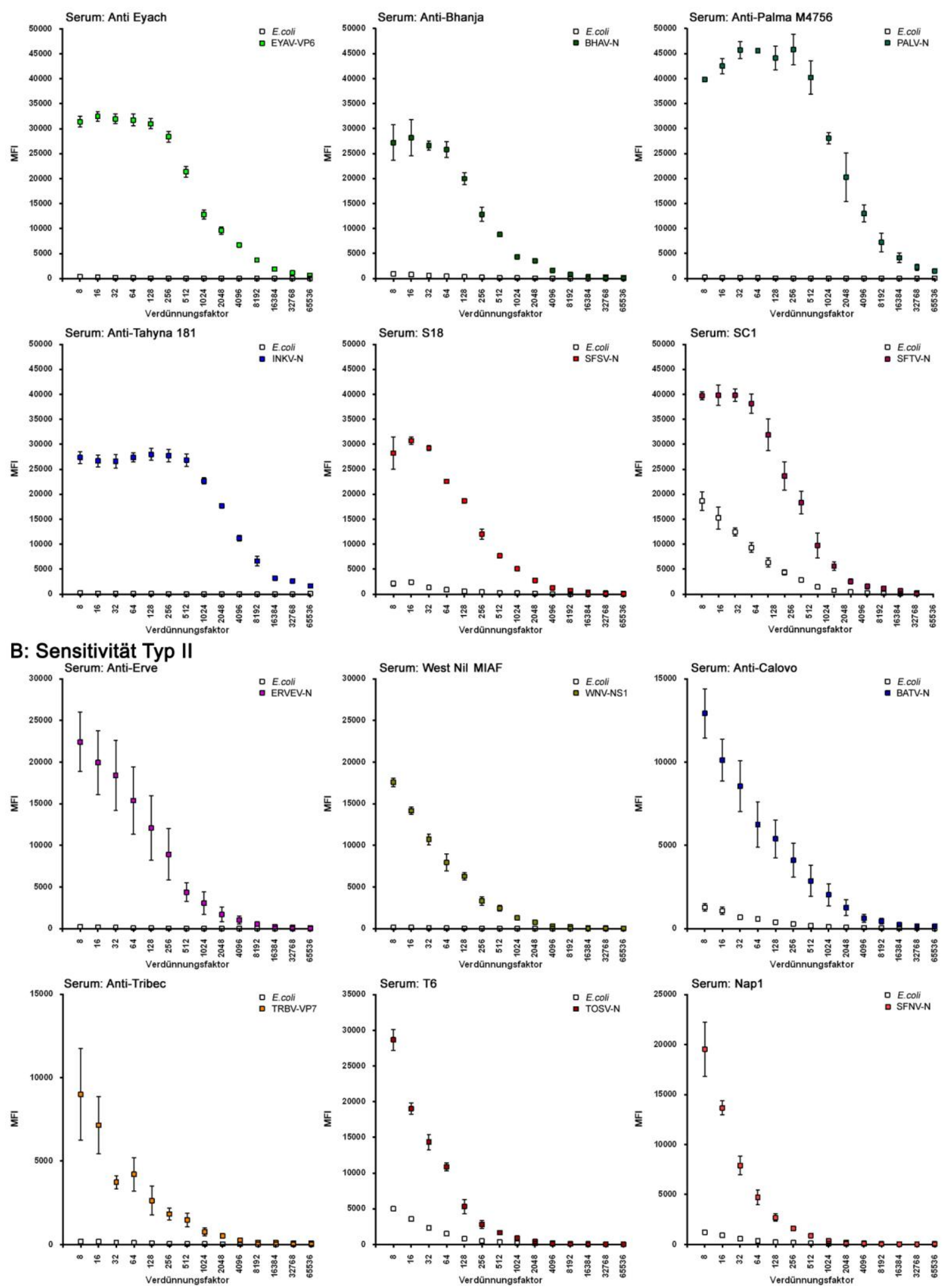

Abb. 6.4: Sensitivitätsmessungen aller Positivseren (IgG). Dargestellt sind die MFI aller Positivseren, jeweils als CBA getestet mit der zugehörigen gekoppelten Beadpopulation und der $E$. coli- Kontrolle. Typ I zeigt sigmoiden Kurvenverlauf, Typ II zeigt linearen Kurvenverlauf. Dargestellt sind die Mittelwerte aus drei Messungen $n=3$ und die daraus resultierenden Fehlerbalken (Software: GraphPad Prism 6). 


\subsection{Zusammenfassung: Ergebnisse Multiplex-CBA Kreuzreaktivitätstest}

\subsubsection{MFI (PE) aller Kreuzreaktivitätstests, IgG-Antikörper, n=3 (Daten)}

Tabelle 6.2: Daten (MFI) nach Messung aller Positivseren als Multiplex-CBA (IgG)

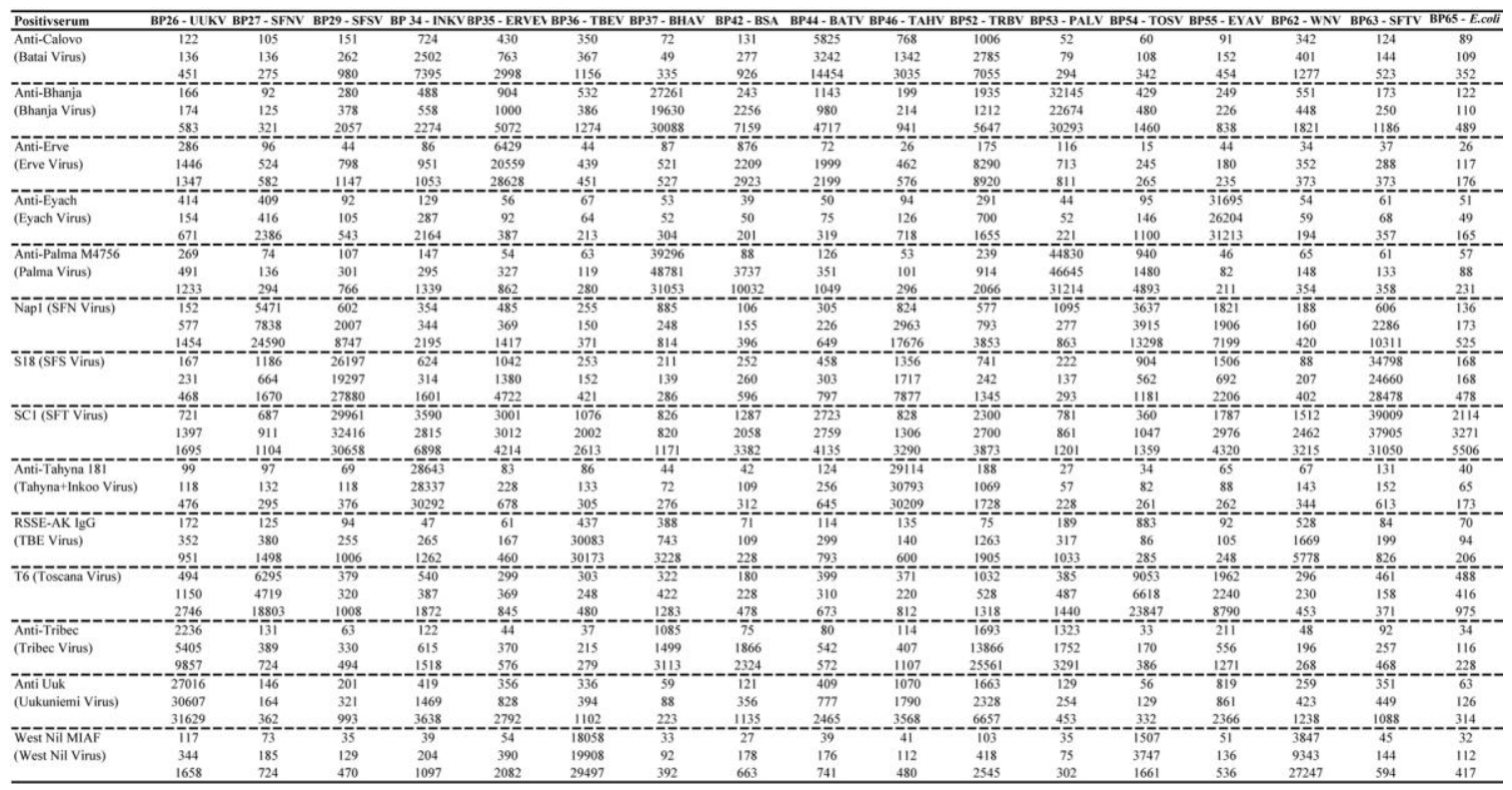

\subsubsection{Kreuzreaktivitätstest mit erwarteten Kreuzreaktionen (GraphPad Prism 6)}
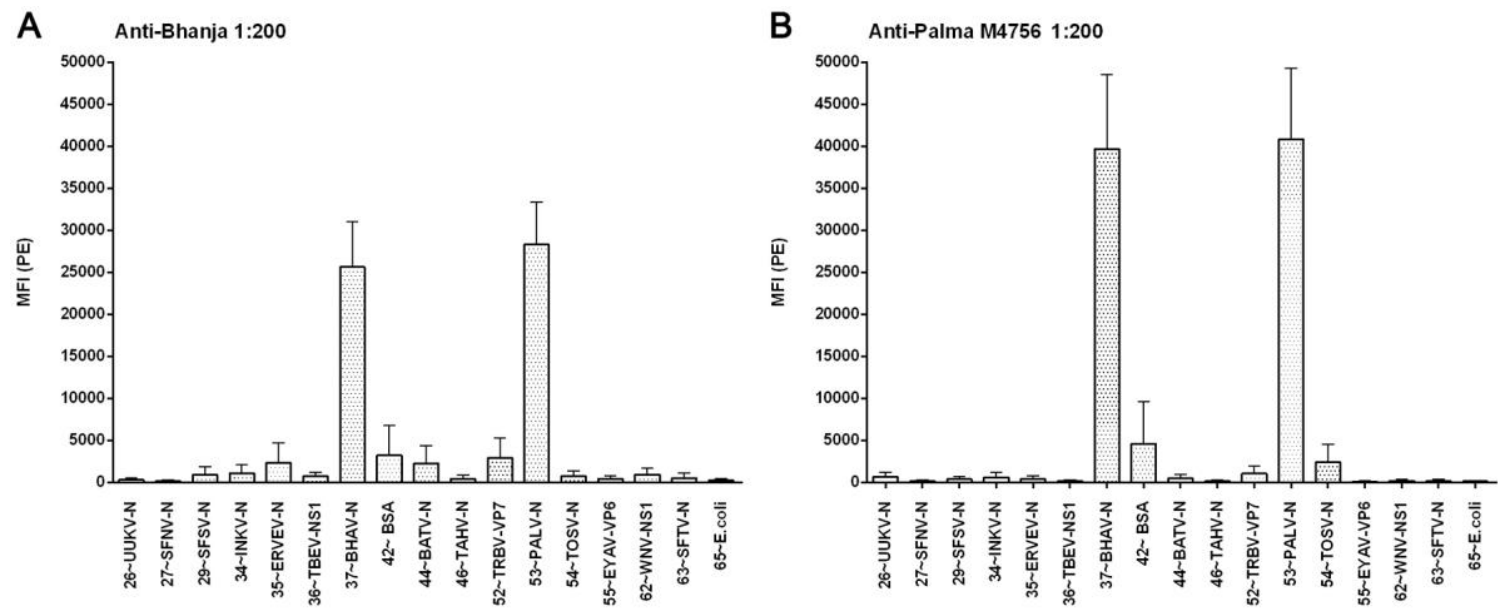

Abb. 6.5: Kreuzreaktivitätstest Multiplex-CBA für BHAV- und PALV-Positivserum (IgG). Dargestellt sind die MFI jeder gekoppelten Beadpopulation gemessen als Multiplex-CBA. A: Positivserum BHAV (Anti-Bhanja) 1:200, n=3. B:Positivserum PALV (Anti-Palma M4756) 1:200, n=3 (Software: GraphPad Prism 6). 

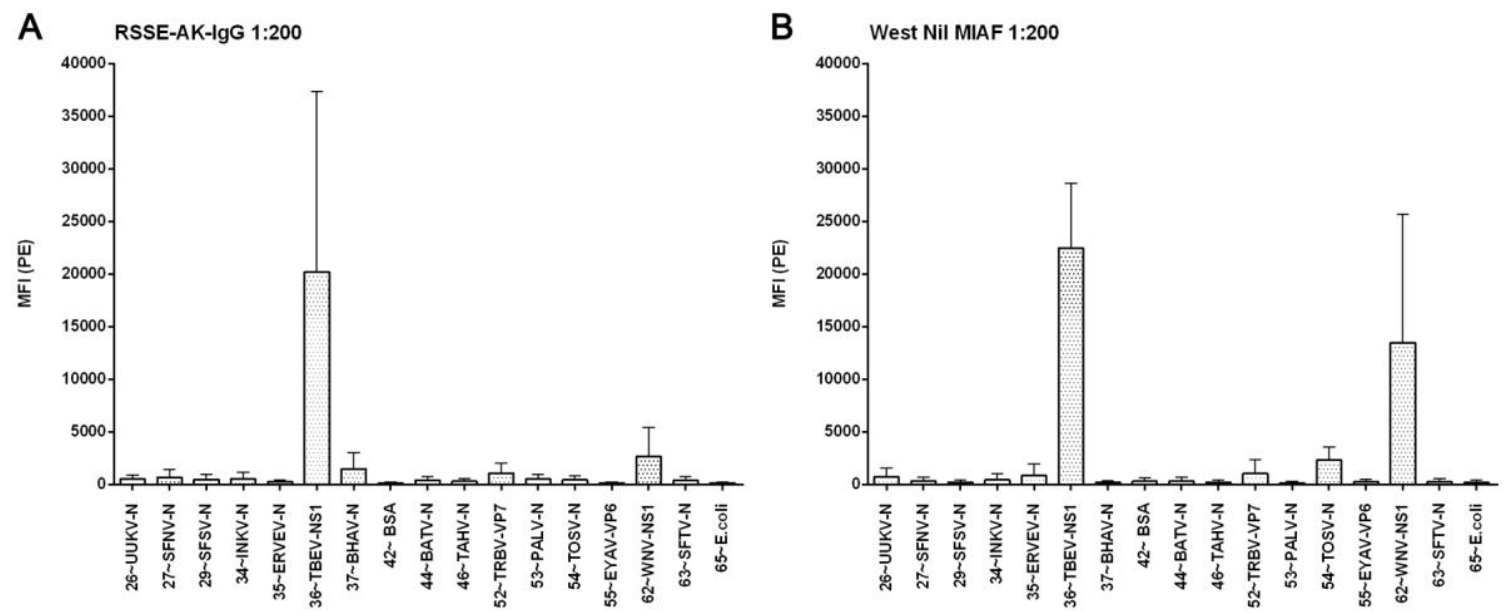

Abb. 6.6: Kreuzreaktivitätstest Multiplex-CBA für TBEV- und WNV-Positivserum (IgG). Dargestellt sind die MFI jeder gekoppelten Beadpopulation gemessen als Multiplex-CBA. A: Positivserum TBEV (RSSE-AK-IgG) 1:200, n=3. B: Positivserum WNV (West Nil MIAF) 1:200, n=3 (Software: GraphPad Prism 6).
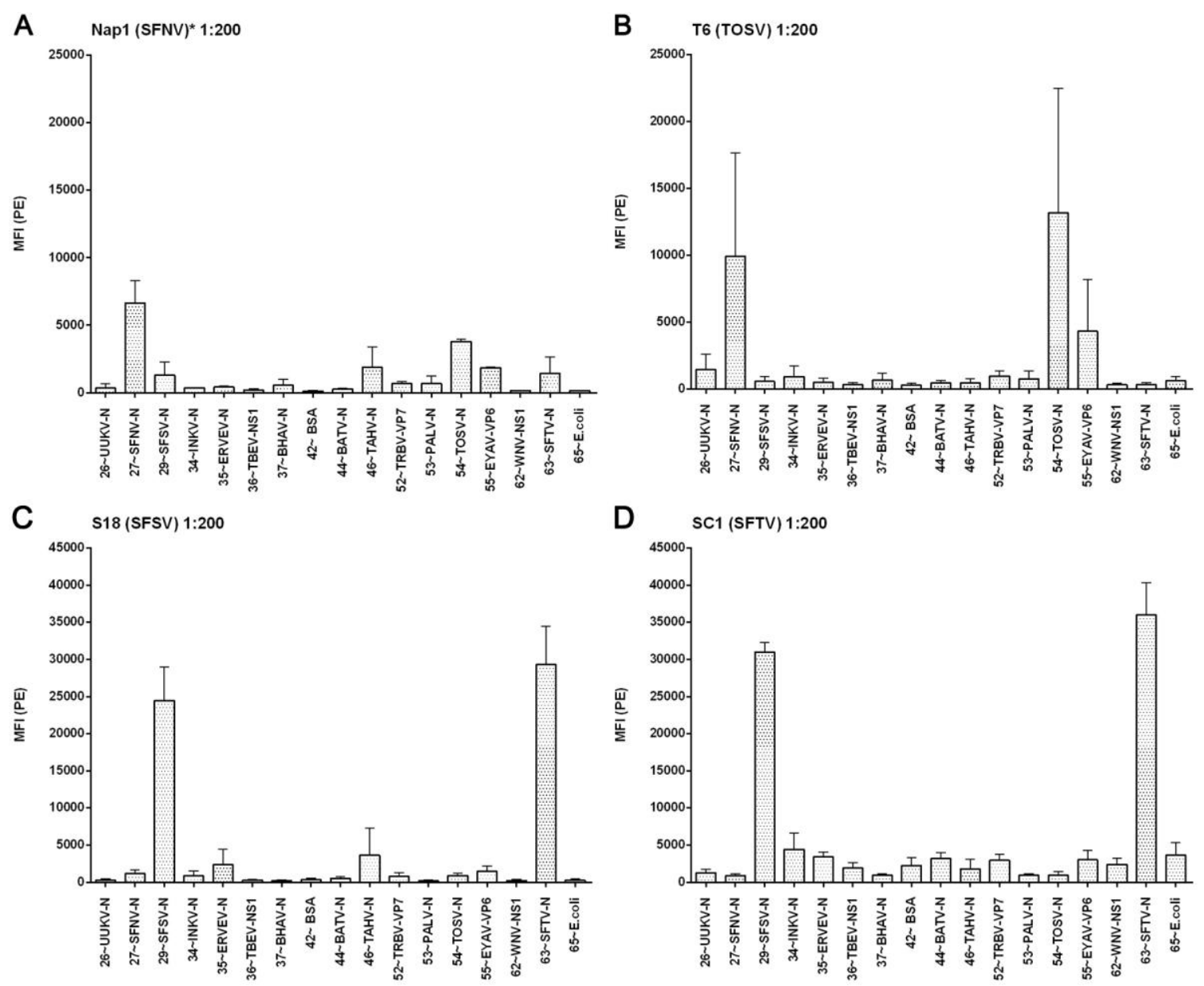

Abb. 6.7: Kreuzreaktivitätstest Multiplex-CBA für SFNV-, TOSV-, SFSV-, und SFTV-Positivserum (IgG). Dargestellt sind die MFI jeder gekoppelten Beadpopulation gemessen als Multiplex-CBA. A: Positivserum SFNV (Nap1) 1:200, ${ }^{*} n=2$. B: Positivserum TOSV (T6) 1:200, n=3. C: Positivserum SFSV (S18) 1:200, n=3. D: Positivserum SFTV (SC1) 1:200, n=3 (Software: GraphPad Prism 6). 


\subsubsection{Kreuzreaktivitätstest ohne Kreuzreaktion (GraphPad Prism 6)}
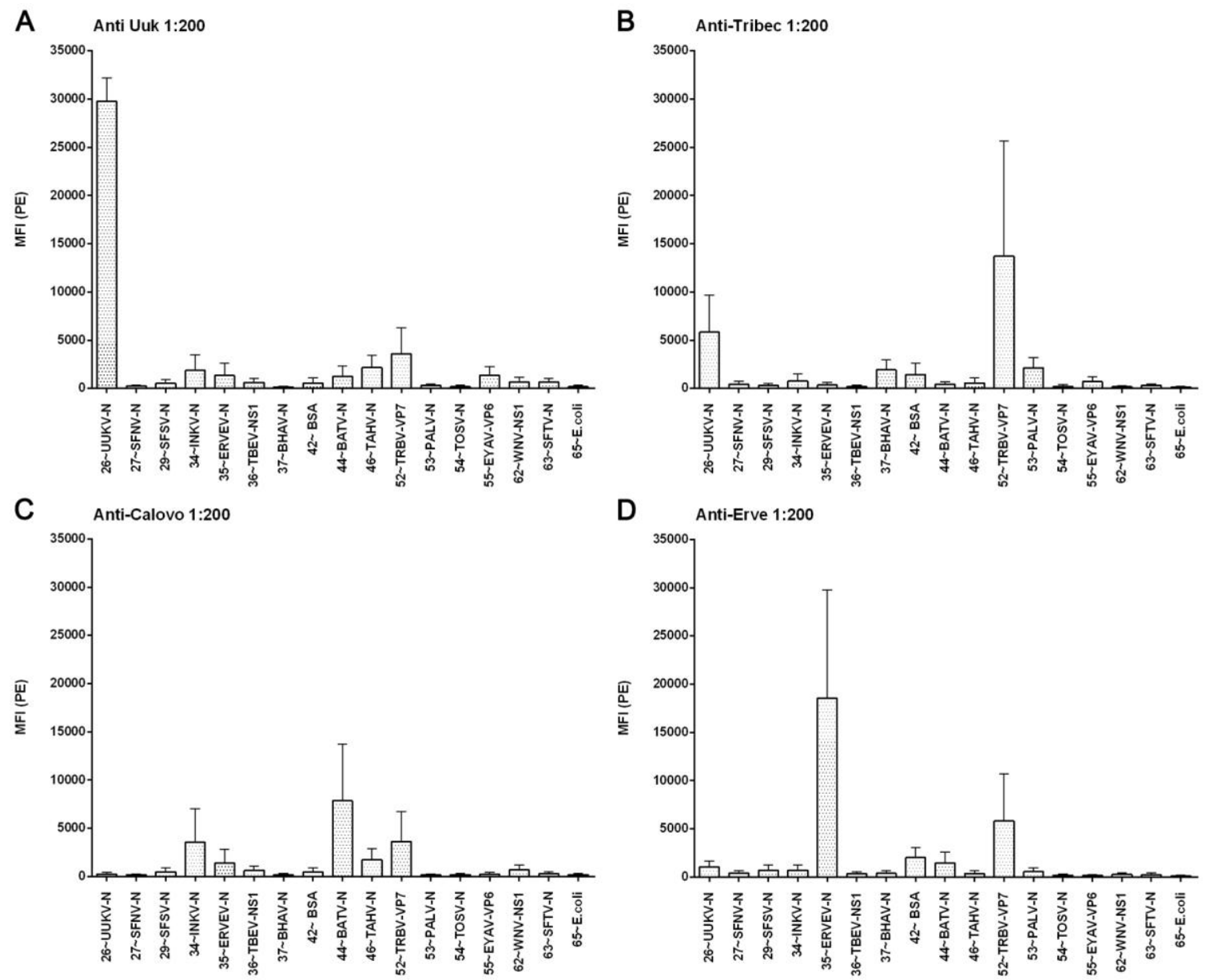

Abb. 6.8: Kreuzreaktivitätstest Multiplex-CBA für UUKV-, TRBV-, BATV- und ERVEVPositivserum (IgG). Dargestellt sind die MFI jeder gekoppelten Beadpopulation gemessen als MultiplexCBA. A: Positivserum UUKV (Anti Uuk) 1:200, n=3. B: Positivserum TRBV (Anti-Tribec) 1:200, $n=3$. C: Positivserum BATV (Anti-Calovo) 1:200, n=3. D: Positivserum ERVEV (Anti-Erve) 1:200, $n=3$ (Software: GraphPad Prism 6). 


\subsection{Zusammenfassung: Ergebnisse Multiplex-CBA Negativseren}

\subsubsection{MFI (PE) 45 Negativseren zur Grenzwertberechnung IgG (Daten)}

Tabelle 6.3: Daten (MFI) nach Messung von 45 Negativseren als Multiplex-CBA: IgG

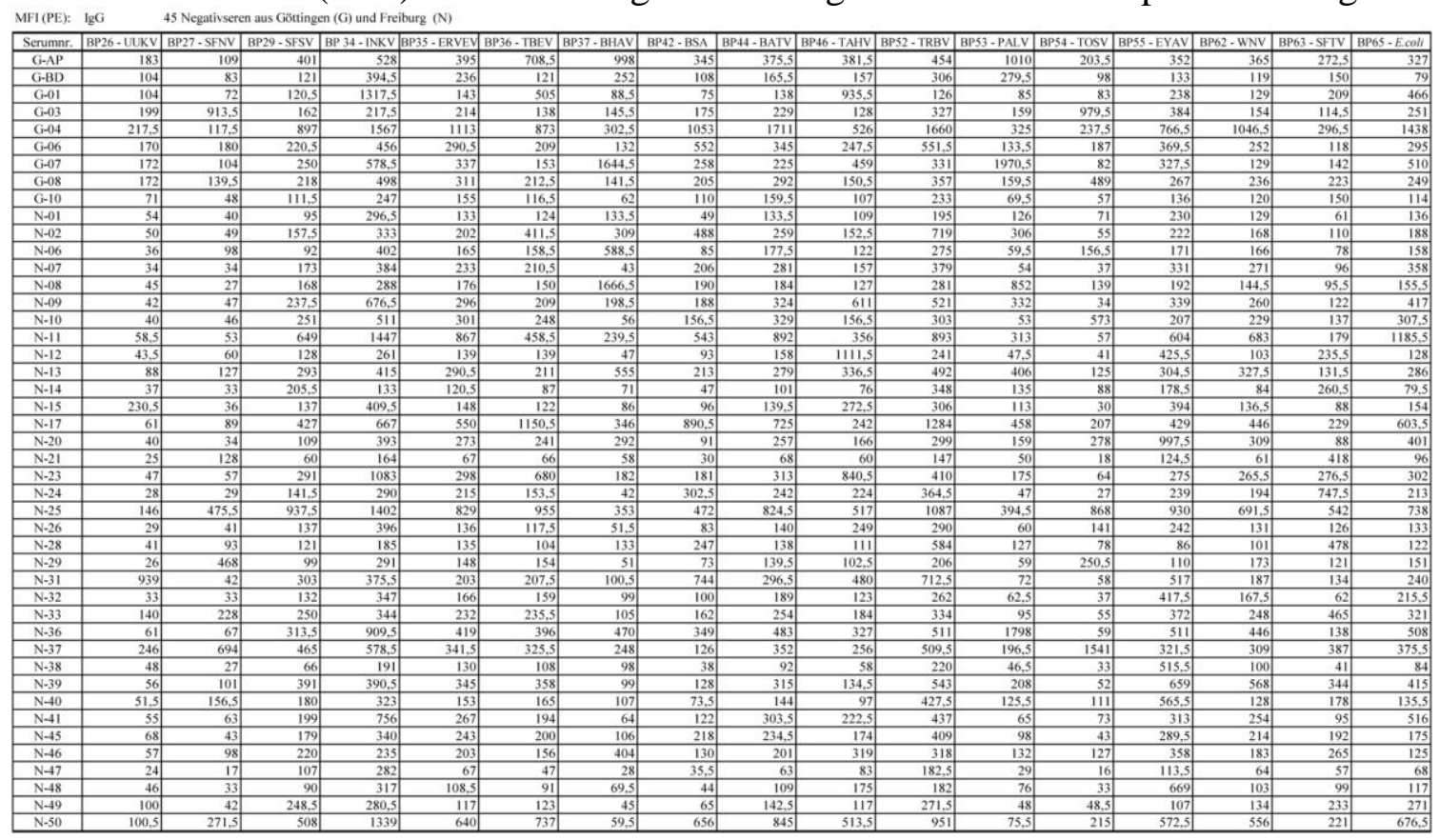

\subsubsection{MFI (PE) 45 Negativseren zur Grenzwertberechnung IgM (Daten)}

Tabelle 6.4: Daten (MFI) nach Messung von 45 Negativseren als Multiplex-CBA: IgM

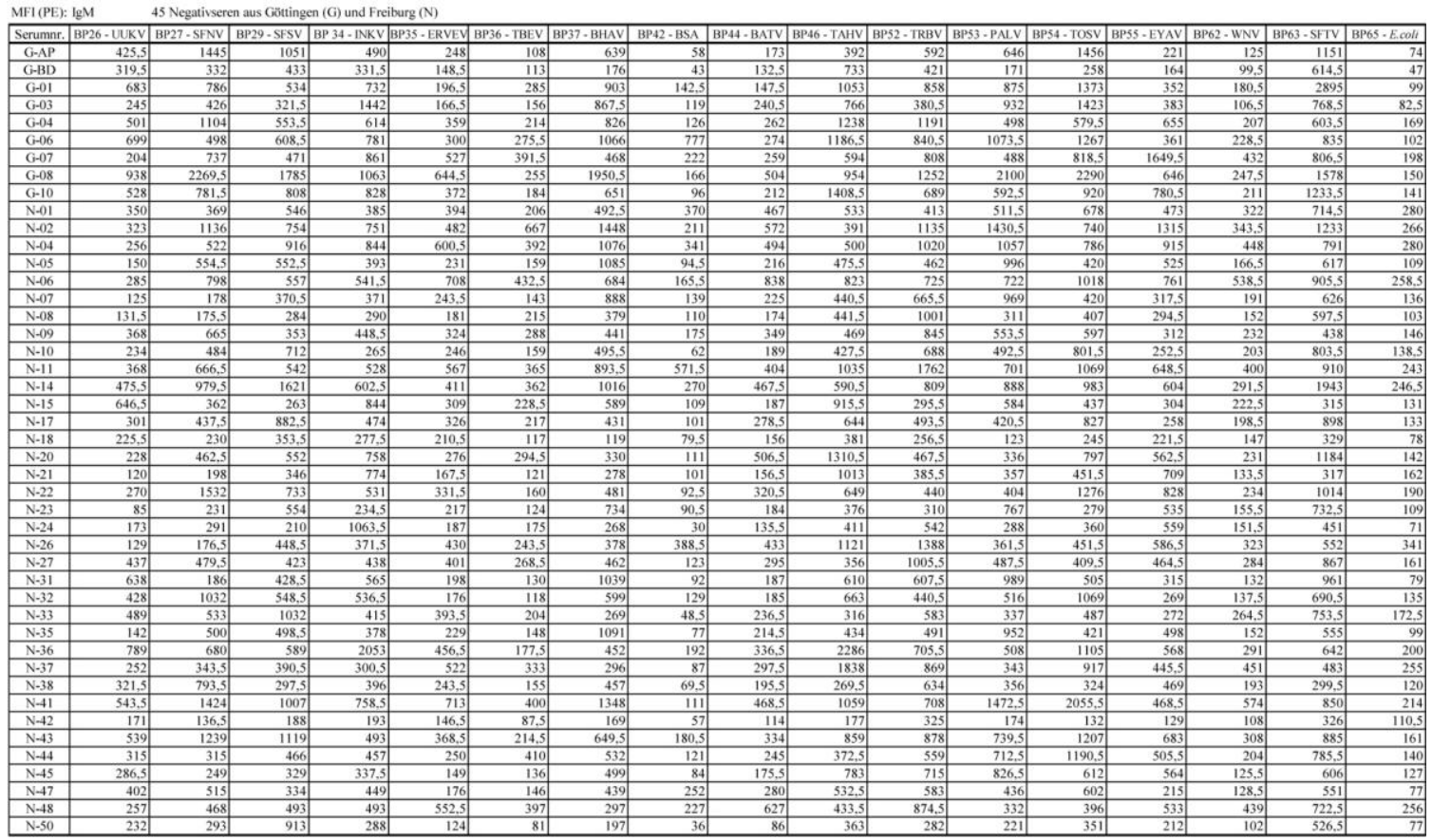




\subsubsection{Zusammenfassung: Grenzwertberechnung IgG und IgM}

Tabelle 6.5: Grenzwertberechnung Methode (A) und (B) IgG-Antikörper

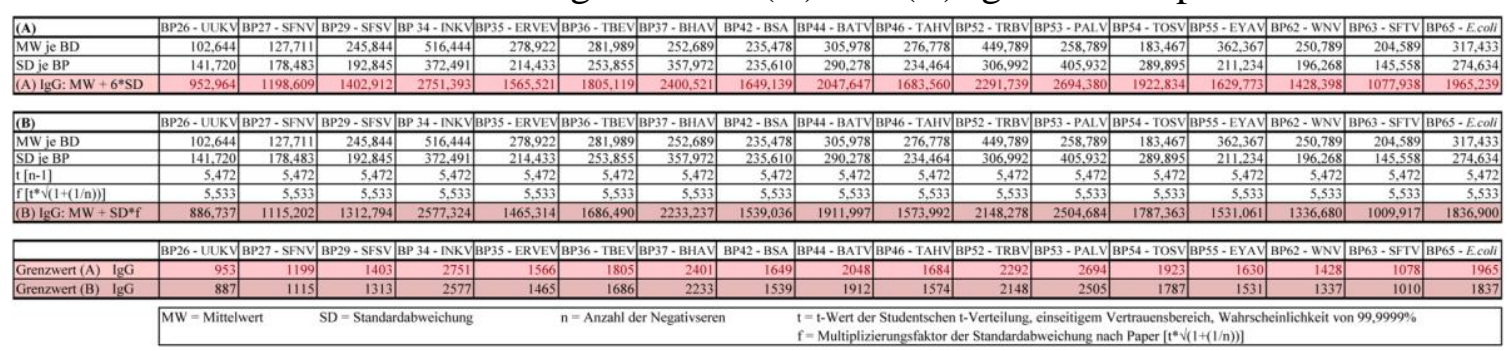

Tabelle 6.6: Grenzwertberechnung Methode (A) und (B) IgM-Antikörper

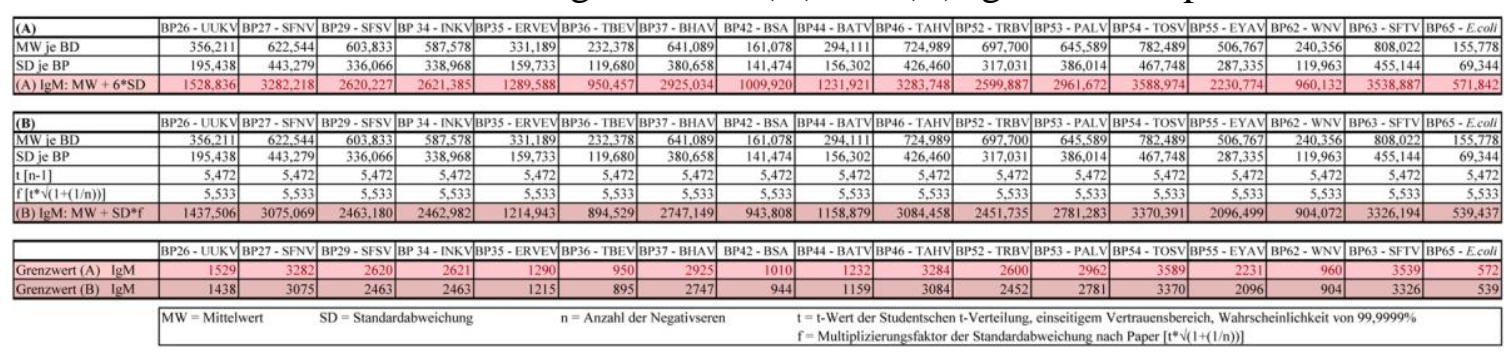

\subsection{Zusammenfassung: Ergebnisse Multiplex-CBA Patientenproben}

\subsubsection{MFI (PE) Patientenproben IgG n=1 (Daten)}

Tabelle 6.7: Daten (MFI) nach Messung von 111 Patientenseren, Multiplex-CBA (IgG) $\mathrm{MFI(PE)}: \lg \mathrm{g} \quad \mathrm{n}=1$ (11 Patienten, "Patienten mit Mehrfachproben-Abgabe (6)

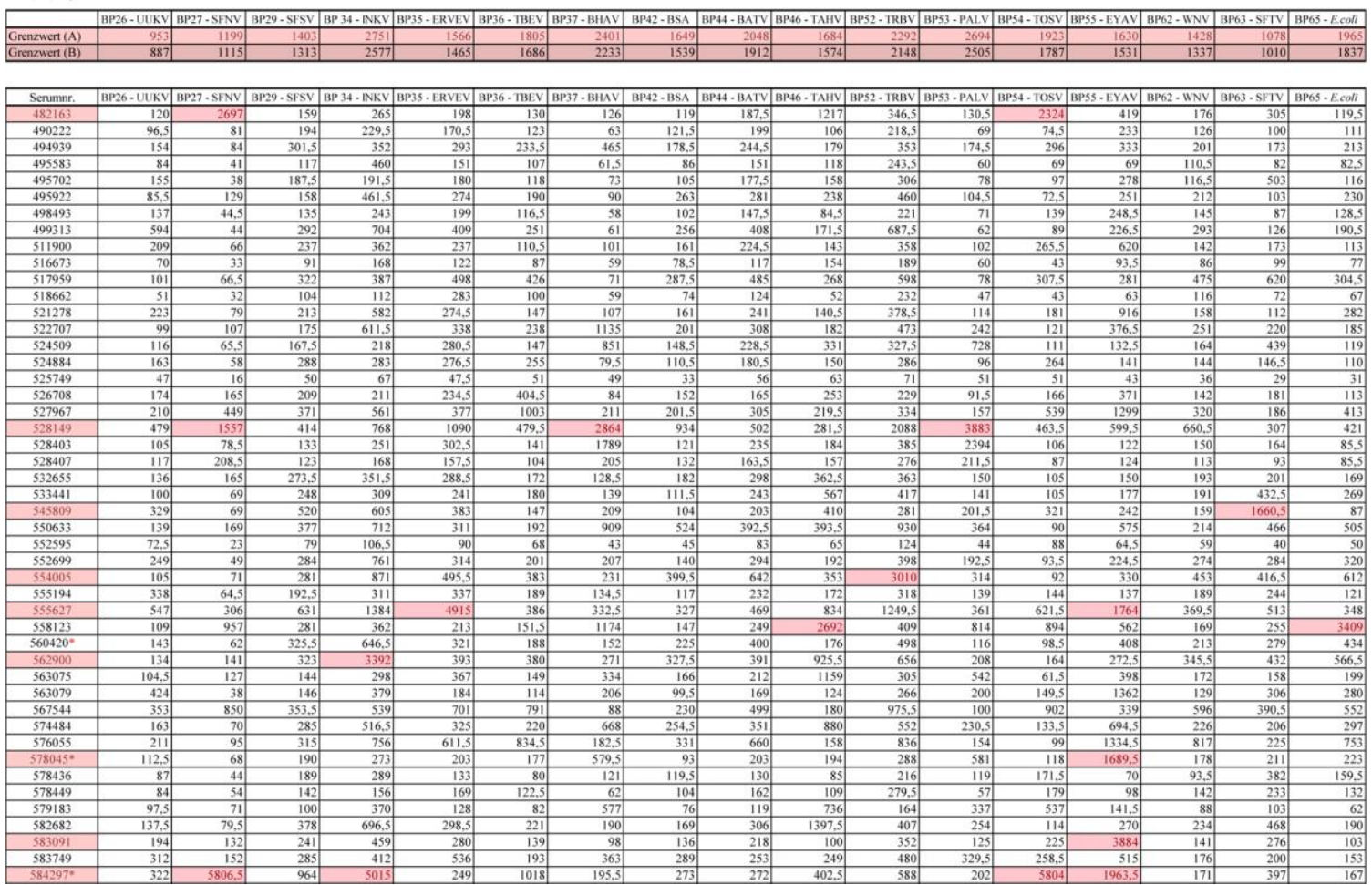




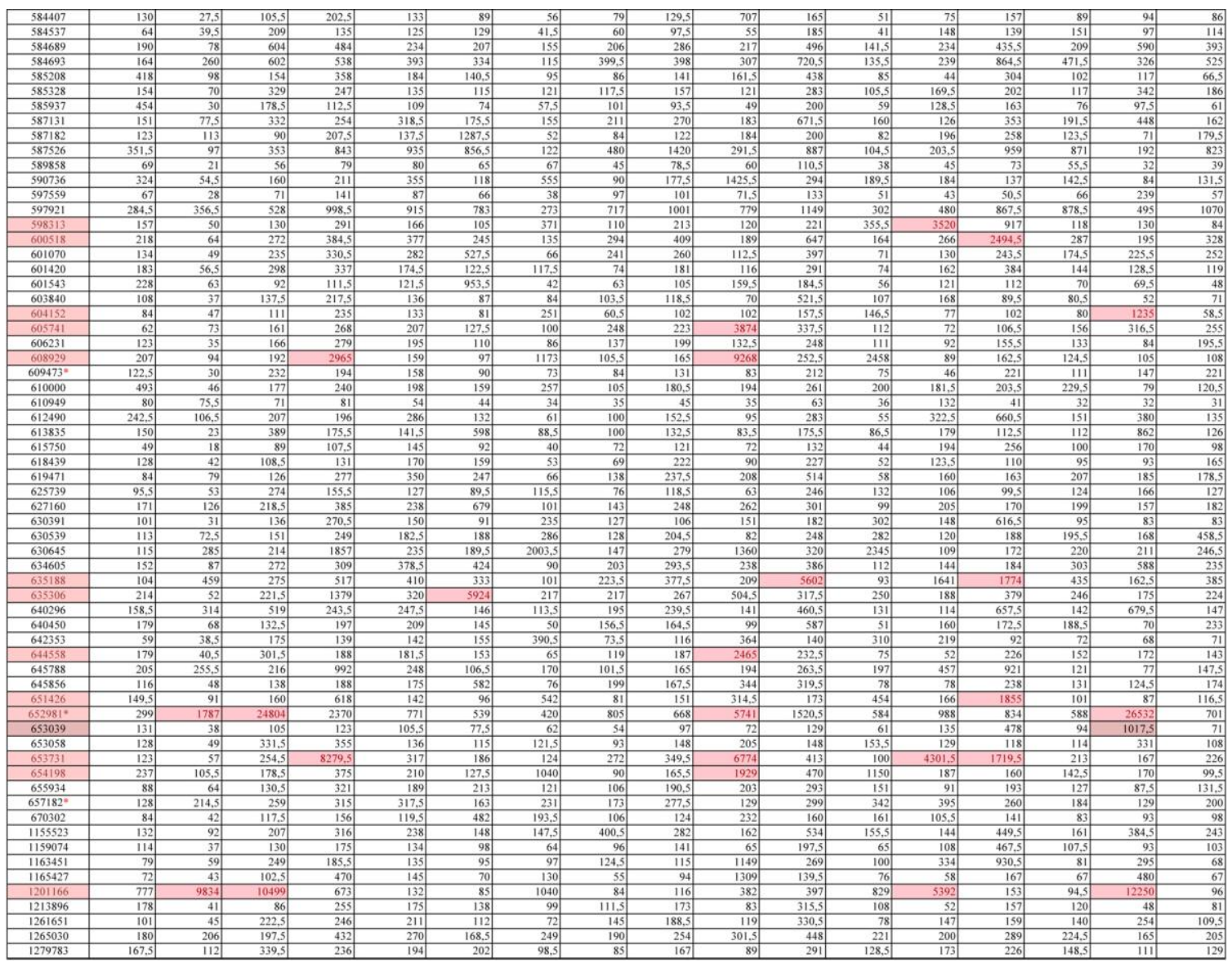

\subsubsection{MFI (PE) Patientenproben IgM $\mathbf{n}=1$ (Daten)}

Tabelle 6.8: Daten (MFI) nach Messung von 111 Patientenseren, Multiplex-CBA (IgM)

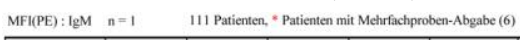

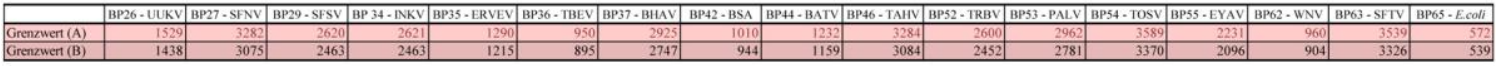

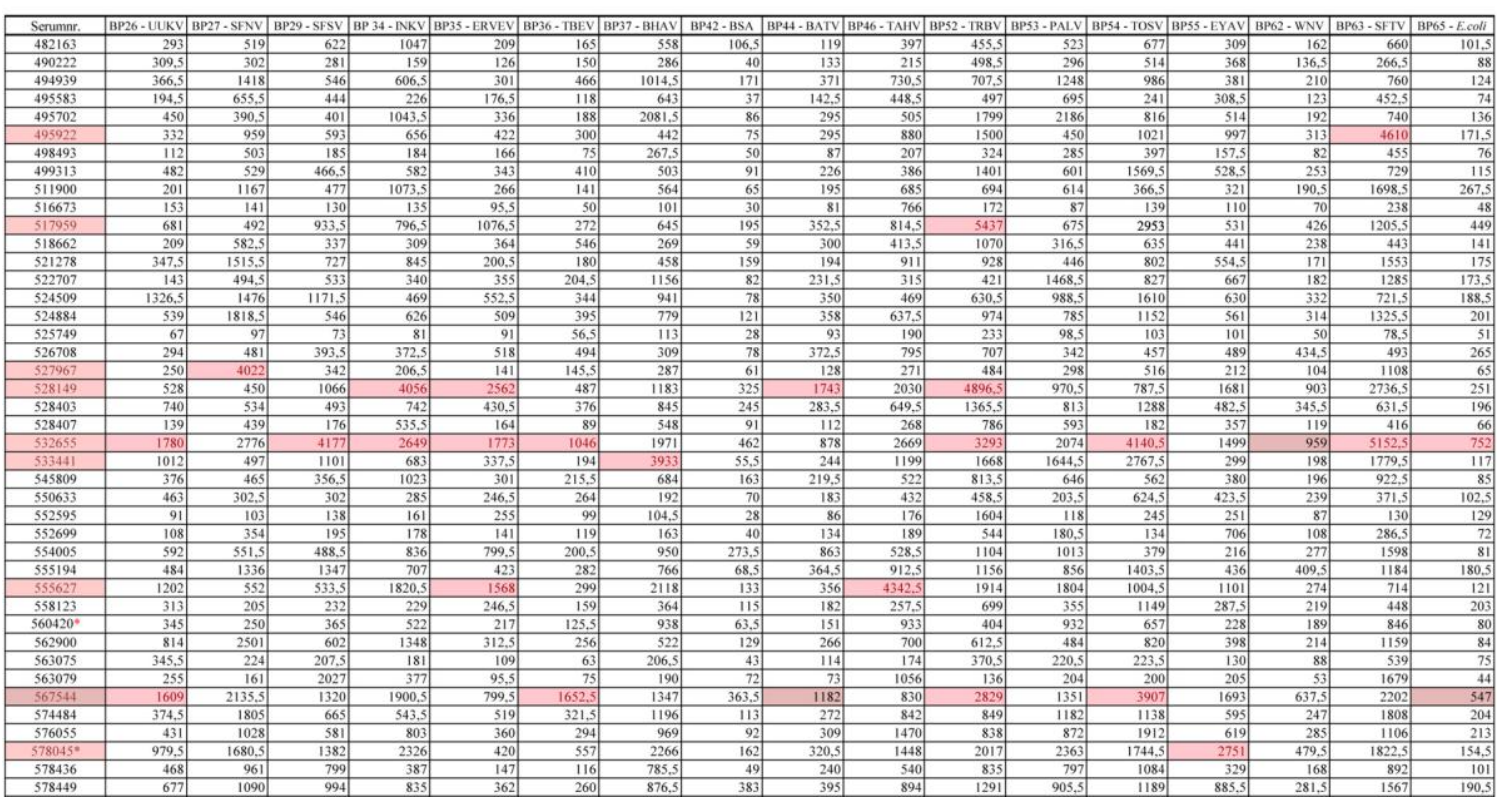




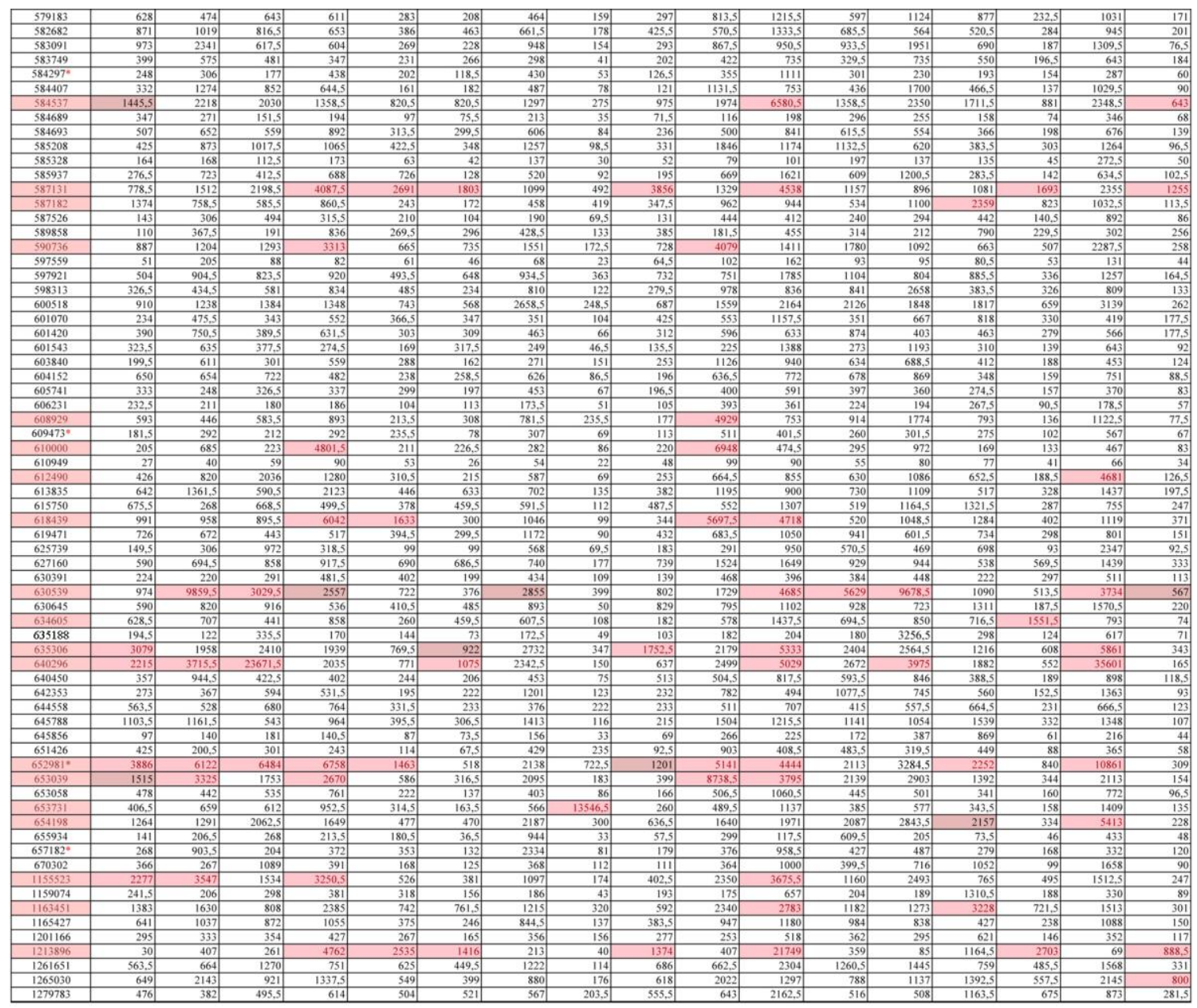

6.6.3 Bestätigung Multiplex-CBA durch Untersuchung weiterer Proben des selben Patienten (Zeitraum der Probennahme innerhalb von zwei Wochen)

Tabelle 6.9: Daten (MFI) nach Messung aller Proben der sechs Patienten* (IgG)

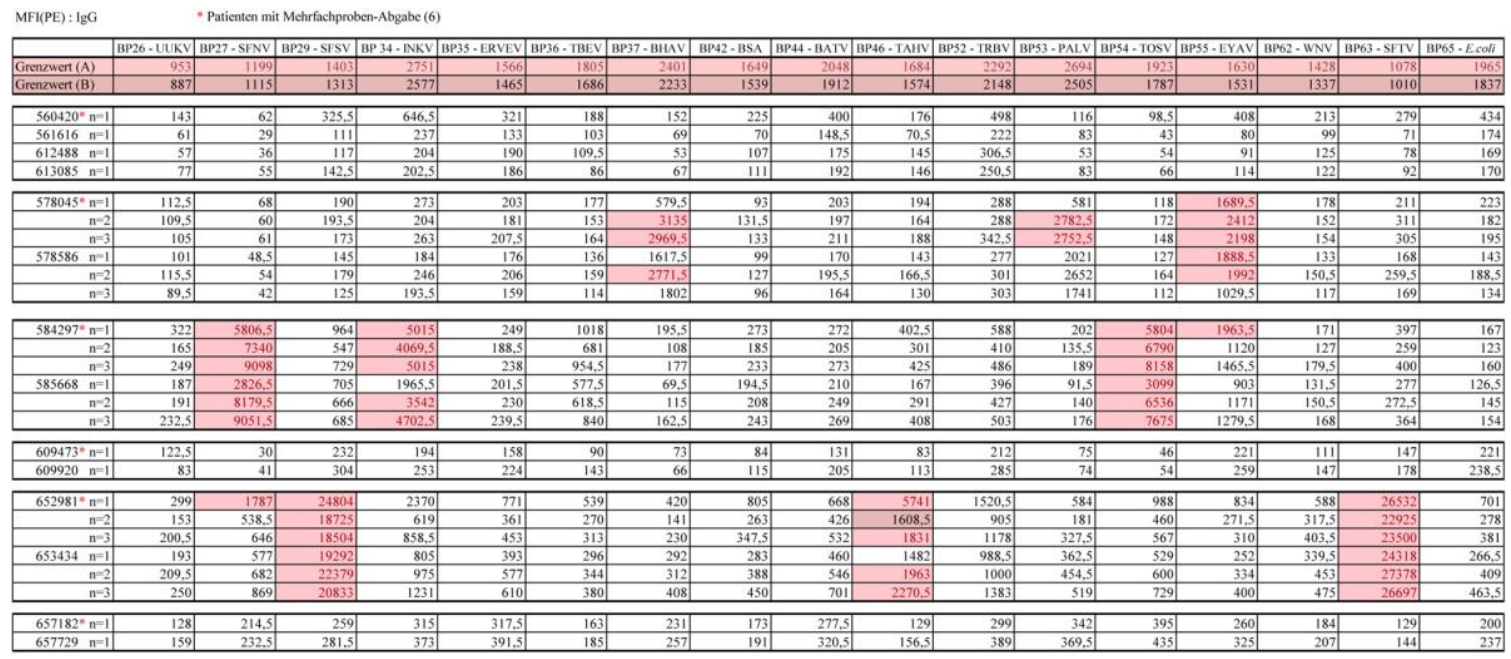


Tabelle 6.10: Daten (MFI) nach Messung aller Proben der sechs Patienten* (IgM) MF(PE) : IgM P Patienter nit Mecrifachporoben-Abgabe (6)

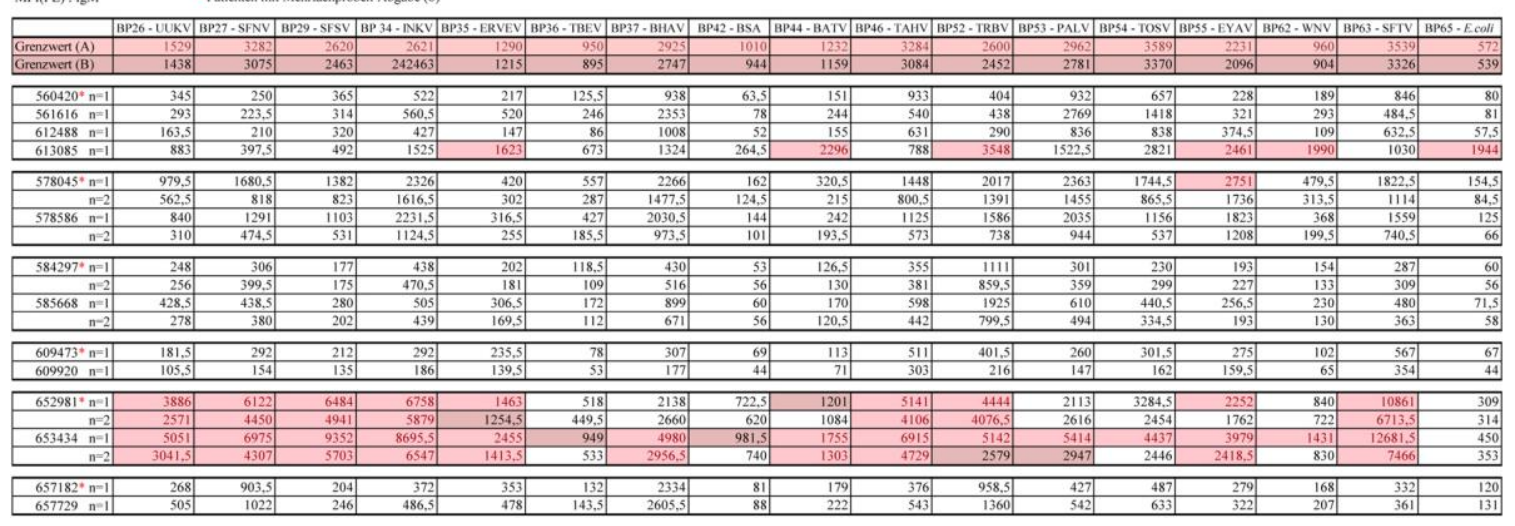

\subsubsection{Bestätigung seropositiver Patientenproben auf arbovirale IgG-Antikörper durch Mehrfachmessung (Daten)}

Tabelle 6.11: Daten (MFI) nach Messung IgG positiver Patientenproben $n=3$ (IgG)

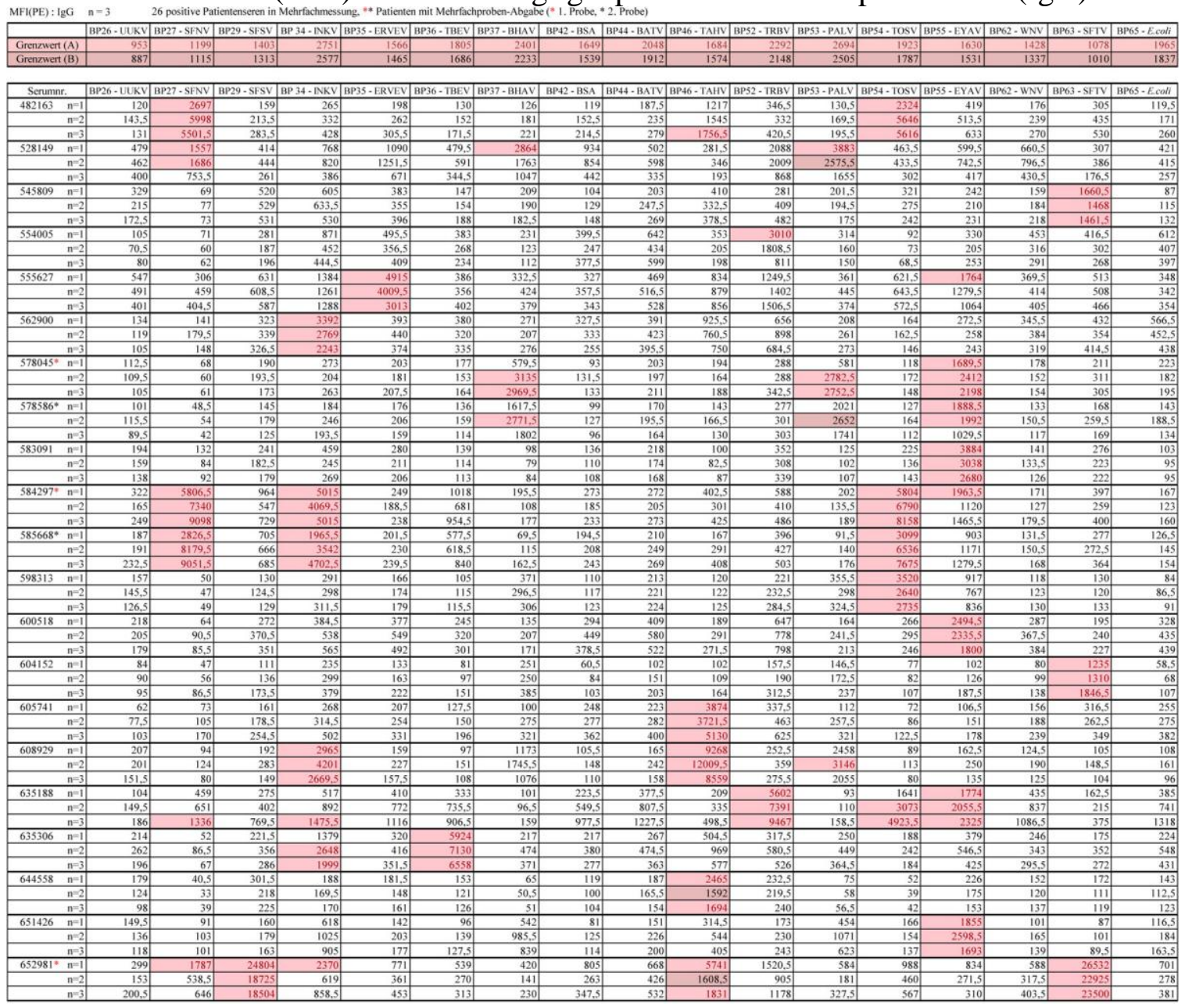




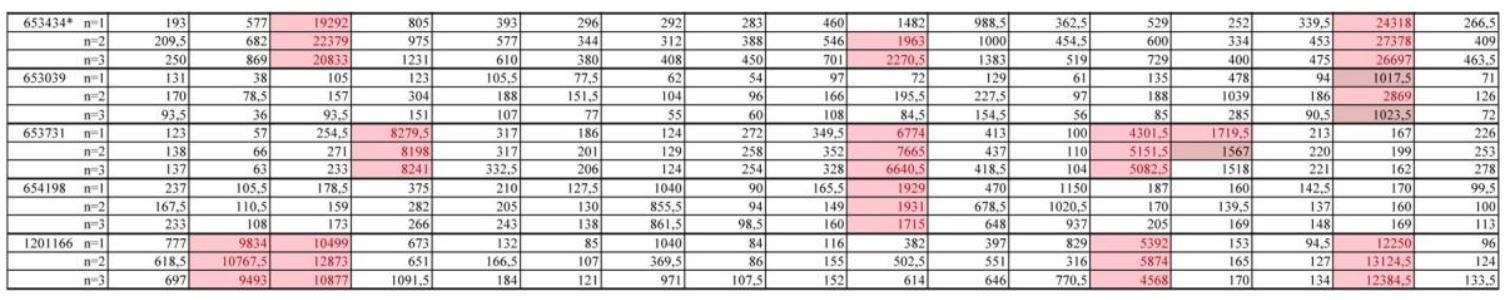

6.6.5 Bestätigung seropositiver Patientenproben auf arbovirale IgM-Antikörper durch Mehrfachmessung (Daten)

Tabelle 6.12: Daten (MFI) der positiven Patientenproben $(\operatorname{IgG}+\operatorname{IgM}) \mathrm{n}=2(\operatorname{IgM})$

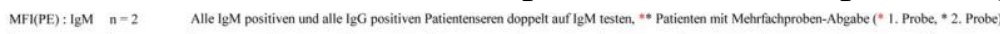

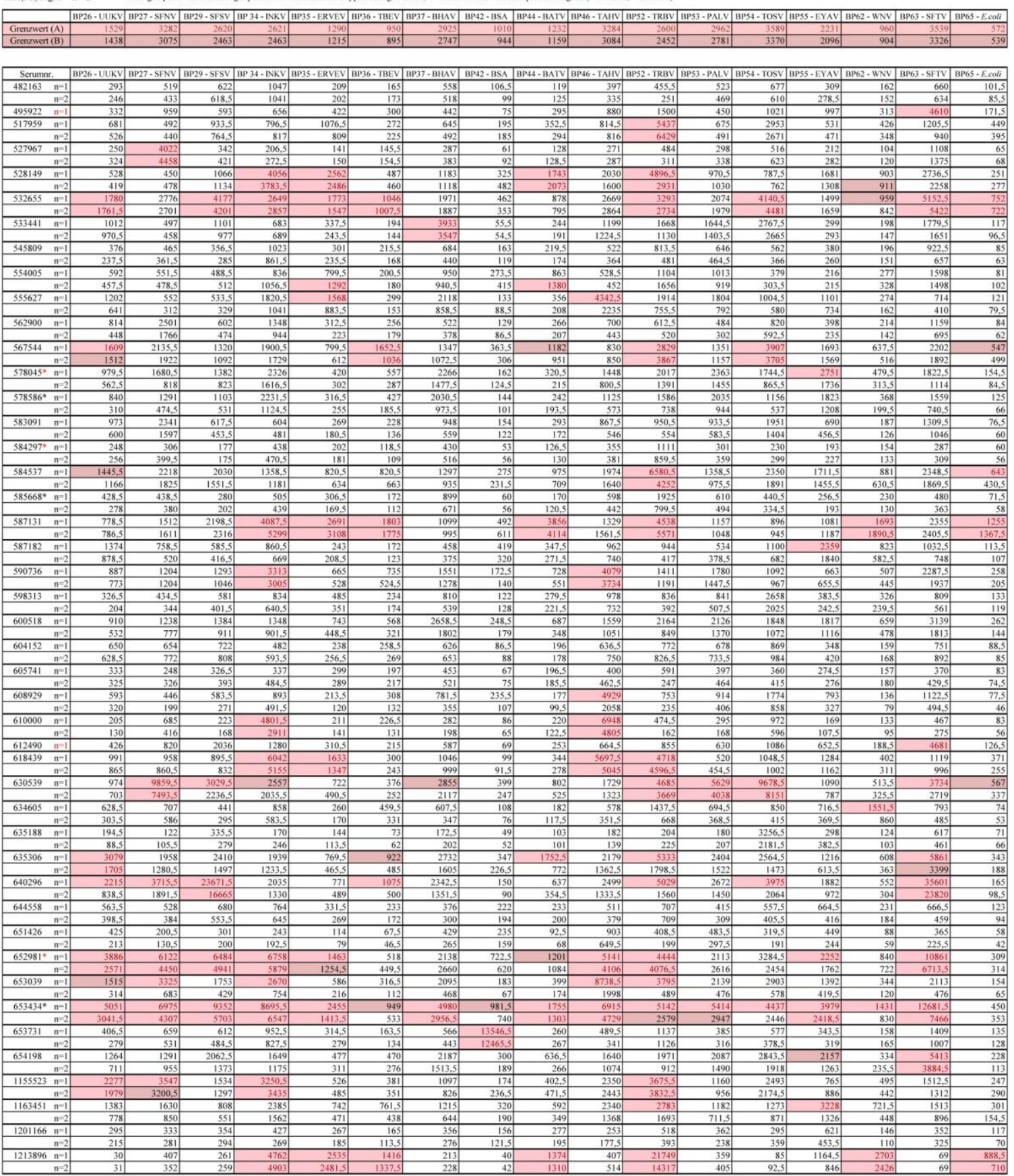




\subsubsection{Graphische Darstellung Patientenseren Fall 2 (GraphPad Prism 6)}
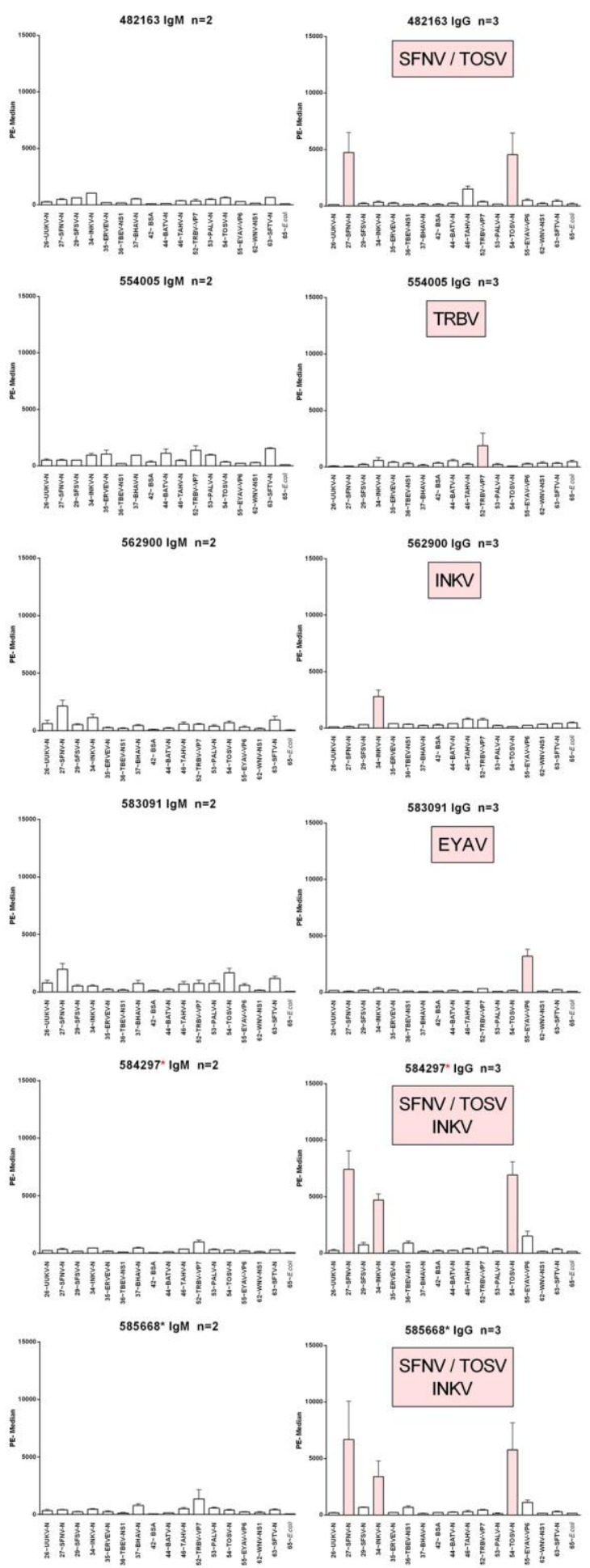
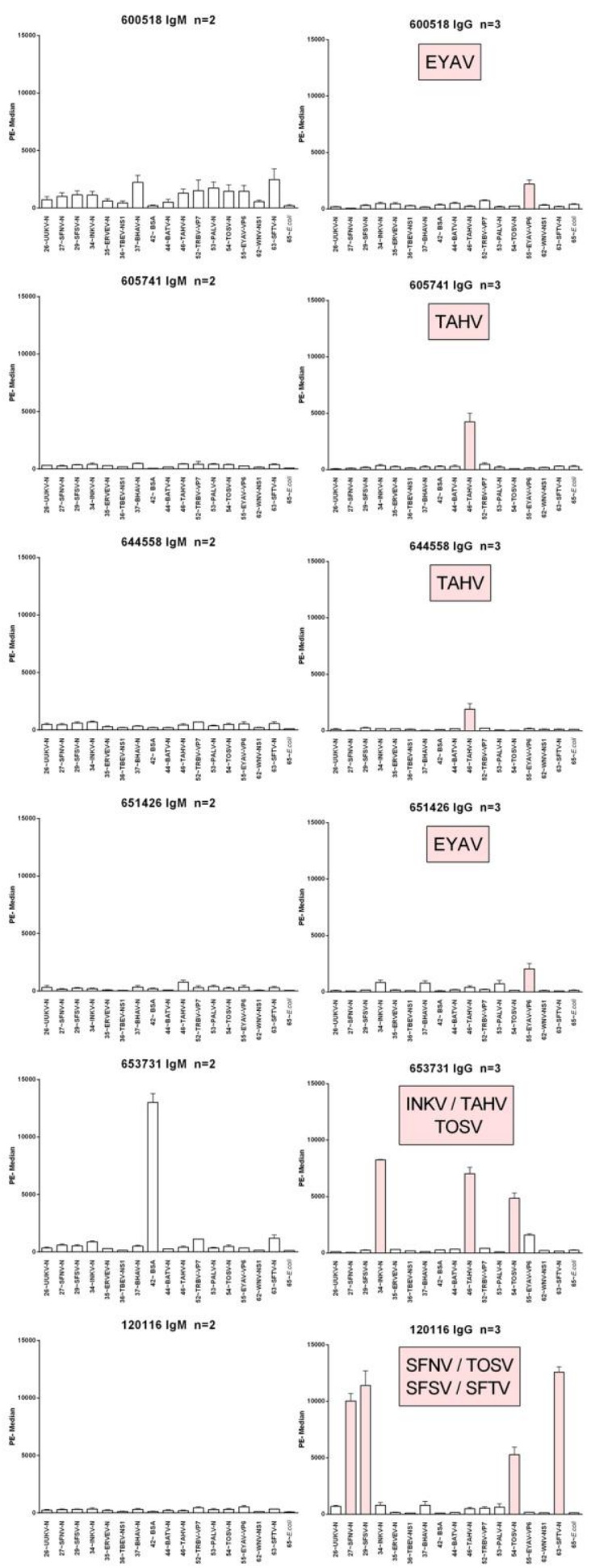

Abb. 6.9: Multiplex-CBA, Seren Fall 2 (IgM -, IgG +). Dargestellt sind die MFI jeder Beadpopulation gemessen als Multiplex-CBA (Software: GraphPad Prism 6). Bei den mit ** gekennzeichneten Seren handelt es sich um eine Person, von der eine weitere Probe zur Untersuchung vorlag. 


\subsubsection{Graphische Darstellung Patientenseren Fall 3 (GraphPad Prism 6)}
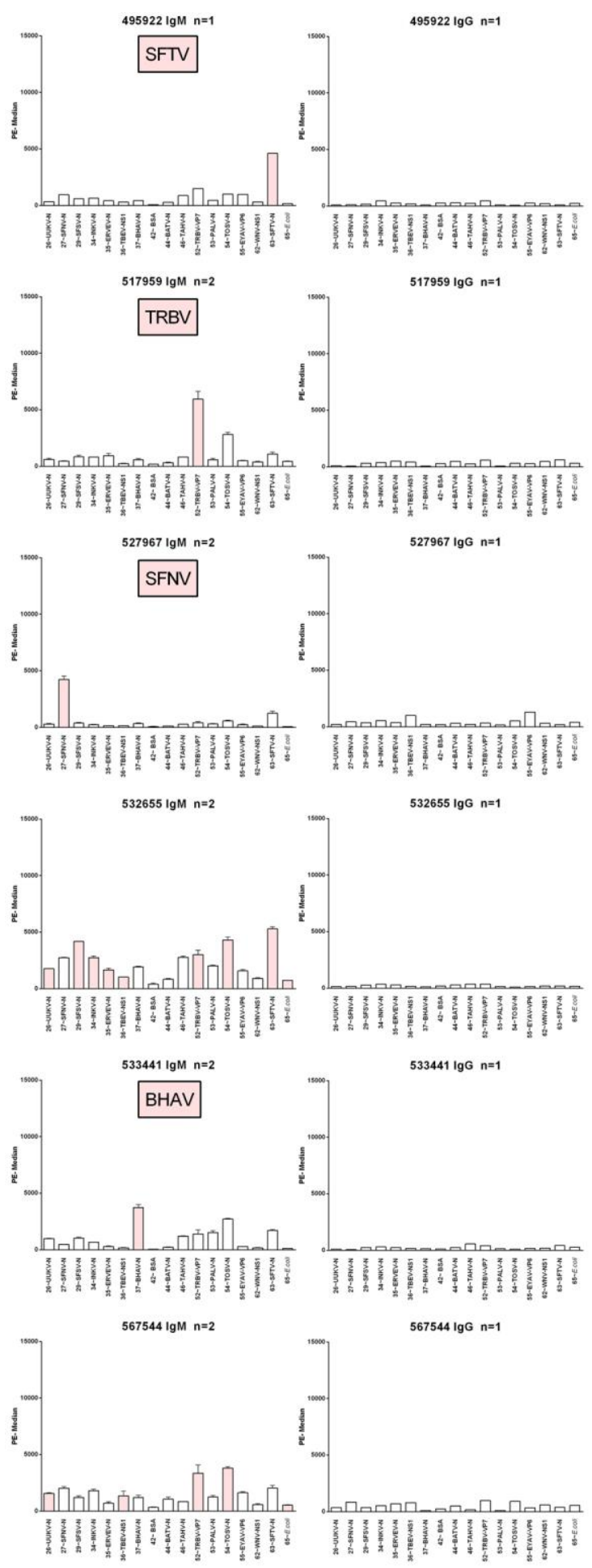
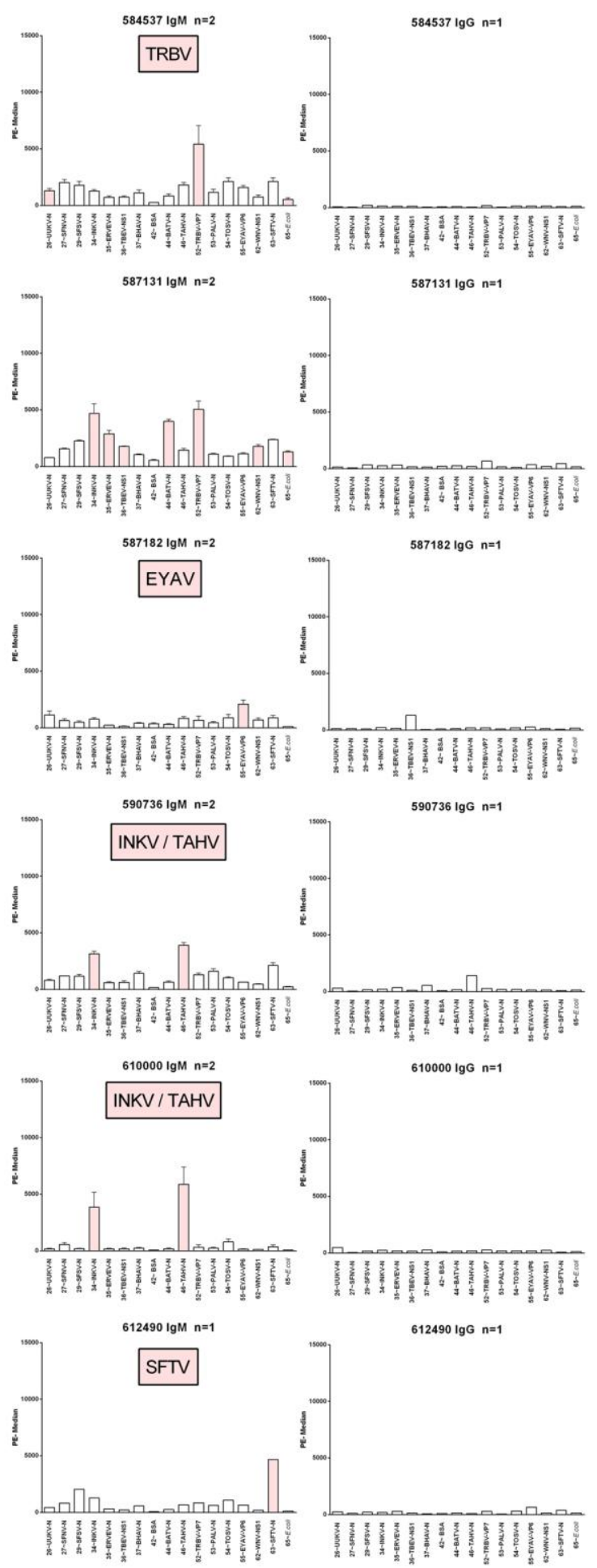

Abb. 6.10: Multiplex-CBA, Seren Fall 3 (IgM +, IgG -), Teil 1 von 2. Dargestellt sind die MFI jeder Beadpopulation gemessen als Multiplex-CBA (Software: GraphPad Prism 6). 

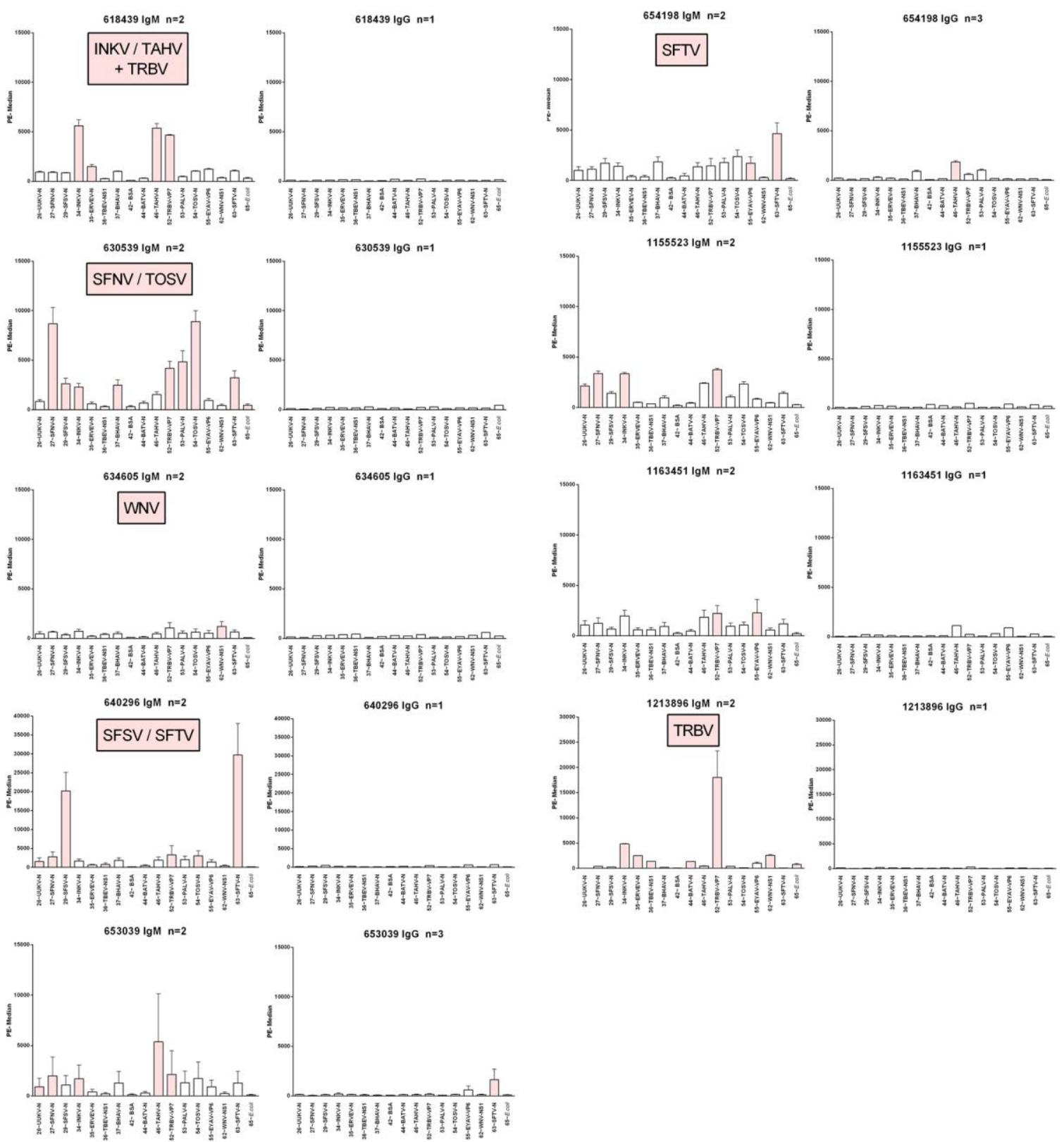

Abb. 6.11: Multiplex-CBA, Seren Fall 3 (IgM +, IgG -), Teil 2 von 2. Dargestellt sind die MFI jeder Beadpopulation gemessen als Multiplex-CBA (Software: GraphPad Prism 6). 


\subsubsection{Graphische Darstellung Patientenseren Fall 4 (GraphPad Prism 6)}
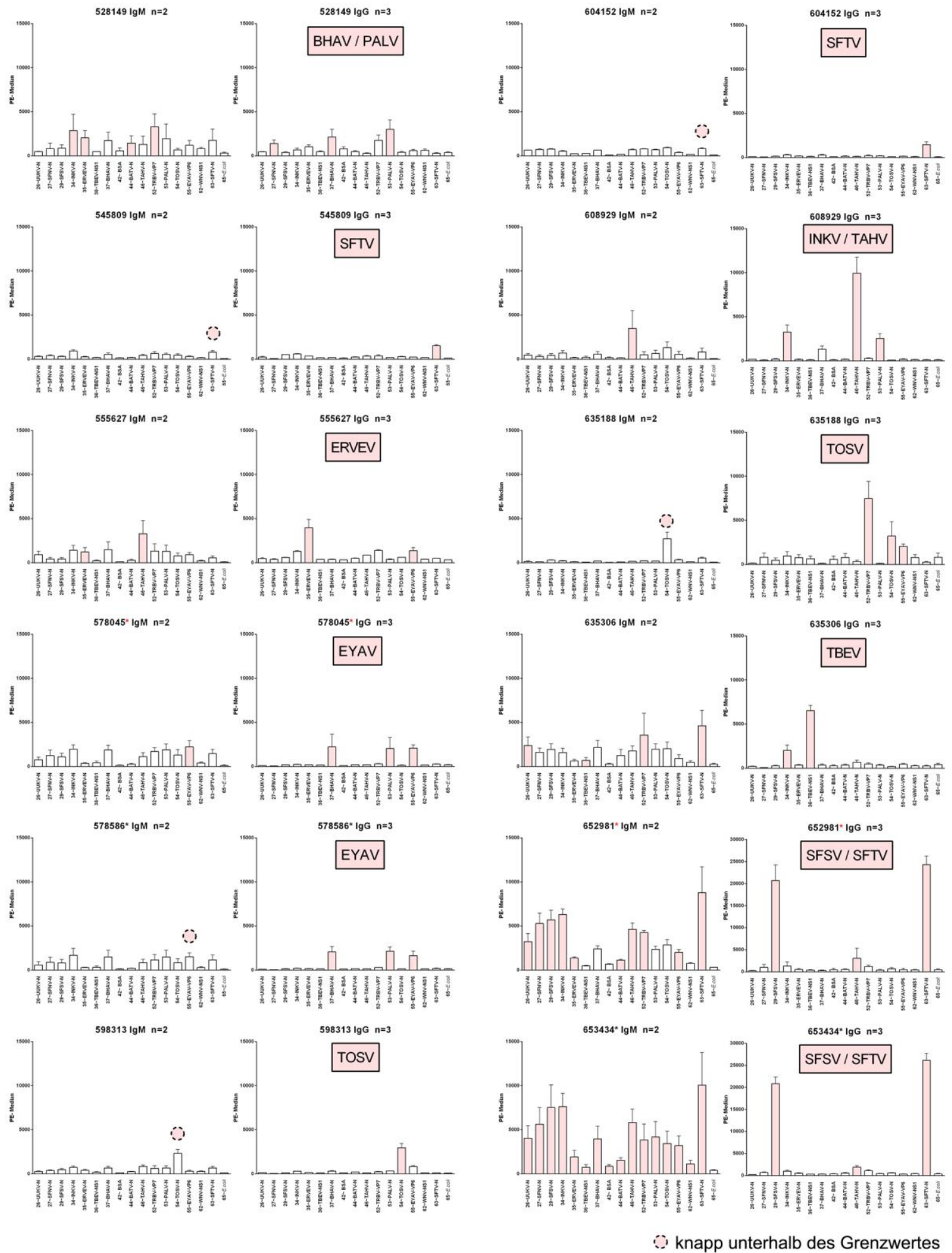

Abb. 6.12: Multiplex-CBA, Seren Fall 4 (IgM +, IgG +). Dargestellt sind die MFI jeder Beadpopulation gemessen als Multiplex-CBA (Software: GraphPad Prism 6). Bei den mit ** gekennzeichneten Seren handelt es sich um eine Person, von der eine weitere Probe zur Untersuchung vorlag. 


\section{$7 \quad$ Literaturverzeichnis}

Alcon, S., Talarmin, A., Debruyne, M., Falconar, A., Deubel, V. \& Flamand, M. (2002). Enzyme-linked immunosorbent assay specific to dengue virus type 1 nonstructural protein NS1 reveals circulation of the antigen in the blood during the experiencing primary acute phase of disease in patients or secondary infections. Journal of Clinical Microbiology 40, 376-381.

Alkan, C., Bichaud, L., De Lamballerie, X., Alten, B., Gould, E. A. \& Charrel, R. N. (2013). Sandfly-borne phleboviruses of Eurasia and Africa: Epidemiology, genetic diversity, geographic range, control measures. Antiviral research 100, 5474.

Anagnostou, V. \& PAPA, A. (2013). Prevalence of antibodies to phleboviruses within the sand fly fever Naples virus species in humans, northern Greece. Clinical microbiology and infection : the official publication of the European Society of Clinical Microbiology and Infectious Diseases 19, 566-70.

Artsob, H., Gubler, D. J., Enria, D. A., Morales, M. A., Pupo, M., Bunning, M. L. \& Dudley, J. P. (2009). West Nile Virus in the New World: trends in the spread and proliferation of West Nile Virus in the Western Hemisphere. Zoonoses and public health 56, 357-69.

BalducCi, M., Verani, P., LOPES, M. C. \& NARDi, F. (1970). Experimental pathogenicity of Bhanja virus for white mice and Macaca mulatta monkeys. Acta virologica 14, 237-43.

BARDOS, V. (1974). Recent state of knowledge of Tahyna virus infections. Folia parasitologica 21, 1-10.

BARDOS, V. \& CUPKOvA, E. (1962). The Calovo virus--the second virus isolated from mosquitoes in Czechoslovakia. Journal of hygiene, epidemiology, microbiology, and immunology 6, 186-92.

Bardos, V. \& Danielova, V. (1959). The Tahyna virus--a virus isolated from mosquitoes in Czechoslovakia. Journal of hygiene, epidemiology, microbiology, and immunology 3, 264-76.

Becker, N., Kruger, A., Kuhn, C., Plenge-Bonig, A., Thomas, S. M., SchmidtChanasit, J. \& TANNICH, E. (2014). Mosquitoes as vectors for exotic pathogens in Germany. Bundesgesundheitsblatt-Gesundheitsforschung-Gesundheitsschutz 57, 531-540.

BIGL, S. (2001). Virus-Meningoenzephalitis im Freistaat Sachsen. In Epidemiologisches Bulletin, pp. 153-156. Robert Koch Institut.

BRINTON, M. A. (2002). The molecular biology of West Nile Virus: a new invader of the western hemisphere. Annu Rev Microbiol 56, 371-402.

BRINTON, M. A. (2014). Replication cycle and molecular biology of the West Nile virus. Viruses 6, 13-53. 
Brown, J. E., Scholte, E.-J., Dik, M., Den Hartog, W., Beeuwkes, J. \& Powell, J. R. (2011). Aedes aegypti mosquitoes imported into the Netherlands, 2010. Emerging infectious diseases 17, 2335-7.

Brummer-Korvenkontio, M., Saikku, P., Korhonen, P., Ulmanen, I., Reunala, T. \& KARVONEN, J. (1973). Arboviruses in Finland. IV. Isolation and characterization of Inkoo virus, a Finnish representative of the California group. The American journal of tropical medicine and hygiene 22, 404-13.

Bugrysheva, J. V., Matveeva, V. A., Dobrikova, E. Y., Bykovskaya, N. V., Korobova, S. A., BaKhValova, V. N. \& Morozova, O. V. (2001). Tick-borne encephalitis virus NS1 glycoprotein during acute and persistent infection of cells. Virus Research 76, 161-169.

BuRKE, D. S. A. M., T. P. (2001). Flaviviruses. In Fields Virology (D. M. Knipe and P. M. Howley, eds.), vol. 1, pp. 1043-1126. Lippincott Williams 6 Wilkins, Philadelphia.

Carhan, A., Uyar, Y., Ozkaya, E., Ertek, M., Dobler, G., Dilcher, M., Wang, Y., SPIEGEL, M., HUfERT, F. \& WEIDMANN, M. (2010). Characterization of a sandfly fever Sicilian virus isolated during a sandfly fever epidemic in Turkey. Journal of clinical virology : the official publication of the Pan American Society for Clinical Virology 48, 264-9.

Charrel, R. N., Gallian, P., Navarro-Mari, J. M., Nicoletti, L., PaPa, A., SanchezSeco, M. P., Tenorio, A. \& DE LAMBAllerie, X. (2005). Emergence of Toscana virus in Europe. Emerg Infect Dis 11, 1657-63.

Chastel, C., Main, A. J., Richard, P., Lelay, G., Legrandquillien, M. C. \& Beaucournu, J. C. (1989). Erve Virus, a Probable Member of Bunyaviridae Family Isolated from Shrews (Crocidura-Russula) in France. Acta Virologica 33, 270-280.

Connie, R., Mahon \& Manuselis, G., JR. (1995). Textbook Of Diagnostic Microbiology. W.B. Saunders Company.

Crill, W. D., Trainor, N. B. \& Chang, G.-J. J. (2007). A detailed mutagenesis study of flavivirus crossreactive epitopes using West Nile virus-like

particles. Journal of General Virology, 1169-1174.

Daniel, M., Danielova, V., KRIZ, B. \& KotT, I. (2004). An attempt to elucidate the increased incidence of tick-borne encephalitis and its spread to higher altitudes in the Czech Republic. International journal of medical microbiology : IJMM 293 Suppl 37, 55-62.

Danielova, V., Holubova, J., Pejcoch, M. \& Daniel, M. (2002). Potential significance of transovarial transmission in the circulation of tick-borne encephalitis virus. Folia parasitologica 49, 323-5.

Danielova, V., Rudenko, N., Daniel, M., Holubova, J., Materna, J., Golovchenko, M. \& SCHWARZOVA, L. (2006). Extension of Ixodes ricinus ticks and agents of tick-borne diseases to mountain areas in the Czech Republic. International journal of medical microbiology: IJMM 296 Suppl 40, 48-53.

Davison, K. L., Crowcroft, N. S., RAmsay, M. E., Brown, D. W. G. \& Andrews, N. J. (2003). Viral encephalitis in England, 1989-1998: what did we miss? Emerging infectious diseases 9, 234-40. 
Dekoninck, W., Hendrickx, F., Vasn Bortel, W., Versteirt, V., CoOsemans, M., Damiens, D., Hance, T., De Clercq, E. M., Hendrickx, G., Schaffner, F. \& Grootaert, P. (2011). Human-induced expanded distribution of Anopheles plumbeus, experimental vector of West Nile virus and a potential vector of human malaria in Belgium. Journal of medical entomology 48, 924-8.

Depaquit, J., Grandadam, M., Fouque, F., Andry, P. E. \& Peyrefitte, C. (2010). Arthropod-borne viruses transmitted by Phlebotomine sandflies in Europe: a review. Euro surveillance : bulletin Europeen sur les maladies transmissibles $=$ European communicable disease bulletin 15, 19507.

Dilcher, M., Alves, M. J., Finkeisen, D., Hufert, F. \& Weidmann, M. (2012a). Genetic characterization of Bhanja virus and Palma virus, two tick-borne phleboviruses. Virus genes 45, 311-5.

Dilcher, M., Hasib, L., Lechner, M., WieseKe, N., Middendorf, M., Marz, M., Koch, A., Spiegel, M., Dobler, G., Hufert, F. T. \& Weidmann, M. (2012b). Genetic characterization of Tribec virus and Kemerovo virus, two tick-transmitted humanpathogenic Orbiviruses. Virology 423, 68-76.

Dilcher, M., Koch, A., Hasib, L., Dobler, G., Hufert, F. T. \& WeidmanN, M. (2012c). Genetic characterization of Erve virus, a European Nairovirus distantly related to Crimean-Congo hemorrhagic fever virus. Virus genes 45, 426-32.

Dilcher, M., SAll, A. A., Hufert, F. T. \& Weidmann, M. (2013). Clarifying Bunyamwera virus riddles of the past. Virus genes 47, 160-3.

DoBLER, G. (1996). Arboviruses causing neurological disorders in the central nervous system. Archives of Virology, 33-40.

Dobler, G., Fingerle, V., Hagedorn, P., Pfeffer, M., Silaghi, C., Tomaso, H., HENNING, K. \& NiEDRIG, M. (2014). [Threat of transmission of infectious pathogens by Ixodes ricinus ticks in Germany]. Bundesgesundheitsblatt Gesundheitsforschung Gesundheitsschutz 57, 541-8.

Dobler, G., JelineK, T., Frosner, G., Nothdurft, H. D. \& Loscher, T. (1997). [Cross reactions of patients with acute dengue fever to tick-borne encephalitis]. Wien Med Wochenschr 147, 463-4.

Dobler, G., Wolfel, R., Schmuser, H., Essbauer, S. \& Pfeffer, M. (2006). Seroprevalence of tick-borne and mosquito-borne arboviruses in European brown hares in Northern and Western Germany. Int J Med Microbiol 296 Suppl 40, 803.

Echevarria, J.-M., De Ory, F., Guisasola, M.-E., SAnchez-Seco, M.-P., Tenorio, A., Lozano, A., Cordoba, J. \& Gobernado, M. (2003). Acute meningitis due to Toscana virus infection among patients from both the Spanish Mediterranean region and the region of Madrid. Journal of clinical virology : the official publication of the Pan American Society for Clinical Virology 26, 79-84.

Eitrem, R., Stylianou, M. \& NikLasson, B. (1991). High prevalence rates of antibody to three sandfly fever viruses (Sicilian, Naples, and Toscana) among Cypriots. Epidemiology and infection 107, 685-91.

Eitrem, R., Vene, S. \& NikLasson, B. (1990). Incidence of sand fly fever among Swedish United Nations soldiers on Cyprus during 1985. The American journal of tropical medicine and hygiene 43, 207-11. 
Ergunay, K., Ismayilova, V., Colpak, I. A., Kansu, T. \& Us, D. (2012). A case of central nervous system infection due to a novel Sandfly Fever Virus (SFV) variant: Sandfly Fever Turkey Virus (SFTV). Journal of clinical virology : the official publication of the Pan American Society for Clinical Virology 54, 79-82.

Ergunay, K., Saygan, M. B., Aydogan, S., Lo, M. M., Weidmann, M., Dilcher, M., Sener, B., HasceliK, G., PINAR, A. \& Us, D. (2011). Sandfly fever virus activity in central/northern Anatolia, Turkey: first report of Toscana virus infections. Clinical microbiology and infection : the official publication of the European Society of Clinical Microbiology and Infectious Diseases 17, 575-81.

Fauquet, C. M., M.A. Mayo, J. Maniloff, U. Desselberger, And Ball L.A. (2005). 8th Reports of the International Committee on Taxonomy of Viruses 2005. Elsevier Academic Press.

Fields, B., KNIPE, D. \& Howley, P. (2007). Virology 5edition. Lippincott Williams \& Wilkins, a Wolters Kluwer Business, Philadelphia, USA.

Filipe, A. R., Alves, M. J., Karabatsos, N., de Matos, A. P., Nuncio, M. S. \& BACELlaR, F. (1994). Palma virus, a new bunyaviridae isolated from ticks in Portugal. Intervirology 37, 348-51.

FreY, A., Di CANZIO, J. \& ZuRAKOWSKI, D. (1998). A statistically defined endpoint titer determination method for immunoassays. Journal of immunological methods $\mathbf{2 2 1}$, 35-41.

GORMAN, B. M. (1983). On the evolution of orbiviruses. Intervirology, 169-180.

Gornall, A. G., Bardawill, C. J. \& David, M. M. (1949). Determination of serum proteins by means of the biuret reaction. The Journal of biological chemistry $\mathbf{1 7 7}$, 751-66.

GRAY, J. S. (2002). Biology of Ixodes species ticks in relation to tick-borne zoonoses. Wien Klin Wochenschr 114, 473-8.

GREINER, M. \& GARDNER, I. A. (2000). Epidemiologic issues in the validation of veterinary diagnostic tests. Prev Vet Med 45, 3-22.

GreINER, M., SOHR, D. \& GobEL, P. (1995). A modified ROC analysis for the selection of cut-off values and the definition of intermediate results of serodiagnostic tests. $J$ Immunol Methods 185, 123-32.

Gresikova, M., Nosek, J., Kozuch, O., Ernek, E. \& Lichard, M. (1965). Study on the ecology of Tribec Virus. Acta Virologica 9, 83-88.

Gresikova, M., RajCANi, J. \& HruZiK, J. (1966). Pathogenicity of Tribec virus for Macaca rhesus monkeys and white mice. Acta Virol 10, 420-4.

Hasib, L., Dilcher, M., Hufert, F., Meyer-Konig, U., Konig-Meyer, U. \& WEIDMANN, M. (2011). Development of a flow-through [corrected] microarray based reverse transcriptase multiplex ligation-dependent probe amplification assay for the detection of European Bunyaviruses. [corrected]. Molecular biotechnology 49, 176-86.

Helling, R. B., Goodman, H. M. \& Boyer, H. W. (1974). Analysis of endonuclease EcoRI fragments of DNA from bacteriophages and other viruses by agarose gel electrophoresis. J. Virol. 14, 1235-1244.

Houser, B. (2012). Bio-Rad's Bio-Plex suspension array system, xMAP technology overview. Archives of physiology and biochemistry 118, 192-6. 
HubALEK, Z. (1987). Experimental pathogenicity of Bhanja virus. Zentralblatt fur Bakteriologie, Mikrobiologie, und Hygiene Series A, Medical microbiology, infectious diseases, virology, parasitology 266, 284-91.

HubaleK, Z. (2008). Mosquito-borne viruses in Europe. Parasitology research 103 Suppl 1, S29-43.

HuBALEK, Z. (2009). Biogeography of tick-borne bhanja virus (bunyaviridae) in europe. Interdiscip Perspect Infect Dis 2009, 372691.

HubALEK, Z. \& HALOUZKA, J. (1999). West Nile fever--a reemerging mosquito-borne viral disease in Europe. Emerging infectious diseases 5, 643-50.

HubAleK, Z. \& Rudolf, I. (2012). Tick-borne viruses in Europe. Parasitology research 111, 9-36.

Hubalek, Z., Zeman, P., Halouzka, J., Juricova, Z., Stovickova, E., Balkova, H., Sikutova, S. \& Rudolf, I. (2005). Mosquitoborne viruses, Czech Republic, 2002. Emerg Infect Dis 11, 116-8.

HubÁLEK, Z. H., JIŘí. (1996). Arthropod-borne viruses of vertebrates in Europe. Acta Scientiarum Naturalium Academiae Scientiarum Bohemicae 30, 95pp.

Hukic, M. \& Salimovic-Besic, I. (2009). Sandfly - Pappataci fever in Bosnia and Herzegovina: the new-old disease. Bosnian journal of basic medical sciences / Udruzenje basicnih mediciniskih znanosti = Association of Basic Medical Sciences 9, 39-43.

INUMARU, S. \& ROY, P. (1987). Production and characterization of the neutralization antigen VP2 of bluetongue virus serotype 10 using a baculovirus expression vector. Virology 157, 472-9.

Jost, H., Bialonski, A., Schmetz, C., Gunther, S., Becker, N. \& Schmidt-Chanasit, J. (2011). Isolation and phylogenetic analysis of Batai virus, Germany. Am J Trop Med Hyg 84, 241-3.

KARABATSOS, N. (1978). Supplement to International Catalogue of Arboviruses including certain other viruses of vertebrates. The American journal of tropical medicine and hygiene 27, 372-440.

Khan, I. H., Kendall, L. V., Ziman, M., Wong, S., Mendoza, S., FAhey, J., Griffey, S. A., BARThold, S. W. \& Luciw, P. A. (2005). Simultaneous serodetection of 10 highly prevalent mouse infectious pathogens in a single reaction by multiplex analysis. Clinical and Diagnostic Laboratory Immunology 12, 513-519.

KILPATRICK, A. M. (2011). Globalization, land use, and the invasion of West Nile virus. Science 334, 323-7.

KILPATRICK, A. M. \& PAPE, W. J. (2013). Predicting human West Nile virus infections with mosquito surveillance data. Am J Epidemiol 178, 829-35.

Kimurakuroda, J. \& Yasui, K. (1986). Antigenic Comparison of Envelope Protein-E between Japanese Encephalitis-Virus and Some Other Flaviviruses Using Monoclonal-Antibodies. Journal of General Virology 67, 2663-2672.

Kolman JM, K. K., WoKounOVÁ D. (1973). Serological examination of the population from the endemic area of the tick-borne encephalitis virus (TBEV) and Uukuniemi virus (UKV). Cesk Epidemiol Mikrobiol Imunol. 22, 153-9. 
Kruger, A., Borstler, J., Badusche, M., Luhken, R., Garms, R. \& Tannich, E. (2014). Mosquitoes (Diptera: Culicidae) of metropolitan Hamburg, Germany. Parasitol Res.

KunITZ, M. \& Simms, H. S. (1928). DIALYSIS WITH STIRRING. The Journal of general physiology 11, 641-4.

Kuno, G., Mitchell, C. J., Chang, G. J. \& SMith, G. C. (1996). Detecting bunyaviruses of the Bunyamwera and California serogroups by a PCR technique. Journal of clinical microbiology 34, 1184-8.

LAEMMLI, U. K. (1970). Cleavage of structural proteins during the assembly of the head of the bacteriophage T4. Nature 227, 680-685.

Lal, G., BAlmer, P., StAnford, E., MARtin, S., Warrington, R. \& Borrow, R. (2005). Development and validation of a nonaplex assay for the simultaneous quantitation of antibodies to nine Streptococcus pneumoniae serotypes. J Immunol Methods 296, 135-47.

Lanciotti, R. S., Roehrig, J. T., Deubel, V., Smith, J., Parker, M., Steele, K., Crise, B., Volpe, K. E., Crabtree, M. B., Scherret, J. H., Hall, R. A., MacKenzie, J. S., Cropp, C. B., Panigrahy, B., Ostlund, E., Schmitt, B., Malkinson, M., Banet, C., Weissman, J., Komar, N., Savage, H. M., Stone, W., McNamara, T. \& GubleR, D. J. (1999). Origin of the West Nile virus responsible for an outbreak of encephalitis in the northeastern United States. Science (New York, NY ) 286, 2333-7.

Libikova, H., RehaceK, J., Gresikova, M., Kozuch, O., Somogyiova, J. \& ERneK, E. (1964). Cytopathic viruses isolated from Ixodes ricinus ticks in Czechoslovakia. Acta Virologica 8, 96.

Libikova, H., Tesarova, J. \& RajCANI, J. (1970). Experimental infection of monkeys with Kemerovo virus. Acta virologica 14, 64-9.

LINDENBACH, B. D. \& RICE, C. M. (1997). trans-Complementation of yellow fever virus NS1 reveals a role in early RNA replication. J Virol 71, 9608-17.

LindGREN, E. \& GUSTAFSON, R. (2001). Tick-borne encephalitis in Sweden and climate change. Lancet 358, 16-8.

Lindgren, E., TALleKLint, L. \& PolfeldT, T. (2000). Impact of climatic change on the northern latitude limit and population density of the disease-transmitting European tick Ixodes ricinus. Environmental health perspectives 108, 119-23.

LINDQUIST, L. \& VAPALAHTI, O. (2008). Tick-borne encephalitis. Lancet 371, 1861-71.

Lisi, P. J., Huang, C. W., Hoffman, R. A. \& Teipel, J. W. (1982). A fluorescence immunoassay for soluble antigens employing flow cytometric detection. Clinica chimica acta; international journal of clinical chemistry 120, 171-9.

Liu, J., Liu, B., CaO, Z., Inoue, S., Morita, K., Tian, K., Zhu, Q. \& GaO, G. (2008). Characterization and application of monoclonal antibodies specific to West Nile virus envelope protein. J Virol Methods 154, 20-6.

Lundstrom, J. O. (1999). Mosquito-borne viruses in western Europe: a review. J Vector Ecol 24, 1-39.

Macdonald, J., Tonry, J., Hall, R. A., Williams, B., Palacios, G., AshoK, M. S., Jabado, O., Clark, D., Tesh, R. B., Briese, T. \& Lipkin, W. I. (2005). NS1 
protein secretion during the acute phase of West Nile virus infection. J Virol 79, 13924-33.

Macfarlane, D. E. \& SommerviLle, R. G. (1969). VERO cells (Cercopithecus aethiops kidney)--growth characteristics and viral susceptibility for use in diagnostic virology. (Brief report). Archiv fur die gesamte Virusforschung 27, 379-85.

MAINO, V. C. \& MAECKER, H. T. (2004). Cytokine flow cytometry: a multiparametric approach for assessing cellular immune responses to viral antigens. Clinical Immunology 110, 222-231.

Malkova, D., Holubova, J., Kolman, J. M., Marhoul, Z., Hanzal, F., Kulkova, H., MARKVART, K. \& SimKOVA, L. (1980). Antibodies against some arboviruses in persons with various neuropathies. Acta virologica 24, 298.

MARTIN PfEFFER, G. D. (2009). What comes after bluetongue--Europe as target for exotic arboviruses. Berliner und Münchener tierärztliche Wochenschrift 122(11-12):45866.

Matveeva, V. A., Popova, R. V., Kvetkova, E. A., Chernicina, L. O., Zlobin, V. I., Puchovskaya, N. M. \& Morozova, O. V. (1995). Antibodies against tick-borne encephalitis virus (TBEV) non-structural and structural proteins in human sera and spinal fluid. Immunol Lett 46, 1-4.

Mertens, N., Remaut, E. \& Fiers, W. (1995). Tight transcriptional control mechanism ensures stable high-level expression from $\mathrm{T} 7$ promoter-based expression plasmids. Biotechnology (N Y) 13, 175-9.

Meyer-König, U., Schneider, K., Özdemir, S., Huthmacher, K., Weidmann, M., Pietsch, J., Kaiser, R., Rauer, S., Dobler, G. \& Hufert, F. T. (2014 in preparation). Endemic Toscana virus infections emerging north of the Alps, PLoS ONE.

Misić, M., Daković, R. \& Ruzić, S. (2009). Post-encephalitic syndrome in patients with tick-borne encephalitis. Acta Med Croatica 63, 269-78.

Mohd JaAfar, F., Attoui, H., De Micco, P. \& De Lamballerie, X. (2004). Recombinant VP6-based enzyme-linked immunosorbent assay for detection of immunoglobulin $\mathrm{G}$ antibodies to Eyach virus (genus Coltivirus). J Clin Virol 30, 248-53.

Morgan, E., Varro, R., Sepulveda, H., Ember, J. A., Apgar, J., Wilson, J., Lowe, L., Chen, R., Shivraj, L., Agadir, A., Campos, R., Ernst, D. \& Gaur, A. (2004). Cytometric bead array: a multiplexed assay platform with applications in various areas of biology. Clinical Immunology 110, 252-266.

Moss, S. R., Ayres, C. M. \& NutTall, P. A. (1987). Assignment of the genome segment coding for the neutralizing epitope(s) of orbiviruses in the Great Island subgroup (Kemerovo serogroup). Virology 157, 137-44.

Mullis, K. B. \& FaloonA, F. A. (1987). Specific synthesis of DNA in vitro via a polymerase-catalyzed chain reaction. Methods in Enzymology 155, 335-350.

Naucke, T. J., Menn, B., Massberg, D. \& Lorentz, S. (2008). Sandflies and leishmaniasis in Germany. Parasitology research 103 Suppl 1, S65-8.

Naucke, T. J. \& Pesson, B. (2000). Presence of Phlebotomus (Transphlebotomus) mascittii Grassi, 1908 (Diptera : Psychodidae) in Germany. Parasitol Res 86, 3356. 
Navarro, J. M., Fernandez-Roldan, C., Perez-Ruiz, M., Sanbonmatsu, S., De la RoSA, M. \& SANCHEZ-SECO, M. P. (2004). [Meningitis by Toscana virus in Spain: description of 17 cases].Meningitis por el virus Toscana en Espana: descripcion de 17 casos. Medicina clinica 122, 420-2.

Nicoletti, L., Ciufolini, M. G. \& Verani, P. (1996). Sandfly fever viruses in Italy. Archives of virology Supplementum 11, 41-7.

Nicoletti, L., Verani, P., Caciolli, S., Ciufolini, M. G., Renzi, A., Bartolozzi, D., Paci, P., LeOnCini, F., PAdovani, P. \& TRaini, E. (1991). Central nervous system involvement during infection by Phlebovirus toscana of residents in natural foci in central Italy (1977-1988). The American journal of tropical medicine and hygiene 45, 429-34.

Niedrig, M., Vaisviliene, D., Teichmann, A., Klockmann, U. \& Biel, S. S. (2001). Comparison of six different commercial IgG-ELISA kits for the detection of TBEV-antibodies. Journal of Clinical Virology 20, 179-182.

NowAK, D. A., BoEHMER, R. \& FUCHS, H. H. (2003). A retrospective clinical, laboratory and outcome analysis in 43 cases of acute aseptic meningitis. European Journal of Neurology 10, 271-280.

Oechtering, J. \& Petzold, G. C. (2012). Acute hydrocephalus due to impaired CSF resorption in Toscana virus meningoencephalitis. Neurology 79, 829-31.

OKer-Blom, N., SAlminen, M. Brummer-Korvenkotio, L. KaEAeriaeinen, and P. Weckstroem. (1964). Isolation Of Some Viruses Other Than Typical Tick-Borne Encephalitis Viruses From Ixodes Ricinus Ticks In Finland., vol. 42, pp. 109-12. Ann Med Exp Biol Fenn.

Papa, A., Konstantinou, G., Pavlidou, V. \& Antoniadis, A. (2006). Sandfly fever virus outbreak in Cyprus. Clinical microbiology and infection : the official publication of the European Society of Clinical Microbiology and Infectious Diseases 12, 192-4.

PILASKI, J. \& MACKENSTEIN, H. (1985). [Isolation of Tahyna virus from mosquitoes in 2 different European natural foci]. Zentralbl Bakteriol Mikrobiol Hyg B 180, 394420.

PRICHARD, P. M. \& CORMIER, M. J. (1968). Studies on the mechanism of the horseradish peroxidase catalyzed luminescent peroxidation of luminol. Biochemical and biophysical research communications 31, 131-6.

PupoAntunez, M., Rodriguez, H., Vazquez, S., Vilaseca, J. C., Alvarez, M., Otero, A. \& Guzman, G. (1997). Monoclonal antibodies raised to the dengue-2 virus (Cuban: A15 strain) which recognize viral structural proteins. Hybridoma 16, 347353.

PUtKuRi, N., VAheri, A. \& VAPALAhTI, O. (2007). Prevalence and protein specificity of human antibodies to Inkoo virus infection. Clin Vaccine Immunol 14, 1555-62.

R.R. BuRgeSS, M. K. K. (1996). Purification of a recombinant protein overproduced in $E$. coli. In Strategies for Protein PuriWcation and Characterization: A Laboratory Manual (ed. J. K. D. Marshak, R. Burgess, M. Knuth, W. Brennan Jr., S.-H. Lin), pp. 205-274. Cold Spring Harbor Press. 
RHESE-KÜPPER B, C. J., RHESE E, ACKERMANN R. (1976). Eyach- an Arbovirus related to Colorado tick fever virus in the Federal Republic of Germany. Acta Virol 20:339346.

Rockx, B., Van Asten, L., Van den Wijngaard, C., Godeke, G. J., Goehring, L., Vennema, H., Van der Avoort, H., Van Pelt, W. \& Koopmans, M. (2006). Syndromic surveillance in the Netherlands for the early detection of West Nile virus epidemics. Vector-Borne and Zoonotic Diseases 6, 161-169.

ROSEN, L. (1981). [Transovarial transmission of arboviruses by mosquitoes (author's transl)].Transmission transovarienne des arbovirus par les moustiques. Medecine tropicale : revue du Corps de sante colonial 41, 23-9.

SABIN, A. B. (1951). Experimental studies on Phlebotomus (pappataci, sandfly) fever during World War II. Archiv fur die gesamte Virusforschung 4, 367-410.

SAmbrooK, J., E. F. Fritsch And T. MANiATIS. (1989). Molecular Cloning: A Laboratory Manual. Cold Spring Harbor, New York, Cold Spring Harbor Laboratory.

SANGER, F., NickLEN, S. \& COULSON, A. (1977). DNA-sequencing with chain-termination inhibitors. Proc Natl Acad Sci U S A 74, 5463-5467.

ScheIBE, J. \& SchUlZ, K. R. (1991). [Headache and unconsciousness--diagnostic indications for meningoencephalitis].

Kopfschmerz und Bewusslosigkeit--diagnostische Hinweise auf eine Meningoenzephalitis. Zeitschrift fur arztliche Fortbildung 85, 437-9.

SCHMIDT, T. G. M. \& SKERRA, A. (2007). The Strep-tag system for one-step purification and high-affinity detection or capturing of proteins. Nature protocols 2, 1528-35.

SCHNEIDER, H. (1931). Über epidemische akute Meningitis serosa. Wr. Klin. Wochenschrift 44, 350-352.

Schoehn, G., Moss, S. R., Nuttall, P. A. \& Hewat, E. A. (1997). Structure of Broadhaven virus by cryoelectron microscopy: correlation of structural and antigenic properties of Broadhaven virus and bluetongue virus outer capsid proteins. Virology 235, 191-200.

Scholte, E., Den Hartog, W., Dik, M., Schoelitsz, B., Brooks, M., Schaffner, F., Foussadier, R., BRAKS, M. \& BEEUWKES, J. (2010). Introduction and control of three invasive mosquito species in the Netherlands, July-October 2010. Euro surveillance : bulletin Europeen sur les maladies transmissibles = European communicable disease bulletin $\mathbf{1 5}$.

Scholte, E. J., Den Hartog, W., Braks, M., Reusken, C., Dik, M. \& Hessels, A. (2009). First report of a North American invasive mosquito species Ochlerotatus atropalpus (Coquillett) in the Netherlands, 2009. Euro surveillance : bulletin Europeen sur les maladies transmissibles = European communicable disease bulletin 14.

Scholte, E. J. J., F.; Linton, Y.; DiJKstRa, E.; Fransen, J.; TAKKEn, W. (2007). First Record of Aedes (Stegomyia) albopictus in the Netherlands. In European Mosquito Bulletin, vol. 22, pp. 5-9. Journal of the European Mosquito Control Association.

Schultze-Amberger, J., Emmerich, P., Gunther, S. \& Schmidt-Chanasit, J. (2012). West Nile virus meningoencephalitis imported into Germany. Emerging infectious diseases 18, 1698-700. 
SCHÜßLER, E. (2000). Tahyna-Virus : Untersuchungen zum Vorkommen am Oberrhein und Sequenzvergleiche des M-Segments bei zehn Virusisolaten http://www.ub.uni-heidelberg.de/archiv/1400.

SCHWARZ, T. F., GILCH, S. \& JAGER, G. (1995). Aseptic meningitis caused by sandfly fever virus, serotype Toscana. Clinical infectious diseases : an official publication of the Infectious Diseases Society of America 21, 669-71.

Schwarz, T. F., GILCH, S. \& SchatzL, H. M. (1998). A recombinant Toscana virus nucleoprotein in a diagnostic immunoblot test system. Res Virol 149, 413-8.

SEedAt, J., Altmann, D. \& Hellenbrand, W. (2014). Aktuelle daten und informationen zu infektionskrankheiten und public health - FSME: Risikogebiete in Deutschland. In Epidemiologisches Bulletin, pp. 1-16. Robert-Koch-Institut.

SemenzA, J. C. \& Menne, B. (2009). Climate change and infectious diseases in Europe. The Lancet infectious diseases 9, 365-75.

SHAH, K. V. \& WORK, T. H. (1969). Bhanja virus: a new arbovirus from ticks Haemaphysalis intermedia Warburton and Nuttall, 1909, in Orissa, India. The Indian journal of medical research 57, 793-8.

Sissy T. Sonnleitner, J. O. L., Raphaela Baumgartner, Josef SimeOni, Harald SCHENNACH, Roland ZElger, ANGElika Prader, ERICH SCHMUTZHARD, NORBERT NOWOTNY, GERNOT WALDER. (2013). Investigations on California serogroup orthobunyaviruses in the Tyrols: First description of autochthonous strains of Tahyna virus in the Alps. In XII International Jena Symposium on Tickborne Diseases, Weimar.

SKERRA, A. (1994). Use of the tetracycline promoter for the tightly regulated production of a murine antibody fragment in Escherichia coli. Gene 151, 131-5.

Smith, P. K., Krohn, R. I., Hermanson, G. T., Mallia, A. K., Gartner, F. H., Provenzano, M. D., Fujimoto, E. K., Goeke, N. M., Olson, B. J. \& Klenk, D. C. (1985). Measurement of protein using bicinchoninic acid. Analytical biochemistry 150, 76-85.

SOlOMON, T., HART, I. J. \& BEECHING, N. J. (2007). Viral encephalitis: a clinician's guide. Pract Neurol 7, 288-305.

Sonnleitner, S. T., Lundstrom, J., Baumgartner, R., Simeoni, J., Schennach, H., Zelger, R., Prader, A., Schmutzhard, E., Nowotny, N. \& Walder, G. (2014). Investigations on California serogroup orthobunyaviruses in the Tyrols: first description of Tahyna virus in the Alps. Vector Borne Zoonotic Dis 14, 272-7.

Studahl, M., Bergstrom, T. \& Hagberg, L. (1998). Acute viral encephalitis in adults a prospective study. Scandinavian Journal of Infectious Diseases 30, 215-220.

Suss, J., Beziat, P., Rohr, H. P., TreiB, J. \& HaAss, A. (1996). Detection of the tickborne encephalitis virus (TBEV) in ticks in several federal "Lander" of Germany by means of the polymerase chain reaction (PCR)--characterization of the virus. Infection 24, 403-4.

Süss J, B. P., RAMELOW C, BERNDT D. (1995). Untersuchungen zur epidemiologischen Situation der FSME in den neuen Bundesländernvon 1992-1994. In Durch Zecken übertragbareErkrankungen.FSME und Lyme-Borreliose, pp. 25-32. Weller, Schriesheim. 
SÜSS J., S. C. (2004). Tick-borne human pathogenic microorganisms found in Europe and those considered non-pathogenic Part I: ticks and viruses. Bundesgesundheitsblatt 47, 392-404.

TERPE, K. (2003). Overview of tag protein fusions: from molecular and biochemical fundamentals to commercial systems. Appl Microbiol Biotechnol 60, 523-33.

TERPE, K. (2006). Overview of bacterial expression systems for heterologous protein production: from molecular and biochemical fundamentals to commercial systems. Appl Microbiol Biotechnol 72, 211-22.

TESH, R. B. \& ChAniotis, B. N. (1975). Transovarial transmission of viruses by phlebotomine sandflies. Annals of the New York Academy of Sciences 266, 12534.

Tesh, R. B. \& Papaevangelou, G. (1977). Effect of insecticide spraying for malaria control on the incidence of sandfly fever in Athens, Greece. Am J Trop Med Hyg 26, $163-6$.

TOwbin, H., StAehlin, T. \& GoRDON, J. (1979). Electrophoretic transfer of proteins from polyacrylamide gels to nitrocellulose sheets: procedure and some applications. Proc Natl Acad Sci U S A 76, 4350-4354.

Treib, J., Dobler, G., HaAss, A., von Blohn, W., Strittmatter, M., Pindur, G., Froesner, G. \& SCHIMrigK, K. (1998). Thunderclap headache caused by Erve virus? Neurology 50, 509-11.

TRUSZKIEWICZ, W. (2011). [Influence of storage conditions on results of antibody level assay in human serum samples]. Med Dosw Mikrobiol 63, 189-93.

Tsai, T. F., Popovici, F., Cernescu, C., CAmpbell, G. L. \& Nedelcu, N. I. (1998). West Nile encephalitis epidemic in southeastern Romania. Lancet 352, 767-71.

TYLER, K. L. (2001). West Nile virus encephalitis in America. The New England journal of medicine 344, 1858-9.

Vapalahti, O., Plyusnin, A., Cheng, Y., Manni, T., Brummer-Korvenkontio, M. \& VAHERI, A. (1996). Inkoo and Tahyna, the European California serogroup bunyaviruses: sequence and phylogeny of the S RNA segment. J Gen Virol 77 ( Pt 8), 1769-74.

VERANI, P., BALDUCCI, M., LOPES, M. C. \& SACCA, G. (1970). Isolation of Bhanja virus from Haemaphysalis ticks in Italy. The American journal of tropical medicine and hygiene 19, 103-5.

Verani, P., Nicoletti, L. \& Ciufolini, M. G. (1984). Antigenic and biological characterization of Toscana virus, a new Phlebotomus fever group virus isolated in Italy. Acta virologica 28, 39-47.

Vignali, D. A. (2000). Multiplexed particle-based flow cytometric assays. Journal of immunological methods 243, 243-55.

Voss, S. \& SKERRA, A. (1997). Mutagenesis of a flexible loop in streptavidin leads to higher affinity for the Strep-tag II peptide and improved performance in recombinant protein purification. Protein engineering 10, 975-82.

Wang, L. F., Gould, A.R., Hyatt, A.D., EAton B.T. (1992). Nature and location of epitopes utilized in competitive ELISA to detect bluetongue virus antibodies. In Bluetongue, African Horsesickness and related Orbiviruses: proceedings of the Second International symposium, pp. 596-603. CRC Press, Paris, France. 
Weidmann, M., Armbruster, K. \& Hufert, F. T. (2008a). Challenges in designing a Taqman-based multiplex assay for the simultaneous detection of Herpes simplex virus types 1 and 2 and Varicella-zoster virus. J Clin Virol 42, 326-34.

Weidmann, M., Meyer-Konig, U. \& Hufert, F. T. (2003a). Rapid detection of herpes simplex virus and varicella-zoster virus infections by real-time PCR. J Clin Microbiol 41, 1565-8.

Weidmann, M., Rudaz, V., Nunes, M. R. T., Vasconcelos, P. F. C. \& Hufert, F. T. (2003b). Rapid detection of human pathogenic orthobunyaviruses. Journal of clinical microbiology 41, 3299-305.

Weidmann, M., Sanchez-Seco, M. P., Sall, A. A., Ly, P. O., Thiongane, Y., Lo, M. M., SCHLEY, H. \& HufERT, F. T. (2008b). Rapid detection of important human pathogenic Phleboviruses. Journal of clinical virology : the official publication of the Pan American Society for Clinical Virology 41, 138-42.

Werner, D., Kronefeld, M., Schaffner, F. \& KAmpen, H. (2012). Two invasive mosquito species, Aedes albopictus and Aedes japonicus japonicus, trapped in south-west Germany, July to August 2011. Euro Surveill 17.

Wong, S. J., Demarest, V. L., Boyle, R. H., Wang, T., Ledizet, M., Kar, K., Kramer, L. D., FIKRIG, E. \& KosKI, R. A. (2004). Detection of human anti-flavivirus antibodies with a West Nile virus recombinant antigen microsphere immunoassay. Journal of Clinical Microbiology 42, 65-72.

WWWN.CDC.GOV/ARBOCAT. International Catalog of Arboviruses. Centers for Disease Control and Prevention, Atlanta, USA.

Youn, S., Ambrose, R. L., Mackenzie, J. M. \& Diamond, M. S. (2013). Non-structural protein-1 is required for West Nile virus replication complex formation and viral RNA synthesis. Virol J 10, 339.

Youn, S., Li, T., McCune, B. T., Edeling, M. A., Fremont, D. H., Cristea, I. M. \& DiAMOND, M. S. (2012). Evidence for a Genetic and Physical Interaction between Nonstructural Proteins NS1 and NS4B That Modulates Replication of West Nile Virus. Journal of Virology 86, 7360-7371.

Zhuo, Q., PiaO, J. H., WANG, R. \& YANG, X. G. (2005). Refolding and purification of non-fusion HPT protein expressed in Escherichia coli as inclusion bodies. Protein Expression and Purification 41, 53-60. 


\title{
Lebenslauf:
}

Persönliche Daten

\begin{tabular}{ll}
\hline Name & Dora Elisabeth Finkeisen \\
Anschrift & Angerstraße 1, 37073 Göttingen \\
geboren & 21.09 .1984 in Northeim
\end{tabular}

\section{Schule und Studium}

$4 / 2010$ bis $7 / 2014$

Promotion an der biologischen Fakultät der Georg-AugustUniversität Göttingen

Dissertationstitel:

„Entwicklung von diagnostischen Methoden zum Nachweis von europäischen humanpathogenen Arboviren "

$10 / 2004$ bis $3 / 2010$

Studium der Dipl. Biologie an der biologischen Fakultät der Georg-August-Universität Göttingen

24.03.2010

Abschluss des Dipl. Studiums Biologie

Hauptfach Mikrobiologie,

Nebenfächer Humangenetik und Pathologie

Diplomarbeitstitel:

„Entwicklung eines zytometrischen-Kugel-Test-Verfahrens zum Nachweis von zeckenübertragenden Viren “

8/1997 bis 6/2004 Ratsgymnasium Goslar mit Abschluss: Abitur

\section{Fort- und Weiterbildungen}

\begin{tabular}{|c|c|}
\hline 2013 & Fortbildung: „, Sicherheitsaspekte der Gentechnik“ \\
\hline 2012 & Fachtagung mit Vortrag: \\
\hline & $\begin{array}{l}\text { „Joint Conference on Emerging an Re-emerging Epidemics } \\
\text { Affecting Global Health } 2012 \text { “in Orvieto, Italien }\end{array}$ \\
\hline 2012 & $\begin{array}{l}\text { Fachtagung mit Posterpräsentation: } \\
\text { „22 } 2^{\text {nd }} \text { Annual Meeting of Society for Virology “ in Essen }\end{array}$ \\
\hline 2011 & $\begin{array}{l}\text { Teilnahme: } \\
\text { „Workshop: Bead-Based-Array-Technologies “ RKI Berlin }\end{array}$ \\
\hline 2010 & Teilnahme: „, Cytokine Workshop“ in Göttingen \\
\hline 2010 & Teilnahme: „,BSL3/BSL4 Training Course“ in Göttingen \\
\hline
\end{tabular}

\section{Berufspraxis}

4/2010 bis 4/2014

\author{
Wissenschaftliche Mitarbeiterin \\ Universitätsmedizin Göttingen (UMG), \\ Abteilung für Virologie Arbeitsgruppe Hufert
}

